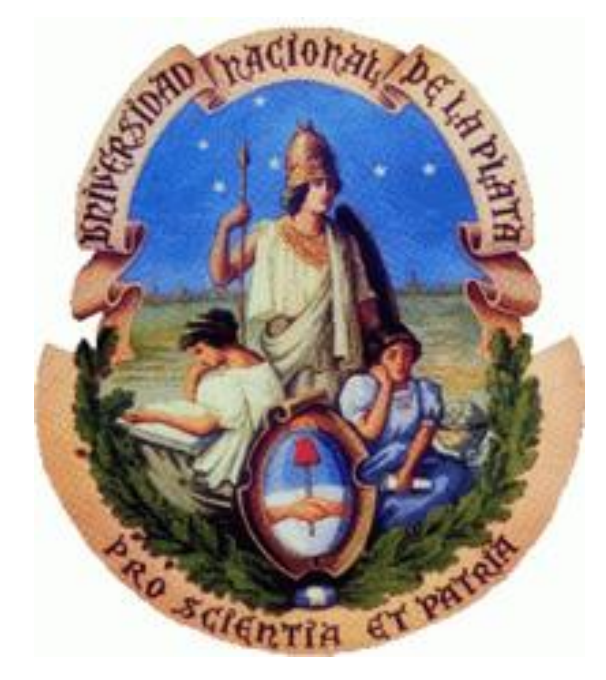

\title{
UNIVERSIDAD NACIONAL DE LA
}

\section{PLATA}

\author{
FACULTAD DE CIENCIAS EXACTAS \\ DEPARTAMENTO DE QUIMICA
}

Trabajo de Tesis Doctoral

Desarrollo de sistemas de liberación controlada de agentes quimioterapéuticos en matrices de celulosa microbiana con aplicaciones biomédicas

Lic. Maximiliano Luis Cacicedo

Director de Tesis: Dr. Guillermo R. Castro

2017

Centro de Investigación y Desarrollo en Fermentaciones

Industriales (CINDEFI)

Universidad Nacional de La Plata (UNLP)

La Plata- Argentina 


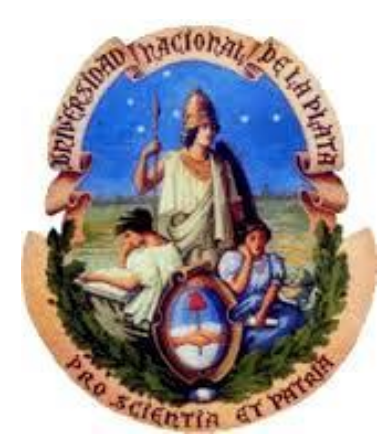

Universidad Nacional de La Plata

Facultad de Ciencias Exactas

Departamento de Química

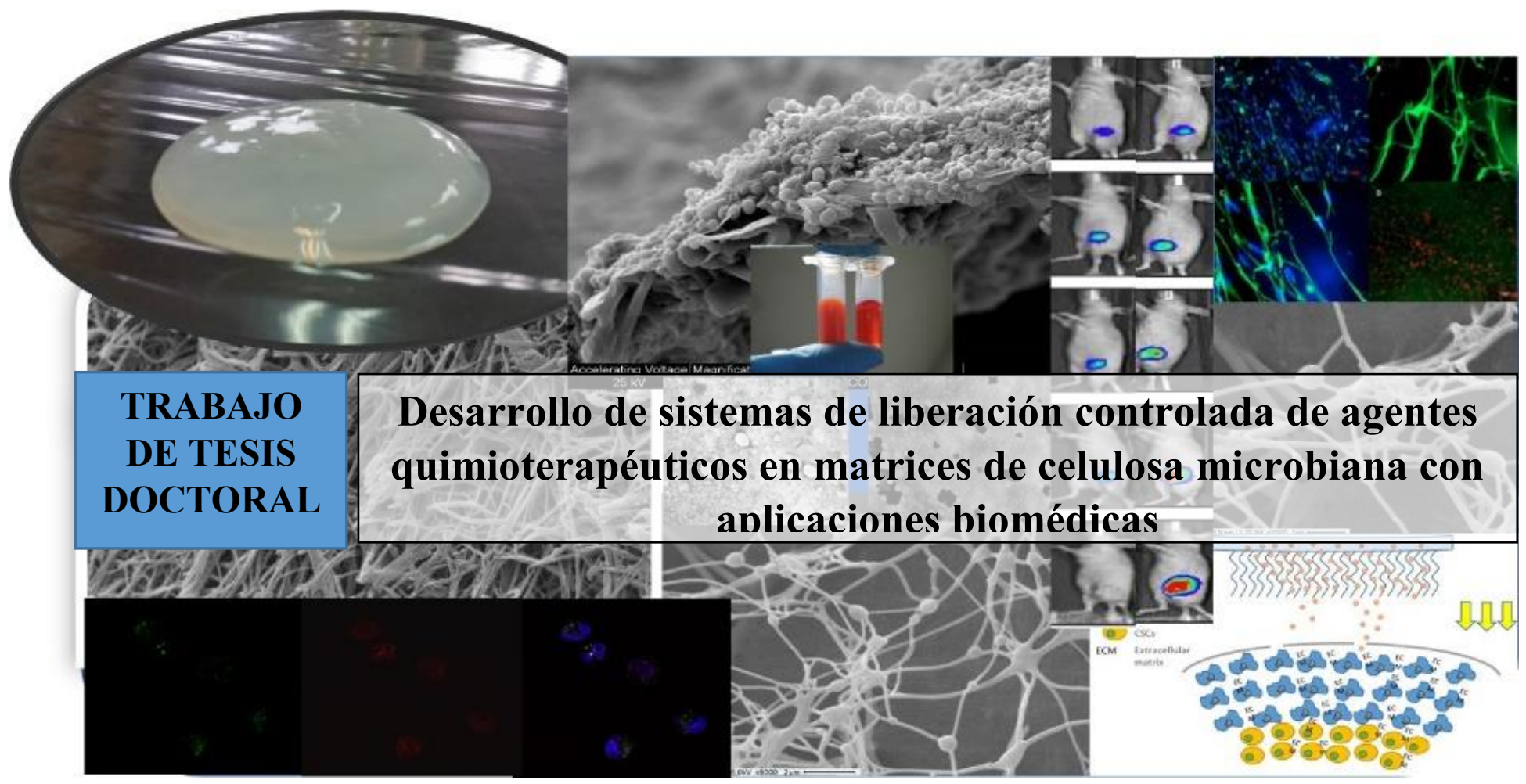

\section{Lic. Maximiliano Luis Cacicedo}

Laboratorio de Nanobiomateriales

Centro de investigación en fermentaciones industriales (CINDEFI)

UNLP-CONICET (CCT La Plata)

Argentina

2017 
El presente trabajo de Tesis, para optar al título de Doctor de la Facultad de Ciencias Exactas, fue realizado en el Centro de Investigación y Desarrollo en Fermentaciones Industriales (CINDEFI), Facultad de Ciencias Exactas, Universidad Nacional de La Plata, gracias al financiamiento de la Universidad Nacional de La Plata, la Agencia Nacional de Promoción Científica y Tecnológica (ANPCyT), y al Consejo Nacional de Investigaciones Científicas y Técnicas (CONICET). 


\section{Agradecimientos}

- A la Facultad de Ciencias Exactas de la Universidad Nacional de La Plata, por brindarme las herramientas e instruirme en mi formación académica.

- Al CINDEFI y a toda su gente, por brindarme un lugar hermoso donde trabajar y compartir.

- Al CONICET por confiar en mí, financiándome durante todo el doctorado.

- A Guiye, por su gran amistad y confianza absoluta. Por permitirme ser parte de su equipo y por alentarme siempre, tanto en lo laboral como en lo personal.

- A Vale, por sus enseñanzas y su paciencia. Por su linda amistad y consejos.

- A Ger, mi hermano del alma. Por su invaluable amistad y confianza, por su compañía incondicional. Por hacerme parte de su familia.

- A Berni gran amigo y compañero de lab. Por los buenos momentos compartidos y por los que vendrán.

- Al Colo, enorme amigo. Por estar siempre ahí para escuchar y aconsejar. Por su apoyo y compañía en la vida.

- A Tato, por su amistad y compañerismo. Por sus consejos y charlas.

- A la Dra. Vera Alvarez, del INTEMA, por auspiciar de co-directora (aunque la burocracia no lo haya permitido). Por su apoyo constante y por toda su colaboración para la caracterización fisicoquímica de los materiales.

- A la Dra. Jimena Gonzales, también del INTEMA, por su ayuda en las caracterizaciones y análisis de los sistemas. 
- Al Dr. Luismar Porto, del INTeLab, Brasil. Por brindarme gentilmente la cepa para la producción de celulosa y por recibirme en su laboratorio.

- A la Dra. Volga Bulmus y a su equipo, del IYTE, Turquía. Por sus enseñanzas respecto a la síntesis de polímeros, por recibirme amablemente en su laboratorio y por todos los momentos compartidos.

- Al Dr. Igor Chourpa y a la Dra. Emilie Allard-Vannier, por permitirme desarrollar los estudios de FSCI en su laboratorio y por su amigable colaboración.

- Al Dr. Simo Schwartz, del Hospital Vall d'Hebron, Barcelona. Por permitirme formar parte de su equipo por unos meses y brindarme la posibilidad de realizar estudios in vivo.

- A todo el increíble equipo del VHIR con el cual he tenido el privilegio de trabajar, Ibane, Yolanda, Vane, Laia, Naty, Sandra, Paty, Anna, Quim. Por hacer de mi estadía algo inolvidable. Por su compañía y amistad.

- A la Fundación BecAR, por confiar en mí otorgándome el financiamiento y apoyo necesario para mi estadía en el instituto de investigación del Hospital Vall d'Hebron (VHIR).

- A mis amigos colegas, el famoso GS, por todos los inolvidables momentos. Por la gran amistad que me regalan.

- A mis grandes amigos de la vida, Vasquito, Pablin, Juan, Santi. Porque realmente son hermanos, porque nunca fallan, porque siempre bancan.

- A mi Equipo Espectros, amigos increíbles. Porque siempre me sacan una sonrisa, por las charlas, los momentos de camaradería imposibles de olvidar.

- A mis abuelos, estrellas guía y ángeles de la guarda. Mi ejemplo a seguir. No recuerdo un solo día en que no haya sido profundamente feliz junto a ellos.

- A mi mamá, por el cariño y la paciencia. Presente en todo momento. 
- A Sabri, mi hermanita, siempre loca linda. Por su apoyo constante con todo.

- Al resto de la linda familia, Ana, Carlos, Maru, Marquitos y Ale. Gracias por aguantarme.

- A mi papá. Por enseñarme a ser hombre, por insistir siempre en que estudie y me esfuerce. Aunque hoy ya no esté, me continúa motivando a seguir adelante.

- A Vir, mi esposa y compañera de la vida. Porque sin ella nada hubiera sido posible y nada de esto tendría mucho sentido. Por estar en los momentos más oscuros y en los más luminosos. Por no dejar de abrazarme un solo día, en estos 14 años juntos.

- Al mejor amigo y compañero de cuatro patitas que la vida me regalo. Mi ángel, Whitey. Porque sos simplemente un ser increíble, porque sos incondicionalmente compañero. Por esa capacidad de sacarme una sonrisa todos los días.

- A todos aquellos animales de laboratorio. Gracias a ellos la ciencia y la medicina avanzan día a día para asegurar nuestro bienestar y calidad de vida. Gracias. 


\section{Índice}

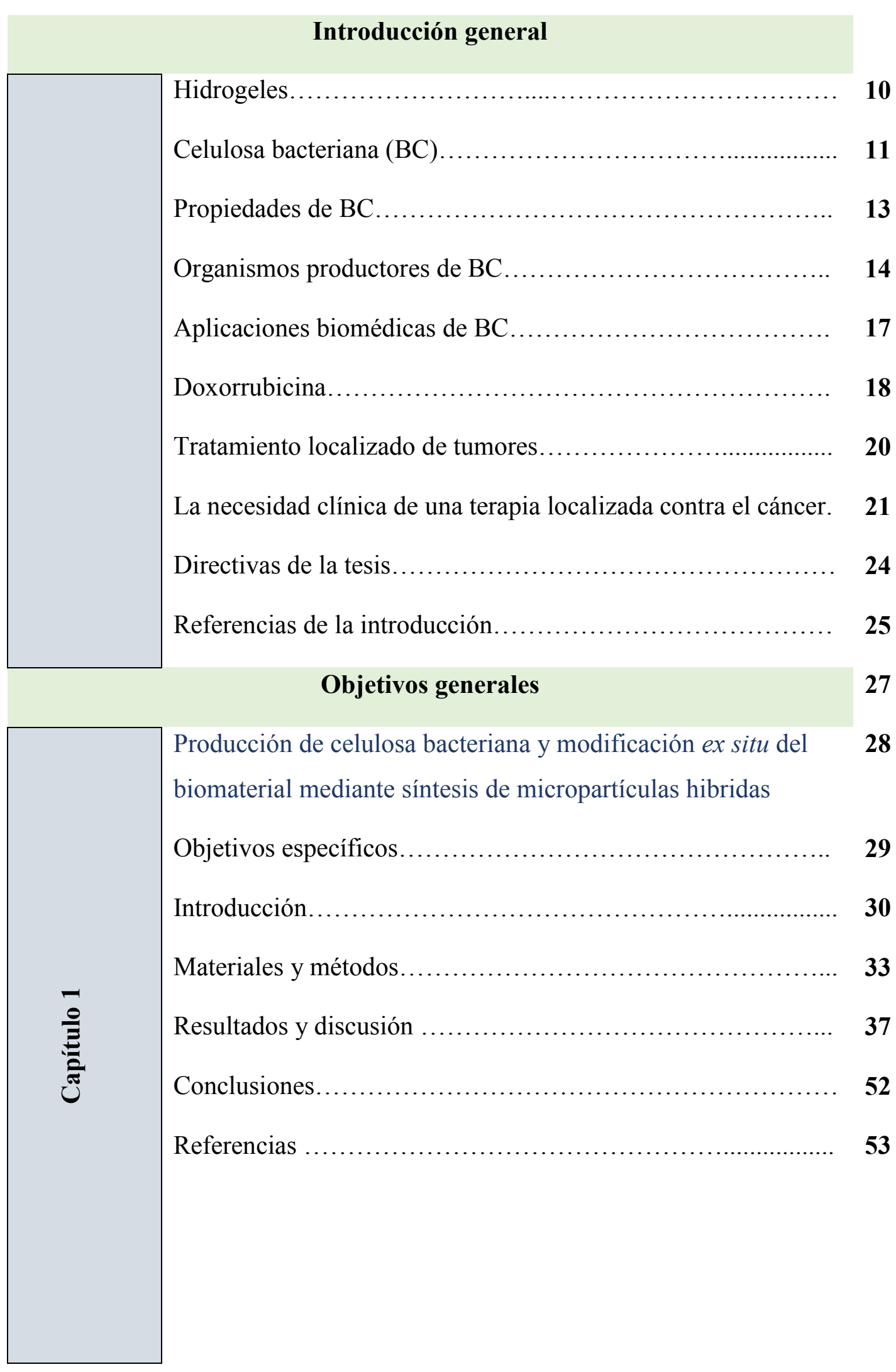




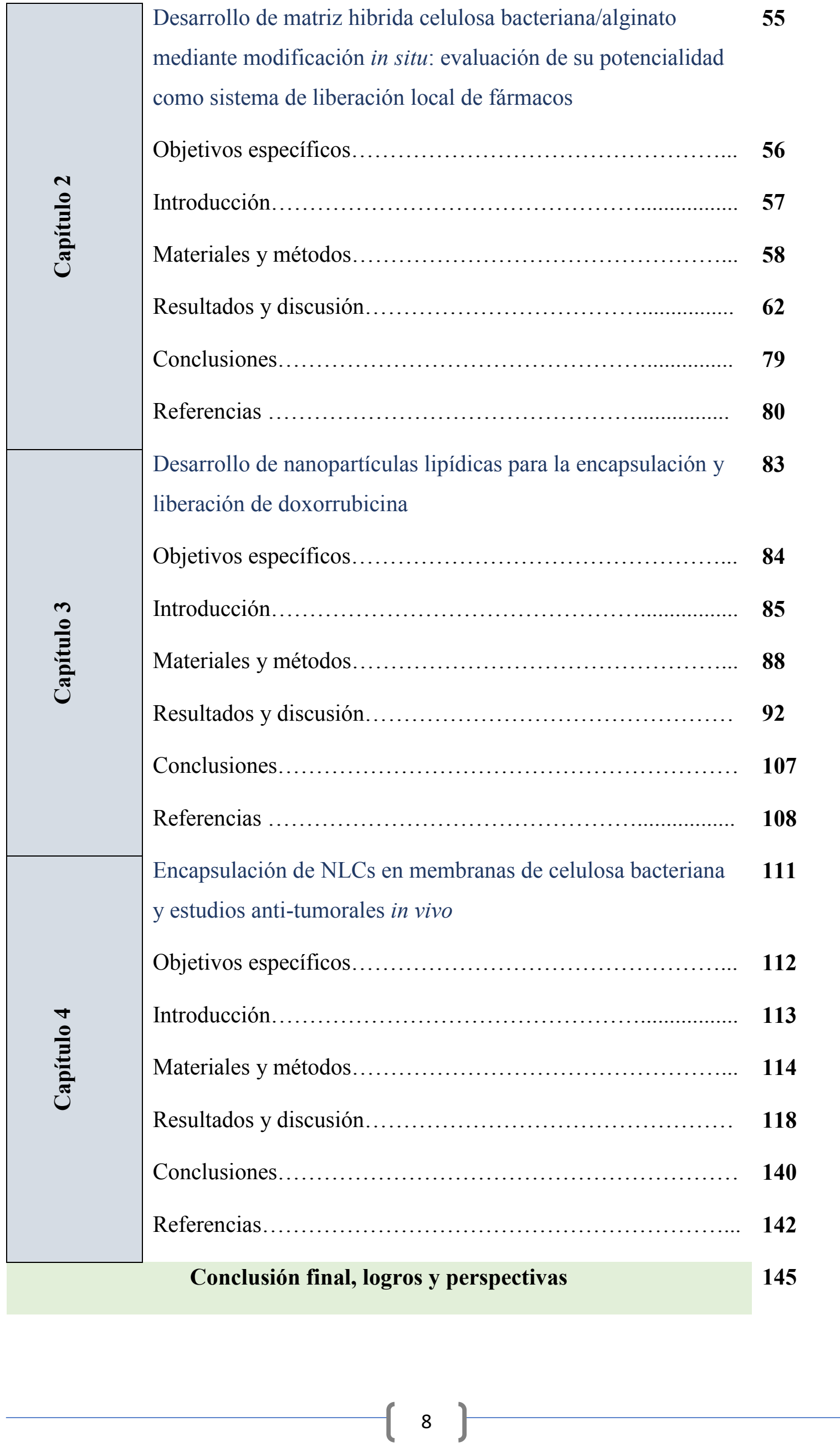




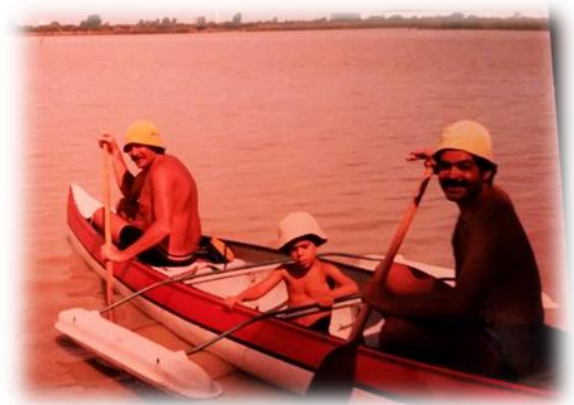

“...nunca te quedes a la deriva..."

A papá y al abue 


\section{Introducción general}

Hidrogeles como redes poliméricas para diversas aplicaciones biomédicas

Los hidrogeles han sido de gran interés en diversos campos de investigación a lo largo de décadas ${ }^{1}$. Se denominan hidrogeles a aquellas estructuras moleculares poliméricas tridimensionales compuestas por polímeros de naturaleza hidrofilica que presentan una gran variedad de propiedades fisicoquímicas. Una notable característica, es que estas matrices pueden absorber de 10-20\% (un límite inferior arbitrario) hasta miles de veces su peso seco en agua. Los hidrogeles pueden ser químicamente estables o se pueden degradar y finalmente desintegrarse y disolverse en el medio. Son utilizados comúnmente para el desarrollo de herramientas en áreas como ingeniería de tejidos, medicina regenerativa, inmovilización de células, entre otras ${ }^{2}$.

Existen diversas estructuras macromoleculares que son posibles de obtener con hidrogeles. Estas incluyen las siguientes: redes reticuladas de homopolímeros, copolímeros lineales, y copolímeros de bloque o de injerto; poli-iónicas multivalentes, estructuras poli-ión-poli-ión y/o complejos formados mediante interacciones de puente $\mathrm{H}$ unidos; redes hidrófilicas estabilizadas por dominios hidrofóbicos, y mezclas físicas. Los hidrogeles también pueden tener diversas formas físicas diferentes, incluyendo (a) sólidos con formas moldeadas (por ejemplo, lentes de contacto blandas), (b) matrices presionadas de polvo (por ejemplo, pastillas o cápsulas para ingestión oral), (c) micropartículas (por ejemplo, como en estructuras bioadhesivas para tratamientos de la heridas), (d) recubrimientos (por ejemplo, en implantes o catéteres; en pastillas o cápsulas, o revestimientos en la pared del capilar en el interior en la electroforesis capilar), (e) membranas o láminas (por ejemplo, como depósitos en un parche transdérmico para el suministro de fármacos, o en geles de electroforesis 2D), (f) encapsulados sólidos (por ejemplo, en bombas osmóticas), y (g) líquidos (por ejemplo, geles en calefacción o refrigeración) ${ }^{1}$.

La elevada porosidad presente en los hidrogeles es la gran responsable de su utilización en el área de liberación controlada de fármacos. Su estructura porosa permite la utilización de sus muchos sitios activos pudiendo, de esta manera, modular el grado de entrecruzamiento y de retención de los activos farmacológicos (Esquema 1). Entonces, los beneficios de los hidrogeles en esta área son farmacocinéticos en el sentido que se puede generar un deposito dentro del cual el activo reside y puede ser liberado de forma sostenida y controlada. Por otro lado, la elevada capacidad de retener 
moléculas de agua y la similaridad física con ciertos tejidos le permiten a los hidrogeles poseer una elevada biocopatibilidad ${ }^{2}$.

Esquema 1. Estrategias físicas (a) y químicas (b) para interacción entre el fármaco y las cadenas poliméricas de un hidrogel utilizado para la liberación controlada de activos. En (a) se puede observar la interacción electrostática entre el polímero y el activo. Por otro lado, en (b) se observa una interacción química debido a que el activo esta conjugado por medio de un puente al polímero.

(a)

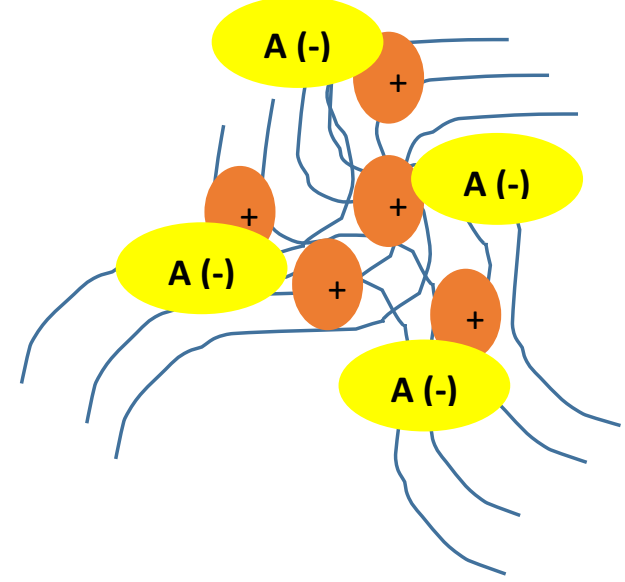

(b)

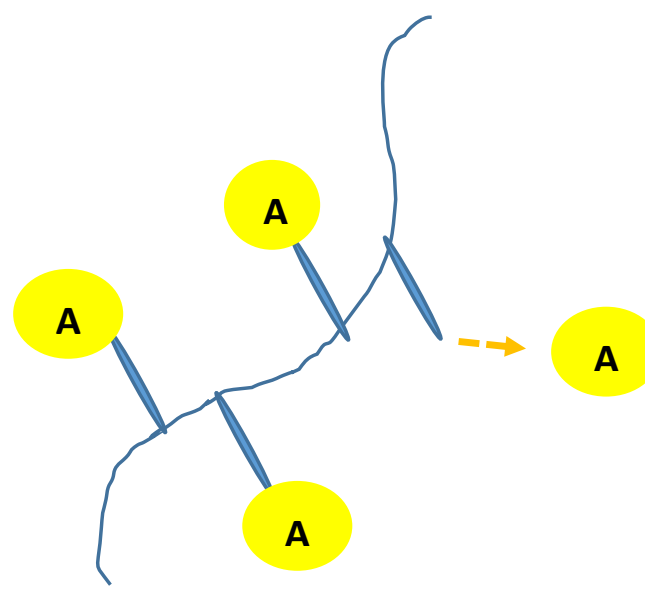

Celulosa bacteriana como biopolímero central para el desarrollo de un sistema de hidrogel para liberación de fármacos.

Un claro ejemplo de hidrogel es la celulosa bacteriana, cuya relevancia en investigación se ha ido incrementando en los últimos años. La celulosa bacteriana fue descubierta hace dos siglos atrás pero recién en las últimas décadas, con los avances en la nanotecnología y la importancia de la química verde, se le empezó a prestar atención (Esquema 2). La celulosa bacteriana (BC, por sus siglas en inglés) es un biopolímero $\beta$ glucano compuesto por unidades de $\beta$-1,4-glucopiranosilo y un grado de polimerización que puede llegar a los cientos de miles. La BC está compuesta por subfibras de $1.5 \mathrm{~nm}$ las cuales se ensamblan en nanofibras de 2-4 $\mathrm{nm}$ de diámetro. La red nanoestructurada de la $\mathrm{BC}$ sumada a la facilidad con que el biomaterial se puede purificar y modificar hacen atractivo a éste biopolímero para diferentes aplicaciones biotecnológicas. 
Esquema 2. Resultado de colocar la palabra bacterial cellulose" en el buscador de Sciencedirect.com; manifiesta un aumento en el número de artículos con relación a la $\mathrm{BC}$ en los últimos 16 años.

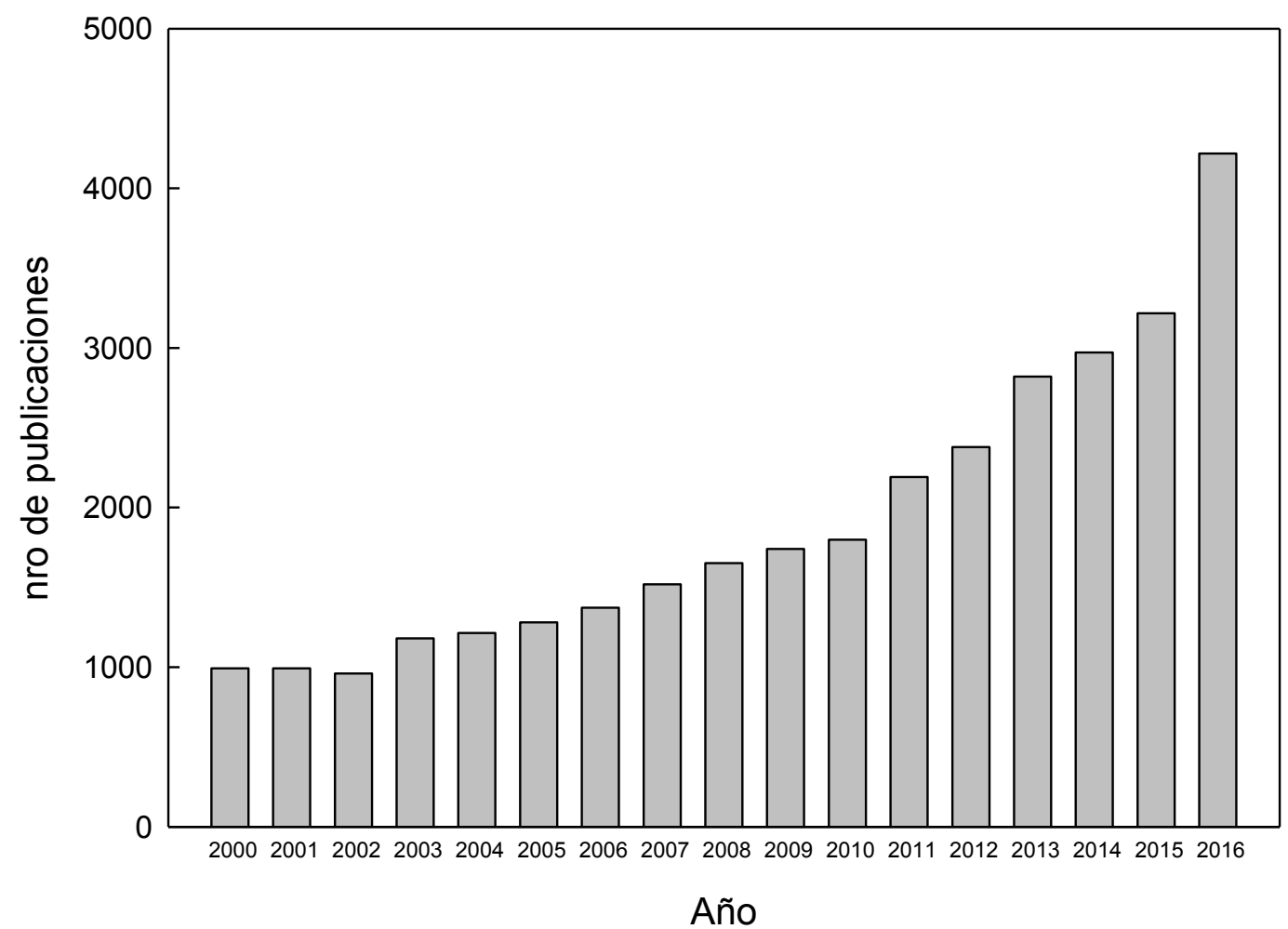

Como se ha mencionado anteriormente, una de las características interesantes de las $\mathrm{BC}$ es que puede ser modificada de diferentes maneras a través de técnicas amigables con el medioambiente. A diferencia de otros materiales poliméricos, la producción y modificación de la celulosa se pueden realizar sin la utilización de solventes orgánicos y/o compuestos tóxicos y de ningún otro compuesto que contamine el medio ambiente. Las estrategias de modificación de la BC pueden dividirse en dos (Esquema 3): por un lado, las modificaciones in situ en donde se adicionan materiales exógenos, como por ejemplo polímeros, al medio de cultivo. Las fibras de celulosa se van auto-ensamblando a medida que se van produciendo, y el material exógeno interfiere mediante la interacción con las mismas fibras. Al final del proceso puede observar una red de fibras hibrida con características fisicoquímicas diferentes a las que se encuentran en una red de $\mathrm{BC}$ nativa. Estas nuevas características son aportadas por el material exógeno y también por su interacción con las fibras de celulosa e implican modificaciones intimas en la estructura de la BC. Por otro lado, las modificaciones ex situ consisten en todas 
aquellas modificaciones que se realizan a la $\mathrm{BC}$ luego de su proceso de producción y purificación. Compuestos tales como nanopartículas, polímeros, sales, entre otros, son incubados junto a la $\mathrm{BC}$ siguiendo protocolos variados. Este tipo de modificación es muy versátil y simple. Sin embargo, el grado de modificación que se obtiene en la red de fibras es en la mayoría de los casos en superficie y no tan relevante desde el punto de vista estructural de la BC como en la modificación in situ. A pesar de esto, sí se consiguen modificar las características del biomaterial obteniéndose nuevas propiedades fisicoquímicas ${ }^{3}$.

Esquema 3. Procesos de modificación de la celulosa bacteriana

Celulosa bacteriana modificada
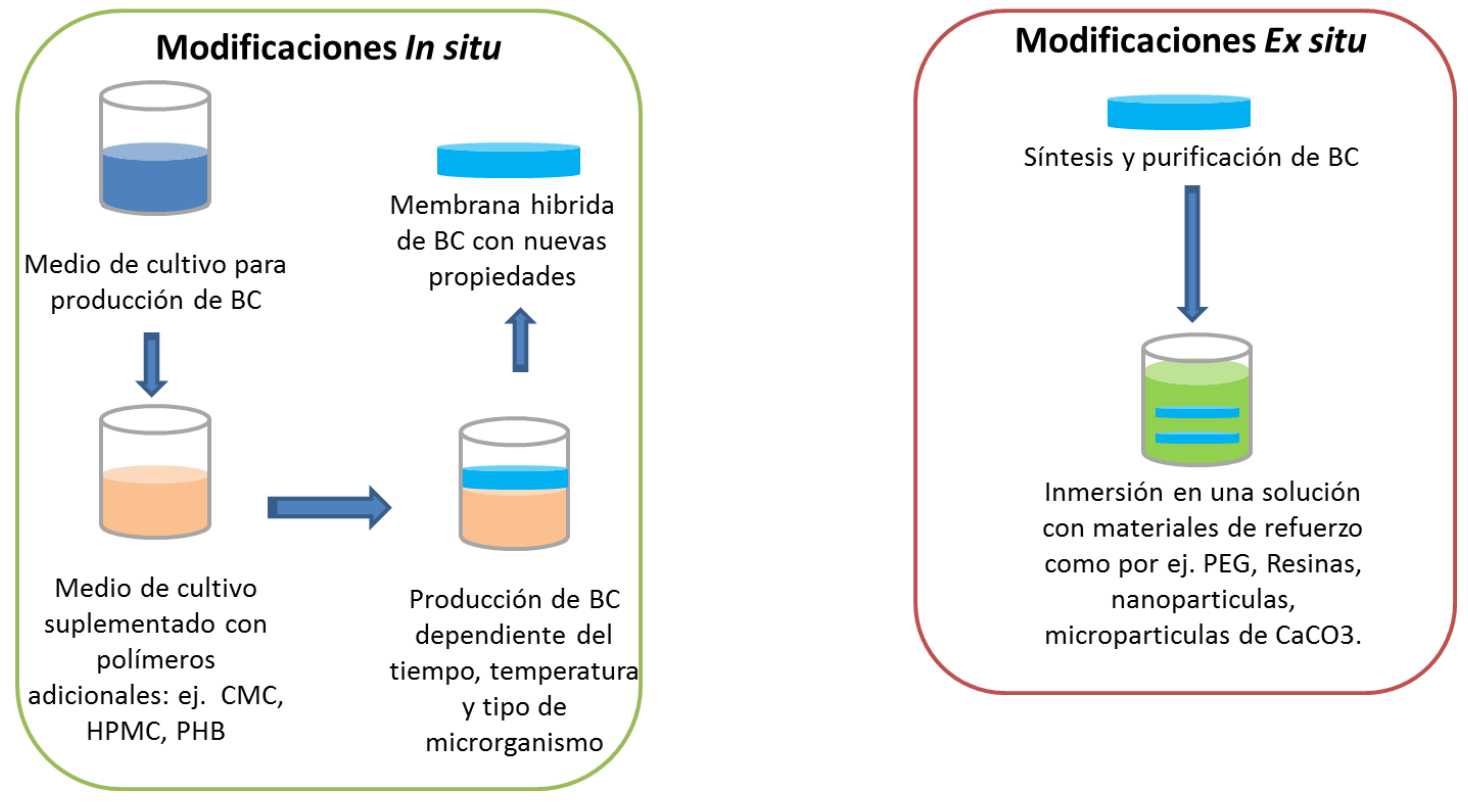

\section{Propiedades de la celulosa bacteriana}

La celulosa proveniente de fuentes vegetales es producida como un polímero lignocelulósico, es decir que las moléculas de celulosa están íntimamente asociadas con otras tales como ligninas, hemicelulosas, entre otras. De hecho, el contenido de celulosa en plantas varía de acuerdo a la fuente. Por ejemplo, el algodón posee alrededor de un $90 \%$ de celulosa mientras que la madera posee un 50\%. Todas estas moléculas accesorias que acompañan a la celulosa vegetal poseen funciones específicas en la fisiología de las plantas. A pesar de ello, son consideradas impurezas cuando se necesita 
utilizar la celulosa en estado puro para diversas aplicaciones, como en el caso de la biomedicina. Además, los procesos de purificación de la celulosa vegetal utilizados para lograr una celulosa de alta pureza implican mecanismos complejos y bastante costosos. Por ejemplo, se suelen utilizar tratamientos mecánicos y pre-tratamientos químicos, los cuales consumen mucha energía eléctrica y son contaminantes del medioambiente ${ }^{4}$.

En contraste, los procesos de purificación utilizados para la $\mathrm{BC}$ son muy simples y no requieren de maquinaria compleja y costosa. Fácilmente se obtienen altos grados de purificación de la celulosa y los métodos utilizados son amigables con el medio ambiente. $\mathrm{BC}$ constituye un biomaterial conformado sólo por moléculas de glucosa y agua, sus propiedades mecánicas pueden ser fácilmente comparadas con las de otros polímeros complejos fabricados por métodos sintéticos. La fuerza de tensión que posee la BC suele estar en valores entre 200 y $300 \mathrm{MPa}$ y su módulo de Young se encuentra entre 15 y $35 \mathrm{GPa}$. Como un ejemplo comparativo, el polipropileno (PP) posee una fuerza de tensión de 30-45 MPa y un módulo de Young de 1,0-1,5 GPa ${ }^{5}$. Estas propiedades mecánicas son una consecuencia directa de las estructuras cristalinas formadas por las nano- y microfibras de celulosa. Además, la elevada cristalinidad y el alto contenido de agua en combinación son los responsables de la buena estabilidad térmica que posee dicho material ${ }^{6}$. Esta última propiedad es muy importante para las aplicaciones biomédicas de la $\mathrm{BC}$ debido a que permite que el biomaterial pueda ser esterilizado fácilmente por esterilización térmica. Pocos son los polímeros utilizados en el campo de la biomedicina que pueden ser expuestos a temperaturas mayores a $100^{\circ} \mathrm{C}$ sin que ello implique cambios irreversibles en sus propiedades (cita).

\section{Organismos productores de celulosa}

La BC fue identificada por primera vez en 1886 durante la fermentación de vinagre. Los microorganismos productores más comunes pertenecen a la familia Acetobactereaceae, particularmente los que pertenecen al género Komagataeibacter (anteriormente denominado Gluconacetobacter) ${ }^{7}$. Las especies microbianas del genero Komagataeibacter son definidas como Gram-negativas, aerobias estrictas, habitan principalmente en frutas y vegetales en descomposición, son capaces de utilizar fuentes de carbono comunes como glucosa, glicerol, sacarosa, fructosa, manitol, entre otras. Son metabólicamente activas a temperaturas entre $25^{\circ} \mathrm{C}$ y $30^{\circ} \mathrm{C}$ a $\mathrm{pH}$ entre 3 y 7 , sin embargo se producen cambios en las propiedades fisicoquímicas y en el rendimiento de la celulosa producida. La celulosa bacteriana es idéntica a la proveniente de fuentes 
vegetales en cuanto a su estructura molecular y polimérica. La bacteria produce celulosa en la interface que existe entre el aire y el medio de cultivo en forma de una membrana flotante que le permite a la bacteria permanecer en esa interface y disponer de una gran cantidad de oxígeno. Además, la membrana permite proteger a la bacteria funcionando como una barrera física contra la radiación UV y procesos redox, aumenta la capacidad de colonizar otros lugares y mantiene un medio ambiente bien higroscópico evitando periodos de deshidratación y falta de humedad ${ }^{8}$. La síntesis de la celulosa bacteriana está basada en un proceso con pasos sincronizados, eficientes y regulados, incluyendo varias enzimas y complejos proteicos. El proceso incluye el transporte de la fuente de carbono desde el exterior hacia adentro de la célula, la síntesis de uridina-difosfoglucosa (UDPG) vía glucosa-6-fosfato y glucosa-1-fosfato. A continuación, tiene lugar la polimerización de la glucosa en cadena por medio de la celulosa sintasa (CS). Las nacientes cadenas de celulosa son excretadas desde la membrana celular. Una simple célula de Komagataeibacter spp. posee entre 50 y 80 poros o complejos terminales (CTs) de $3.5 \mathrm{~nm}$ de diámetro para excretar la celulosa. A través de los poros la bacteria excreta las cadenas poliméricas, las cuales se unen formando subfibras (10-15 canales) (Esquema 4). Las subfibras forman nanofibras, como ya se mencionara anteriormente, y luego forman estructuras en forma de cintas de 40-60 $\mathrm{nm}$ de ancho y con un espesor de 3-8 $\mathrm{nm}^{9}$. Las fibras de BC presentan una muy elevada área superficial y construyen una red tridimensional excepcional. Debido a esta estructura supramolecular, la celulosa ha sido considerada como un polímero semicristalino en cuyo estado original o nativo presenta polimorfismo tipo I con una mezcla de alomorfismos Ia y Ib, y una relación $\mathrm{Ia} / \mathrm{Ib}$ que puede variar de acuerdo a las condiciones de cultivo. Por ejemplo, la celulosa vegetal es rica en alomorfismos $\mathrm{Ib}$, mientras que la $\mathrm{BC}$ es rica en alomorfismos Ia. Por otro lado, el arreglo en el espacio de la agregación de las pre-microfibras le adjudica a la BC una alta cristalinidad de $80-90 \%$, mientras que la celulosa vegetal llega al 40-60\% 10. La elevada organización de las nanofibras de BC conducen a la formación de un elevado número de puentes de hidrogeno entre sus cadenas en comparación con la celulosa vegetal y además las cadenas de $\mathrm{BC}$ poseen un elevado grado de polimerización (puede alcanzar valores de 20,000 unidades de glucosa). Como se mencionara anteriormente, la red polimérica constittuida por un elevado número de puentes de hidrogeno lo que permite una buena capacidad para interaccionar con otras moléculas como polímeros, partículas e incluso agua. De hecho, la BC posee una elevada capacidad de contener agua dentro de su estructura (99\%) y específicamente 
atribuido a los puentes de hidrogeno. La cristalinidad de la $\mathrm{BC}$, la cual es una función de la cantidad de puentes de hidrogeno, es una de las grandes responsables de conferirle a la matriz las ya mencionas propiedades mecánicas ${ }^{11}$.

Esquema 4. Esquema del proceso de síntesis, excreción y autoensamblado de celulosa
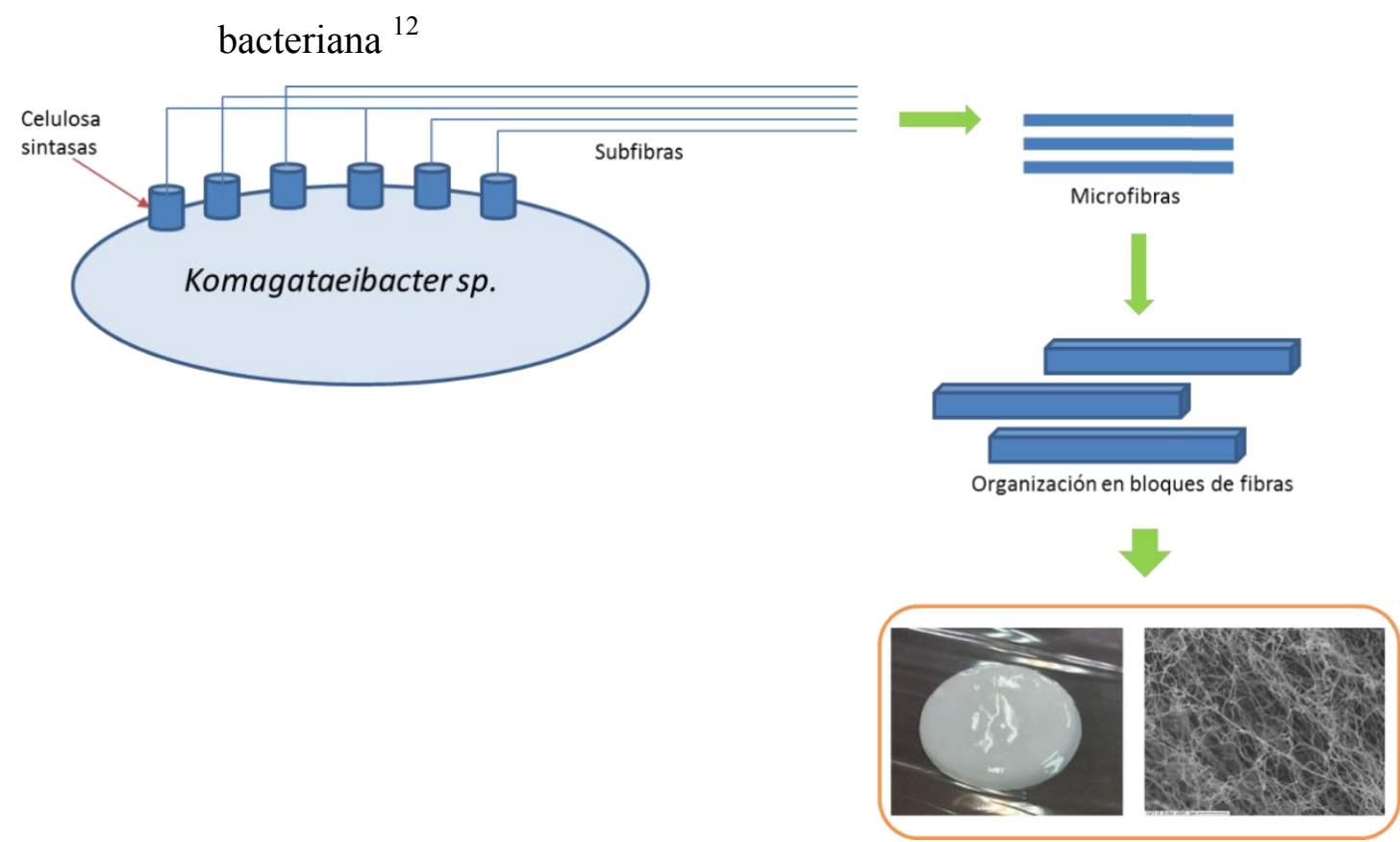

\section{Aplicaciones biomédicas de la celulosa bacteriana}

Existen diversos tipos de aplicaciones en donde la $\mathrm{BC}$ ocupa un rol importante, en campos muy distantes desde materiales para construcción hasta aplicaciones biomédicas. Aquí se describirán algunas de las aplicaciones biomédicas más destacadas de la celulosa bacteriana ${ }^{13}$.

Las características fisicoquímicas mencionadas de la BC sumadas a su excelente biocompatibilidad, han abierto una gran ventana para diversas aplicaciones relacionadas con la salud humana. Por ejemplo, membranas de BC están siendo utilizadas para el tratamiento de heridas y, especialmente, de quemaduras graves debido a que constituyen un sistema no-inmunogénico, que garantiza la humedad y evita la pérdida de agua por evaporación en los pacientes. Además, funciona como filtro selectivo evitando el acceso de microorganismos oportunistas y permitiendo el acceso de oxígeno ${ }^{13}$. Por otro lado, la biocopatibilidad de $\mathrm{BC}$ ha sido rigurosamente estudiada mediante su implantación subcutánea en ratas mostrando resultados muy prometedores debido a la ausencia de procesos de fibrosis alrededor del implante. De igual manera, no fueron detectados signos macroscópicos de inflamación tales como enrojecimiento, edema o exudación. 
Incluso se ha podido observar crecimiento celular dentro de la membrana de BC formando nuevo tejido integrado con el biomaterial, evidenciándose vascularización y síntesis de colágeno mostrando una integración completa con la zona de implantación 14. La bioestabilidad de la $\mathrm{BC}$ ha sido ensayada incluso utilizando al material como remplazo de vasos sanguíneos en ovejas. Los autores del mencionado trabajo detallan la existencia de compatibilidad con la sangre, ausencia de inflamación y estabilidad funcional del implante pasados los tres meses ${ }^{15}$. Sin embargo, también es muy relevante remarcar que la celulosa bacteriana no puede ser degradada por mamíferos debido a la ausencia de beta-glucanohidrolasas. Para ciertas aplicaciones biomédicas esta característica es ventajosa, como en el caso de válvulas cardiacas o meniscos, debido a que se demanda que el material sea estable y funcional en el tiempo. En otros casos, la no degradabilidad puede llegar a ser una desventaja. Generalmente se considera que para los casos en donde se coloca un material para inducir la regeneración de un tejido, este debe ir desplazando al material a medida que va creciendo. Sin embargo, se ha observado como la $\mathrm{BC}$ puede integrarse con el tejido nuevo sin problemas como ya mencionamos anteriormente. Por otro lado, con la finalidad de generar una $\mathrm{BC}$ degradable algunos investigadores han desarrollado estrategias interesantes. Por ejemplo, se ha elaborado una BC oxidada mediante el uso de dióxido de nitrógeno. Esta modificación permitió que la celulosa posea una cinética de degradación plausible para uso en sistemas en donde se requiera la degradación de la matriz ${ }^{16}$. En otro estudio, se lograron inmovilizar celulasas en la matriz obteniéndose también un proceso de degradación controlado ${ }^{17}$.

En el presente trabajo, se pretende desarrollar un sistema de liberación controlada de fármacos para aplicación localizada. Dicho sistema tendrá como polímero base la celulosa bacteriana, utilizando como fármaco modelo la doxorrubicina y como problemática el tratamiento de ciertos tipos de tumores sólidos.

\section{Doxorrubicina - breves antecedentes}

En su forma inalterada, la doxorrubicina (Doxo) ha mostrado gran potencial para el tratamiento de tumores, siendo considerado como uno de los más potentes quimioterapéuticos aprobados por la FDA ${ }^{18}$. La capacidad de combatir las células tumorales que se dividen rápidamente y la lenta progresión de la enfermedad han hecho que éste fármaco sea utilizado desde hace varias décadas hasta la actualidad, siendo su 
uso solo limitado por su toxicidad sobre las células no cancerosas en el cuerpo humano. La Doxo es una antraciclina no-selectiva de clase I, posee componentes aglicónico y de azúcar. La aglicona se compone de un anillo tetracíclico con quinina-hidroquinona como grupos adyacentes, un sustituyente metoxilo de cadena lateral corta seguido por el grupo carbonilo (Esquema 5). El componente de azúcar (también conocido como daunosamina) está unido a uno de los anillos por un enlace glucosídico. Este se compone de una 3-amino-2,3,4 trideoxi-L-fucosilo ${ }^{19}$.

Esquema 5. Estructura molecular de la doxorrubicina

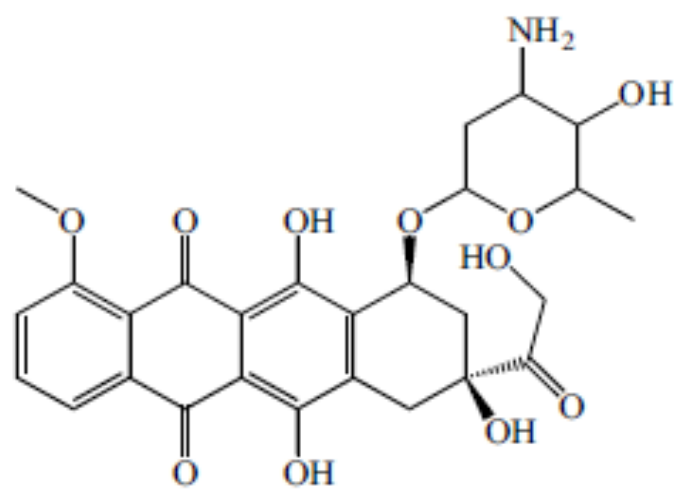

\section{Doxorrubicina}

La Doxo actúa uniéndose a enzimas asociadas al ADN y también se puede intercalar entre los pares de bases de la doble hélice del $\mathrm{ADN}^{19}$. Mediante la unión a múltiples objetivos moleculares tales como enzimas topoisomerasas I y II, una serie de efectos citotóxicos se producen conjuntamente con el efecto antiproliferativo, lo que resulta en daños en el $\mathrm{ADN}^{20}$. La vía de la apoptosis es desencadenada cuando los intentos de reparar las roturas en el ADN fallan y el crecimiento celular se inhibe en las fases G1 y G2. También se sabe que la Doxo se intercala mismo en el ADN, con la inhibición tanto de ADN y ARN polimerasa, en última instancia cesa la replicación del ADN y la transcripción de ARN.

Los principales efectos secundarios de las antraciclinas son los efectos citotóxicos multidireccionales, con cardiotoxicidad siendo el más prominente (Esquema 6). La Doxo genera modificaciones estructurales sobre los cardiomiocitos alargándolos. Los genes responsables de esto son el péptido natriuretico del cerebro (BNP) y el péptido natriurético atrial (ANP). Cuando se encuentran sobreexpresados, estos genes producen hipertrofia cardiaca. Por otro lado, la Doxo tiene un efecto toxico sobre las mitocondrias 
de las células del musculo cardiaco. Alterando los niveles de expresión de proteínas mitocondriales, el ciclo redox de la Doxo y de la NADH dehidrogenasa se ven elevados, potenciando la producción de especies reactivas de oxigeno (ROS) ${ }^{21}$. Cuando estos niveles de ROS incrementan se desencadenan vías apoptóticas generando muerte celular.

Durante las evaluaciones clínicas de Doxo en la década de 1970, en las fases II y III, los estudios mostraron efectos de vómitos agudos $\mathrm{y}$ náuseas, problemas gastrointestinales, calvicie, y disturbios para el sistema neurológico (a menudo causando alucinaciones y mareo). Lamentablemente, la Doxo no se dirige específicamente al tumor, y puede afectar el crecimiento de muchos otros tipos de células en el cuerpo, particularmente en células madre y las líneas celulares de la sangre. Este hecho resulta en una depresión del transporte de gases y del sistema inmune, y como el número de células inmunes se reducen significativamente, el paciente se vuelve más susceptible a infecciones microbianas, a fatiga y el tiempo de curación aumenta. La gravedad de estos efectos y su ocurrencia depende de la dosis y de la capacidad de regeneración de la médula ósea del paciente. Mediante la administración continua de Doxo en una pequeña vena, problemas tales como flebosclerosis (engrosamiento de las paredes de las venas) pueden ocurrir, y si hay extravasaciones en tejidos u órganos locales, puede surgir necrosis. Por otro lado, efectos de la extravasación incluyen celulitis, tromboflebitis y limitación de movimiento de las articulaciones como resultado de la induración dolorosa (endurecimiento patológico de tejido) ${ }^{21}$.

Esquema 6. Vías de generación de cardiotoxicidad por tratamiento con Doxo 


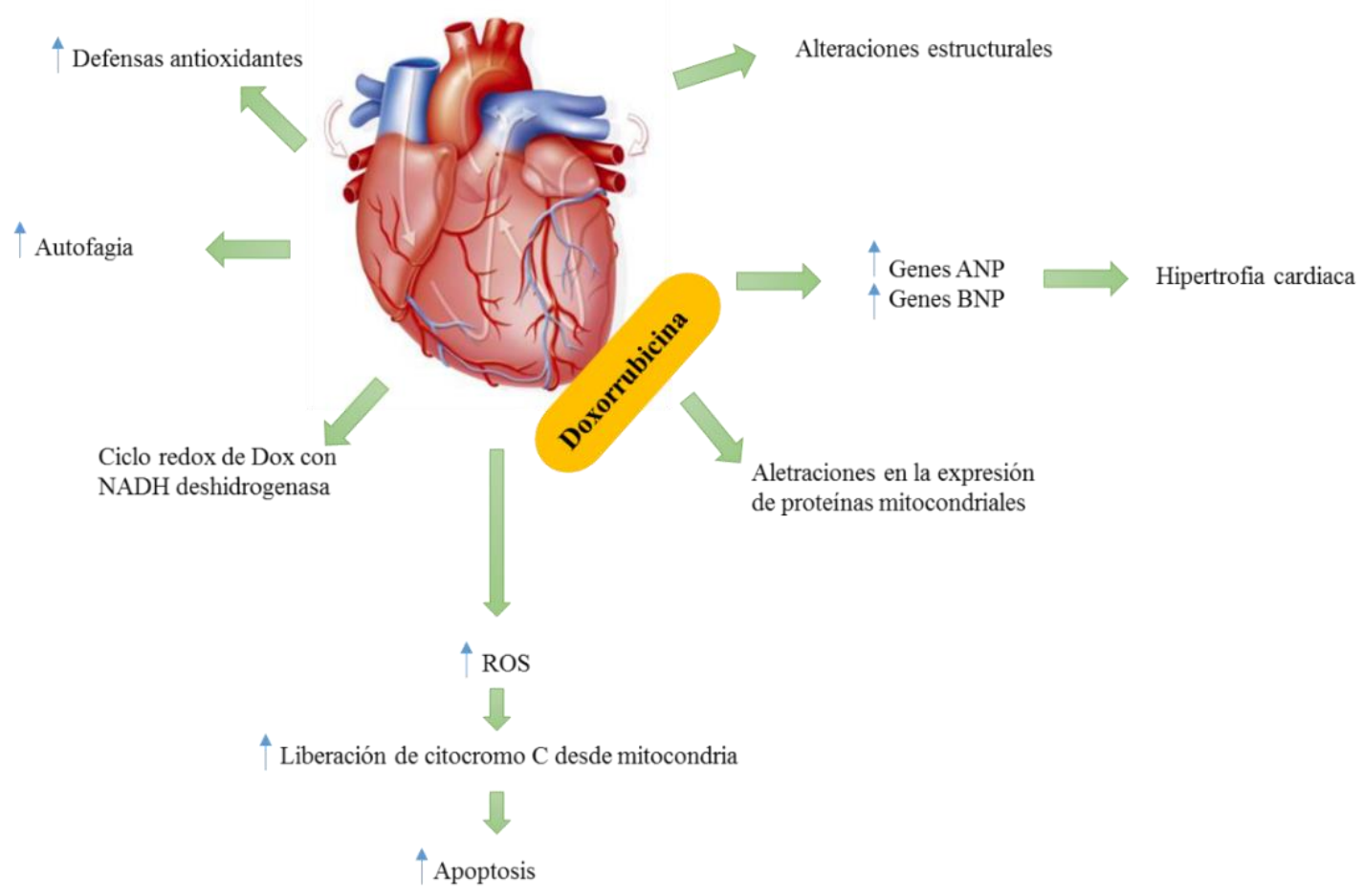

Tratamiento localizado de tumores: una opción como terapia adyuvante Sistemas para liberación sostenida de fármacos basados en distintos tipos de polímeros han sido investigados en las últimas décadas con el fin de obtener, básicamente, concentraciones terapéuticas de la droga en el sitio de acción (e.g., tumor maligno) ${ }^{22-25}$. El desarrollo de éstas tecnologías se basa en la búsqueda de una mejora en la tasa de sobrevida y en la calidad de vida de pacientes con cáncer. Para ello, se ha intentado aumentar la biodisponibilidad de la droga en el sitio especifico de acción, incrementando la solubilidad de algunos fármacos y minimizando los efectos tóxicos, entre otros. Los sistemas desarrollados hasta el momento se pueden dividir en dos grupos basándonos en el método de administración y el mecanismo de acción. El primer grupo consiste en aquellos sistemas administrados por vía sistémica como nanopartículas poliméricas, liposomas, etcétera. Por otro lado, el segundo grupo consiste en sistemas poliméricos para administración local mediante implantación en la zona del tumor $\mathrm{y} / \mathrm{o}$ en zonas adyacentes al tejido canceroso.

\section{La necesidad clínica de una terapia localizada contra el cáncer}

La necesidad de desarrollo de nuevas terapias y estrategias contra el cáncer queda en evidencia luego de observar las estadísticas de mortalidad y de incidencias referidas a pacientes con cáncer ${ }^{26}$. El tratamiento que un paciente requiere esta determinado por el tipo de cáncer, localización, el estadio patológico al momento del diagnóstico y la 
tolerancia del paciente a las terapias prescriptas. Los tumores son clasificados, generalmente, de acuerdo al sistema TNM (tumor, nodo, metástasis) el cual da una idea de lo diseminado o avanzado del cáncer. El grado de avance o estadio puede también ser definido entre temprano, intermedio o avanzado. Los tumores en estadio temprano están localizados en un sitio anatómico definido sin mostrar evidencias de haberse diseminado. En el caso de aquellos en etapas intermedias se pueden encontrar masas tumorales más grandes y evidencias de que nodos linfáticos están siendo implicados. Por otro lado, los tumores de grado avanzado ya presentan metástasis desde el tejido primario hacia otras regiones del organismo. Estadísticamente se ha manifestado que la mayoría de los pacientes son diagnosticados en casos en que el tumor se encuentra localizado.

La gran mayoría de los tumores que se encuentran en estas distintas etapas de avance pueden ser sometidos a una terapia localizada que permita un mejor control del cáncer limitando la zona a ser extirpada mediante cirugía, intentando impedir el uso de radioterapia (o posibilitando un uso mínimo), y permitiendo reducir drásticamente aquellas toxicidades sujetas al uso de quimioterapia. De tal manera, se estaría maximizando la preservación del tejido funcional.

La extirpación del tumor primario y/o nodos linfáticos adyacentes es el tratamiento elegido habitualmente para la mayoría de los tumores en estadio temprano (localizados) o en estadio intermedio con el acompañamiento regional de nodos linfáticos. Por otro lado, para el caso de aquellos tumores en estadios más tardíos se suele aplicar una extirpación parcial (denominado debulking) pudiendo, en algunos casos, obtenerse un efecto paliativo que mejora la calidad de vida del paciente ${ }^{27}$. Luego de la cirugía es probable que queden remanentes células cancerígenas que no se pueden detectar, es por ello que se procede con un tratamiento con radiación y/o quimioterapia con el fin de evitar posibles recurrencias del tumor.

Habitualmente, la quimioterapia se reserva para aquellos canceres que se encuentran en estadios intermedios a avanzados, y se puede administrar junto con radioterapia o sola. Estas drogas se pueden administrar antes o después de la cirugía. También se suelen utilizar de manera más agresiva en aquellos casos en donde el tumor no puede ser extirpado mediante una cirugía, debido a su tamaño y/o localización. Aunque puede resultar trivial, es importante remarcar que la administración sistémica de agentes quimioterapéuticos actualmente no está específicamente dirigida al tumor, y de hecho, es muy difícil alcanzar niveles terapéuticos de droga en la zona tumoral o adyacente al 
tumor. Es por eso que se utilizan concentraciones muy elevadas de estos fármacos, observándose en la gran mayoría de los casos una acumulación en tejidos sanos, lo que lleva a los severos efectos secundarios tóxicos. Por ejemplo, se ha reportado que casi la mitad de una dosis de paclitaxel administrada por vía intravenosa es eliminada durante las primeras 24 horas y, además, menos del 0,5\% de la dosis total llega a estar disponible para atacar el tumor en un cáncer de pulmón ${ }^{28}$.

Dentro de las prácticas clínicas estándares en pacientes oncológicos, se pueden observar como la falla en los tratamientos en tumores en estadio temprano e intermedio afecta notablemente los índices de mortalidad de pacientes con cáncer. En tal sentido, es necesariamente urgente el desarrollo no solo de nuevas tecnologías al respecto, como ya se ha mencionado previamente, sino también el planteo de nuevas estrategias para atacar tumores.

Con el presente marco, podemos introducir algunos beneficios de la quimioterapia localizada la cual resulta una opción con elevado potencial terapéutico. Este tipo de terapia se aplica directamente sobre la zona afectada por un tumor y posee como objetivos centrales optimizar la eficiencia del tratamiento y reducir el daño generado por el mismo sobre el paciente. Los sistemas de este tipo están constituidos por implantes que tienen la propiedad de transportar fármacos. Estos implantes son administrados directamente en la zona afectada por el cáncer ofreciendo algunas ventajas sobre la administración sistémica tradicional, a saber: 1) estabilización de las moléculas de droga y preservación de su actividad anticancerígena, 2) liberación controlada y prolongada de la droga para asegurar una adecuada difusión e internalización celular en células cancerígenas, 3) carga y liberación de moléculas insolubles en condiciones fisiológicas, 4) liberación directamente sobre el sitio de acción resultando en menos droga perdida, 5) aplicación única, y 6) efectos secundarios disminuidos debido a que se evita o reduce drásticamente la circulación sistémica de los fármacos altamente citotóxicos, prolongando además su exposición sobre las células tumorales.

Se debe considerar que se espera que sólo entre un $10 \%$ a un $15 \%$ de las células tumorales se encuentren en mitosis en un tiempo dado. Por tal motivo, es tan necesaria la continua exposición de estas células a los agentes quimioterapéuticos ${ }^{29}$.

El uso de este tipo de sistemas terapéuticos está pensado para aquellos casos en donde a) la prevención de recurrencias locales mediante métodos tradicionales no puede ser garantizada sin afectar aún más el estado clínico del paciente, b) se recibe un paciente en estado avanzado y el tumor localizado es inoperable o no puede ser tratado mediante 
métodos tradicionales, y/o c) el control local del tumor ofrece la oportunidad de llevar a cabo una cirugía de extirpación de manera menos invasiva ${ }^{30}$.

Por último, uno de los temas a considerar es la capacidad de penetración de la droga liberada. A pesar de que estos sistemas de administración local garantizan niveles altos de fármaco en la zona de acción, la eficacia del tratamiento continúa dependiendo de la capacidad de penetración de ese fármaco en el tejido tumoral. En el caso de la prevención de recurrencias, la capacidad de penetración del fármaco es también muy relevante de manera que este pueda alcanzar todas las zonas con células cancerígenas remanentes. Aumentando, en estos casos, el radio de tratamiento efectivo garantizará un incremento en el número de pacientes que puedan eliminar recurrencias locales.

\section{Directivas de la tesis}

El presente trabajo de Tesis pretende abordar una problemática que se basa en el desarrollo de herramientas biomédicas para conseguir un tratamiento más efectivo contra el cáncer. La estrategia se basa en el tratamiento localizado de tumores sólidos mediante la implantación de un dispositivo capaz de liberar de forma controlada y sostenida un activo quimioterapéutico. Para ello, se ha procedido a desarrollar un sistema polimérico basado en celulosa bacteriana. En el primer capítulo se describirá la producción, purificación y esterilización de celulosa bacteriana. Además, se procederá a modificar en superficie membranas de BC para carga y liberación sostenida de doxorrubicina. En el segundo capítulo se abordará la modificación in-situ de BC, mediante el agregado de un polímero exógeno en el medio de producción de la celulosa. Se procederá a analizar los efectos estructurales sobre la matriz mediante métodos biofísicos a fin de definir ventajas y desventajas para que la misma pueda cumplir con su finalidad como sistema de liberación de fármacos. En el tercer capítulo se procederá al desarrollo de una formulación a base de nanopartículas lipídicas para la encapsulación de la Doxo, teniendo como finalidad mejorar el índice terapéutico en comparación con la droga libre. A continuación, en el cuarto capítulo las nanoparticulas se combinarán con el hidrogel de celulosa incluyendo las mismas dentro de la matriz polimérica. La integración de ambas estructuras permitirá explotar las ventajas de cada una de ellas. Finalmente, el potencial terapéutico de la matriz de $\mathrm{BC}$ con las nanopartículas será evaluado frente a una línea celular agresiva de cáncer de mama. 
Además, la misma línea será utilizada para generar un modelo tumoral ortotópico donde se implantará la matriz polimérica y se estudiará su acción anti-proliferativa.

\section{Bibliografía de la introducción}

(1) Hoffman, A. S. Hydrogels for Biomedical Applications. Adv. Drug Deliv. Rev. 2012, 64 (SUPPL.), 18-23.

(2) Hoare, T. R.; Kohane, D. S. Hydrogels in Drug Delivery: Progress and Challenges. Polymer (Guildf). 2008, 49 (8), 1993-2007.

(3) Shah, N.; Ul-Islam, M.; Khattak, W. A.; Park, J. K. Overview of Bacterial Cellulose Composites: A Multipurpose Advanced Material. Carbohydr. Polym. 2013, 98 (2), 1585-1598.

(4) Siró, I.; Plackett, D. Microfibrillated Cellulose and New Nanocomposite Materials: A Review. Cellulose 2010, 17 (3), 459-494.

(5) Ruka, D. R.; Simon, G. P.; Dean, K. M. In Situ Modifications to Bacterial Cellulose with the Water Insoluble Polymer Poly-3-Hydroxybutyrate. Carbohydr. Polym. 2013, 92 (2), 1717-1723.

(6) Qiu, K.; Netravali, A. N. A Review of Fabrication and Applications of Bacterial Cellulose Based Nanocomposites. Polym. Rev. 2014, 54 (4), 598-626.

(7) Ruka, D. R.; Simon, G. P.; Dean, K. M. Bacterial Cellulose and Its Use in Renewable Composites. Nanocellulose Polym. Nanocomposites 2015, 89-130.

(8) Cacicedo, M. L.; Cesca, K.; Bosio, V. E.; Porto, L. M.; Castro, G. R. Self-Assembly of Carrageenin-CaCO3 Hybrid Microparticles on Bacterial Cellulose Films for Doxorubicin Sustained Delivery. J. Appl. Biomed. 2015, 13 (3), 239-248.

(9) Shi, Z.; Zhang, Y.; Phillips, G. O.; Yang, G. Utilization of Bacterial Cellulose in Food. Food Hydrocoll. 2014, 35, 539-545.

(10) Huang, Y.; Zhu, C.; Yang, J.; Nie, Y.; Chen, C.; Sun, D. Recent Advances in Bacterial Cellulose. Cellulose 2014, 21 (1), 1-30.

(11) Cacicedo, M. L.; E. León, I.; S. Gonzalez, J.; M. Porto, L.; A. Alvarez, V.; Castro, G. R. Modified Bacterial Cellulose Scaffolds for Localized Doxorubicin Release in Human Colorectal HT-29 Cells. Colloids Surfaces B Biointerfaces 2016, 140, 421-429. 
(12) Cacicedo, M. L.; Castro, M. C.; Servetas, I.; Bosnea, L.; Boura, K.; Tsafrakidou, P.; Dima, A.; Terpou, A.; Koutinas, A.; Castro, G. R. Progress in Bacterial Cellulose Matrices for Biotechnological Applications. Bioresour. Technol. 2016.

(13) Petersen, N.; Gatenholm, P. Bacterial Cellulose-Based Materials and Medical Devices: Current State and Perspectives. Appl. Microbiol. Biotechnol. 2011, 91 (5), 1277-1286.

(14) Helenius, G.; Buckdahl, H.; Bodin, A.; Nannmark, U.; Gatenholm, P.; Risberg, B. In Vivo Biocompatibility of Bacterial Cellulose. J. Biomed. Mater. Res. - Part A 2006, 76 (2), 431-438.

(15) Scherner, M.; Reutter, S.; Klemm, D.; Sterner-Kock, A.; Guschlbauer, M.; Richter, T.; Langebartels, G.; Madershahian, N.; Wahlers, T.; Wippermann, J. In Vivo Application of TissueEngineered Blood Vessels of Bacterial Cellulose as Small Arterial Substitutes: Proof of Concept? J. Surg. Res. 2014, 189 (2), 340-347.

(16) Peng, S.; Zheng, Y.; Wu, J.; Wu, Y.; Ma, Y.; Song, W.; Xi, T. Preparation and Characterization of Degradable Oxidized Bacterial Cellulose Reacted with Nitrogen Dioxide. Polym. Bull. 2012, $68(2), 415-423$.

(17) Hu, W.; Chen, S.; Yang, J.; Li, Z.; Wang, H. Functionalized Bacterial Cellulose Derivatives and Nanocomposites. Carbohydr. Polym. 2014, 101 (1), 1043-1060.

(18) Carvalho, C.; Santos, R. X.; Cardoso, S.; Correia, S.; Oliveira, P. J.; Santos, M. S.; Moreira, P. I. Doxorubicin: The Good, the Bad and the Ugly Effect. 2009, 3267-3285.

(19) Hilmer, S. N.; Cogger, V. C.; Muller, M.; Couteur, D. G. Le. The Hepatic pharmacokinetics of doxorubicin and liposonal doxorubicin. Drug Metab. Dispos. 2004, 32 (8), 794-799.

(20) Buchholz, T.; Stivers, D.; Stec, J.; Ayers, M.; Clark, E.; Bolt, A.; Sahin, A.; Symmans, W.; Hess, K.; Kuerer, H.; Valero, V.; Hortobagyi, G.; Pusztai, L. Global Gene Expression Changes during Neoadjuvant Chemotherapy for Human Breast Cancer. Cancer J. 2002, 8 (6), 461-468.

(21) Tacar, O.; Sriamornsak, P.; Dass, C. R. Doxorubicin: An Update on Anticancer Molecular Action, Toxicity and Novel Drug Delivery Systems. J. Pharm. Pharmacol. 2013, 65 (2), 157170.

(22) Davis, M. E.; Chen, Z. G.; Shin, D. M. Nanoparticle Therapeutics: An Emerging Treatment Modality for Cancer. Nat. Rev. Drug Discov. 2008, 7 (9), 771-782.

(23) De Souza, R.; Zahedi, P.; Allen, C. J.; Piquette-Miller, M. Polymeric Drug Delivery Systems for Localized Cancer Chemotherapy. Drug Deliv. 2010, 17 (6), 365-375.

(24) Hoffman, A. S. The Origins and Evolution Of -eontrolled" drug Delivery Systems. J. Control. Release 2008, 132 (3), 153-163.

(25) Torchilin, V. P. Multifunctional Nanocarriers. Adv. Drug Deliv. Rev. 2006, 58 (14), 1532-1555.

(26) American Council on Science and Health. Latest Cancer Stats Show Ongoing Reduction in Deaths | American Council on Science and Health http://acsh.org/news/2016/01/08/latest-cancerstats-show-ongoing-reduction-in-deaths/ (accessed Mar 28, 2016).

(27) Fornaro, L.; G., M.; F., L.; E., V.; A., F. Palliative Treatment of Unresectable Metastatic Colorectal Cancer. Expert Opin. Pharmacother. 2010, 11 (1), 63-77.

(28) Sparreboom, A.; Tellingen, O. van; Nooijen, W. J.; Beijnen, J. H. Tissue Distribution, Metabolism and Excretion of Paclitaxel in Mice. Anticancer Drugs 1996, 7, 78-86. 
(29) DeVita, V. T. L.; Rosenberg, T. S. DeVita, Hellman, and Rosenberg's Cancer: Principles and Practice of Oncology; Lippincott, W., Wilkins, Eds.; 2008.

(30) Wolinsky, J. B.; Colson, Y. L.; Grinstaff, M. W. Local Drug Delivery Strategies for Cancer Treatment: Gels, Nanoparticles, Polymeric Films, Rods, and Wafers. J. Control. Release 2012, 159 (1), 14-26. 


\section{Objetivos generales}

* Estudiar el diseño de una matriz biopolimérica basada en celulosa bacteriana para su potencial aplicación como sistema local de liberación de fármacos con fines antitumorales y antineoplásicos.

* Desarrollar una matriz de BC transportadora de fármacos eficiente, sencilla y de bajo costo. Este desarrollo implicará procesos de modificación de la matriz de celulosa bacteriana para elevar la eficiencia en la encapsulación y liberación la coinmovilización de dos moléculas con función complementaria y el desarrollo de sistemas de liberación controlada de fármacos para reducir los efectos secundarios generados por las altas dosis empleadas en administraciones convencionales. 


\title{
Capítulo 1
}

\section{Producción de celulosa bacteriana y modificación ex}

\author{
situ del biomaterial mediante síntesis de
} microparticulas hibridas
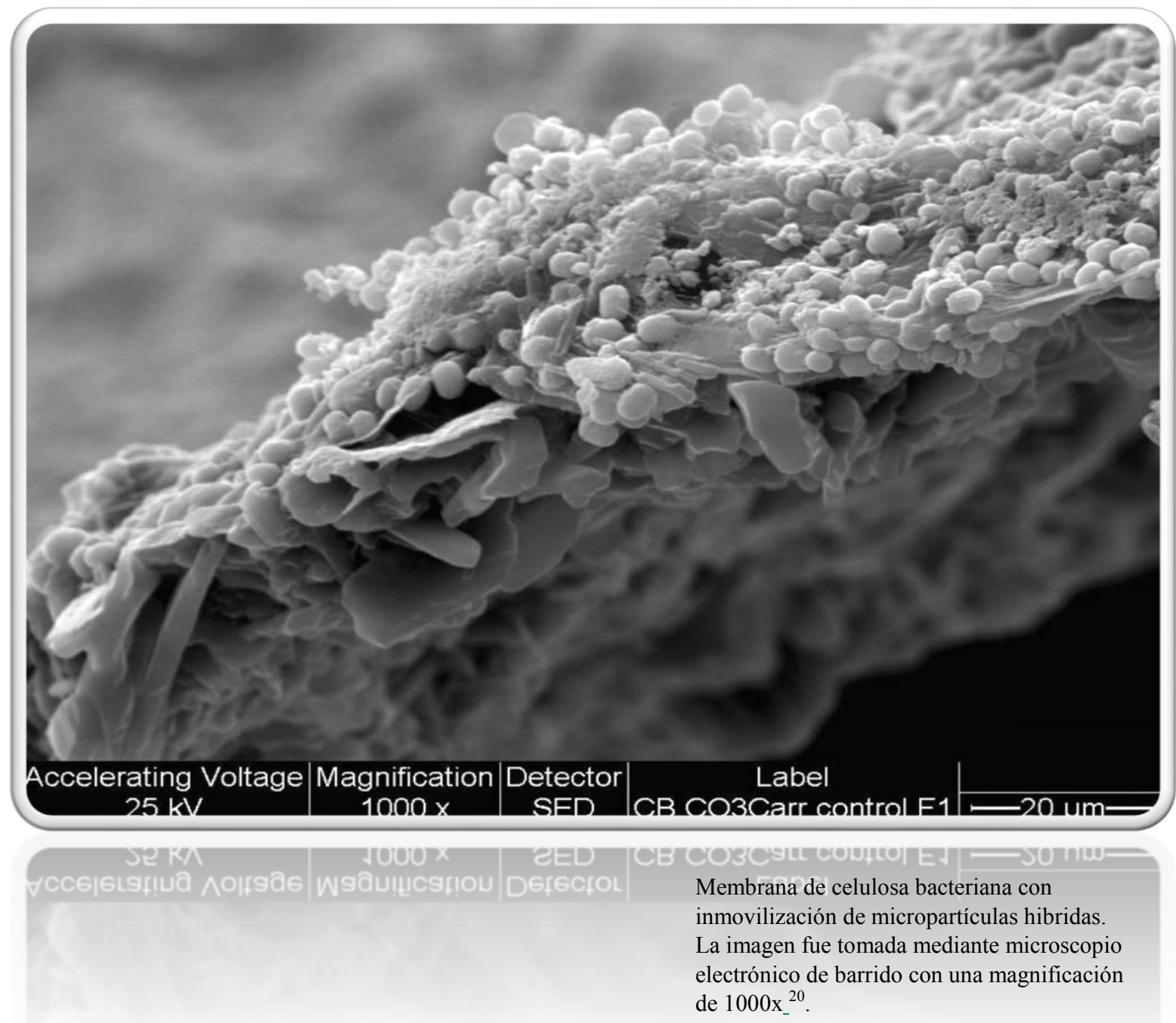


\section{Objetivos específicos:}

Producción de celulosa bacteriana (BC) con diferentes estructuras.

* Purificación y esterilización de la BC.

* Evaluar encapsulación de Doxorrubicina (Doxo) en BC nativa.

* Diseñar estrategia de modificación ex situ con el fin de optimizar encapsulación de Doxo.

Síntesis de micropartículas híbridas sobre matriz de celulosa.

* Incrementar la eficiencia de encapsulación y liberación sostenida de Doxo.

* Caracterización biofísica de la matriz compuesta. 


\subsection{Introducción}

\subsubsection{Producción de celulosa bacteriana (BC)}

La BC puede ser producida en varias formas y tamaños diferentes de acuerdo a las condiciones de cultivo, que comprenden desde películas de espesor micrométrico bajo condiciones de cultivo estático hasta fibras y partículas esféricas en cultivos agitados ${ }^{1}$. Cada forma y tamaño se ajustará a la aplicación para la cual el material es producido. Por otro lado, muchos esfuerzos se realizan a diario para que la producción de celulosa sea económica y para que pueda ser fácilmente escalable ${ }^{2}$.

La síntesis de celulosa bacteriana está relacionada con el metabolismo oxidativo de los carbohidratos ${ }^{3}$. Se ha propuesto que una glucokinasa, fosfoglucomutasa y uridina difosfato (UDP)-glucosa pirofosforilasa son las principales enzimas implicadas en la biosíntesis de $\mathrm{BC}^{4}$. Las vías metabólicas para la síntesis de $\mathrm{BC}$ han sido estudiadas para Komagataeibacter Xylinus (anteriormente llamada Gluconacetobacter Xylinus), la especie productora de $\mathrm{BC}$ más estudiada hasta el momento. K. Xylinus posee dos vías anfibólicas operativas de donde se obtienen los metabolitos para la síntesis de BC: el ciclo de las pentosas para la oxidación de carbohidratos y el ciclo de Krebs para la oxidación de ácidos orgánicos y compuestos relacionados ${ }^{5}$. El nutriente de mayor relevancia para lograr la síntesis de celulosa es la fuente de carbono. Muchos azucares o alcoholes de azucares se utilizan para su producción, desde azucares pequeños como glucosa o fructosa a azucares más complejos como almidón ${ }^{2}$. En algunos estudios comparativos entre azucares simples y complejos, la glucosa ha demostrado poseer el rendimiento más alto en la producción de celulosa ${ }^{6}$. Sin embargo, la glucosa tiene un costo elevado si se piensa en el escalado de la producción de BC. Es por esta razón que muchos trabajos han sido publicados utilizando fuentes alternativas de carbono como desechos industriales y agropecuarios ${ }^{7}$.

Es interesante remarcar que el rendimiento en la producción de celulosa es afectado por la concentración de glucosa inicial en el medio de cultivo. Cuanta más glucosa se consume menor es la producción de celulosa. Este hecho estaría asociado a la acumulación de altas cantidades de ácido glucónico producido a partir del metabolismo de la glucosa. En este sentido, se ha reportado que el uso de alcoholes de azucares como el manitol o D-arabitol pueden generar aumentos de hasta 6 veces en la producción de BC. Luego del cultivo con estas fuentes de carbono no se detectaron descensos de $\mathrm{pH}$ o acumulación de ácido glucónico ${ }^{8}$. 
Respecto a las fuentes de nitrógeno, ha sido reportado que fuentes complejas de nitrógeno como peptona, extracto de levadura o licor de maíz fermentado conducen a una elevada productividad de $\mathrm{BC}$ en comparación con fuentes inorgánicas de nitrógeno ${ }^{7}$. De hecho, la especie productora utilizada durante este trabajo de tesis, K. hansenii, ha sido estudiada en particular por Rani y colaboradores demostrando altos índices de productividad con peptona como fuente de nitrógeno. Además, estos autores han logrado establecer parámetros de máxima producción de BC (Figura 1.1). A partir de ellos se han establecido los mismos valores para nuestra producción de celulosa obteniéndose los valores buscados ${ }^{9}$.

En la Figura 1.1 se puede observar el efecto de la temperatura, del $\mathrm{pH}$, del inoculo y de la glucosa inicial sobre los gramos de BC producida por litro de cultivo. En éste sentido, se expone una temperatura máxima de producción de $27^{\circ} \mathrm{C}$ y un $\mathrm{pH}$ óptimo de 5.5-6.5. El efecto del inoculo inicial parece no ser muy relevante para porcentajes por debajo del 10\%, sugiriéndose la utilización de un inoculo del 5\%. Por último, se describe el efecto de la glucosa sobre la productividad obteniéndose resultados similares a los expresados por Oikawa y colaboradores. Aparentemente la utilización de concentraciones elevadas de glucosa afecta significativamente la producción de $\mathrm{BC}^{8}$.

Figura 1.1 Efectos de diferentes variables de cultivo sobre la producción de BC en $K$. hansenii $^{9}$.
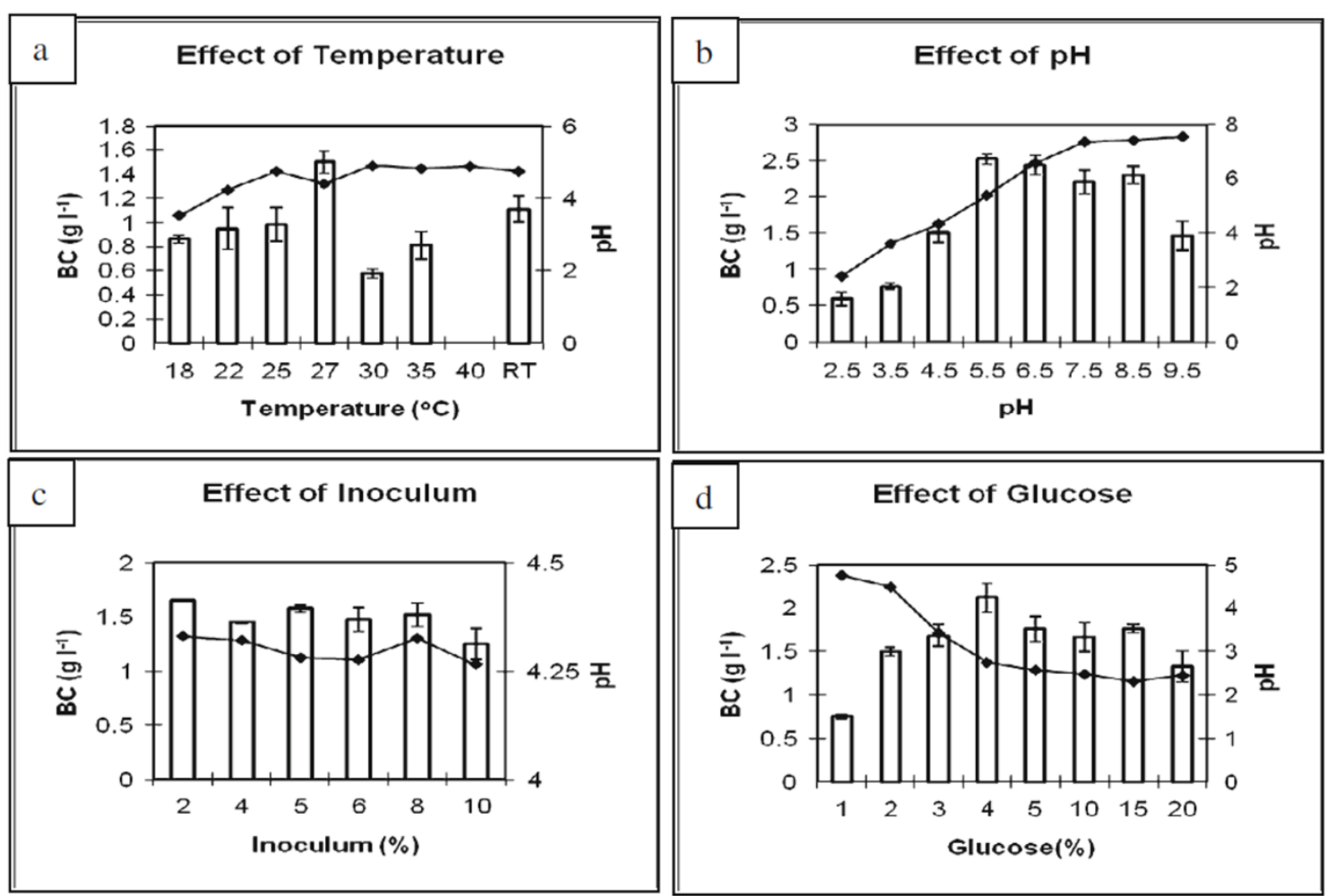


\subsubsection{Modificación ex situ de BC}

Las modificaciones ex-situ de celulosa bacteriana permiten obtener variaciones en las propiedades del biomaterial y también nuevas características matriciales. La estrategia de modificación es básica y simple, consiste en realizar una inmersión de la matriz de celulosa en una solución o suspensión del componente modificante. Este compuesto de incorporará a la matriz tridimensional y se generarán interacciones entre el mismo y las fibras de la celulosa. La interacción puede ser física o química, a través de los numerosos puentes de hidrogeno que se encuentran formando parte de la estructura de la celulosa. Aquellas substancias liquidas con componentes de peso molecular pequeño o también nanopartículas pueden penetrar la red de fibras de celulosa rápidamente y quedar atrapadas dentro de ella. Los numerosos grupos - $\mathrm{OH}$ presentes dentro de la matriz generan rápidamente puentes de hidrogeno con las sustancias incorporadas. Habitualmente se suelen utilizar las membranas de BC, producidas a través de cultivo estático, para este tipo de modificaciones ${ }^{10}$. El mayor obstáculo asociado a este tipo de estrategia corresponde a la naturaleza y tamaño del material de refuerzo debido a que solo compuestos por debajo del micrómetro podrán penetrar e impregnar la matriz. Del mismo modo sucede con los materiales altamente hidrofóbicos, por su naturaleza no pueden penetrar la matriz. Por otro lado, la estructuración de la matriz de BC no es siempre homogénea y por esta razón a veces algunos de estos materiales pueden incorporarse parcialmente.

\subsubsection{Partículas hibridas de $\mathrm{CaCO}_{3}$ como transportadores de fármacos}

El carbonato de calcio constituye uno de los materiales más abundantes de la naturaleza y puede ser encontrada en seis diferentes polimorfismos. Dentro de estos, la vaterita es la forma más estable y con capacidad para poder sintetizar materiales híbridos en presencia de polímeros de diferente naturaleza. La razón de ello radica en el tamaño del cristal, su distribución y geometría ${ }^{11}$. Varios intentos se han llevado a cabo para poder controlar y determinar el polimorfismo y la morfología de la estructura cristalina de $\mathrm{CaCO}_{3}$ de manera de obtener el tamaño, forma y orientación de agregación que uno quiere. Recientemente se ha desarrollado un material basado en la síntesis de $\mathrm{CaCO}_{3}$ en forma laminar sobre membranas de $\mathrm{BC}$ con la finalidad de generar una matriz con potencial aplicación en ingeniería de tejidos ${ }^{12}$. Distintos cambios morfológicos en los

cristales de $\mathrm{CaCO}_{3}$ en presencia de $\mathrm{BC}$ han sido reportados ${ }^{13}$. Sin embargo, estas estrategias han llevado a la obtención de morfologías muy heterogéneas y estructuras 
cristalinas mixtas (vaterita-calcita) de las matrices $\mathrm{BC}-\mathrm{CaCO}_{3}$, las cuales son inestables en condiciones ambientales y no son apropiadas para objetivos tecnológicos como la aplicación en liberación controlada de fármacos.

Las partículas utilizadas durante esta primera etapa de tesis corresponden a un desarrollo propio de nuestro laboratorio. Son partículas híbridas compuestas por cristales de $\mathrm{CaCO}_{3}$ y otra parte polimérica de $\lambda$-carragenina. Las carrageninas son polímeros lineales compuestos por esteres de sulfato de galactosa y 3,6-anhidro galactosa unidos por enlaces $\alpha-1,3$ y $\beta-1,4$. Son materiales económicos, producidos por procesos amigables con el medio ambiente y actualmente son utilizados como agentes gelificantes, espesantes, emulsificantes y estabilizantes en la industria alimenticia y farmacéutica. Además, se han reportado ciertas actividades biológicas de estos polímeros como anticoagulantes, inmunomoduladores, antivirales, antitromboticos y antitumorales ${ }^{14}$.

Estas partículas, denominadas \#anostructured hybrid microparticles" (N-hMPs), fueron analizadas por diferentes técnicas biofísicas que incluyen técnicas espectroscópicas y de microscopia. Los resultados indican que poseen una estructura esférica y una conformación cristalina de hasta un $95 \%$ de vaterita ${ }^{15}$. Dichas partículas son consideradas muy estables y con estructuras inteligentes" debido a que poseen una respuesta de liberación del fármaco sensible al $\mathrm{pH}$ del entorno. Sumado a ello, se demostró que las N-hMPs poseen una elevada eficiencia de carga de Doxorrubicina y una citotoxicidad prácticamente nula.

\subsection{Materiales y métodos}

\subsubsection{Materiales}

La carragenina lambda fue adquirida a Satiagel (SKW Biosystems, Buenos Aires, Argentina). La Doxorrubicina (Doxo, $\mathrm{PM}=543,0$ ) fue donada por la empresa farmacéutica LKM (Argentina). Todos los demás reactivos utilizados fueron de grado analítico y microbiológico adquiridos a Sigma-Aldrich (St. Louis, MO) o Merck (Darmstadt).

\subsubsection{Producción de celulosa bacteriana (BC)}

La síntesis de celulosa bacteriana se llevó a cabo mediante el cultivo de Komagataeibacter hansenii (ATCC 23769). La cepa fue cedida por el Prof. Luismar Porto (Universidad Federal de Santa Catarina (UFSC), Brasil). El medio de cultivo fue 
preparado con los siguientes componentes: manitol (25 gr/L), extracto de levadura (5 gr/L), peptona (3 gr/L). Finalmente se ajusta el $\mathrm{pH}$ a 6,5 y se esteriliza con autoclave. El cultivo fue mantenido en condiciones estáticas (sin agitación) para la correcta producción de las membranas de celulosa.

El cultivo se realizó por diferentes periodos de tiempo, en condiciones estáticas a $30^{\circ} \mathrm{C}$. Las membranas fueron recolectadas y colocadas en una solución de hipoclorito de sodio $(0.1 \%)$ por 10 minutos. Luego se lavaron reiteradas veces con agua destilada y se las coloca en solución de $\mathrm{NaOH}(1.0 \mathrm{~N})$ por 24 horas a $60^{\circ} \mathrm{C}$. Posteriormente de este proceso las membranas se vuelven a lavar reiteradas veces con agua destilada hasta obtener en el sobrenadante un $\mathrm{pH}$ aproximadamente neutro. Por último, se colocan en un recipiente de vidrio con tapa y se autoclavlan a $121^{\circ} \mathrm{C}$ por $15-20$ minutos.

\subsubsection{Síntesis de micropartículas hibridas de $\mathrm{CaCO}_{3}$ (N-hMPs)}

Las micropartículas se sintetizaron en vasos de precipitado de vidrio mediante cristalización coloidal de en presencia de glicina (Gly), $\mathrm{NaCl}, \mathrm{Na}_{2} \mathrm{CO}_{3}$ y lambda carragenina. Una solución acuosa de $\mathrm{CaCl}_{2}(3,2 \%)$ en buffer de $\mathrm{Gly}-\mathrm{NaCl} 1,25 \mathrm{M}$ (pH= 10) fue preparada y guardada a $-20^{\circ} \mathrm{C}$ hasta el momento de ser utilizada. Por otro lado, se preparó una solución de $3,2 \% \mathrm{Na}_{2} \mathrm{CO}_{3}$ al en agua MilliQ para ser usada inmediatamente. En una síntesis típica, 9,0 ml de la solución 3,2\% de $\mathrm{Na}_{2} \mathrm{CO}_{3}$ se mezcla con $2,0 \mathrm{ml}$ de solución $1.0 \%$ de lambda-carragenina en un vaso de precipitado con agitación de $1000 \mathrm{rpm}$ por $1 \mathrm{~min}$ a $0^{\circ} \mathrm{C}$. Seguido, 9,0 $\mathrm{ml}$ de $\mathrm{CaCl}_{2}(3,2 \%)$ en buffer de Gly- $\mathrm{NaCl} 1,25 \mathrm{M}(\mathrm{pH}=10)$ se adicionan y mezclan por agitación durante 5 minutos. La concentración final de la mezcla es $0,1 \%$ del polímero y $1,6 \%$ de los iones $\mathrm{Ca}^{+2} \mathrm{y} \mathrm{CO}_{3}{ }^{-2}$. Luego se adicionan $30,0 \mathrm{ml}$ de agua MilliQ previamente enfriada a $4^{\circ} \mathrm{C}$ y el precipitado de $\mathrm{CaCO}_{3}$-biopolimero se colecta por centrifugación. El precipitado se lava nuevamente con $30,0 \mathrm{ml}$ de agua MilliQ y se vuelve a centrifugar. Por último, el precipitado es congelado con nitrógeno líquido y liofilizado. El producto se almacena en desecador a temperatura ambiente hasta ser utilizado ${ }^{15}$.

\subsubsection{Síntesis de N-hMPs sobre matriz de BC}

Las micropartículas se sintetizaron sobre membranas de $\mathrm{BC}$. El proceso se inicia colocando las membranas en la solución de $3,2 \%$ de $\mathrm{Na}_{2} \mathrm{CO}_{3}$ con de solución $1,0 \%$ de lambda carragenina en un vaso de precipitado con agitación de $100 \mathrm{rpm}$ y a temperatura ambiente por 20 minutos. Luego, se coloca rápidamente la solución de $\mathrm{CaCl}_{2}(3,2 \%)$ en buffer de Gly- $\mathrm{NaCl} 1.25 \mathrm{M}(\mathrm{pH}=10)$ y se aumenta la agitación a $300 \mathrm{rpm}$, dejando la 
solución en estas condiciones por 20 minutos. Luego del proceso, cada membrana es lavada en agua destilada para desprender todas aquellas microparticulas que no estén embebidas en ella.

\subsubsection{Caracterización físico-química del biomaterial}

\subsubsection{Análisis de termogravimetría (TGA)}

Se llevaron a cabo medidas termogravimétricas de las matrices basadas en celulosa bacteriana utilizando un equipo Shimadzu TGA-50 (Tokio, Japón). Los ensayos se realizaron en un rango de temperatura de entre $20^{\circ} \mathrm{C}$ y $900^{\circ} \mathrm{C}$ a una velocidad de calentamiento de $10^{\circ} \mathrm{C} / \mathrm{min}$ bajo una atmosfera de $\mathrm{N}_{2}$.

\subsubsection{Espectroscopia de transformada de Fourier (FTIR)}

El espectro de FTIR de las muestras liofilizadas fue analizado mediante un espectrofotómetro de IR (Thermo Scientific Nicolet, 6700 model, CT, USA) con un módulo de ATR (attenuated total reflectance) acoplado. Se realizaron 32 escaneos de cada muestra en el rango de $600-4000 \mathrm{~cm}^{-1}$ y con una resolución de $4 \mathrm{~cm}^{-1}$.

\subsubsection{Estudios de microcopia}

\subsubsection{Microscopia de barrido electrónico (SEM)}

Las muestras se deshidrataron completamente mediante la técnica de punto crítico. Luego, la superficie fue recubierta con un metalizado de oro (BalzersSCD 030) obteniendo una cobertura de entre $15 \mathrm{~nm}$ y $20 \mathrm{~nm}$ de espesor. La superficie de las muestras y la morfología se observó mediante SEM (Philips SEM 505model, Rochester, NY, USA). Las imágenes fueron analizadas mediante un software de digitalización de imágenes (Soft Imaging System ADDA II).

\subsubsection{Microscopía confocal (confocal laser scanning microscopy, CLSM)}

Imágenes de fluorescencia mediante CLSM fueron tomadas utilizando la autofluorescencia de Doxo. Membranas de celulosa con y sin carga de Doxo fueron analizadas mediante el microscopio confocal (Leica model TCS SP5, Leica Microsystems CMS GmbH, Mannheim, Alemania). El microscopio colectó imágenes de 8 bits utilizando cuatro detectores de fluorescencia y un detector de trasmisión para los campos más brillantes. El objetivo utilizado fue un HCX PL APO CS 63,0, con una banda de emisión de 415-485 nm. La configuración del pinole [m] 191,1 mm, y pinhole [air] 2,0 con un modo de barrido en XYZ. El software utilizado para el control del microscopio y análisis de las imágenes fue Leica Application Suite Advanced Fluorescence (LAS AF) software. 


\subsubsection{Ensayos de encapsulación del fármaco Doxorrubicina (Doxo) y evaluación de la eficiencia de encapsulación (\%EE)}

Los distintos sistemas de BC fueron inmersos en soluciones de distinta concentración de Doxo, en el rango entre 258,6 y $2586,6 \mathrm{nmols} / \mathrm{ml}$. Las soluciones se prepararon en buffer MES $100 \mathrm{mM}(\mathrm{pH}=6,5)$ y se agitaron a $300 \mathrm{rpm}$ por 20 horas a temperatura ambiente. Se realizó la cuantificación de Doxo mediante espectrofluorimetría (Perkin Elmer LS 50B, Japan) con una $\lambda_{\text {exc }}=473 \mathrm{~nm}$ y $\lambda_{\mathrm{em}}=588 \mathrm{~nm}$. Las membranas fueron retiradas de los viales y la Doxo residual se analizó en los sobrenadantes. Seguido las membranas fueron lavadas 3 veces en solución $145 \mathrm{mM} \mathrm{NaCl}$ con $100 \mathrm{mM}$ buffer MES $(\mathrm{pH}=6,5)$. La eficiencia de encapsulación se calculó de la siguiente manera:

$$
\text { Encapsulación de Doxo }=\frac{\text { Doxo }_{0}-\text { Doxo }_{t}}{W_{B C}}
$$

En donde Doxo $_{0}$ y Doxo $_{t}$ corresponden a los micromoles de Doxo en la solución de inmersión a tiempo cero y a tiempos $t$ respectivamente. $\mathrm{Y} \mathrm{W}_{\mathrm{BC}}$ representa la masa de la membrana de celulosa bacteriana en gramos.

\subsubsection{Ensayos de liberación de Doxorrubicina}

Las membranas de $\mathrm{BC}$ fueron colocadas en $1,5 \mathrm{ml}$ de buffer PBS $10 \mathrm{mM}$ en tubos tipo Eppendorf de $2,0 \mathrm{ml} \mathrm{a} 37^{\circ} \mathrm{C}$. Se tomaron muestras de $500 \mu \mathrm{l}$, reemplazando el volumen con medio fresco a intervalos de tiempo definidos. La concentración de Doxo fue determinada por fluorescencia. Tres experimentos independientes de liberación fueron llevados a cabo por duplicado o triplicado para cada sistema de membrana y para cada concentración inicial de Doxo ensayada. La liberación de la Doxo desde las matrices se estudió en un rango de $\mathrm{pH}$ de 5,8-7,4 utilizando buffer fosfato $10 \mathrm{mM}$.

\subsubsection{Análisis estadístico}

Todos los ensayos, incluyendo las caracterizaciones del biomaterial, fueron realizados al menos por duplicado de forma independiente. Se realizaron las comparaciones de las medias de cada ensayo por un análisis de varianza (ANOVA) seguido por un análisis de Fisher para evaluar la existencia de diferencias significativas. 


\subsection{Resultados y discusión}

\subsubsection{Producción de la celulosa bacteriana}

Las condiciones de cultivo que utilizamos fueron establecidas específicamente para la cepa K. Hansenii (ATCC 23769). Sin embargo, se debe mencionar que las diferencias en la temperatura y en el tiempo de incubación, generan membranas de celulosa de diferente espesor. Cuanto más tiempo mayor espesor tendrá la membrana, pero se debe tener cuidado de que la misma no se reseque. Esto suele suceder a tiempos de cultivo prolongados, en general mayores a los 14 días. Por otro lado, si la incubación no se realiza en un intervalo de temperatura determinada la celulosa puede incluso no producirse. En los experimentos desarrollados se ha establecido la temperatura de producción a $29^{\circ} \mathrm{C}$, y se ha trabajado de manera constante en las mismas condiciones experimentales. Si la temperatura se eleva dos grados por encima de la establecida, no se registra formación de las membranas de celulosa. Si la temperatura es inferior a los $26^{\circ} \mathrm{C}$ la membrana de celulosa se forma, pero se enlentece considerablemente su velocidad de producción.

Se ha producido $\mathrm{BC}$ con diferentes formas debido a que ésta adopta la morfología de la superficie del recipiente en que se realiza el cultivo. Habitualmente los cultivos se han realizado en placas de pocillos, Las placas poseen distinto número de pocillos, cuanto más pequeño el número, el pocillo es de mayor diámetro.

Las membranas de $\mathrm{BC}$ se limpiaron en primer término con hipoclorito de sodio por medio de una inmersión de 10 minutos. Luego se lavan con abundante agua destilada y se las incuba por 12 horas a $60^{\circ} \mathrm{C}$ en una solución $1,0 \mathrm{~N}$ de $\mathrm{NaOH}$. El hidróxido de sodio permite hidrolizar el material celular remanente y otras moléculas. Por último, las membranas se lavan con agua destilada reiteradas veces hasta obtener un $\mathrm{pH}$ neutro y se esterilizan por autoclave en un recipiente conteniendo agua destilada.

Una vez estériles las membranas pueden permanecer sin mostrar signos visibles de contaminación bacteriana o fúngica por más de dos años.

\subsubsection{Modificación de la matriz}

En principio se realizaron pruebas de encapsulación y liberación con celulosa nativa, es decir, sin modificación alguna. Esto nos permitiría conocer macroscópicamente las propiedades de interacción entre la celulosa y la Doxo, las cuales serían las responsables de retener al fármaco dentro de la matriz y permitir su liberación gradual. Por las 
propiedades conocidas y reportadas de la BC como su elevada hidrofilicidad y un espacio interfibras grande, podíamos plantear la hipótesis de que tanto la encapsulación como liberación de la Doxo serían poco eficientes. Los resultados de estos ensayos se muestran a continuación:

\begin{tabular}{cc}
\hline BC sin modificar & $\mathbf{( \% )}$ \\
\hline Encapsulación & $11.0 \pm 1.8$ \\
\hline Liberación & $85.0 \pm 7.2$ \\
\hline
\end{tabular}

Las membranas de BC se incubaron por 24 horas con una solución de 1,0 mg/ml de Doxo. Luego de los lavados correspondientes se colocaron en buffer fosfato a $\mathrm{pH}$ 7,4 y se incubó por 72 horas a $37^{\circ} \mathrm{C}$, observándose una perdida casi total de la Doxorrubicina encapsulada en la matriz.

Observando los resultados expresados anteriormente pudimos corroborar la hipótesis planteada y nos encontramos en la necesidad de plantear una estrategia de modificación de la BC para garantizar una mayor retención de la Doxo. El método de modificación debía cumplir ciertos requisitos fundamentales, a saber: 1) el biomaterial híbrido, es decir una vez modificado, debería poseer las propiedades básicas de la celulosa, 2) el método de modificación debería ser mediante el uso de técnicas de Química Verde de manera de poder minimizar el daño al medioambiente, 3) el biomaterial debía continuar siendo completamente biocompatible.

En un trabajo previo de nuestro laboratorio fue descrita la síntesis de micropartículas basadas en una estructura de $\mathrm{CaCO}_{3}$ producidas con distintos biopolímeros solubles ${ }^{15}$. Las micropartículas hibridas (N-hMPs) demostraron poseer una excelente capacidad de encapsulación de Doxo y una liberación gradual en el tiempo. El presente desafío fue como poder inmovilizar dichas partículas en las membranas de BC.

En un primer término, se procedió a seleccionar un biopolímero como agente nucleante para la formación de las micropartículas. Se ha podido establecer que entre un grupo de polímeros seleccionados (pectinas y carrageninas), que la $\lambda$-carragenina fue la que demostró mayor interacción con la Doxo debido a la presencia de un mayor número de grupos polares (e.g., $\mathrm{R}-\mathrm{SO}_{3}{ }^{-}$). Los grupos sulfonato presentes en el biopolímero pueden interaccionar mediante sus grupos polares con la Doxo ${ }^{15}$. Una vez establecido el tipo de partícula con la que se trabajaría, se procedió a intentar modificar la síntesis 
de las N-hMPs de manera de poder colocar las membranas de celulosa dentro del medio de síntesis.

Luego de ajustar diversos parámetros experimentales de la síntesis se logró adaptar una metodología que permitió la generación de las N-hMPs en la membrana de BC. Se inicia con una deshidratación parcial de las membranas colocándolas por 10 min en flujo laminar. La deshidratación de la $\mathrm{BC}$ nativa es un proceso completamente reversible hasta un grado de deshidratación en que no es posible volver a la conformación estructural inicial de la matriz de $\mathrm{BC}{ }^{16}$. Cuando la membrana se encuentra parcialmente deshidratada se la introduce en la solución de $\mathrm{Na}_{2} \mathrm{CO}_{3}$ (ver concentraciones en Materiales y Métodos) por 20 minutos con agitación constante con el fin de adsorber la mayor cantidad de $\mathrm{Na}_{2} \mathrm{CO}_{3}$ sobre la membrana. A continuación, se coloca la solución de $\lambda$-carragenina y se deja nuevamente en agitación por 20 minutos más. Luego de estas dos etapas la membrana se observa completamente rehidratada y se adiciona el buffer con $\mathrm{CaCl}_{2}$ para lograr la co-precipitación del $\mathrm{CaCO}$. El proceso de precipitación se mantiene por 20 minutos en agitación. Posteriormente, se retiran las membranas realizando varios lavados con agua destilada. Y posteriormente, se llevan adelante los ensayos de caracterización del biomaterial para poder analizar y comprender las propiedades del mismo.

El análisis de estabilidad y descomposición térmica de las membranas de $\mathrm{BC}$ se realizaron mediante análisis termogravimétrico (TGA) (Figura 1.3A). Los controles efectuados fueron $\mathrm{BC}-\lambda$-carragenina, sin el proceso de co-precipitación; también se utilizaron las membranas de $\mathrm{BC}$ con la formación de partículas de $\mathrm{CaCO}_{3}$ pero sin el agregado de $\lambda$-carragenina. En la tabla I se observa que los comportamientos de descomposición térmica son relativamente similares en todos los casos a excepción del control $\mathrm{BC}-\mathrm{CaCO}_{3}$, donde básicamente se observa una perdida más rápida en el peso del material. 
Tabla I. Parámetros correspondientes a TGA para las membranas de BC con N-hMPs y sus respectivos controles.

\begin{tabular}{ccccc}
\hline & \multicolumn{4}{c}{ Celulosa Bacteriana } \\
\cline { 2 - 5 } Parámetro & Nativa & BC-Carr & BC-CaCO 3 & $\begin{array}{c}\text { BC N- } \\
\text { hMPs }\end{array}$ \\
\hline $\begin{array}{c}\text { Pérdida de masa (\%) } \\
\left(200-400^{\circ} \mathrm{C}\right)\end{array}$ & 42.8 & 44.4 & 48.4 & 47.0 \\
$\mathrm{~T}_{50 \%}\left({ }^{\circ} \mathrm{C}\right)$ & 390.0 & 371.3 & 357.2 & 376.0 \\
Residuo a $800^{\circ} \mathrm{C}(\%)$ & 30.8 & 34.5 & 27.0 & 29.3 \\
\hline $\begin{array}{l}\text { Nota: Nativa corresponde a la BC sin modificar. BC-Carr, corresponde a la BC con agregado de } \lambda \text {-carragenina } y \\
\text { sin partículas. BC-CaCO3, corresponde a las partículas sin } \lambda \text {-carragenina. BC N-hMPs, corresponde a BC } \\
\text { con partículas hibridas. }\end{array}$
\end{tabular}

La presencia de la $\lambda$-carragenina $y$, en consecuencia, de las N-hMPs permite obtener un comportamiento más similar al del material sin modificar en cuanto a lo que respecta a los parámetros de la Tabla I.

En la Figura 1.3B se pueden observar dos pasos de descomposición tanto para la BC sin modificar y como para la modificada. El primer escalón se puede atribuir al contenido de agua sin interacción fuerte con la matriz, observable en el rango de temperatura desde $65^{\circ} \mathrm{C}$ a $100^{\circ} \mathrm{C}$, y en donde se observa una pérdida de masa de aproximadamente $7 \%$ en ambas muestras. El segundo paso o escalón se puede atribuir a la descomposición térmica del biomaterial para ambos casos. En este caso, se puede observar en la Figura 1.3C, en donde se grafica la primera derivada de la curva de TGA (DTGA un corrimiento en la temperatura de descomposición térmica desde $315.8^{\circ} \mathrm{C}$ a $357.9^{\circ} \mathrm{C}$ para la $\mathrm{BC}$ y $\mathrm{BC} \mathrm{N}-\mathrm{hMPs}$, respectivamente. En consecuencia, es posible considerar como un aumento en la estabilidad térmica del material atribuido a la presencia de las N-hMPs. Este último hecho, podría estar asociado a la presencia predominante de una conformación estructural de vaterita presente en las N-hMPs. 
Figura 1.3 Análisis termogravimétrico: (A) curvas de TGA para BC N-hMPs y los controles correspondientes, (B) curvas de TGA solo para BC N-hMPs y el control de BC nativa, (C) curvas de DTGA para BC N-hMPs y el control de BC nativa.

A

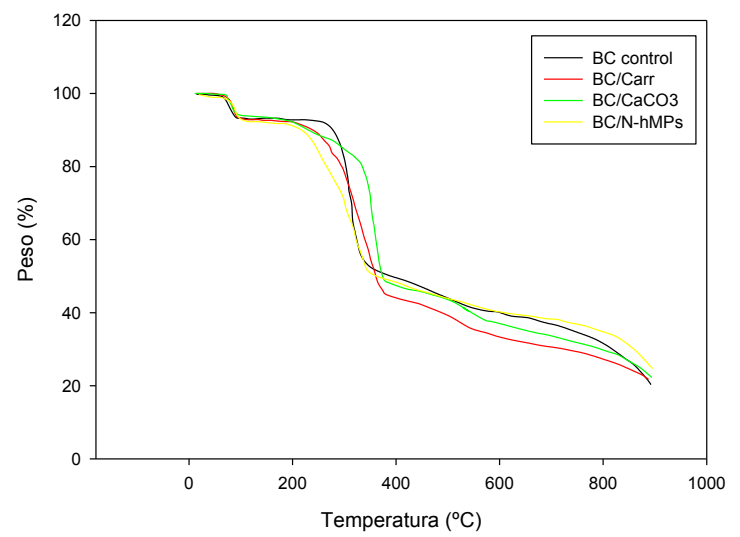

B

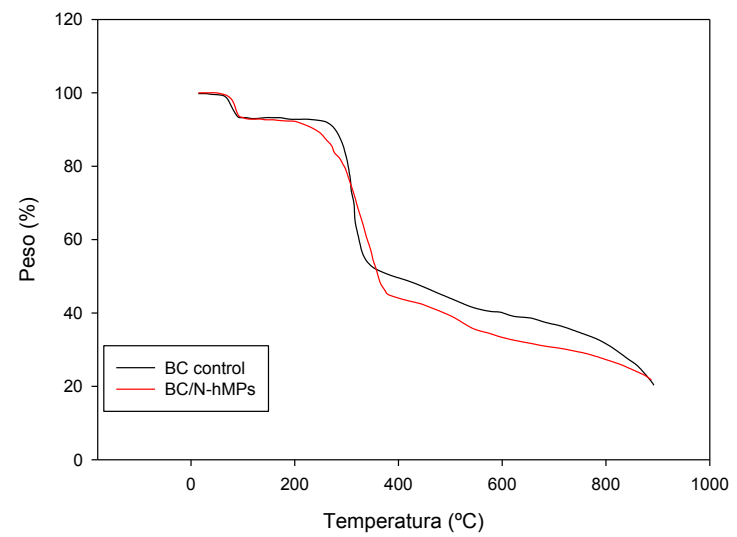

C

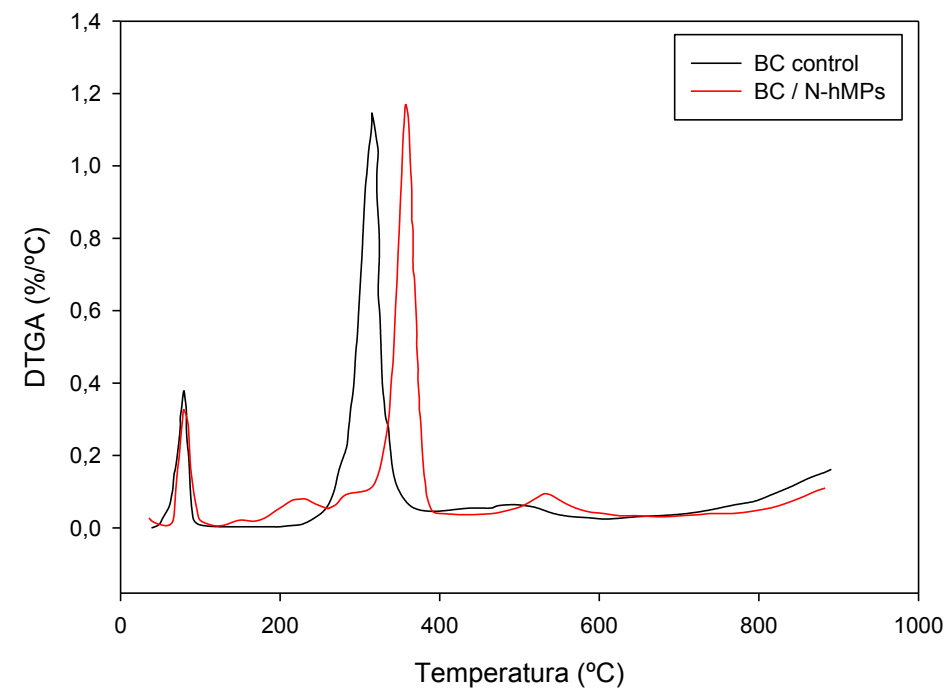

Las imágenes obtenidas mediante microscopía electrónica de barrido (SEM) se observa la morfología de las N-hMPs cuando la síntesis se realiza sin la presencia de las membranas de BC (Figura 1.4A). La síntesis de N-hMPs permite obtener una suspensión de partículas homogénea en tamaño y morfología ${ }^{15}$. La Figura 1.4B exhibe la estructura de la red de celulosa bacteriana nativa en donde las fibras de BC se entrecruzan entre si formando una densa matriz tridimensional. La estructura de las membranas de $\mathrm{BC}$ contiene dos caras totalmente diferentes. Por un lado, la cara de la 
membrana que queda en contacto con el aire en el cultivo posee una estructura bien cerrada y densa. Por el otro lado, la cara de la membrana que queda en contacto con el medio de cultivo posee una estructura más laxa con forma de gel en donde el entrecruzado de las fibras de celulosa es más abierto y con cadenas de celulosa pendientes de la membrana. Cuando las membranas se colocan en la solución de síntesis de las N-hMPs, las partículas se forman en la cara más laxa con consistencia gelatinosa. Las partículas se sintetizan entre las fibras de celulosa como se ha podido observar en la imagen de SEM de la Figura 1.4C.

Es relevante mencionar, que las imágenes de microscopía han permitido observar las micropartículas formadas en las membranas de $\mathrm{BC}$ son muy similares en cuanto a morfología y tamaño (2-3 mm de diámetro) con las micropartículas libres reportadas en la bibliografia ${ }^{15,17}$.

Figura 1.4 Microscopia de barrido electrónico. (A) N-hMPs, (B) BC native, (C y D) NhMPs en la red de BC.

A

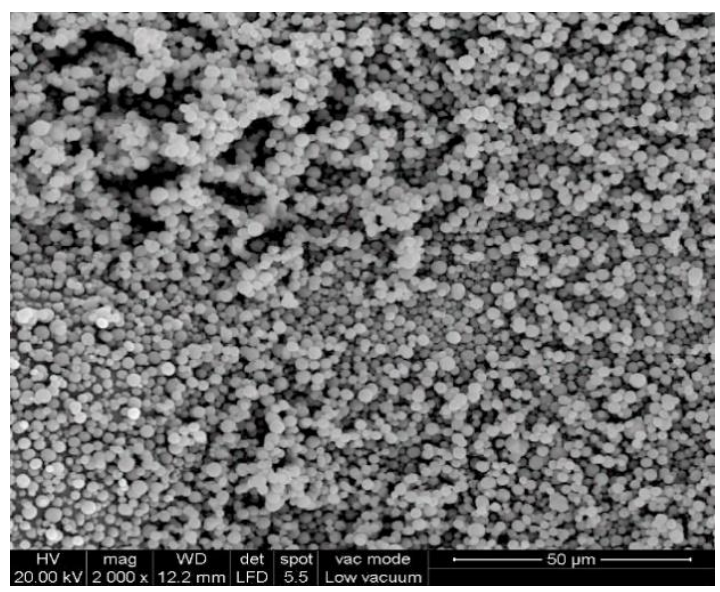

C

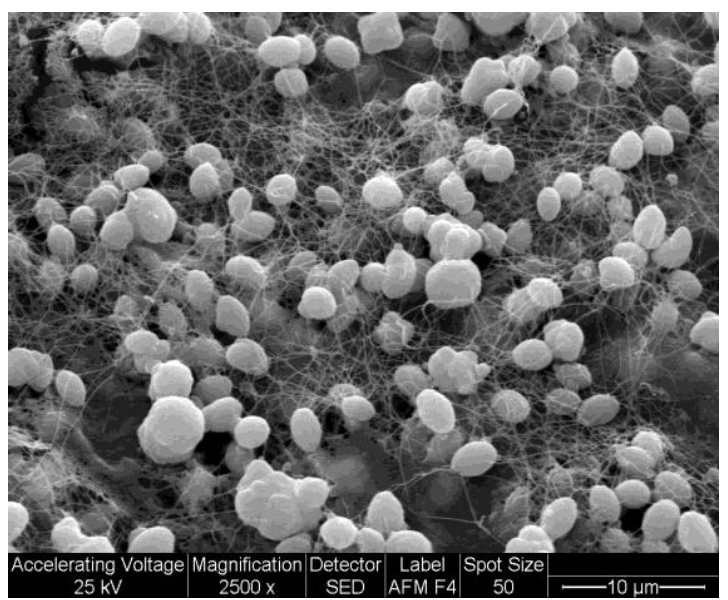

B

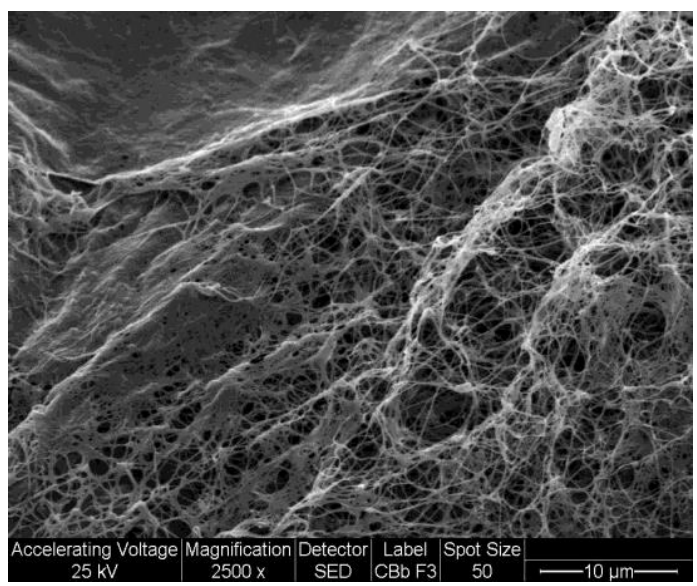

D

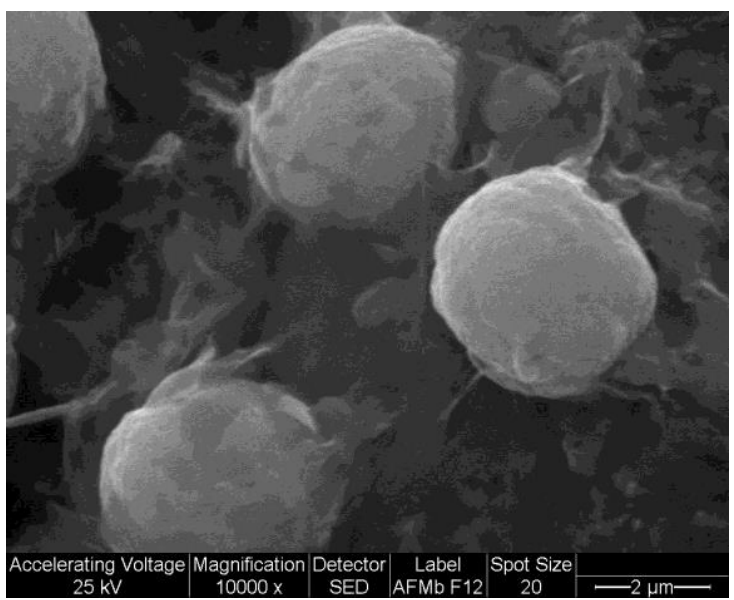


A continuación, se procedió a realizar cortes trasversales de las membranas $\mathrm{BC} / \mathrm{N}$ hMPs. En tal sentido, se colocaron las membranas de BC en nitrógeno líquido. De manera muy rápida se retiran y se parten las membranas por la mitad sin dar lugar a que se pierda su estado solidificado. Acto seguido, se colocan nuevamente en nitrógeno líquido y se pasa a realizar el proceso de liofilización para poder ser analizadas por SEM. Las imágenes obtenidas de estas muestras (Figura 1.5 A y B) dejan de manifiesto que las partículas se forman sólo en la superficie más gelatinosa de la membrana observándose como las fibras de celulosa pueden interaccionar con las N-hMPs de forma directa y favorecer su proceso de síntesis sobre la membrana. Por otro lado, no se observó la presencia o restos de partículas en el interior de la red de celulosa.

Figura 1.5 Cortes transversales de membranas BC/N-hMPs observados por SEM a diferentes aumentos.

A

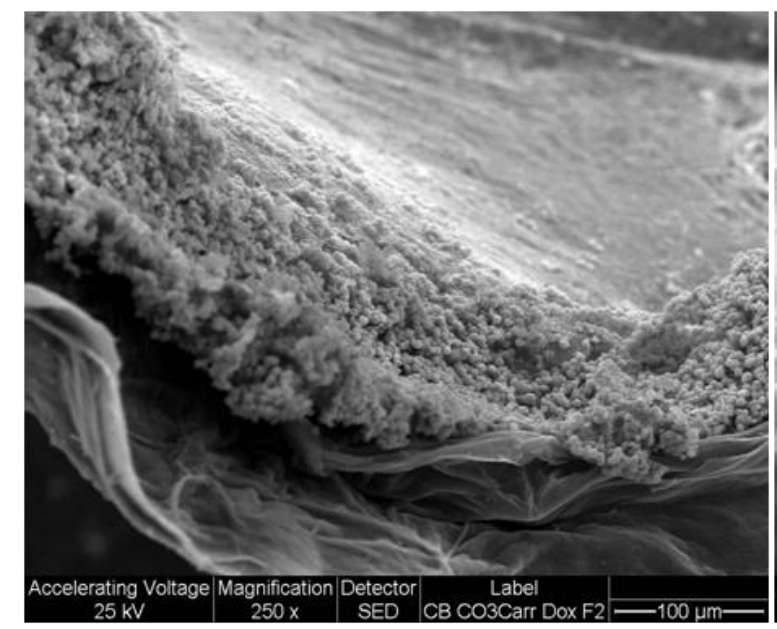

B

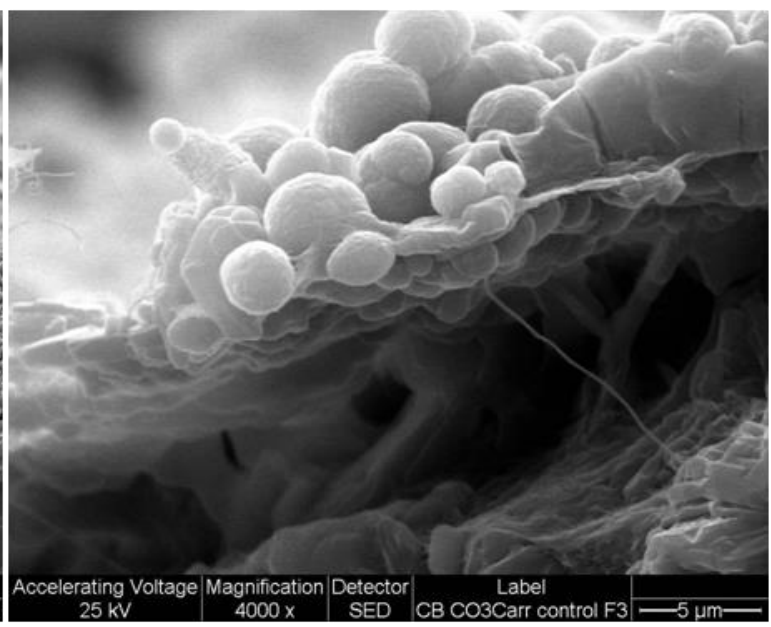

Uno de los factores que podía alterar la estructura de la matriz BC/N-hMPs, ya sea por la agitación o por el cambio en las condiciones del medio, es el proceso de carga de Doxo. Por esta razón, luego de realizar la carga se tomaron imágenes de SEM nuevamente. La Figura 1.6 muestra que la carga de Doxo no modifica la distribución, tamaño o morfología de las N-hMPs en la membrana de BC. Basándonos en la conformación molecular de la Doxo y en las propiedades de las N-hMPs, estimamos que la Doxo incorporada en la matriz se encontraría nucleada mayoritariamente en las partículas. Para confirmar la nucleación de la Doxo en las micropartículas se realizaron 
pruebas de microscopia confocal con el fin de, utilizando la autofluorescencia de la Doxo, poder localizar su posición en la membrana.

Figura 1.6. Imágenes de SEM de BC/N-hMPs con una carga de $37 \mu$ moles de Doxo por gramo de matriz.

A

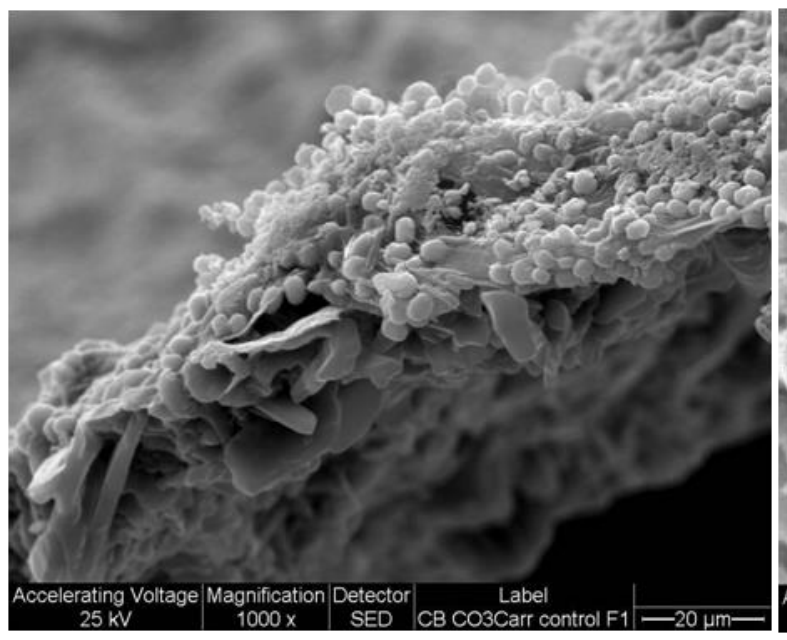

B

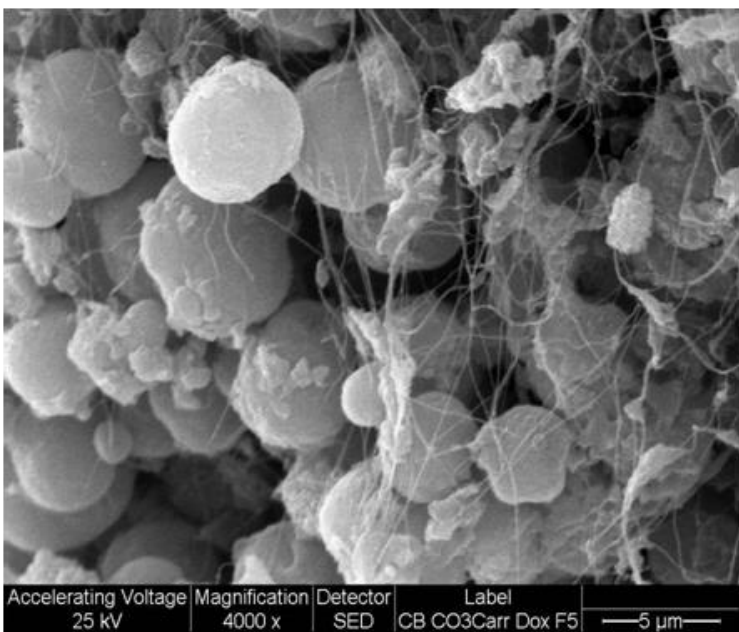

Las imágenes de microscopía confocal de las matrices de $\mathrm{CB}$ pueden ser observadas en la Figura 1.7. La Figura 1.7A muestra como la Doxo se distribuye de manera homogénea en una membrana de $\mathrm{BC}$ sin encontrarse una preferencia en cuanto a la localización de la droga. Cuando la membrana de $\mathrm{BC}$ se embebe en una solución de $\lambda$-carragenina y luego se la expone al proceso de carga de la Doxo, es posible observar como nuevamente la carga del fármaco se distribuye de forma homogénea en todo el material. Algunos puntos se pueden observar con una mayor intensidad de fluorescencia probablemente debido a la presencia de zonas con mayor cantidad de $\lambda$-carragenina y/o de un fenómeno de agregación de la Doxo (Figura 1.7B). Por otro lado, cuando se realiza el control de las membranas con partículas de $\mathrm{CaCO}_{3}$ se puede observar algo similar a lo mencionado anteriormente, aunque la intensidad de fluorescencia detectada es más baja en la membrana. En el caso de las membranas BC/N-hMPs se detectó que la fluorescencia se concentra específicamente en las micropartículas. Muy pocos indicios de fluorescencia fueron observados en zonas de la membrana donde no había partículas (Figura 1.7D). La concentración de la fluorescencia observada hizo evidente el hecho de que efectivamente la Doxo encapsulada se nucleaba en las partículas. 
Figura 1.7 Imágenes de microscopia confocal realizadas para diferentes membranas cargadas con $37 \mu$ moles de Doxo por gramo de matriz. (A), BC; (B), BC$\lambda$-Car; (C), BC-CaCO3; (D), BC/N-hMPs.

A

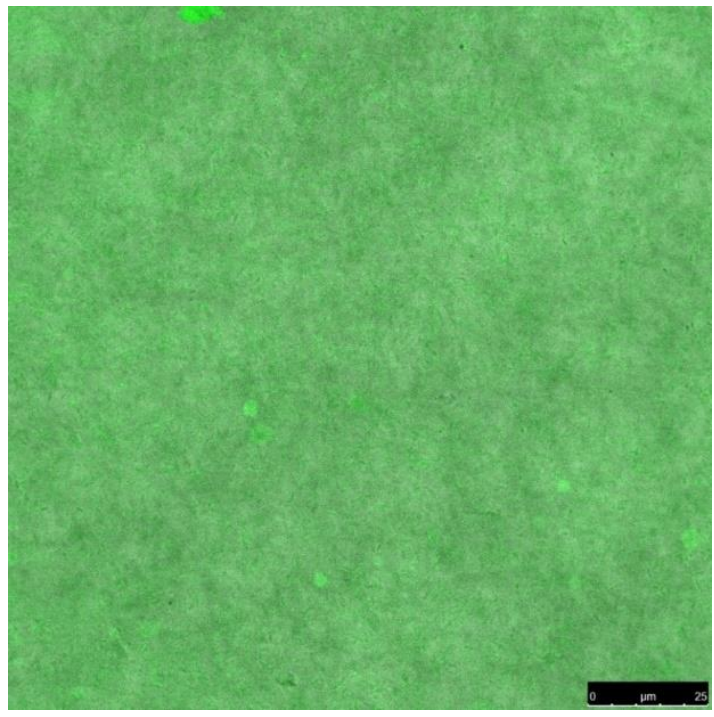

C

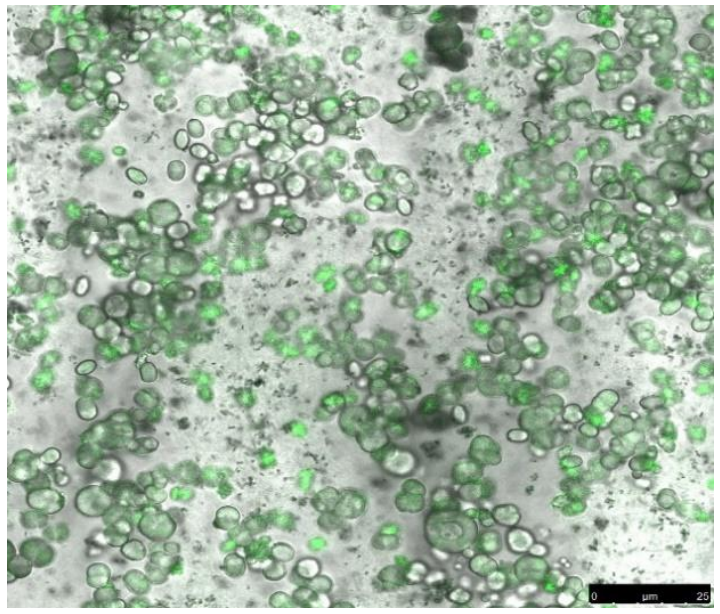

B

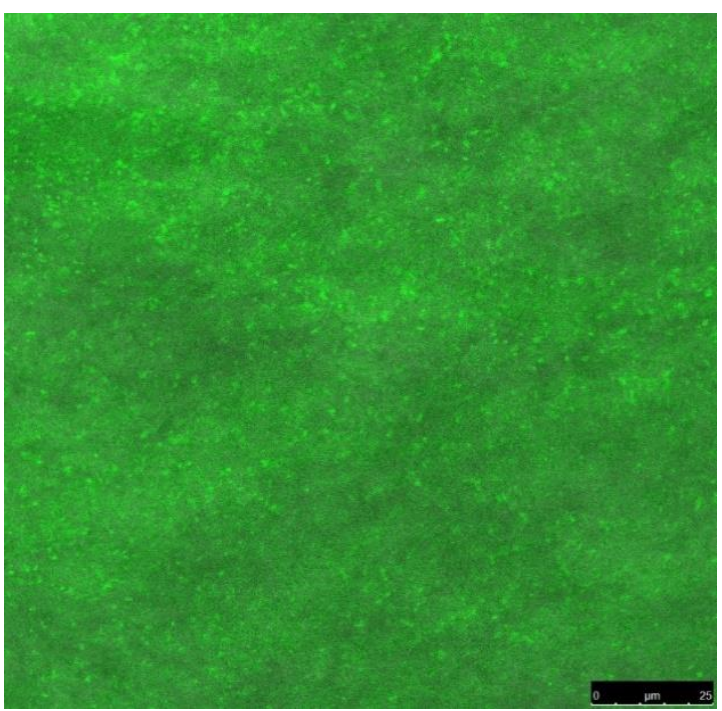

D

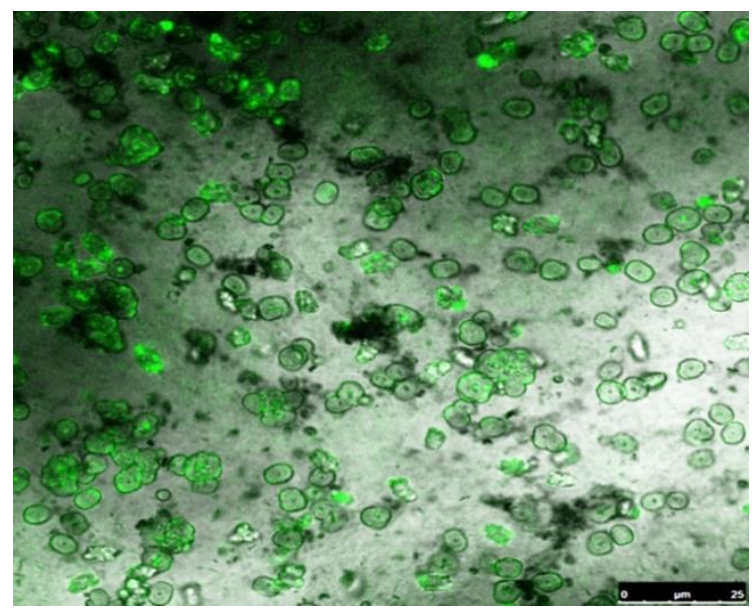

En cada una de las muestras se realizó una exploración por diversas varias zonas con el fin de observar si existían diferencias entre el área donde se capturó la imagen y el resto de la membrana. Además, en cada caso se realizó un barrido espectral de la Doxo para poder corroborar que la fluorescencia observada corresponda a dicha molécula y para analizar cambios o corrimientos en los picos característicos. El espectro de emisión puede ser observado en la Figura 1.8, donde se muestra un espectro habitualmente observado para la molecula de Doxo con un máximo en $595 \mathrm{~nm}$. En el caso de las muestras donde había presencia de partículas, se pudo evidenciar un corrimiento 
batocromico a 610-620 nm sugiriendo la existencia de interacciones entre las partículas y la Doxo.

Figura 1.8 Barrido de longitud de onda a partir de los análisis realizados por medio de microscopia confocal: BC, BC-Carr, BC-CaCO3 and BC/N-hMPs.

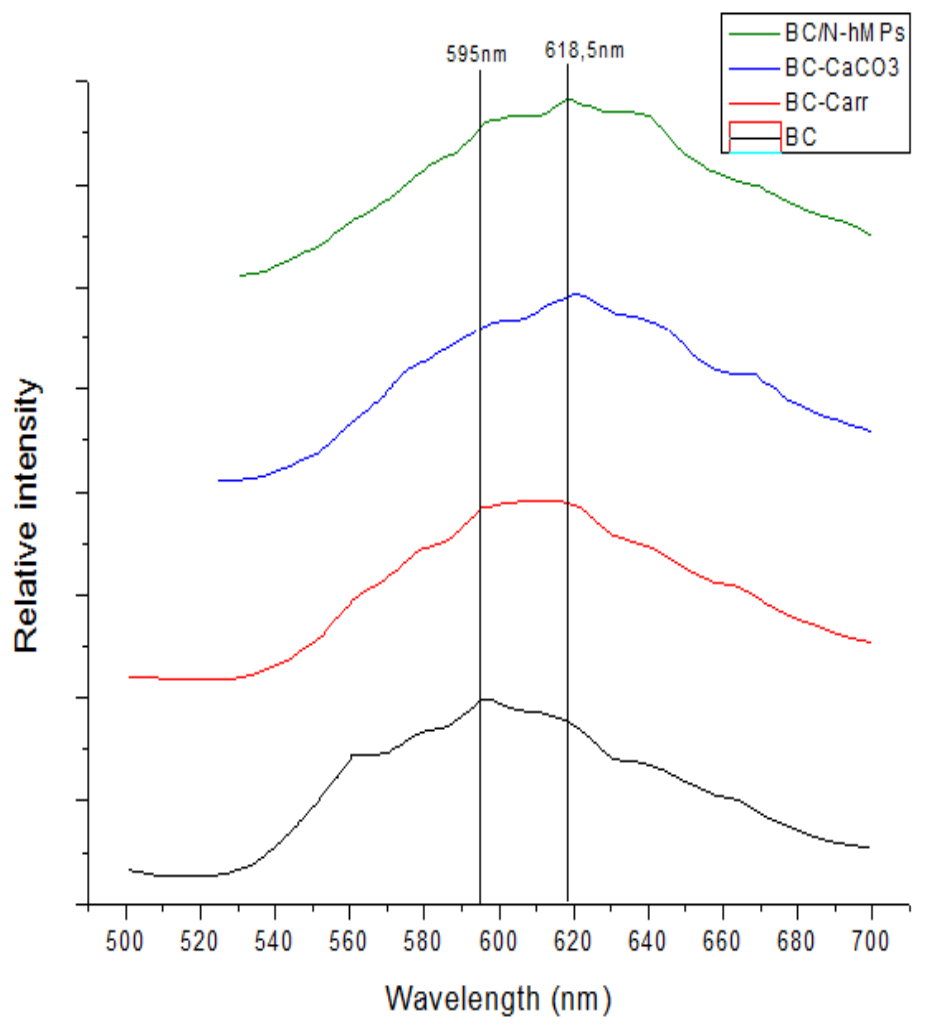

\subsubsection{Ensayos de encapsulación y liberación de Doxorrubicina (Doxo)}

El primer ensayo de liberación que se realizó fue con todas las matrices caracterizadas previamente, es decir, con la $\mathrm{BC} / \mathrm{N}-\mathrm{hMPs}$ y los controles. Las membranas se cargaron con la solución inicial de Doxo de 1293 nmoles/ml, encapsulando $37 \mu$ moles/gr. Luego se procedió a realizar la liberación en buffer $\mathrm{PBS}(\mathrm{pH}=7.4)$ y a $37^{\circ} \mathrm{C}$ (Tabla II).

La liberación de la Doxo a partir de estas cuatro muestras de BC (Tabla II) puede ser dividida en dos grupos basándose en si la liberación fue rápida o lenta. En ambos grupos la liberación del fármaco puede correlacionarse con la presencia o ausencia de partículas en la matriz. La presencia de las partículas con o $\sin \lambda$-carragenina disminuye en gran medida la velocidad de liberación, aproximadamente en un 88-93\% comparado con las membranas sin partículas. Como se mencionara anteriormente, las N-hMPs funcionan como núcleo de carga y liberación de la Doxo. 
Tabla II. Liberación de Doxorrubicina de matrices de $\mathrm{BC}$ en solución buffer a $\mathrm{pH}=7,4$, a $37^{\circ} \mathrm{C}$ por 24 horas.

\begin{tabular}{cc}
\hline Matriz & $\begin{array}{c}\text { Doxo liberada } \\
(\mathbf{\%})\end{array}$ \\
\hline $\mathrm{BC}$ & $15.95 \pm 1.86^{*}$ \\
\hline $\mathrm{BC}-\mathrm{Carr}$ & $12.63 \pm 2.41^{*}$ \\
\hline $\mathrm{BC}-\mathrm{CaCO}_{3}$ & $1.32 \pm 0.10^{\#}$ \\
\hline $\mathrm{BC} / \mathrm{N}-\mathrm{hMPs}$ & $1.72 \pm 0.15^{\#}$
\end{tabular}

Nota: *, análisis por test-T muestra diferencias significativas entre las muestras $(\mathrm{P} \leq 0.05)$. *, Análisis de test-T muestra que no hay diferencias significativas entre las muestras marcadas $(\mathrm{P} \geq 0.05)$.

Por otro lado, la carga de Doxo que se pudo obtener en las membranas de BC sin modificar fue solo del $11 \%$ de la masa inicial. Este hecho puede ser atribuido a la elevada hidrofilicidad de la celulosa y a que la red de nanofibras se encuentra bastante abierta permitiendo que las moléculas de Doxo difundir fácilmente desde la membrana. El agregado de $\lambda$-carragenina a la matriz modifica el entorno electrónico debido a que cada dímero de carragenina contiene tres grupos sulfonato cargados negativamente. Esta nueva conformación puede aumentar la capacidad de interacción entre la Doxo y la red tridimensional, y es por esta razón que se puede observar un aumento en la encapsulación hasta un 16.6\% (Figura 1.9). El agregado de las micropartículas a la matriz incrementó en gran medida la carga del fármaco, observándose valores del $83.3 \%$ y $87.3 \%$ para $\mathrm{CaCO}_{3}$ y $\mathrm{N}-\mathrm{hMPs}$, respectivamente. La conformación nanoestructurada de las micropartículas permite que las moléculas de Doxo queden atrapadas dentro de las mismas, lo que permite interacciones más fuertes debido a un aumento en el área superficial. Además, una vez atrapadas, las moléculas de Doxo deben superar una cierta tortuosidad capilar para poder ser liberadas desde las micropartículas, razón por la cual los perfiles de liberación también se ven modificados. A pesar de que se observa un pequeño incremento del $4.3 \%$ en los niveles de Doxo encapsulada para $\mathrm{BC}-\mathrm{CaCO}_{3}$ y $\mathrm{BC} / \mathrm{N}-\mathrm{hMPs}$, las diferencias alcanzan a ser significativas estadísticamente luego de ser evaluadas mediante un test de Student $(p \leq 0.05)$. Sin embargo, el agregado de $\lambda$-carragenina en las partículas para generar N-hMPs tiene un fundamento más estructural. Además de tener la capacidad de interaccionar con la 
Doxo, el biopolímero permite una mejor nucleación de las partículas al momento de la síntesis, una menor polidispersidad y una mejor estabilidad ${ }^{15}$.

Figura 1.9 Incorporación de Doxo en las diferentes matrices de CB con una concentración inicial de $1.293 \mathrm{nmoles} / \mathrm{ml}$.

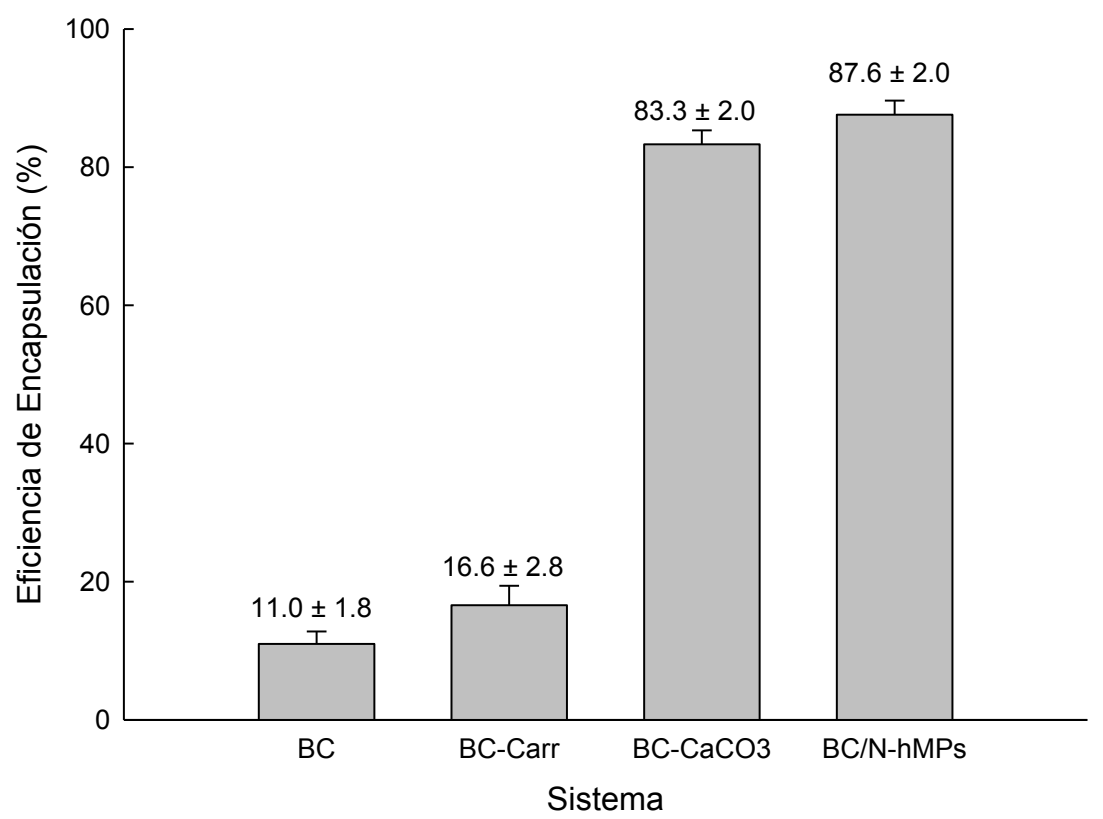

A continuación, la capacidad de carga de las membranas BC/N-hMPs fue ensayada colocando las membranas en soluciones con distinta concentración de Doxo, en un rango de 258.6 a 2586.3 nmoles/ml (Figura 1.10). Los resultados de estos ensayos han mostrado que la cantidad de Doxo encapsulada en el sistema aumenta en el rango de concentraciones utilizado, de manera lineal en función de la concentración de Doxo inicial $\left(\mathrm{r}^{2}=0.997\right)$. Además, el sistema BC/N-hMPs incorporó alrededor de un $80 \%$ de la Doxo en todas las concentraciones iniciales ensayadas.

Por otro lado, se observó un aumento de un 15\% en la encapsulación de Doxo a la concentración más alta ensayada $(2.586,3 \mathrm{nmoles} / \mathrm{ml})$ lo cual se puede asociar a eventos de interacción $\pi-\pi$ entre los anillos aromáticos de las moléculas de Doxo generando fenómenos de apilamiento (denominado $\pi$-stacking). 
Figura 1.10 Relación entre las soluciones iniciales de Doxo y la capacidad de carga de las membranas BC/N-hMPs.

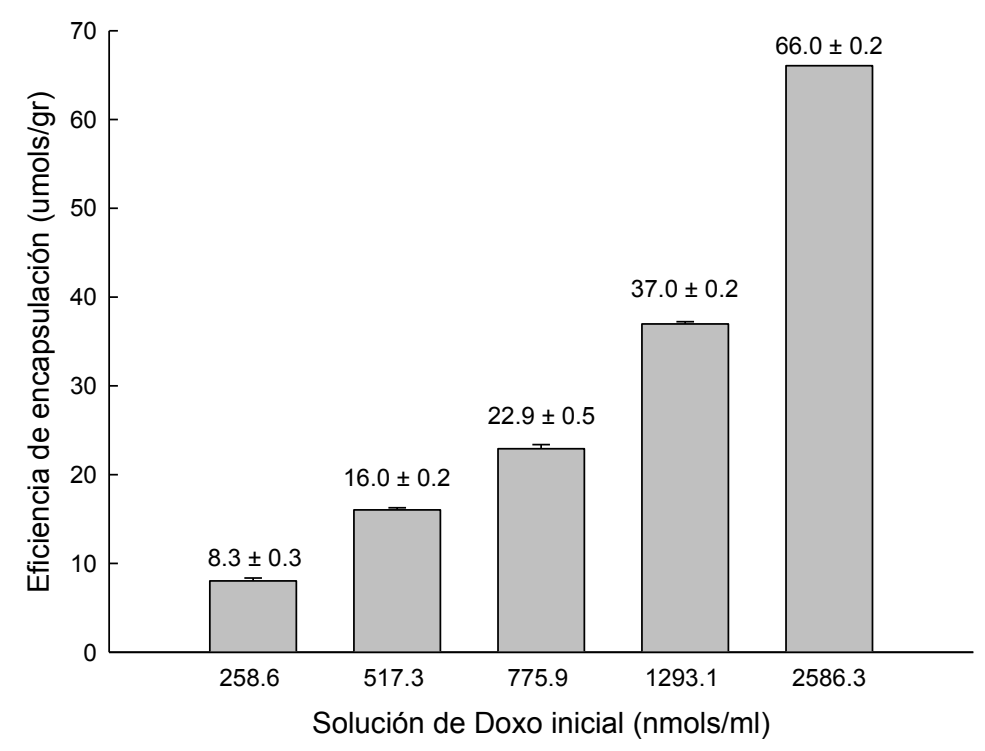

Luego de estos ensayos de encapsulación de Doxo en la matriz se procedió a estudiar los perfiles de liberación del fármaco en condiciones similares a las fisiológicas. El primer ensayo se realizó con el sistema BC/N-hMPs cargado con las mismas cantidades de Doxo obtenidas en el ensayo de la Figura 1.11. Las liberaciones se realizaron por 7 días en buffer PBS ( $\mathrm{pH}$ 7.4). Resulta relevante mencionar que lo que se busca como objetivo principal en un sistema de implantable para liberación local de un fármaco es que la liberación sea sostenida en el tiempo por periodos prolongados. Si se obtiene una liberación completa luego de 2 o 3 días de implantar el sistema, no estaríamos cumpliendo con la finalidad buscada. En este sentido, la Figura 1.11 muestra las curvas hiperbólicas obtenidas a partir de las liberaciones de Doxo. Al inicio de las liberaciones se presenta el escalón característico (burst) en todas las concentraciones ensayadas. La Doxo liberada es este primer paso corresponde a aquella con poca interacción con la matriz, aquella que se encuentra en las zonas más superficiales, con la cual el medio externo tiene contacto directo y el sistema no le impone prácticamente tortuosidad alguna para poder ser liberada. A continuación, la relación entre el medio circundante y la matriz empieza a cobrar cierta importancia. Los iones fosfato del buffer PBS son capaces de formar complejos con los iones $\mathrm{Ca}^{+2}$ de las partículas, la formación de dichos complejos se encuentra favorecida por el Kps $\mathrm{Ca}_{3 \mathrm{PO} 4}\left(2.0 \times 10^{-25}\right)$ mientras que los Kps de las otras sales como $\mathrm{CaCO}_{3}\left(3,36-6,0 \times 10^{-9}\right.$, para calcita y aragonita respectivamente) y $\mathrm{CaSO}_{4}\left(4,93 \times 10^{-5}\right)$ son bastante más bajos. Entonces, se puede 
considerar que la formación de $\mathrm{CaPO}_{4}$ se encuentra favorecida en un orden cercano a $10^{20}$. Por esta razón, la liberación de Doxo en esta segunda etapa se puede asociar con el proceso de disolución de las partículas.

Figura 1.11 Cinéticas de liberación de Doxo para BC/N-hMPs conteniendo distintas cantidades de fármaco. El medio utilizado fue buffer $\mathrm{PBS}(\mathrm{pH} 7.4)$ a $37^{\circ} \mathrm{C}$ por 7 días. Símbolos: •, $8.3 \mu \mathrm{mols} / \mathrm{g} ;$ o, $16.0 \mu \mathrm{mols} / \mathrm{g} ; \boldsymbol{\nabla}, 22.9 \mu \mathrm{mols} / \mathrm{g}$; $\Delta, 37.0 \mu \mathrm{mols} / \mathrm{g} ; \mathbf{\square}, 66.0 \mu \mathrm{mols} / \mathrm{g}$.

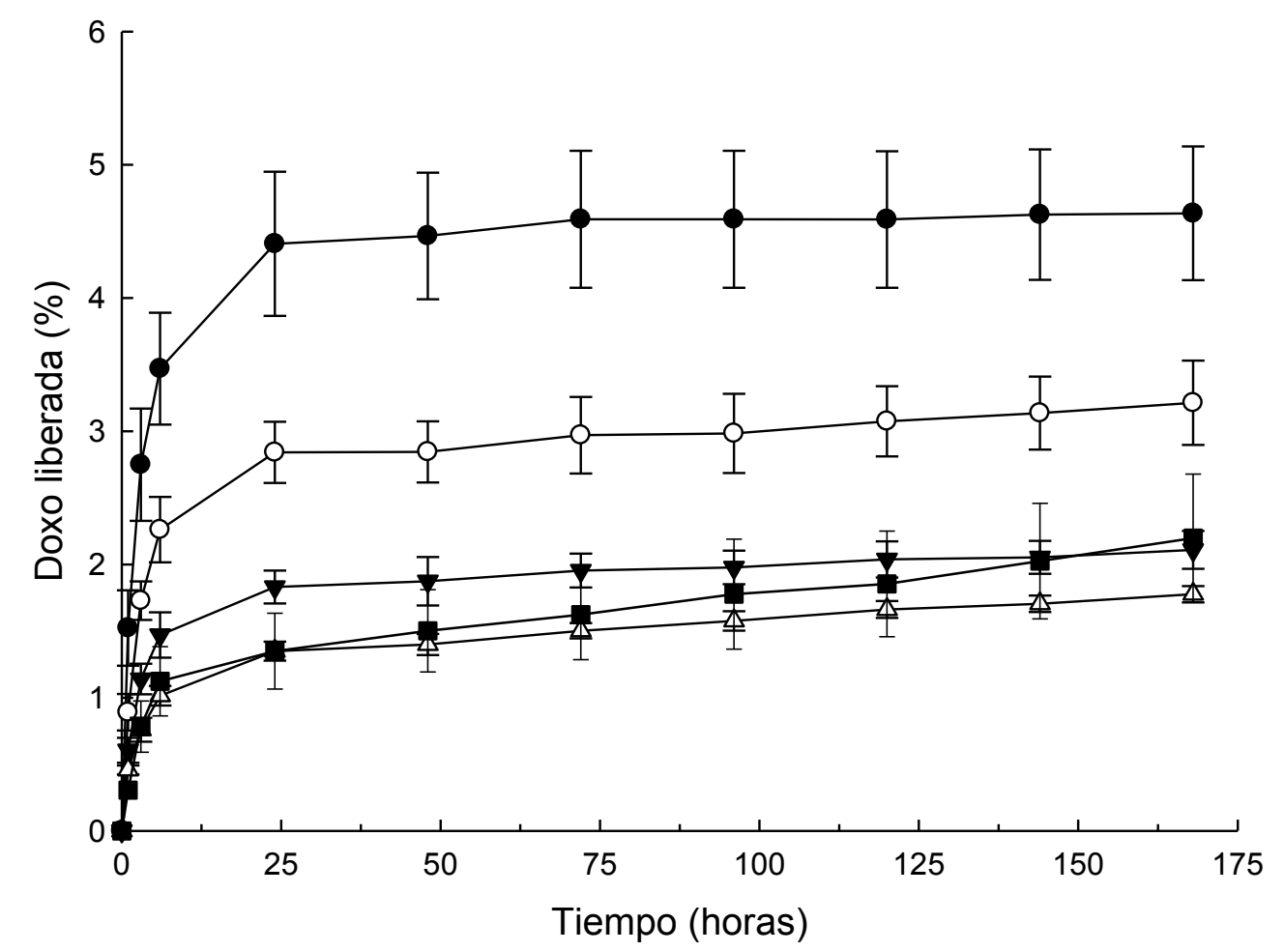

Se ha podido establecer una relación entre la Doxo incorporada en la matriz y la Doxo liberada desde ella (Figura 1.12). La relación es lineal para aquellas ocasiones en donde la incorporación se encuentra en el rango de 8,3-22,9 $\mu$ moles/g. La correlación encontrada en este intervalo es inversamente proporcional, es decir, a mayor capacidad de incorporación de Doxo menor es la velocidad de liberación de la misma. A concentraciones más elevadas $(37,0-66,0 \mu$ moles/g) la relación pierde linealidad y la correlación parece cambiar de pendiente. Es relevante mencionar que las cantidades de Doxo incorporadas en estas membranas son equivalentes a aquellas reportadas para ensayos in vivo en sistemas terapéuticos de aplicación local ${ }^{18}$. 
Figura 1.12 Relación entre Doxo cargada y liberada en membranas BC/N-hMPs en buffer PBS (pH=7.4) a $37^{\circ} \mathrm{C}$ y luego de 20 horas de incubación.

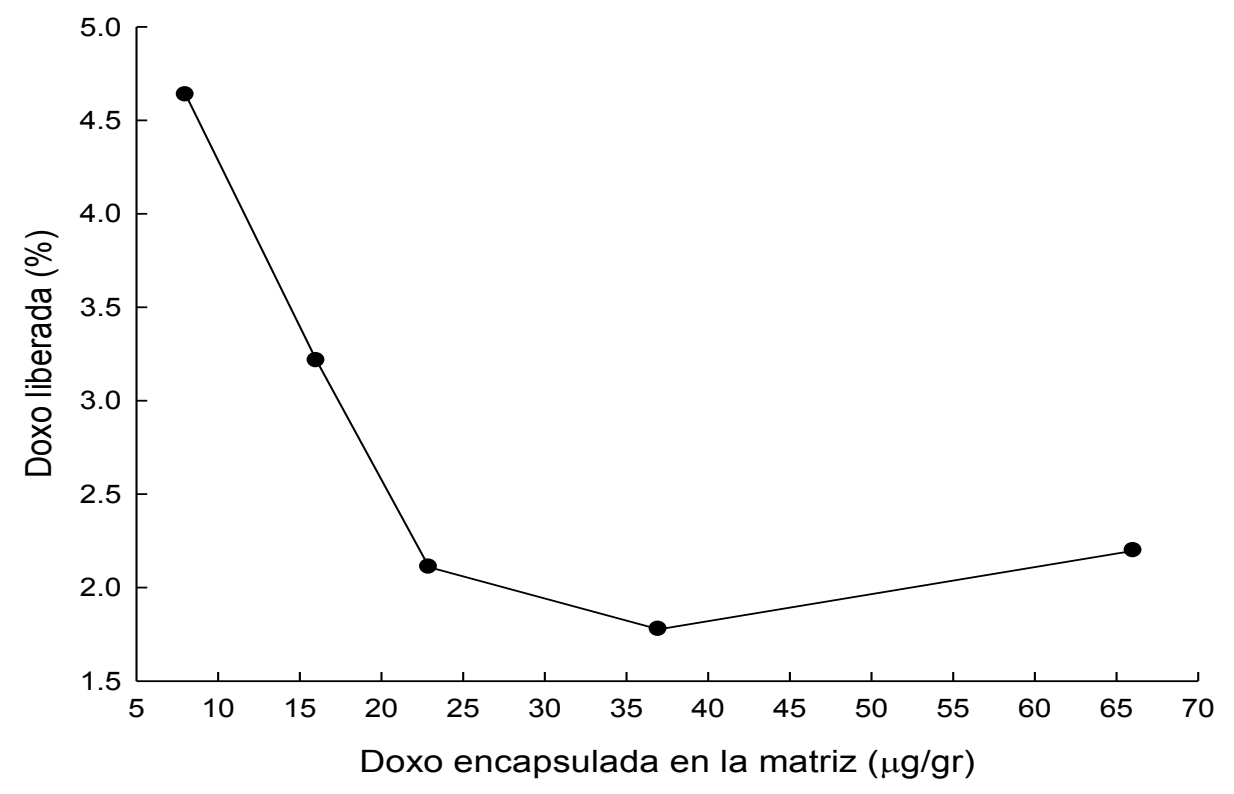

Por último, se estableció la relación de los perfiles de liberación en un determinado rango de $\mathrm{pH}$. Este factor es muy importante para un sistema a ser aplicado sobre un tumor sólido. El elevado metabolismo anaeróbico presente en muchas de las células que se encuentran dentro del tumor solido junto con otros factores, conlleva a un aumento de la acidosis debido a que el pH del entorno tumoral puede disminuir en un desde de 7,4 hasta $5,8^{19}$. Por este motivo, se establecieron cinéticas de liberación de Doxo en el rango de $\mathrm{pH}$ 5,8-7,4 por el lapso de 28 días (Figura 1.13). Se puede observar como el fármaco se libera más rápido a medida que el $\mathrm{pH}$ desciende. La colocación de este sistema sobre un tumor o en la zona donde se estaría generando un tumor que presente como característica el descenso del $\mathrm{pH}$ del medio circundante, estaría generando un aumento en la tasa de liberación del fármaco anticancerígeno en una tasa cercana al $50 \%$. 
Figura 1.13. Cinética de liberación para BC/N-hMPs cargada con $22,9 \mu$ moles de Doxo/gr de matriz por 28 días. Símbolos: $\boldsymbol{\nabla}, \mathrm{pH}=5,8 ; \circ, \mathrm{pH}=6,6 ; \bullet$, $\mathrm{pH}=7,4$

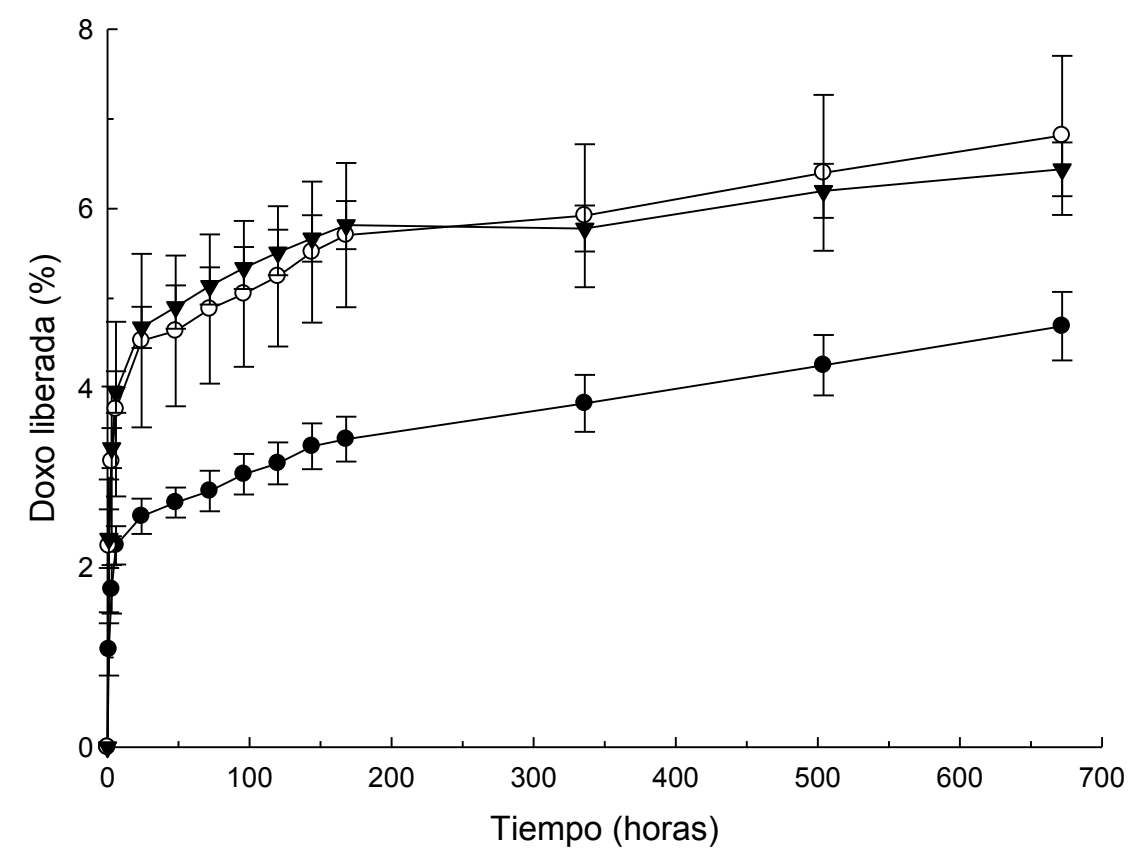

Estos resultados pueden ser explicados considerando que los cristales de $\mathrm{CaCO}_{3}$ vaterita presentan un detrimento en su estabilidad a medida que el $\mathrm{pH}$ desciende, y a su vez que se produce un aumento en la solubilidad de la Doxo.

\subsection{Conclusiones}

- El sistema microparticulado definido como transportador (carrier) de Doxorrubicina puede ser incorporado en membranas de celulosa bacteriana.

- Un nuevo método de modificación ex-situ para celulosa bacteriana ha sido desarrollado y descrito.

- No se observaron cambios morfológicos ni estructurales de la micropartículas incorporadas en la matriz de BC.

- El nuevo biomaterial hibrido basado en BC presenta características fisicoquímicas muy similares a las de la celulosa bacteriana sin modificar.

- Se ha alcanzado la capacidad del sistema de cargar hasta $66 \mu$ moles de Doxo por gramo de matriz. 
- Existe una relación directa entre la carga de fármaco y las cinéticas de liberación del mismo.

- Se demostró que el sistema carga Doxo utilizando como núcleos a las partículas hibridas.

- Las cinéticas de liberación fueron descriptas, obteniéndose tiempos prolongados de liberación de Doxo.

- Se demostró que al disminuir el pH del entorno el sistema puede liberar hasta un $50 \%$ más de fármaco, lo cual lo hace ventajoso para su aplicación sobre tumores sólidos.

\subsection{Referencias}

(1) Hu, Y., and J. M. C. Formation and Characterization of Sphere like Bacterial Cellulose Particles Produced by Acetobacter Xylinum JCM 9730 Strain. Biomacromolecules 2010, 11(7), 17271734.

(2) Qiu, K.; Netravali, A. N. A Review of Fabrication and Applications of Bacterial Cellulose Based Nanocomposites. Polym. Rev. 2014, 54 (4), 598-626.

(3) Cannon, R. E.; Ph, D.; Anderson, S. M. Biogenesis of Bacterial Cellulose. Crit Rev Microbiol. 1991, 17 (6), 435-447.

(4) Ross, P.; Mayer, R.; Benziman, M. Cellulose Biosynthesis and Function in Bacteria. Microbiol. Rev. 1991, 55 (1), 35-58.

(5) Ha, J. H.; Shah, N.; Ul-Islam, M.; Khan, T.; Park, J. K. Bacterial Cellulose Production from a Single Sugar ??-Linked Glucuronic Acid-Based Oligosaccharide. Process Biochem. 2011, 46 (9), $1717-1723$.

(6) Mikkelsen, D.; Flanagan, B. M.; Dykes, G. A.; Gidley, M. J. Influence of Different Carbon Sources on Bacterial Cellulose Production by Gluconacetobacter Xylinus Strain ATCC 53524. J. Appl. Microbiol. 2009, 107 (2), 576-583.

(7) Huang, Y.; Zhu, C.; Yang, J.; Nie, Y.; Chen, C.; Sun, D. Recent Advances in Bacterial Cellulose. Cellulose 2014, 21 (1), 1-30.

(8) Oikawa, T.; Ohtori, T.; Ameyama, M. Production of Cellulose from D-Mannitol by Acetobacter Xylinum KU-1. Biosci. Biotechnol. Biochem. 1995, 59 (2), 331-332.

(9) Rani, M. U.; Appaiah, A. Optimization of Culture Conditions for Bacterial Cellulose Production from Gluconacetobacter Hansenii UAC09. Ann. Microbiol. 2011, 61 (4), 781-787.

(10) Shah, N.; Ul-Islam, M.; Khattak, W. A.; Park, J. K. Overview of Bacterial Cellulose Composites: A Multipurpose Advanced Material. Carbohydr. Polym. 2013, 98 (2), 1585-1598.

(11) Beuvier, T.; Calvignac, B.; Delcroix, G. J.-R.; Tran, M. K.; Kodjikian, S.; Delorme, N.; Bardeau, J.-F.; Gibaud, A.; Boury, F. Synthesis of Hollow Vaterite CaCO3 Microspheres in Supercritical 
Carbon Dioxide Medium. J. Mater. Chem. 2011, 21, 9757.

(12) Liu, X.; Ma, Y.; Zhou, Y.; Pei, C.; Yin, G. A Promising Hybrid Scaffold Material: Bacterial Cellulose in-Situ Assembling Biomimetic Lamellar CaCO3. Mater. Lett. 2013, 102-103, 91-93.

(13) Stoica-Guzun, A.; Stroescu, M.; Jinga, S. I.; Jipa, I. M.; Dobre, T. Microwave Assisted Synthesis of Bacterial Cellulose-Calcium Carbonate Composites. Ind. Crops Prod. 2013, 50, 414-422.

(14) Campo, V. L.; Kawano, D. F.; Silva, D. B. da; Carvalho, I. Carrageenans: Biological Properties, Chemical Modifications and Structural Analysis - A Review. Carbohydr. Polym. 2009, 77 (2), $167-180$.

(15) Bosio, V. E.; Cacicedo, M. L.; Calvignac, B.; Le??n, I.; Beuvier, T.; Boury, F.; Castro, G. R. Synthesis and Characterization of CaCO3-Biopolymer Hybrid Nanoporous Microparticles for Controlled Release of Doxorubicin. Colloids Surfaces B Biointerfaces 2014, 123, 158-169.

(16) Cai, Z.; Kim, J. Bacterial Cellulose/poly(ethylene Glycol) Composite: Characterization and First Evaluation of Biocompatibility. Cellulose 2010, 17 (1), 83-91.

(17) Islan, G. A.; Cacicedo, M. L.; Bosio, V. E.; Castro, G. R. Development and Characterization of New Enzymatic Modified Hybrid Calcium Carbonate Microparticles to Obtain NanoArchitectured Surfaces for Enhanced Drug Loading. J. Colloid Interface Sci. 2015, 439, $76-87$.

(18) Seib, F. P.; Kaplan, D. L. Doxorubicin-Loaded Silk Films: Drug-Silk Interactions and in Vivo Performance in Human Orthotopic Breast Cancer. Biomaterials 2012, 33 (33), 8442-8450.

(19) Gerweck, L. E.; Vijayappa, S.; Kozin, S. Tumor pH Controls the in Vivo Efficacy of Weak Acid and Base Chemotherapeutics. Mol. Cancer Ther. 2006, 5 (May), 1275-1279.

(20) Cacicedo, M. L.; Cesca, K.; Bosio, V. E.; Porto, L. M.; Castro, G. R. Self-Assembly of Carrageenin-CaCO3 Hybrid Microparticles on Bacterial Cellulose Films for Doxorubicin Sustained Delivery. J. Appl. Biomed. 2015, 13 (3), 239-248. 


\section{Capítulo 2}

Desarrollo de matriz híbrida celulosa

bacteriana/alginato mediante modificación in-situ:

evaluación de su potencialidad como sistema de

liberación local de fármacos
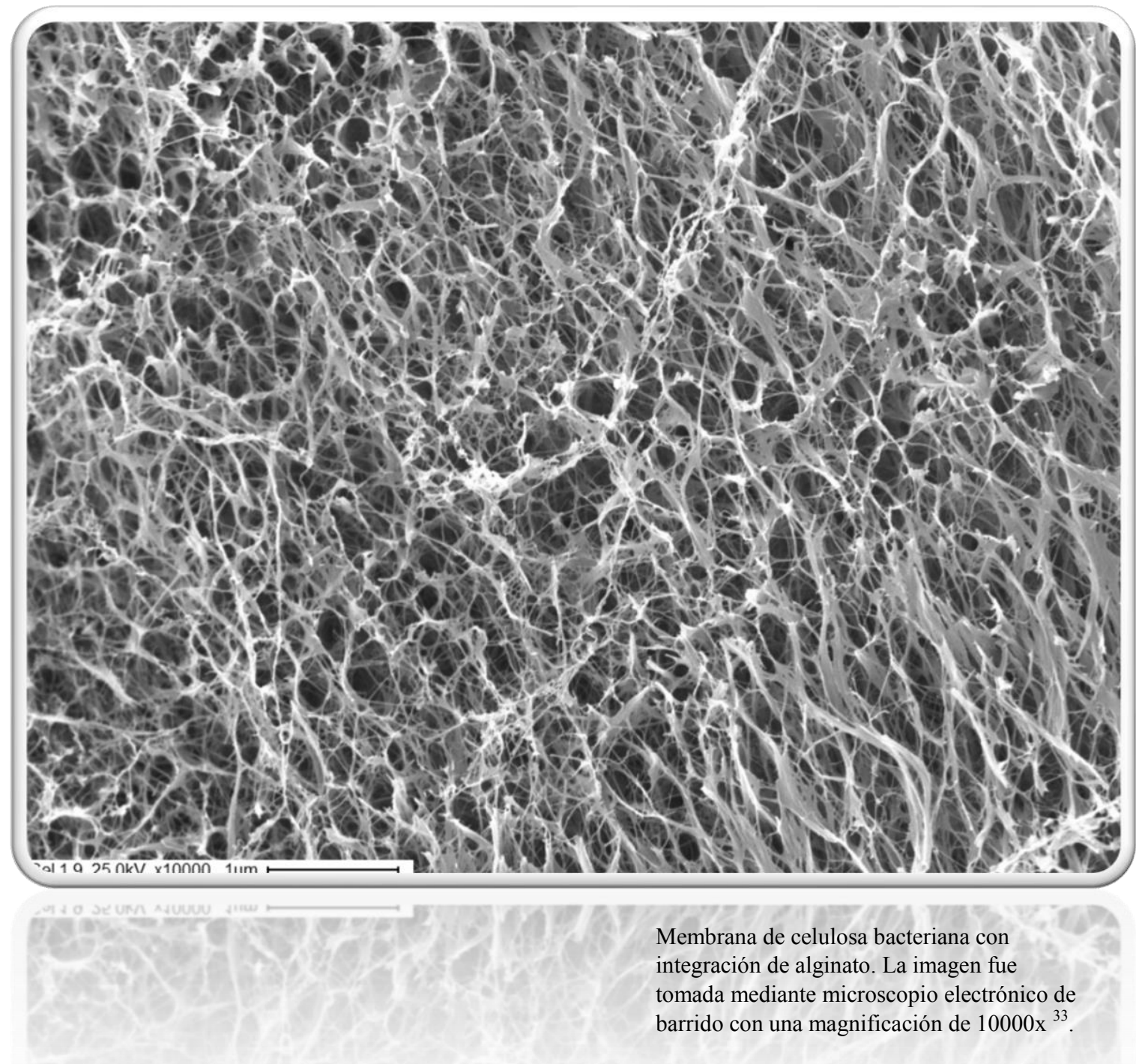


\section{Objetivos:}

* Generar una matriz híbrida de celulosa bacteriana conteniendo alginato

* Estudiar la incorporación del alginato en la matriz de BC mediante el método insitu

* Analizar de las propiedades fisicoquímicas del nuevo biomaterial hibrido.

* Evaluar la potencialidad para encapsular y liberar doxorrubicina

* Realizar pruebas de viabilidad celular y citotoxicidad en una línea de cáncer humana. 


\subsection{Introducción}

Las matrices compuestas por sistemas híbridos de biopolímeros son candidatos prometedores para el desarrollo de sistemas de liberación de activos. Estas matrices biopolímericas presentan varias ventajas tales como métodos de síntesis basados en Química Verde, disponibilidad en grandes cantidades y propiedades no tóxicas. Además, son recursos renovables, de fácil manipulación, biodegradables, disponibles comercialmente y, en general, de bajo costo. Entre ellos, uno de los biopolímeros que sobresale es el alginato. La presencia de otro biopolímero con estas propiedades dentro de la matriz de celulosa bacteriana permitiría obtener un sistema híbrido que podría ser moldeado para cumplir con los objetivos fijados desde el punto de vista de su aplicación biomédica.

El alginato es un polisacárido aniónico lineal constituido de residuos de ácidos $\beta-\mathrm{D}-$ manurónico (M) y ácidos $\alpha$-L-gulurónico (G) unidos por enlaces 1-4 producido comercialmente por algas. Sus propiedades incluyen: ser atóxicos ${ }^{1}$, no generar respuesta inmune y ser biocompatibles. Los alginatos puede ser gelificados en presencia de cationes multivalentes en una disposición espacial denominada como -aja de huevos" ${ }^{2}$. De los alginatos ricos en ácido manurónico $(\mathrm{M})$ se obtiene un gel elástico; mientras que aquellos ricos en ácido gulurónico $(\mathrm{G})$ se obtiene un gel firme y quebradizo (Figura 2.1.). Como su pKa se encuentra alrededor de 3,0 los geles de alginato son insolubles a $\mathrm{pHs}$ menores a dicho valor, mientras que a $\mathrm{pH}$ alcalinos tienden a disolverse en medios acuosos. Por otro lado, los geles de alginato son inestables en presencia de agentes quelantes de cationes (tales como fosfato o EDTA) o cationes no gelificantes que compiten por los sitios ocupados por el calcio dentro de la matriz (tales como el sodio o el potasio), los cuales se encuentran presentes en los fluidos biológicos.

Se ha mencionado en el anterior capítulo, la BC no es capaz de retener activos y liberarlos de modo sostenido. Por lo que se decidió avanzar con la modificación in situ de la matriz por medio de la adición de alginato al medio de cultivo. Se ha reportado que la modificación por esta metodología permite conseguir cambios más profundos en la matriz de BC además de obtener las propiedades de cada uno de los biopolímeros. Cuando matrices de $\mathrm{BC}$ fueron modificadas con colágeno, quitosano o gelatina se obtuvieron propiedades únicas en el material ${ }^{4}$. La adición de alginato permitiría obtener un Sistema con una capacidad potenciada de interacción con Doxo, como fuera reportado previamente para un modelo pectina-Doxo ${ }^{5}$. 
Figura 2.1. Proceso de gelificación iónica de las cadenas de alginato en presencia de iones divalente (en éste caso, ion calcio) que da origen a la formación de un gel compacto ${ }^{3}$
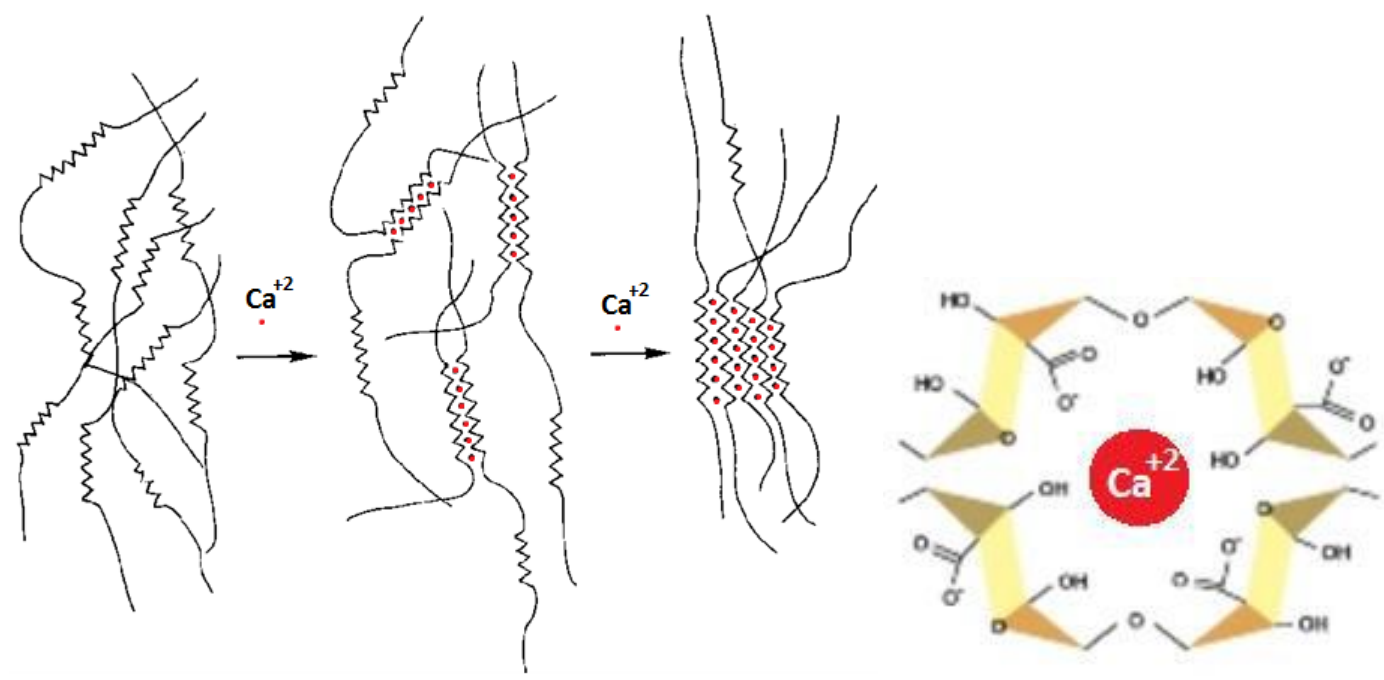

Recientemente, matrices compuestas de BC-alginato fueron descriptas por su capacidad y versatilidad para crecer células eucariotas gracias a la ductilidad y funcionalidad de la red de fibras celulosa-alginato ${ }^{6-8}$. Por otro lado, matrices de BCalginato fueron generadas por el método ex situ para liberación sostenida de sulfadizina de plata ${ }^{9}$.

En el presente capítulo se desarrollará el trabajo de modificación de $\mathrm{BC}$ con alginato mediante modificación in-situ. Se evaluarán las propiedades fisicoquímicas del material, se analizará su potencial como matriz para liberación sostenida de doxorrubicina, y los efectos de citotoxicidad en una línea celular tumoral.

\subsection{Materiales \& Métodos}

\subsubsection{Materiales}

El alginato de sodio fue donado por Monsanto Co. La Doxorrubicina (Doxo, PM= $543,0)$ fue donada por la empresa LKM (Argentina). Todos los demás reactivos utilizados fueron de grado analítico o microbiológico adquiridos a Sigma-Aldrich (St. Louis, MO) o Merck (Darmstadt, Alemania).

La Doxo se cuantificó mediante espectrofluorimetría (Perkin Elmer LS 50B, Japón) utilizando una $\lambda_{\text {ext }}=476 \mathrm{~nm}$ y de $\lambda_{\mathrm{em}}=588 \mathrm{~nm}$ con las correspondientes curvas de calibración para cada caso. Los materiales para el cultivo de las células fueron Corning 
(Princeton, NJ, USA), DMEM (Dulbecco's Modified Eagles Medium), TrypLE ${ }^{\mathrm{TM}}$ de Gibco (Gaithersburgo, MD, USA), y el suero fetal bovino (FBS) adquiridos a Internegocios SA (Argentina). Todos los demás reactivos fueron de Sigma Chemical Co. (St. Louis, MO).

\subsubsection{Producción de celulosa bacteriana con adición de alginato de sodio}

La celulosa bacteriana fue sintetizada a partir de Komagataeibacter Hansenii (ATCC 23769). El cultivo se realizó estático en el siguiente medio (expresado en g/L): 25,0 manitol, 5,0 extracto de levadura, 3,0 peptona. El alginato de sodio se adicionó en una concentración de 1,0\%. El pH del medio se ajustó a 6,5 antes de ser esterilizado. El cultivo se mantuvo estático en placas de 96 pocillos a $27^{\circ} \mathrm{C}$ por 14 días.

\subsubsection{Purificación de la $\mathrm{BC}$}

BC nativa e híbrida fueron colectadas de las placas de cultivo para el proceso de purificación. Se lavaron tres veces con etanol $70 \%$ por 60 min con agitación. Luego, la purificación se llevó adelante utilizando una solución de etanol 70\%/NaOH $0,1 \mathrm{~N}$ por 24 horas a $30^{\circ} \mathrm{C}$. A continuación, se realizaron reiterados lavados con etanol $70 \%$ y agua hasta neutralidad del $\mathrm{pH}$. Por último, las membranas se colocaron en solución $70 \%$ etanol/ $0.5 \mathrm{M} \mathrm{CaCl}_{2}$ con el objetivo de generar una gelación iónica del alginato en el interior de la membrana de BC.

\subsubsection{Caracterización del biomaterial}

\subsubsection{Análisis termogravimétrico (TGA)}

Medidas dinámicas de termogravimetría fueron realizadas $\mathrm{BC}$ sin modificar como para la modificada utilizando un equipo Shimadzu TGA-50 (Tokio, Japón). Las pruebas se realizaron desde $20^{\circ} \mathrm{C}$ hasta los $900^{\circ} \mathrm{C}$ a una velocidad de calentamiento de $10^{\circ} \mathrm{C} / \mathrm{min}$ bajo atmosfera de nitrógeno.

\subsubsection{Difracción de rayos $\mathrm{X}(\mathrm{XRD})$}

Los patrones de XRD para las membranas se colectaron en el modo reflexión sobre un portaobjeto de vidrio. Las medidas fueron realizadas con un instrumento Analytical Expert utilizando una radiación $\mathrm{Cu}-\mathrm{K} \alpha(\lambda=1,54 \AA)$ desde $2 \Theta=10^{\circ}$ hasta $70^{\circ}$ en modo continuo con distancias de $0,07^{\circ}$. Los resultados se analizaron utilizando el software Origin.

\subsubsection{Espectroscopia de transformada de Fourier (FTIR)}

Los espectros de FTIR de las muestras previamente liofilizadas fue tomado con un espectrómetro (ThermoScientific Nicolet, modelo 6700, CT, USA) acoplado a un 
accesorio de ATR (Reflectancia total atenuada). Se llevaron a cabo 32 escaneos de cada muestra en el rango de 600 a $4000 \mathrm{~cm}^{-1}$ y una resolución de $4 \mathrm{~cm}^{-1}$.

\subsubsection{Isotermas de adsorción de nitrógeno (BET)}

Se evaluó la capacidad de adsorción y desorción de nitrogeno a 77K con un baño a $195,8^{\circ} \mathrm{C}$. El área superficial, volumen de poro y tamaño de poro de las membranas fueron calculados con el software Micromeritics ASAP 2020 v3.00 utilizando la ecuación de Brunauer-Emmett-Teller (BET) y el metodo Barrett-Joyner-Halenda (BJH)

\subsubsection{Estudios de microscopia}

\subsubsection{Microscopia de barrido electrónico (SEM)}

Las muestras fueron deshidratadas por la técnica de punto crítico. Luego, la superficie fue recubierta con oro utilizando un metalizador (BalzersSCD 030), obteniendo una capa cobertura de 15-20 nm de espesor. La superficie de las membranas, así como también sus morfologías, fueron observadas por SEM (Philips SEM 505, Rochester, NY, USA), y las imágenes fueron procesadas por un programa de digitalización de imágenes (Soft Imaging System ADDAII).

\subsubsection{Análisis de Rugosidad}

Las imágenes de SEM fueron analizadas por medio del software ImageJ (NIH, USA). La rugosidad de las superficies fue analizada como la variación estándar de los valores de grises en todos los pixeles de la imagen. Primero, las imágenes de SEM fueron abiertas en el software y convertidas a una imagen de 8-bit. Luego, todos los pixeles de la imagen fueron seleccionados y estadísticamente medidos. Cuanta más chica es la variación estándar más suave es la superficie. Además, se realizaron los histogramas de las imágenes de SEM de 1000x de aumento.

\subsubsection{Microscopia óptica y de fluorescencia}

Membranas híbridas cargadas con Doxo fueron colocadas en placas de 96 pocillos con las mismas condiciones con las que se realizaron los ensayos en células. Luego de 24 y 48 horas de incubación se tomaron muestras y se analizaron por microscopía. Las imágenes de microscopías ópticas y de fluorescencia fueron adquiridas mediante un microscopio Leica DM2500 (Wetzlar, Alemania) equipado con un filtro N2.1 para excitación en la zona verde. Filtro de excitación BP: 515-560 nm, espejo monocromático: $580 \mathrm{~nm}$, filtro supresor LP: $590 \mathrm{~nm}$. 


\subsubsection{Estudios de encapsulación de Doxorrubicina}

Los diferentes sistemas de BC fueron colocadas por inmersión en soluciones con distintas cantidades de Doxo, comprendida entre 3,7 moles a 11,0 moles, en etanol 80\%. Las condiciones de incubaciones fueron: agitación de $230 \mathrm{rpm}$ a $25^{\circ} \mathrm{C}$ por un periodo de tiempo de 20 horas. El pH de la solución se midió antes y después del procedimiento sin observarse cambios en el mismo $(\mathrm{pH}=7,0)$. Luego, las membranas fueron retiradas y la Doxo remanente en los sobrenadantes se midió con un espectrofluorimetro. A su vez, las membranas fueron lavadas con etanol $80 \%$ y en solución salina por 10 minutos cada vez. La capacidad de carga de las membranas fue expresada, a saber:

$$
\text { Doxo incorporada }=\frac{(\text { Doxo }- \text { DoxoS })}{W B C}
$$

Donde Doxo $_{0}$ corresponde a los $\mu$ moles de Doxo a tiempo cero, Doxos $\mu$ moles de Doxo medida en los sobrenadantes y $\mathrm{WBC}$ es la masa de BC expresada en gramos. Es relevante mencionar que se realizaron procedimientos de control sin la presencia de las membranas de celulosa y no fue observada degradación o cambios en el máximo de fluorescencia de la Doxo.

\subsubsection{Ensayos de liberación de Doxo in vitro}

Las membranas de $\mathrm{BC}$ se colocaron en 1,5 ml de solución fisiológica en tubos plásticos de $2 \mathrm{ml}$ de capacidad y se termostatizaron a $37^{\circ} \mathrm{C}$. Se recolectaron muestras de $500 \mu \mathrm{y}$ se adicionaron $500 \mu \mathrm{l}$ de medio fresco cada vez. Las concentraciones de Doxo se determinaron por fluorescencia. Los experimentos de liberación se realizaron dos veces de manera independiente y por cuadruplicado para cada concentración ensayada.

\subsubsection{Cultivo de células y condiciones de crecimiento celular}

Células de la línea HT-29 de adenocarcinoma de colon humano (HTB-38TM) fueron crecidas en DMEM conteniendo $10 \%$ de FBS, 100U/ml de penicilina y $10 \mathrm{~g} / \mathrm{ml}$ de Streptomicina a $37^{\circ} \mathrm{C}$ en una atmosfera con $5 \% \mathrm{CO} 2$. Las células se sembraron en un frasco de $75 \mathrm{~cm}^{2}$ y cuando la confluencia llego al 70-80\% se realizó un subcultivo utilizando $1 \mathrm{ml}$ de TrypLETM por frasco de $25 \mathrm{~cm}^{2}$. Para los experimentos las células se crecieron en placas de cultivo (multiwell). Cuando se alcanzó la confluencia deseada, la monocapa se lavó con DMEM y se incubaron bajo las condiciones deseadas. 


\subsubsection{Viabilidad celular: ensayo de cristal violeta}

Un ensayo mitogénico fue llevado a cabo como fuera descrito previamente con algunas modificaciones ${ }^{10}$. Las células se crecieron en placas de 48 pocillos. Para los experimentos, $3,0 \times 10^{4}$ celulas $/ \mathrm{ml}$ se crecieron por 24 horas a $37^{\circ} \mathrm{C}$. Luego, las monocapas fueron incubadas por 24 y 48 horas con diferentes concentraciones de Doxo libre $(100-200 \mu \mathrm{M})$ o con las diferentes matrices de $\mathrm{BC}$ con y sin fármaco para los ensayos de viabilidad. Luego de este tratamiento las monocapas fueron lavadas con PBS y fijadas con $5 \%$ de glutaraldehido/PBS a temperatura ambiente por 10 minutos. Posteriormente, las células fueron teñidas con $0,5 \%$ de cristal violeta/ $25 \%$ metanol por 10 min. A continuación, la solución de colorante fue descartada y la placa se lavó con agua y se secó. El colorante atrapado por las células fue extraído utilizando $500 \mu 1 /$ well de buffer $100 \mathrm{mM}$ glicina/ $\mathrm{HCl}(\mathrm{pH} 3,0) / 30 \%$ metanol y se transfirió todo a tubos de ensayo. La absorbancia fue medida a $540 \mathrm{~nm}^{11}$.

\subsubsection{Análisis estadístico}

Todos los ensayos, incluyendo las caracterizaciones del biomaterial, fueron realizados al menos por duplicado de forma independiente. Se realizaron las comparaciones de las medias de cada ensayo por un análisis de varianza (ANOVA) seguido por un análisis de Fisher para evaluar la existencia de diferencias significativas.

\subsection{Resultados y discusión}

\subsubsection{Caracterización del biomaterial}

Las propiedades térmicas de la celulosa bacteriana (BC), alginato (Alg) y las membranas hibridas de alginato-celulosa (BC-Alg) fueron analizadas mediante termogravimetría (Figura 2.1). La termogravimetría (TGA) de la BC sin modificar mostró dos etapas de descomposición en la curva, por otro lado los perfiles de pérdida de peso del Alg y BC-Alg mostraron tres etapas de descomposición. La primera etapa o escalón de la curva se atribuyó a la pérdida de agua, observándose a temperaturas en el rango de $30^{\circ} \mathrm{C}$ a $120^{\circ} \mathrm{C}$. A $180^{\circ} \mathrm{C}$ el porcentaje de pérdida de peso fue cercano al $7 \%$ para BC, $18 \%$ para Alg y $20 \%$ para BC-Alg. Los resultados mostraron un aumento en el contenido de agua para la matriz híbrida en comparación con la membrana $\mathrm{BC}$ nativa, debido a la naturaleza hidrofílica del alginato. Generalmente se acepta que el agua funciona como plastificante en las matrices poliméricas ${ }^{12}$. El incremento en la hidrofilicidad de la matriz de $\mathrm{BC}$ es ventajoso debido a que se puede relacionar con un 
aumento en la capacidad de retener moléculas hidrofílicas dentro de la matriz, como es el caso de la Doxo.

El segundo escalón de $\mathrm{BC}$ y $\mathrm{BC}-\mathrm{Alg}$ en las curvas de TGA fue atribuido a la descomposición térmica de los biomateriales (Figura 2.1 A). La temperatura de descomposición entre $\mathrm{BC}$ y $\mathrm{BC}-\mathrm{Alg}$ se vió reducida de $350^{\circ} \mathrm{C}$ a $300^{\circ} \mathrm{C}$. Particularmente, la pérdida de peso fue de un $30 \%$ en el rango $200-400^{\circ} \mathrm{C}$ para las membranas de $\mathrm{BC}$ Alg, que aproximadamente corresponde a la mitad de lo perdido por las membranas de BC en las mismas condiciones experimentales (Tabla I). La elevada estabilidad térmica de las membranas de BC-Alg comparada con la de BC sin modificar o de alginato, sugirió enfáticamente una interpenetración importante entre ambos polímeros ${ }^{6,13}$. Esta hipótesis fue también confirmada por el incremento en la temperatura máxima de degradación (Tp) a causa de la presencia de alginato en la matriz de celulosa. La Tp es considerado un importante parámetro estructural relacionado con el peso molecular, la cristalinidad y la orientación de los polímeros ${ }^{14}$. El hecho de que el valor de Tp para BC-Alg fuera intermedio entre los dos polímeros por separado habló de una fuerte interacción entre las fibras de celulosa y de alginato (Tabla I).

Tabla I. Valores relevantes de los parámetros de degradación térmica de la celulosa bacteriana sin modificar, de la celulosa bacteriana-alginato y del alginato.

\begin{tabular}{cccc}
\hline \multirow{2}{*}{ Parámetro } & \multicolumn{3}{c}{ Componentes } \\
\cline { 2 - 4 } & Celulosa & Alginato & BC-Alg \\
\hline $\begin{array}{c}\text { Pérdida de masa en el } \\
\text { rango } 200-400^{\circ} \mathrm{C}(\%)\end{array}$ & 67,2 & 40,6 & 31,8 \\
\hline $\mathrm{T}_{\mathrm{p}}\left({ }^{\circ} \mathrm{C}\right)$ & 345,6 & 243,0 & 265,3 \\
\hline Residuos a $750^{\circ} \mathrm{C}(\%)$ & 13,5 & 24,1 & 29,5 \\
\hline
\end{tabular}

Los análisis de DTGA de las membranas de BC-Alg mostraron un pequeño tercer pico a $650^{\circ} \mathrm{C}$, similar al pico encontrado para el Alg en el rango $700-750^{\circ} \mathrm{C}$. Además, no fue observado ningún pico similar para las membranas de BC nativas (Figura 2.1 B). Este resultado confirma la presencia de alginato en la red de fibras de celulosa. Esencialmente, el análisis termogravimétrico de BC-Alg sugiere fuertes interacciones intermoleculares entre la $\mathrm{BC}$ y el Alg. El tipo de estas interacciones fue analizado a continuación mediante técnicas de XRD y FTIR. 
Figura 2.1 Análisis termogravimétrico de celulosa bacteriana (-), celulosa bacterianaalginato (---) y alginato (…). Curvas (A) TGA y (B) DTGA.

A

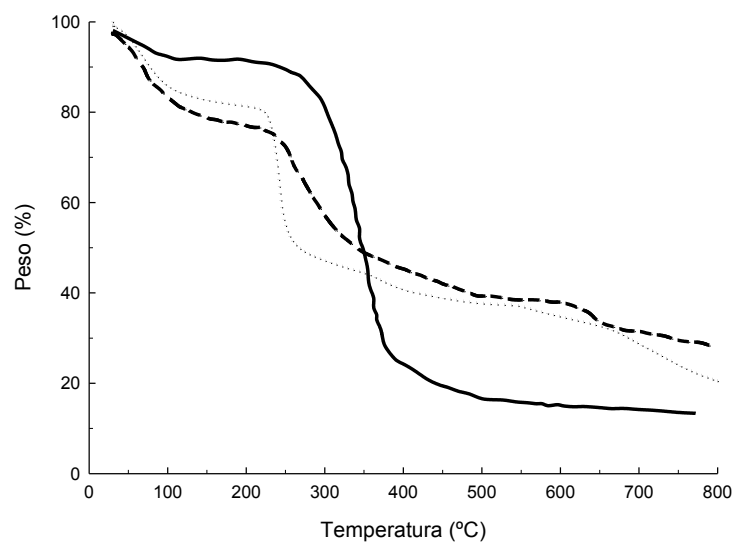

$\mathrm{B}$

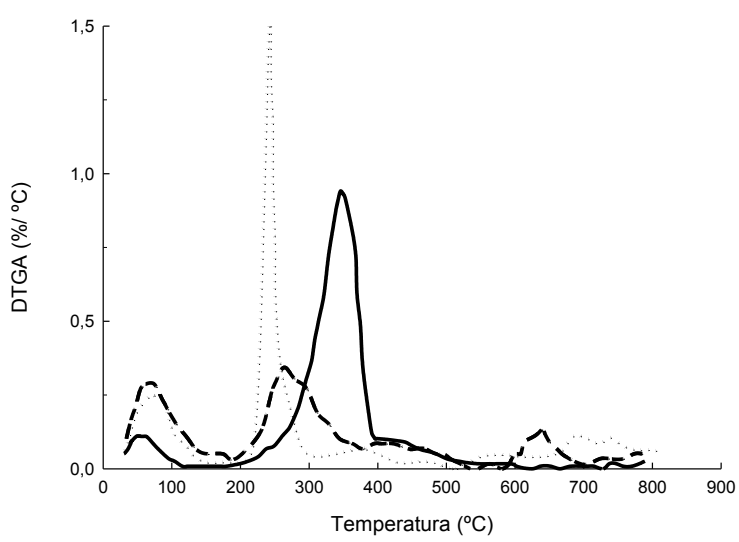

Las propiedades estructurales de las membranas de celulosa bacteriana conteniendo alginato fueron estudiadas por XRD (Figura 2.2). Los perfiles de XRD de BC y BCAlg muestran ángulos de Bragg característicos para ambas matrices a $2 \Theta=14,6^{\circ}, 16,9^{\circ}$ y 22,8 , los cuales están indexados como planos de reflexión $\left(\begin{array}{lll}1 & 1 & 0\end{array}\right),\left(\begin{array}{lll}0 & 1 & 0\end{array}\right)$ y $\left(\begin{array}{lll}1 & 0 & 0\end{array}\right)$ respectivamente. Los resultados revelaron la presencia de cristales de celulosa tipo I en las membranas BC, como ya se ha reportado previamente ${ }^{15}$. El espectro de XRD de BC y BC-Alg muestra perfiles similares relacionados a la posición y distribución de los picos; dichos resultados indican que la adición del alginato durante el cultivo de la celulosa bacteriana no altera la estructura cristalina del material, como fue también previamente reportado ${ }^{13}$. Sin embargo, el análisis comparativo de ambos espectros de XRD mostró dos importantes diferencias asociadas a el cambio de intensidad en el pico (1 110$)$ de BC-Alg, el cual es al menos tres veces más bajo que el de BC; y también el pico $\left(\begin{array}{lll}1 & 0 & 0\end{array}\right)$ en BC-Alg es más ancho que el mismo pico en BC. Estos resultados sugieren algunos cambios en la orientación preferencial de los planos $\left(\begin{array}{lll}1 & 1 & 0\end{array}\right)$ y $\left(\begin{array}{lll}1 & 0 & 0\end{array}\right)$, como fue previamente reportado para BC suplementada con otros polímeros como polietilenglicol, carboximetil- e hidroximetil-celulosa o por la remoción por completo del contenido de agua ${ }^{15,16}$. Los cambios observados en el nanocompuesto de BC-Alg pueden ser atribuidos a la interacción entre los polímeros altamente hidroxilados a través de interacciones puente de hidrogeno. La presencia de alginato reduce el índice de cristalinidad de membranas de BC cerca de 1,4 veces, desde $71,0 \%$ a $49,7 \%$, pero 
con una superficie estructural homogénea como fue observado con imágenes de SEM. Particularmente, la reducción de los índices de cristalinidad se la relaciona, en general, con un incremento en la fase amorfa del material y consecuentemente con un incremento en la capacidad de absorción de agua.

Figura 2.2 Espectros de difracción de rayos X (XRD) para las matrices de celulosa bacteriana (BC) y de celulosa bacteriana-alginato (BC-Alg).

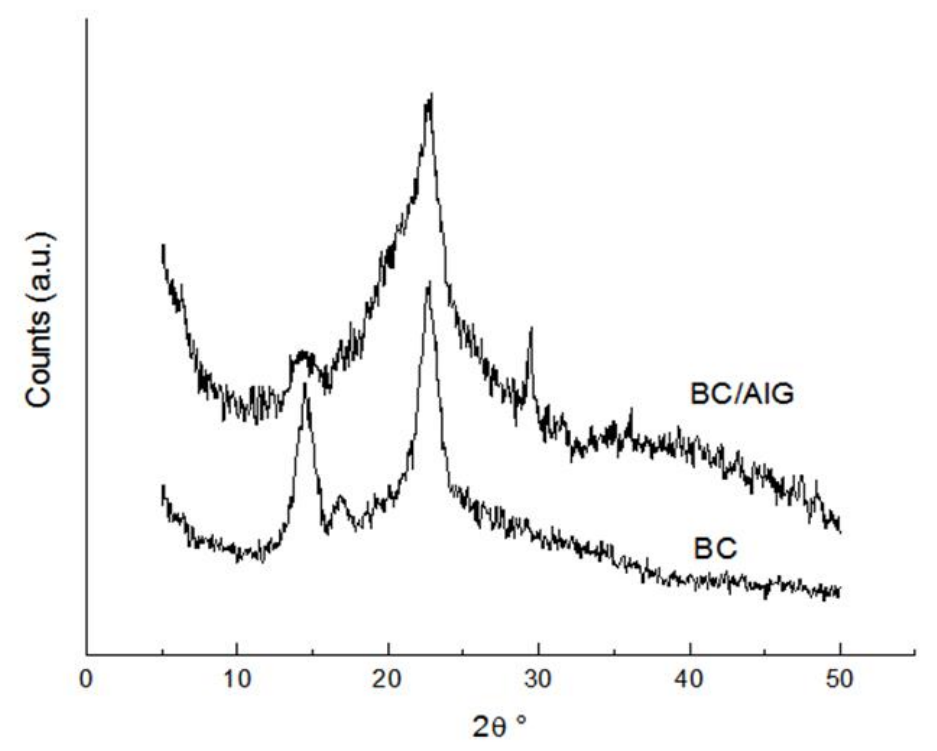

Una reducción drástica en el índice de cristalinidad atribuida a la adición de diferentes moléculas exógenas como Tween 80, urea, Calcofluor White ST, hidroxipropilmetil celulosa y carboximetil celulosa, adicionada en los medios de fermentación afectaron la síntesis de la red de celulosa como ha sido publicado previamente para $K$. Xylinus ${ }^{15}$. A su vez, fueron previamente reportados valores bajos de cristalinidad de la celulosa modificada por el método in situ a través de la adición de $0,04 \%$ de alginato a cultivos agitados de K. Xylinum $^{13}$. Sin embargo, el análisis de XRD no ha sido conclusivo debido a que las imágenes de SEM muestran estructuras muy heterogéneas dentro de las matrices de BC-Alg (Figura 2.3). 
Figura 2.3 Imágenes de SEM correspondientes a las matrices de BC (A1, B1, C1) y de BC-Alg (A2, B2, C2). Aumentos: (A) 1000X, (B) 5000X, (C) 10000X.

A1

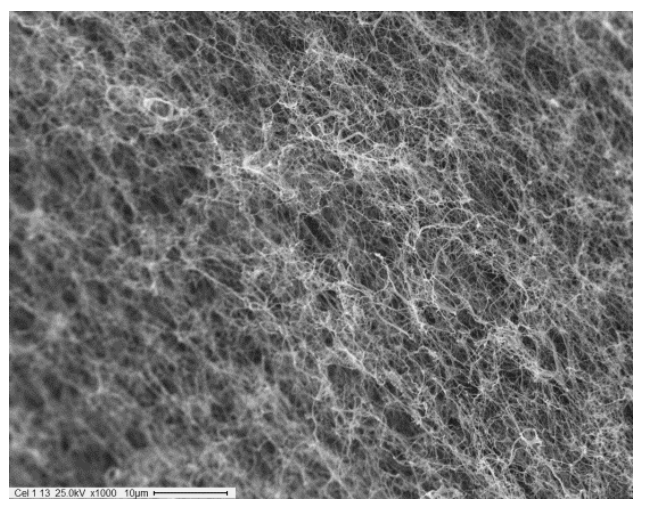

B1

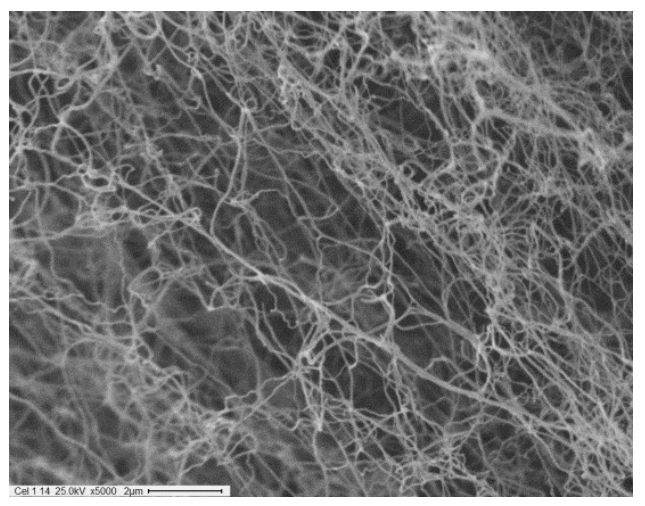

C1

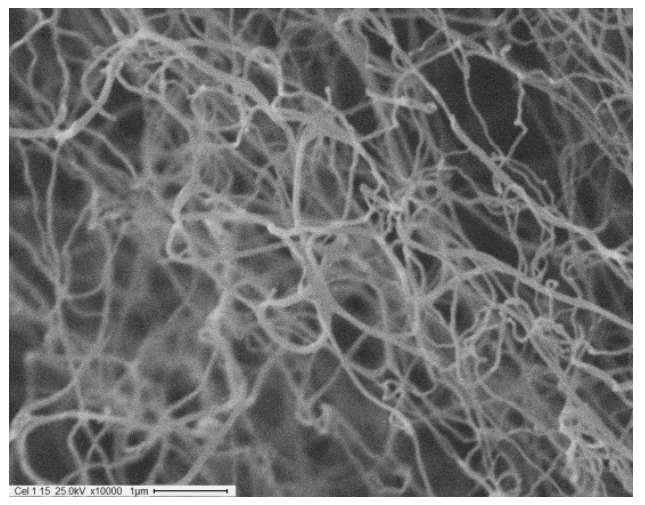

A2

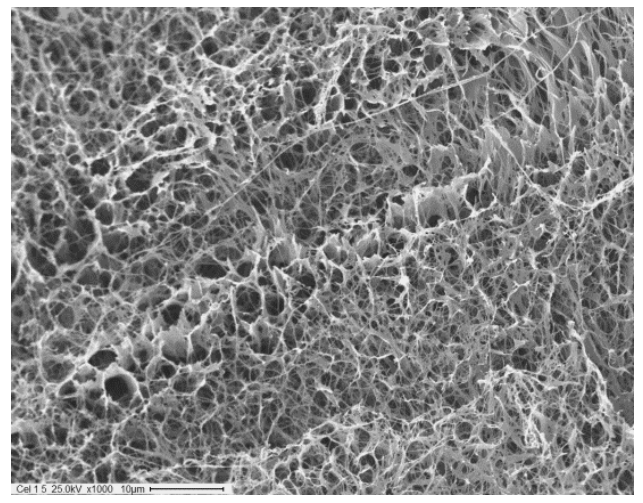

B2

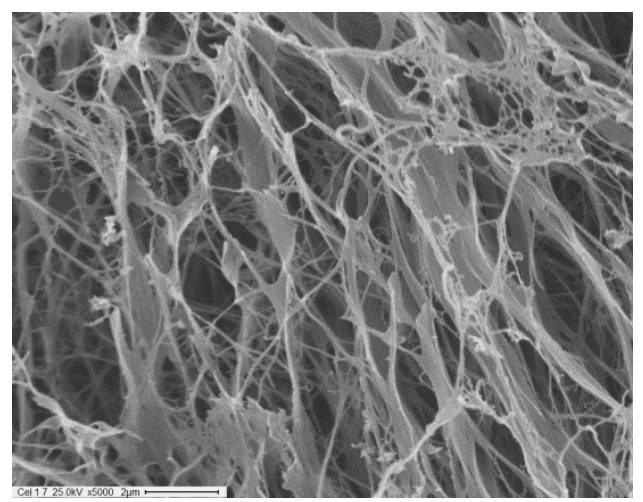

C2

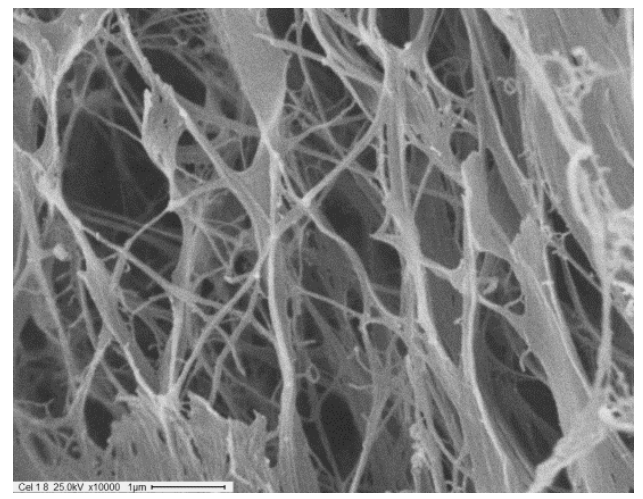

Las imágenes de $\mathrm{BC}$ y $\mathrm{BC}$-Alg muestran superficies homogéneas, pero con diferentes características morfológicas. Las membranas de $\mathrm{BC}$ mostraron la típica red encontrada en la celulosa bacteriana compuesta por largas y entrecruzadas fibras de celulosa ${ }^{17}$. Por otro lado, las membranas de BC-Alg mostraron estructuras homogéneas y con una red 3D más cerrada. La presencia de alginato en el cultivo estático permitió la formación de una fuerte red cooperativa entre ambos polímeros sin la presencia de 
gránulos de alginato, contrario a lo que fuera reportado previamente ${ }^{13}$. Nuestros resultados indican que la reducción de cristalinidad puede solo ser atribuida a la fuerte interconexión entre las fibras de celulosa y el alginato.

La rugosidad de la superficie de las membranas fue evaluada por medio de la desviación estándar de los valores en la escala de grises de un área seleccionada en las imágenes $(200 \times 300 \mu \mathrm{m})$ (Figuras 2.3A y B). El incremento en la desviación estándar es proporcional a la rugosidad de la superficie analizada. Este análisis mostró un aumento del $23 \%$ en la desviación estándar de BC-Alg que puede ser correlacionado con una estructura altamente porosa (Figura 2.4). El análisis comparativo de las medias mostró también que BC-Alg (136.063) era mayor que BC nativa (114.560) en casi un 19\%, indicando un espaciado estructural más regular en las cadenas de polímero debido a la presencia de alginato. Estos resultados también indican la formación de una fuerte red cooperativa entre ambos polímeros permitiendo una red con estructura más regular. A la vez, BC-Alg mostró un amplio rango en los valores de grises debido principalmente a la formación de la red entrelazada constituida por ambos biopolímeros.

Figura 2.4 Análisis estadístico de la rugosidad de las superficies de (A) BC y (B) BCAlg. Las imágenes analizadas corresponden a las Figuras 2.3. A1 y A2, respectivamente.

A

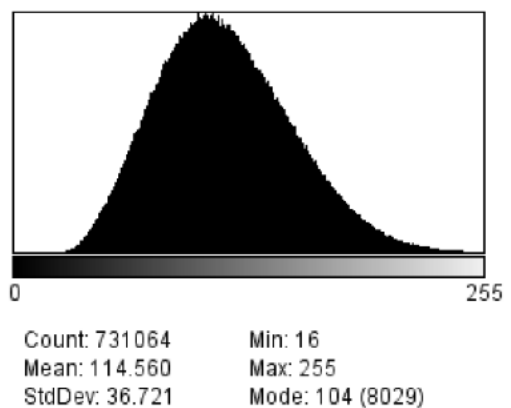

B

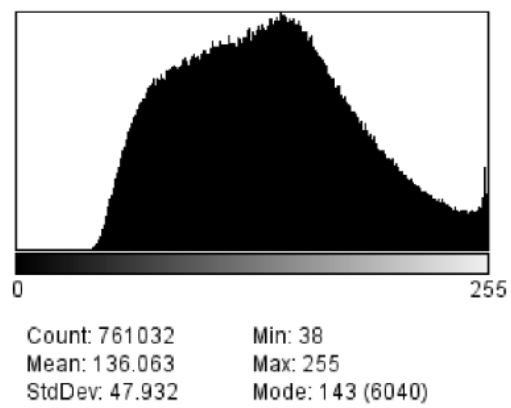

Luego, las potenciales interacciones entre $\mathrm{BC}$ y $\mathrm{Alg}$ en el biomaterial fueron analizadas por FTIR (Figura 2.5). Las membranas de celulosa bacteriana presentaron máximos centrados en $3348 \mathrm{~cm}^{-1}$ y $2890 \mathrm{~cm}^{-1}$, asignados a estiramientos de $\mathrm{O}-\mathrm{H}$ y C-H respectivamente. Además, se observaron picos centrados en $1375 \mathrm{~cm}^{-1}$ y $1033 \mathrm{~cm}^{-1}$ asignándolos a flexiones de $\mathrm{C}-\mathrm{H}$ y vibraciones características de anillos de azucares, respectivamente ${ }^{18}$. Por otro lado, el alginato puro mostró máximos característicos a 
$1406 \mathrm{~cm}^{-1}$ y $1593 \mathrm{~cm}^{-1}$, los cuales son comúnmente relacionados con bandas de estiramiento simétrico y asimétrico correspondientes al grupo carboxilo (COO),

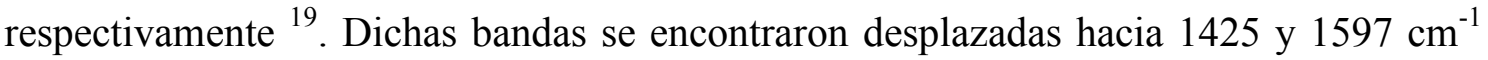
en los análisis de BC-Alg (Tabla II).

Tabla II Análisis de FTIR para los polímeros BC, Alg y BC-Alg.

\begin{tabular}{|c|c|c|c|}
\hline BC & $\begin{array}{r}\text { Alginato } \\
\text { de onda. }\end{array}$ & $\begin{array}{l}\text { BC-alg } \\
\text { (-1) }^{-1}\end{array}$ & Asignaciones \\
\hline 3348 & 3290 & 3342 & OH elongación \\
\hline 2890 & 2929 & 2942 & $\mathrm{C}-\mathrm{H}$ elongación \\
\hline- & 1593 & 1597 & Elongación asimetrica $-\mathrm{COO}$ \\
\hline- & 1406 & 1425 & Elongación simetrica $-\mathrm{COO}$ \\
\hline 1375 & - & - & $\mathrm{C}-\mathrm{H}$ doblamiento \\
\hline 1033 & 1026 & 1024 & $\begin{array}{l}\text { Elongación de } \mathrm{C}-\mathrm{O}-\mathrm{C} \text { y } \mathrm{C}-\mathrm{O}-\mathrm{H} \\
\text { vibraciones en anillo de azucares }\end{array}$ \\
\hline
\end{tabular}

Estos resultados sugieren que el agua incluida en las membranas de $\mathrm{BC}$ fue, al menos parcialmente, desplazada por el alginato debido a que es un polímero altamente hidrofílico. Los cambios observados en las bandas en BC-Alg pueden atribuirse a los puentes de hidrogeno intermoleculares basados en los grupos funcionales expuestos del alginato y la celulosa, con grupos funcionales carboxilatos e hidroxilos respectivamente 8,13 . Las principales interacciones moleculares determinadas por FTIR entre ambos polímeros claramente sugieren una alta compatibilidad y la formación de una red interconectada por medio de un mecanismo de co-gelación, siguiendo los lineamientos del modelo de Morris ${ }^{20}$. Para discutir los mecanismos combinatorios de gelación de sistemas poliméricos de dos componentes, Morris describió tres modelos posibles ${ }^{21}$. Dichos modelos corresponden a polímeros activos capaces de formar una estructura en red. El Modelo I hace referencia a una red interconectada formada por dos polímeros activos que son estructuralmente cooperativos debido principalmente al entrelazado de las dos redes. De esta manera, se puede establecer que el alginato juega un papel crucial en las propiedades fisicoquímicas de la matriz híbrida BC-Alg. La presencia del alginato dentro de dicha matriz expone grupos hidrofílicos que pueden aumentar aún más la hidrofilicidad de la red. Un incremento en la hidrofilicidad de la membrana es 
ventajoso debido a que puede relacionarse con la capacidad de retener moléculas hidrofílicas como la Doxo.

La Doxo es una molécula soluble en agua, pero su hidrofilicidad depende del $\mathrm{pH}$ del medio circundante. Es una base débil con un grupo amino primario el cual tiene un pKa de $8,46^{22}$. A pH comprendido entre 7,34 (pKa del grupo fenol) y 8,46 (pKa del grupo amino) la Doxo se encuentra predominantemente en su forma zwitterionica ${ }^{23}$. A pH inferior a 8,0 la Doxo posee una carga neta positiva de su grupo amina (Esquema 1) 24,25

Esquema 1. Ionización de la Doxo en solución acuosa.
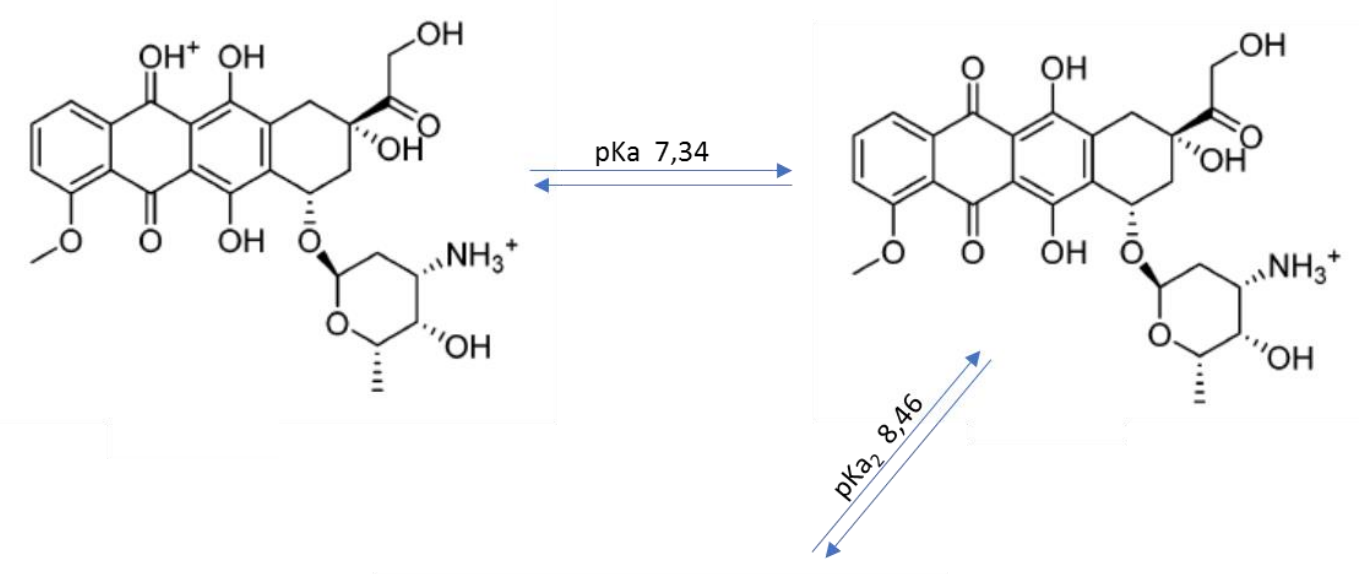<smiles>COc1cccc2c1C(=O)c1c(O)c3c(c(O)c1C2=O)C[C@@](O)(C(=O)CO)C[C@H]3O[C@H]1C[C@H](N)[C@H](O)[C@H](C)O1</smiles> 
Figura 2.5 Espectro de FTIR para BC (1), Alg (2) y BC-Alg (3).

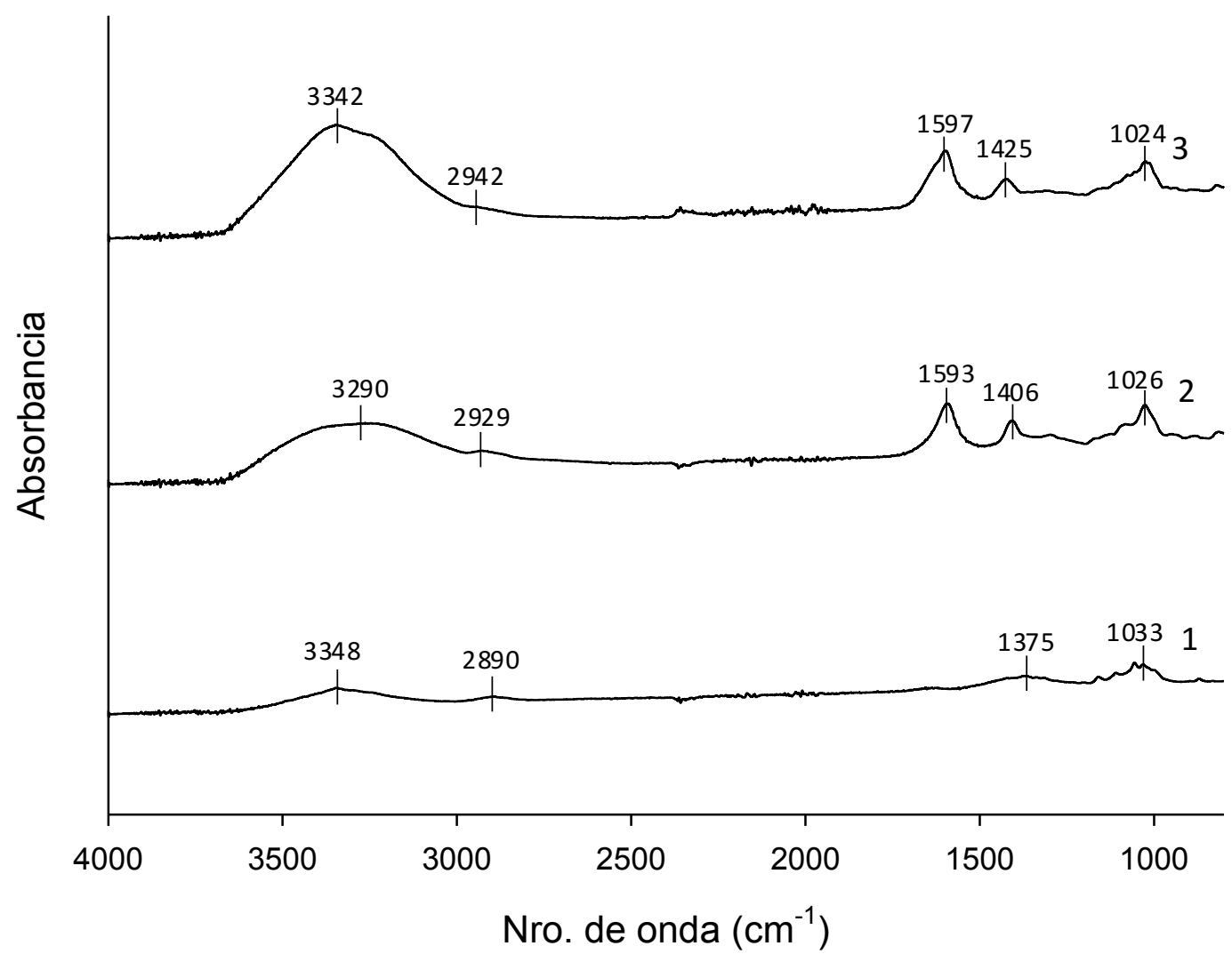

El análisis comparativo por medio de Brunauer-Emmett-Teller (BET) de las membranas mostró un incremento en el área superficial de alrededor del $84 \%$ y un incremento en el volumen de poro de más del 200\% para BC-Alg (Tabla III). Además, el tamaño de poro determinado por el modelo de Barrett-Joyner-Halenda (BJH) mostró diferencias significativas entre BC y BC-Alg. Estos cambios, atribuidos a la formación de una red cooperativa entre ambos polímeros, pueden también contribuir a la encapsulación de activos como la Doxorrubicina ${ }^{26,27}$. En conclusión, los análisis de las membranas de BC-Alg por medio de diversas técnicas como TGA, XRD, FTIR y SEM mostraron un contacto íntimo entre las fibras de celulosa y las cadenas de alginato generando un incremento en la fase amorfa del material aumentando su hidrofilicidad. Las características homogéneas de estas membranas de BC-Alg son relevantes para el desarrollo de un sistema de liberación de drogas ya que los perfiles de liberación y el nivel de carga pueden ser predichos, modelados y escalados. 
Tabla III. Análisis de adsorción y desorción de $\mathrm{N}_{2}$ por medio de BET para las membranas de $\mathrm{BC}$ y BC-Alg.

\begin{tabular}{|c|c|c|c|c|}
\hline \multirow{2}{*}{$\begin{array}{l}\text { Composición } \\
\text { de la matriz }\end{array}$} & \multirow{2}{*}{$\begin{array}{c}\text { Área } \\
\text { superficial } \\
\left(\mathrm{m}^{2} / \mathrm{g}\right)\end{array}$} & \multirow{2}{*}{$\begin{array}{l}\text { Volumen } \\
\text { de poro } \\
\left(\mathrm{cm}^{3} / \mathrm{g}\right)^{*}\end{array}$} & \multicolumn{2}{|c|}{ Tamaño de poro $(\mathrm{nm})$} \\
\hline & & & adsorción BJH & $\begin{array}{c}\text { Método } \\
\text { BET }\end{array}$ \\
\hline BC & 19,97 & 0,077 & 22,22 & 15,10 \\
\hline BC-Alg & 36,76 & 0,23 & 27,95 & 22,11 \\
\hline
\end{tabular}

\subsubsection{Encapsulación de Doxorrubicina}

Las membranas de BC-Alg fueron cargadas con doxorrubicina por un método de adsorción. Primero, celulosa sin modificar y modificada fueron colocadas en una solución con 3,7 $\mu$ moles de Doxo. La carga del fármaco fue unas tres veces superior en la membrana híbrida, atribuido a la presencia del alginato en la red de celulosa (Tabla IV).

Tabla IV Encapsulación de Doxo (1,0 mg/ml, 3,7 $\mu$ moles) en membrana de BC y BCAlg. Incubadas por 20 horas a $37^{\circ} \mathrm{C}$. Los errores fueron calculados mediante la desviación estándar de tres experimentos independientes.

\begin{tabular}{cc}
\hline Sistema & $\begin{array}{c}\text { Encapsulación de Doxo } \\
\mathbf{( \% )}\end{array}$ \\
\hline BC & $5,00 \pm 0,44$ \\
\hline BC-Alg & $16,20 \pm 3,18$ \\
\hline
\end{tabular}

El incremento en el área superficial, volumen y tamaño de poro en BC-Alg comparado con lo encontrado en $\mathrm{BC}$ sin modificar, pudo ser correlacionado con un incremento en las interacciones droga-matriz y con la difusión de la droga desde el medio hacia el interior de la membrana. Consecuentemente, mas Doxo podría ser encapsulada en la red 28 . Más específicamente, considerando que el alginato posee grupos carboxilatos $\left(\mathrm{pK}_{\mathrm{a}} \mathrm{s} \approx\right.$ 
1.5 - 3.5) y el pH del medio cercano a 7.0, en donde la doxo posee carga residual positiva, es factible considerar la interacción entre ambos grupos funcionales, lo que conduce a un aumento de la carga del fármaco en la matriz ${ }^{5}$.

De manera de determinar y estudiar la capacidad de carga de Doxo las membranas hibridas fueron colocadas por inmersión en soluciones con diferentes cantidades del fármaco, desde 3,7 a 11,0 $\mu$ moles/ml (Figura 2.6).

Figura 2.6 Encapsulación de Doxo a partir de diferentes soluciones iniciales. La Doxo encapsulada se expresa como $\mu$ moles de Doxo por gramo de matriz BCAlg.

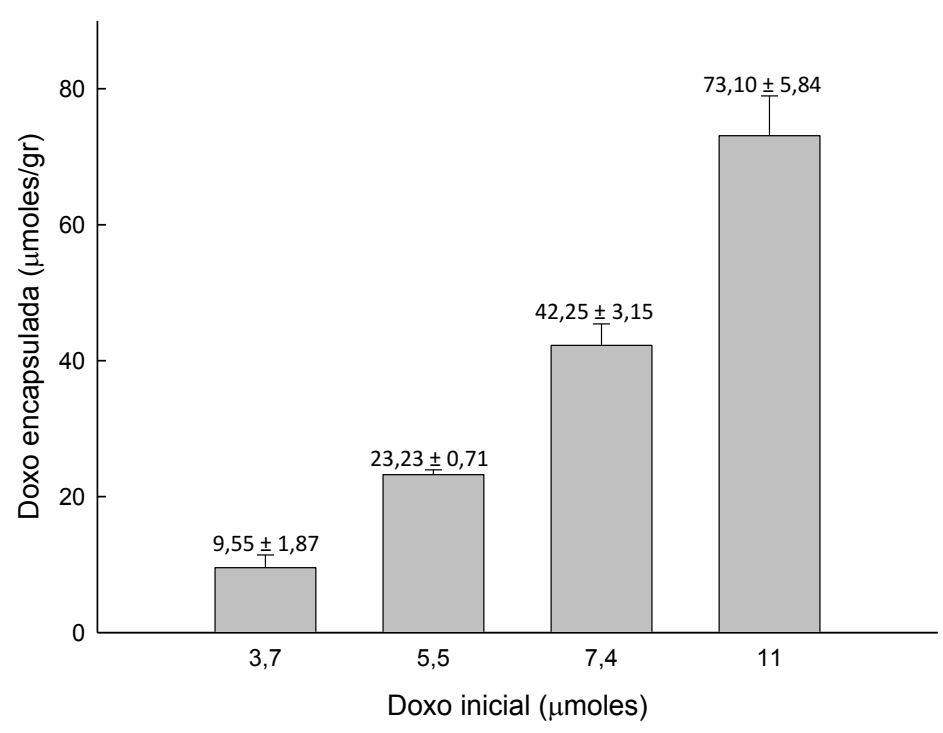

Una carga de Doxo equivalente a $10 \mu \mathrm{moles} /$ gramo de matriz se observó en el caso de la solución inicial de menor concentración $(3,7 \mu$ moles $/ \mathrm{ml})$. Sin embargo, la capacidad de carga de Doxo por parte de las membranas BC-Alg aumentó de manera lineal $\left(\mathrm{r}^{2}=0,95\right)$ cuando las soluciones iniciales de inmersión contenían concentraciones de Doxo mayores a los 3,7 $\mu$ moles/ml. Particularmente, cuando la solución inicial fue de $11,0 \mu \mathrm{moles} / \mathrm{ml}$ la Doxo incorporada fue seis veces mayor en comparación con la incorporada con la solución de 3,7 $\mu$ moles $/ \mathrm{ml}$. Este hecho es ventajoso debido a que sugiere que la carga de Doxo en las membranas puede ser modulada de acuerdo a las necesidades específicas de cada tratamiento (e.g., terapias personalizadas). La baja capacidad de carga en la primera solución se atribuyó solo a interacciones Doxo-matriz. Cuando la concentración de la solución inicial aumenta, empiezan a ser relevantes las 
interacciones Doxo-Doxo dentro de la matriz de celulosa y un fenómeno denominado apilamiento $\pi-\pi$ adquiere importancia ${ }^{29}$.

\subsubsection{Ensayos de liberación de Doxorrubicina}

Membranas de BC-Alg conteniendo distintas cantidades de Doxo encapsulada se incubaron en buffer PBS ( $\mathrm{pH} 7,4)$ mostrando perfiles hiperbólicos respecto a la liberación de la droga (Figura 2.7). Luego de la liberación muy rápida inicial (burst) los porcentajes de liberación permanecieron prácticamente constantes por al menos 14 días, aunque la cantidad neta de fármaco liberado no fue la misma en cada caso (Tabla V).

Figura 2.7. Perfiles de liberación de Doxo desde membranas BC-Alg cargando distintas cantidades de activo. Símbolos de las cantidades iniciales de Doxo: $\bigcirc, 9,55$ $\mu$ moles/g; $\nabla, 23,23 \mu$ moles/g; $\triangle, 42,25 \mu$ moles/g y $\boldsymbol{\bullet}, 73,10 \mu$ moles/g.

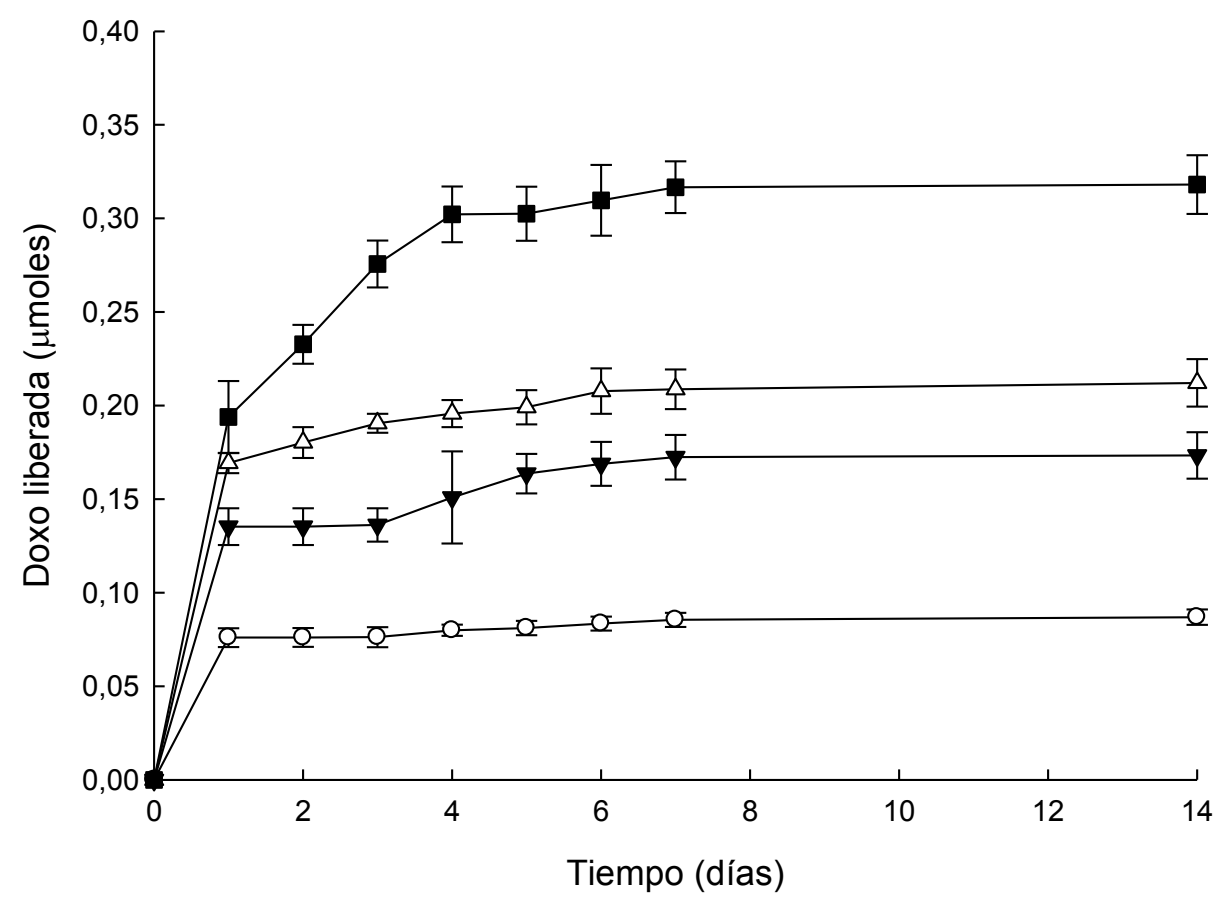

La liberación de Doxo desde las membranas puede ser explicada por la presencia de interacciones moleculares diferentes entre el fármaco y la matriz. Cuando las cantidades de droga encapsulada son bajas, las principales interacciones que se encuentran son aquellas existentes entre el fármaco y la matriz, como fuera mencionado y también reportado previamente ${ }^{5}$. Por otro lado, cuando la cantidad de Doxo atrapada es elevada otras interacciones cobran relevancia como las interacciones de tipo $\pi-\pi$ entre los anillos 
aromáticos de las moléculas de Doxo generando un fenómeno de apilamiento molecular. Este fenómeno modifica la capacidad de la membrana de liberar el activo generando cambios también en los perfiles de liberación.

Tabla V Doxo liberada $(\mu$ moles $/ \mathrm{ml})$ desde BC-Alg cargadas con 9,55 y 42,25 $\mu \mathrm{moles} / \mathrm{g}$, de acuerdo a las cinéticas de liberación de la Figura 2.7.

\begin{tabular}{cc|c}
\hline \multirow{2}{*}{$\begin{array}{c}\text { Tiempo } \\
\text { (horas) }\end{array}$} & \multicolumn{2}{c}{ Carga de Doxo $(\boldsymbol{\mu m o l e s} / \mathbf{g r})$} \\
\cline { 2 - 3 } & $\mathbf{9 , 5 5}$ & $\mathbf{4 2 , 2 5}$ \\
\cline { 2 - 3 } & \multicolumn{2}{c}{ Doxo liberada (\%) } \\
\hline $\mathbf{2 4}$ & $13,57 \pm 0,89$ & $6,87 \pm 0,20$ \\
\hline $\mathbf{4 8}$ & $13,75 \pm 0,89$ & $7,32 \pm 0,32$ \\
\hline
\end{tabular}

Finalmente, se ha establecido una relación lineal (Figura 2.8.) entre la cantidad de Doxo encapsulada y la cantidad liberada $\left(r^{2}=0,97\right)$, siendo este un dato interesante al momento de adaptar el sistema para una terapia personalizada.

Figura 2.8 Relación encontrada entre la capacidad de carga y la capacidad de liberación de Doxo a los 14 días en condiciones físiológicas simuladas.

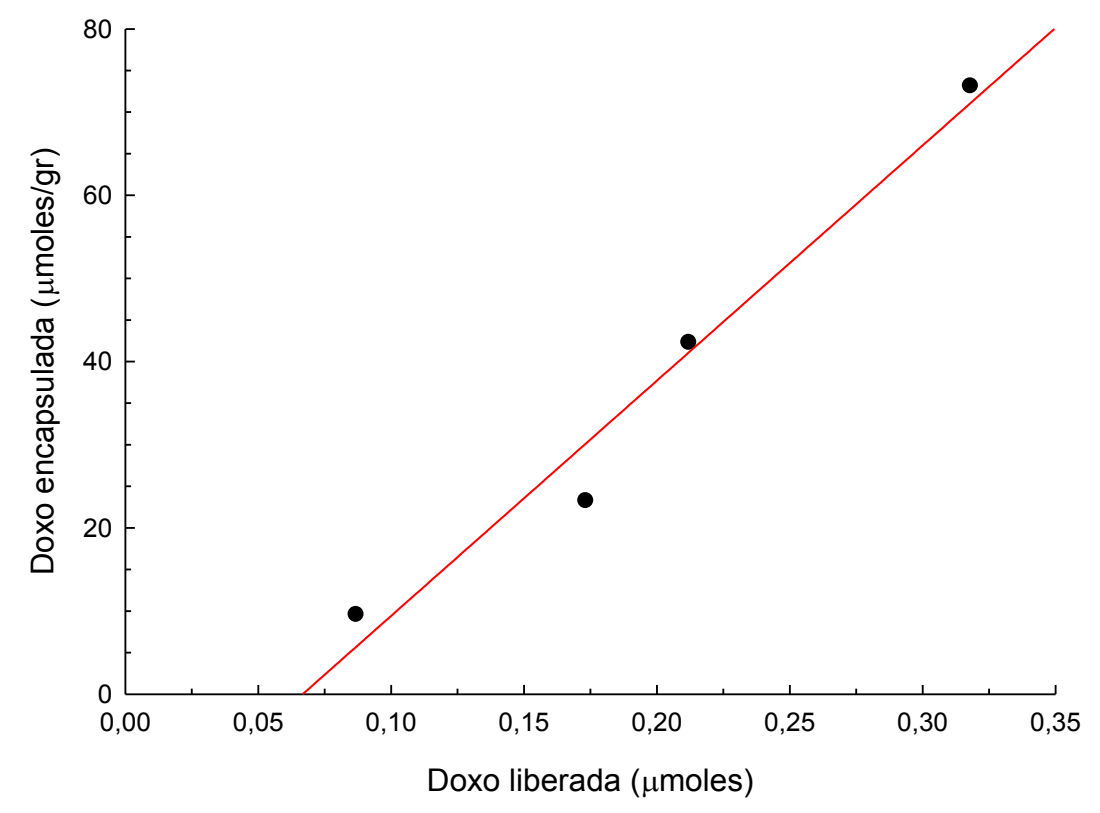




\subsubsection{Ensayos de viabilidad celular}

Se realizaron ensayos de viabilidad celular en cultivos de células de adenocarcinoma de colon humano (HT-29) por 24 y 48 horas de exposición a membranas BC-Alg cargadas con 9,55 y 42,25 $\mu$ moles de Doxo/g de matriz. La liberación del activo desde estas membranas se cuantificó luego de incubar las membranas cargadas en las mismas condiciones que el cultivo de células por 24 y 48 horas. Las cantidades de Doxo liberadas alcanzaron concentraciones de $76 \mu \mathrm{M}$ a $24 \mathrm{~h}$ y $77 \mu \mathrm{M}$ a $48 \mathrm{~h}$ para las membranas cargadas con $9,55 \mu$ moles/g; y 169 y $181 \mu \mathrm{M}$ a 24 y $48 \mathrm{~h}$ respectivamente para las membranas cargadas con $42,25 \mu$ moles/g. Por otro lado, se realizaron controles colocando Doxo libre en contacto con las células a concentraciones en el rango de 100$200 \mu \mathrm{M}$. Para el caso de los cultivos a $48 \mathrm{~h}$, se tomaron imágenes ópticas y de fluorescencia de los sobrenadantes (Figura 2.9 y 2.10) por medio de microscopio. 
Figura 2.9 Imágenes en el visible (Izquierda) y en el ultravioleta (derecha) utilizando un microscopio óptico sobre los cultivos de células luego de $48 \mathrm{~h}$ de incubación. Se observaron los pocillos con Doxo libre y con Doxo liberada desde BC-Alg con 42,25 $\mu$ moles/gr.

Visible
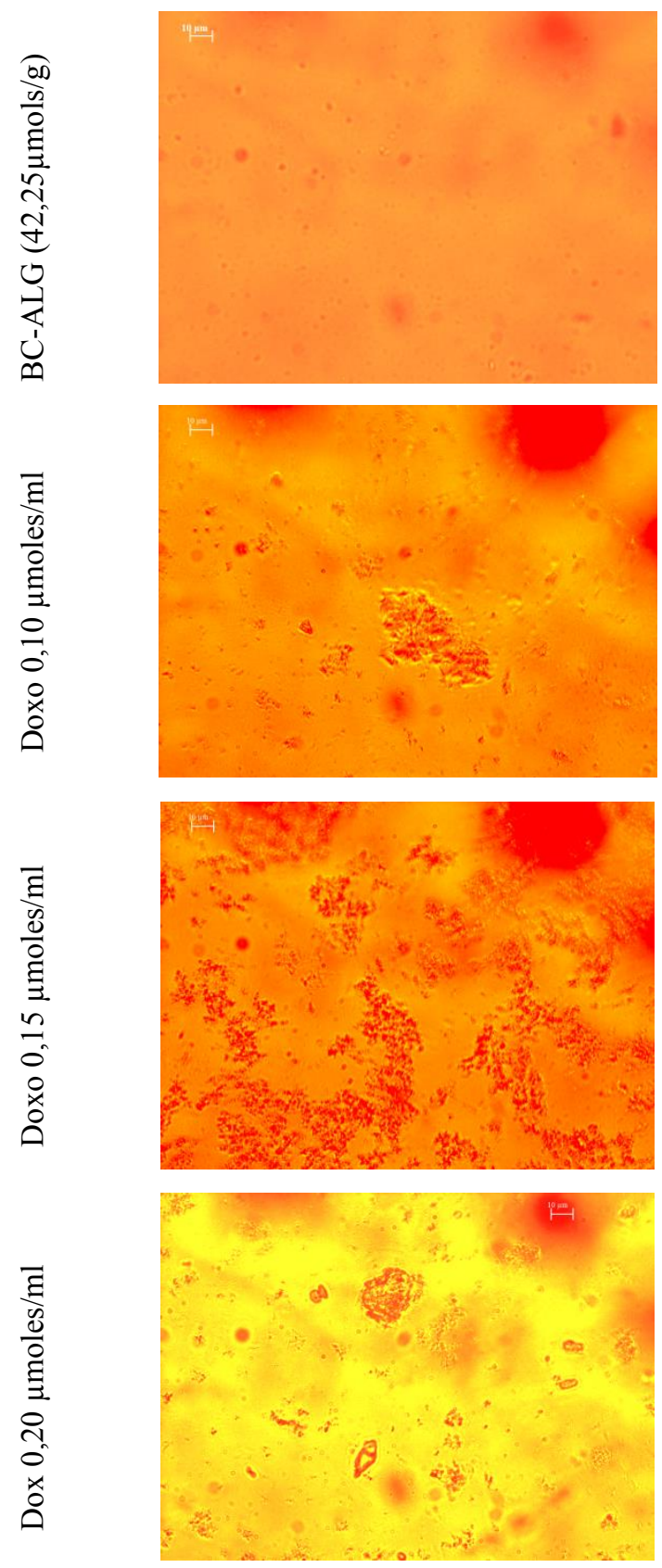

Fluorescencia
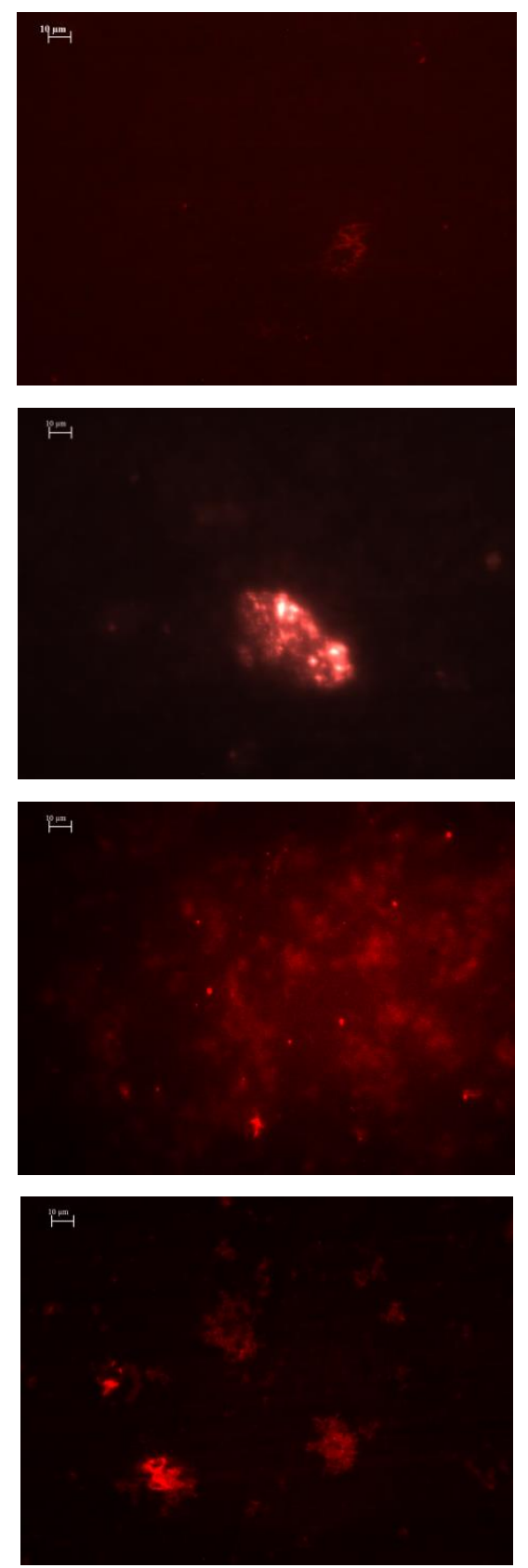

Se observaron precipitados de Doxo en todos los casos. Sin embargo, se pudieron observar amplias diferencias en los cristales de Doxo presentes para los casos de Doxo libre y en aquellos pocillos donde había Doxo liberada desde las membranas. El tamaño y la cantidad de cristales fue lo que se diferenció en ambos casos. En aquellos pocillos 
donde había Doxo libre se observaron los cristales de mucho mayor tamaño y en mayor cantidad. En contraste, en los casos de la Doxo liberada desde las membranas se observa una gran reducción de tamaño y cantidad en los cristales de droga. Se considera que este hecho puede ser atribuido a la presencia de los polímeros que actúan como agente inhibidor de la nucleación de los cristales y, por otro lado el efecto estérico generado por la red tridimensional de la matriz también generaría un efecto de inhibición en la formación de los precipitados ${ }^{30,31}$.

Figura 2.10 Fotografía óptica de los pocillos luego de 48 horas de cultivo, observándose un precipitado en el caso de la Doxo libre.

\section{Doxo libre ( $\mu \mathrm{moles} / \mathrm{ml})$}

\section{BC-ALG}

\begin{tabular}{lll}
\hline $\mathbf{0 , 1 0}$ & $\mathbf{0 , 1 5}$ & $\mathbf{0 , 2 0}$ \\
\hline & & \\
\hline & & \\
\hline & & \\
\hline
\end{tabular}

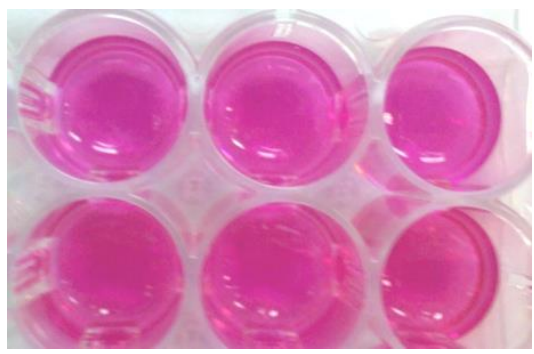

$42,25 \mu \mathrm{moles} / \mathrm{gr}$

El análisis espectrofluorimetrico de los sobrenadantes conteniendo Doxo liberada desde las membranas $\mathrm{BC}$-Alg no mostró corrimientos en los espectros de emisión de fluorescencia sugiriendo la ausencia de formación de complejos entre el fármaco y los polímeros luego de la liberación que podrían afectar el efecto de la Doxo sobre las células.

Estudios de viabilidad celular mostraron poco efecto sobre las células en el caso de la Doxo libre en el rango 100-200 $\mu \mathrm{M}$ luego de 24 horas de exposición continua. Sin embargo, se observó cerca del $75 \%$ de viabilidad en presencia de 100 y $150 \mu \mathrm{M}$ de Doxo libre y un $63 \%$ de viabilidad para el caso de $200 \mu \mathrm{M}$ luego de 48 horas de exposición continua (Tabla VI). 
Tabla VI. Ensayos de viabilidad celular en la línea HT-29 de adenocarcinoma de colon humano. Las células fueron expuestas de modo continuo por 24 y 48 horas a membranas BC-Alg cargadas con Doxo (9,55 y 42,25 $\mu$ moles/gr). En paralelo se trató las células con Doxo libre $(100,150$ y $200 \mu \mathrm{M})$ a modo de control.

\begin{tabular}{|c|c|c|c|c|c|}
\hline \multirow{2}{*}{ Sistema } & \multirow{2}{*}{\multicolumn{3}{|c|}{$\begin{array}{c}\text { Concentración de Doxo } \\
\qquad(\mu \mathrm{M})\end{array}$}} & \multicolumn{2}{|c|}{ Viabilidad celular $(\%)$} \\
\hline & & & & 24 horas & 48 horas \\
\hline \multirow{3}{*}{ Doxo libre } & & 100 & & $94,0 \pm 3,7$ & $74,0 \pm 2,7$ \\
\hline & & 150 & & $93,0 \pm 3,3$ & $73,0 \pm 2,7$ \\
\hline & & 200 & & $95,0 \pm 2,7$ & $63,0 \pm 2,1$ \\
\hline \multirow{5}{*}{ BC-ALG } & & Doxo & Doxo & \multicolumn{2}{|c|}{ Viabilidad celular $(\%)$} \\
\hline & $\begin{array}{c}\text { encapsulada } \\
(\mu \mathrm{moles} / \mathrm{g})\end{array}$ & $\begin{array}{l}\text { liberada } \\
(\mu \mathrm{M}) \text { a las } \\
24 \text { horas }\end{array}$ & $\begin{array}{c}\text { liberada } \\
(\mu M) \text { a las } \\
48 \text { horas }\end{array}$ & 24 horas & 48 horas \\
\hline & 0,00 & $0,0 \pm 0,0$ & $0,0 \pm 0,0$ & $103,0 \pm 3,1$ & $97,4 \pm 2,1$ \\
\hline & $9,55 \pm 1,87$ & $76,0 \pm 5,0$ & $169,0 \pm 5,0$ & $59,0 \pm 7,2$ & $55,0 \pm 8,2$ \\
\hline & $42,25 \pm 3,15$ & $77,0 \pm 5,0$ & $181,0 \pm 8,0$ & $53,0 \pm 1,6$ & $37,0 \pm 0,5$ \\
\hline
\end{tabular}

Por otro lado, en el caso de BC-Alg sin presencia de Doxo atrapada no se observaron cambios en la viabilidad celular a ambos periodos de tiempo. Luego, la viabilidad celular se vio disminuida drásticamente a 59\% y 53\% para el caso de BC-Alg con 9,55 y 42,25 $\mu$ moles de Doxo/g, respectivamente luego de 24 horas de exposición. Luego de 48 horas de incubación se observó que aquellas células expuestas a BC-Alg con 9,55 $\mu$ moles/g mostraban una viabilidad del 55\%, sugiriendo una ausencia de diferencias significativas en comparación con el mismo caso a 24 hs $(p<0,05)$. Para el caso de BCAlg con 42,25 $\mu$ moles/ml fueron observadas diferencias debido a que a las $48 \mathrm{~h}$ se obtuvo una viabilidad del 37\% (Tabla VI). Estos resultados junto con las imágenes mostradas por microscopía claramente demuestran que la vehiculización de la Doxo en sistemas poliméricos mejora su actividad por medio de la inhibición, al menos parcial, de la formación de cristales. 


\subsection{Conclusiones}

En el presente capítulo se modificó in-situ una matriz de celulosa bacteriana por medio de la incorporación de alginato al medio de cultivo en condiciones estáticas. Como resultado se obtuvo una matriz biopolimérica homogénea con nuevas propiedades estructurales y con capacidad de encapsular el activo quimioterapéutico Doxorrubicina. Las técnicas biofísicas empleadas para la caracterización (TGA, FTIR, SEM) confirmaron una interacción intima entre el alginato y la celulosa por medio de fuerzas electrostáticas débiles permitiendo, en conjunto, la formación de una fuerte red de fibras entrecruzadas con un homogéneo aumento de la fase amorfa (verificado por XRD). El aumento de la fase amorfa lleva a la exposición de grandes cantidades de grupos hidroxilo del alginato por dentro de la matriz polimérica, esto podría optimizar la absorción de Doxo en las membranas. Además, el incremento en el área superficial y tamaño de poro también aumentaría la capacidad de matriz de retener moléculas de Doxo. Luego, los ensayos de encapsulación demostraron que se podían encapsular elevadas cantidades de Doxo en la matriz BC-Alg en comparación con BC sin modificar. La carga de fármaco en $\mathrm{BC}$-Alg permitió tener más de $70 \mu$ moles de Doxo por gramo de matriz. Los perfiles de liberación de la droga desde BC-Alg, obtenidos con diferentes cargas de Doxo, sugirieron una relación linear entre la cantidad de Doxo encapsulada y las cantidades liberadas, brindando importante información sobre las interacciones BC-Alg/Doxo. La capacidad de modular la carga de Doxo y su liberación podría ayudar a definir terapias personalizadas bajo los requerimientos específicos de cada paciente.

Las membranas de BC-Alg fueron ensayadas sobre una línea celular de adenocarcinoma de colon humano (HT-29). Dicha línea celular fue elegida por su reconocida resistencia a la Doxo ${ }^{32}$. La exposición directa a Doxo por 24 horas mostró que prácticamente no se producían cambios en la viabilidad celular, pero luego de 48 horas de exposición la viabilidad celular fue cercana al 70\% en todos los casos. Por comparación las células expuestas a BC-Alg mostraron un significativo descenso en la viabilidad a ambos tiempos. Las concentraciones de Doxo liberada se midieron en los sobrenadantes encontrándose valores similares a aquellos utilizados para los ensayos control con Doxo libre. Además, se obtuvieron imágenes ópticas de los sobrenadantes observándose una menor tendencia de la Doxo a formar cristales para el caso de la 
droga liberada desde BC-Alg. Por esta razón se sugiere que la Doxo liberada desde la matriz ha logrado ser más efectiva sobre las células. En conclusión, las membranas de BC-Alg fueron desarrolladas de modo exitoso obteniéndose una matriz hibrida, homogénea y con capacidad de encapsular un activo antitumoral. Este sistema muestra tener una potencial aplicación como un dispositivo implantable para terapias locales contra el cáncer.

\subsection{Referencias}

(1) FDA. Food Additives \&amp; Ingredients - Food Additive Status List

http://www.fda.gov/Food/IngredientsPackagingLabeling/FoodAdditivesIngredients/ucm091048.h tm (accessed Jan 7, 2017).

(2) Velings, N. M.; Mestdagh, M. M. Physico-Chemical Properties of Alginate Gel Beads. Polym. Gels Networks 1995, 3 (3), 311-330.

(3) Augst, A. D.; Kong, H. J.; Mooney, D. J. Alginate Hydrogels as Biomaterials. Macromol. Biosci. 2006, $6(8), 623-633$.

(4) Shah, N.; Ul-Islam, M.; Khattak, W. A.; Park, J. K. Overview of Bacterial Cellulose Composites: A Multipurpose Advanced Material. Carbohydr. Polym. 2013, 98 (2), 1585-1598.

(5) Bosio, V. E.; Machain, V.; López, A. G.; De Berti, I. O. P.; Marchetti, S. G.; Mechetti, M.; Castro, G. R. Binding and Encapsulation of Doxorubicin on Smart Pectin Hydrogels for Oral Delivery. Appl. Biochem. Biotechnol. 2012, 167 (5), 1365-1376.

(6) Park, M.; Lee, D.; Hyun, J. Nanocellulose-Alginate Hydrogel for Cell Encapsulation. Carbohydr. Polym. 2015, 116, 223-228.

(7) Kirdponpattara, S.; Khamkeaw, A.; Sanchavanakit, N.; Pavasant, P.; Phisalaphong, M. Structural Modification and Characterization of Bacterial Cellulose-Alginate Composite Scaffolds for Tissue Engineering. Carbohydr. Polym. 2015, 132, 146-155.

(8) Chiaoprakobkij, N.; Sanchavanakit, N.; Subbalekha, K.; Pavasant, P.; Phisalaphong, M. Characterization and Biocompatibility of Bacterial Cellulose/alginate Composite Sponges with Human Keratinocytes and Gingival Fibroblasts. Carbohydr. Polym. 2011, 85 (3), 548-553.

(9) Shao, W.; Liu, H.; Liu, X.; Wang, S.; Wu, J.; Zhang, R.; Min, H.; Huang, M. Development of Silver Sulfadiazine Loaded Bacterial Cellulose/sodium Alginate Composite Films with Enhanced Antibacterial Property. Carbohydr. Polym. 2015, 132, 351-358.

(10) Okajima, T.; Nakamura, K.; Zhang, H.; Ling, N.; Tanabe, T.; Yasuda, T.; Rosenfeld, R. G. Sensitive Colorimetric Bioassays for Insulin-like Growth Factor (IGF) Stimulation of Cell Proliferation and Glucose Consumption: Use in Studies of IGF Analogs. Endocrinology 1992, $130(4), 2201-2212$.

(11) Leon, I. E.; Porro, V.; Di Virgilio, A. L.; Naso, L. G.; Williams, P. A. M.; Bollati-Fogol??n, M.; Etcheverry, S. B. Antiproliferative and Apoptosis-Inducing Activity of an oxidovanadium(IV) 
Complex with the Flavonoid Silibinin against Osteosarcoma Cells. J. Biol. Inorg. Chem. 2014, 19 (1), 59-74.

(12) Lourdin, D.; Coignard, L.; Bizot, H.; Colonna, P. Influence of Equilibrium Relative Humidity and Plasticizer Concentration on the Water Content and Glass Transition of Starch Materials. Polymer (Guildf). 1997, 38 (21), 5401-5406.

(13) Zhou, L. L.; Sun, D. P.; Hu, L. Y.; Li, Y. W.; Yang, J. Z. Effect of Addition of Sodium Alginate on Bacterial Cellulose Production by Acetobacter Xylinum. J. Ind. Microbiol. Biotechnol. 2007, 34 (7), 483-489.

(14) Ouajai, S.; Shanks, R. A. Composition, Structure and Thermal Degradation of Hemp Cellulose after Chemical Treatments. Polym. Degrad. Stab. 2005, 89 (2), 327-335.

(15) Huang, H. C.; Chen, L. C.; Lin, S. Bin; Chen, H. H. Nano-Biomaterials Application: In Situ Modification of Bacterial Cellulose Structure by Adding HPMC during Fermentation. Carbohydr. Polym. 2011, 83 (2), 979-987.

(16) Cai, Z.; Kim, J. Bacterial Cellulose/poly(ethylene Glycol) Composite: Characterization and First Evaluation of Biocompatibility. Cellulose 2010, 17 (1), 83-91.

(17) Kwak, M. H.; Kim, J. E.; Go, J.; Koh, E. K.; Song, S. H.; Son, H. J.; Kim, H. S.; Yun, Y. H.; Jung, Y. J.; Hwang, D. Y. Bacterial Cellulose Membrane Produced by Acetobacter Sp. A10 for Burn Wound Dressing Applications. Carbohydr. Polym. 2015, 122, 387-398.

(18) Kacuráková, M. FT-IR Study of Plant Cell Wall Model Compounds: Pectic Polysaccharides and Hemicelluloses. Carbohydr. Polym. 2000, 43 (2), 195-203.

(19) Daemi, H.; Barikani, M. Synthesis and Characterization of Calcium Alginate Nanoparticles, Sodium Homopolymannuronate Salt and Its Calcium Nanoparticles. Sci. Iran. 2012, 19 (6), 2023-2028.

(20) Huang, H. C.; Chen, L. C.; Lin, S. Bin; Hsu, C. P.; Chen, H. H. In Situ Modification of Bacterial Cellulose Network Structure by Adding Interfering Substances during Fermentation. Bioresour. Technol. 2010, 101 (15), 6084-6091.

(21) Morris, V. J. Multicomponent Gels. In Gums and stabilizers for food industry; Philips, G. O., Wedlock, D. J., Williams, P. A., Eds.; Elsevier Applied Science Publishers Ltd., 1985; pp 87-99.

(22) Goncalves, M.; Figueira, P.; Maciel, D.; Rodrigues, J.; Shi, X.; Tom??s, H.; Li, Y. Antitumor Efficacy of Doxorubicin-Loaded Laponite/alginate Hybrid Hydrogels. Macromol. Biosci. 2014, 14 (1), 110-120.

(23) NIH U.S. National Library of Medicine National Center for Biotechnology Information. Doxorubicin Hydrochloride - PubChem https://pubchem.ncbi.nlm.nih.gov/compound/Doxorubicin_Hydrochloride\#section=Stability (accessed Feb 19, 2017).

(24) Ahmadi, M.; Madrakian, T.; Afkhami, A. Solid Phase Extraction of Doxorubicin Using Molecularly Imprinted Polymer Coated Magnetite Nanospheres prior to Its Spectrofluorometric Determination. New J. Chem. 2015, 39 (1), 163-171.

(25) Fülöp, Z.; Gref, R.; Loftsson, T. A Permeation Method for Detection of Self-Aggregation of Doxorubicin in Aqueous Environment. Int. J. Pharm. 2013, 454 (1), 559-561. 
(26) Arias, J. L.; Ruiz, M. A.; Lopez-Viota, M.; Delgado, A. V. Poly(alkylcyanoacrylate) Colloidal Particles as Vehicles for Antitumour Drug Delivery: A Comparative Study. Colloids Surfaces B Biointerfaces 2008, 62 (1), 64-70.

(27) Zhu, Y.-F.; Shi, J.-L.; Li, Y.-S.; Chen, H.-R.; Shen, W.-H.; Dong, X.-P. Hollow Mesoporous Spheres with Cubic Pore Network as a Potential Carrier for Drug Storage and Its In Vitro Release Kinetics. J. Mater. Res. 2005, 20 (1), 54-61.

(28) Ahern, R. J.; Hanrahan, J. P.; Tobin, J. M.; Ryan, K. B.; Crean, A. M. Comparison of Fenofibrate-Mesoporous Silica Drug-Loading Processes for Enhanced Drug Delivery. Eur. J. Pharm. Sci. 2013, 50 (3-4), 400-409.

(29) Islan, G. A.; De Verti, I. P.; Marchetti, S. G.; Castro, G. R. Studies of Ciprofloxacin Encapsulation on Alginate/pectin Matrixes and Its Relationship with Biodisponibility. Appl. Biochem. Biotechnol. 2012, 167 (5), 1408-1420.

(30) A-sasutjarit, R.; Sirivat, A.; Vayumhasuwan, P. Viscoelastic Properties of Carbopol 940 Gels and Their Relationships to Piroxicam Diffusion Coefficients in Gel Bases. Pharm. Res. 2005, 22 (12), 2134-2140.

(31) Trovatti, E.; Freire, C. S. R.; Pinto, P. C.; Almeida, I. F.; Costa, P.; Silvestre, A. J. D.; Neto, C. P.; Rosado, C. Bacterial Cellulose Membranes Applied in Topical and Transdermal Delivery of Lidocaine Hydrochloride and Ibuprofen: In Vitro Diffusion Studies. Int. J. Pharm. 2012, 435 (1), 83-87.

(32) Garrido, C.; Mehlen, P.; Fromentin, a; Hammann, a; Assem, M.; Arrigo, a P.; Chauffert, B. Inconstant Association between 27-kDa Heat-Shock Protein (Hsp27) Content and Doxorubicin Resistance in Human Colon Cancer Cells. The Doxorubicin-Protecting Effect of Hsp27. Eur. J. Biochem. 1996, 237 (3), 653-659.

(33) Cacicedo, M. L.; E. León, I.; S. Gonzalez, J.; M. Porto, L.; A. Alvarez, V.; Castro, G. R. Modified Bacterial Cellulose Scaffolds for Localized Doxorubicin Release in Human Colorectal HT-29 Cells. Colloids Surfaces B Biointerfaces 2016, 140, 421-429. 


\section{Capítulo 3}

Desarrollo de nanopartículas lipídicas para la encapsulación y liberación de doxorrubicina

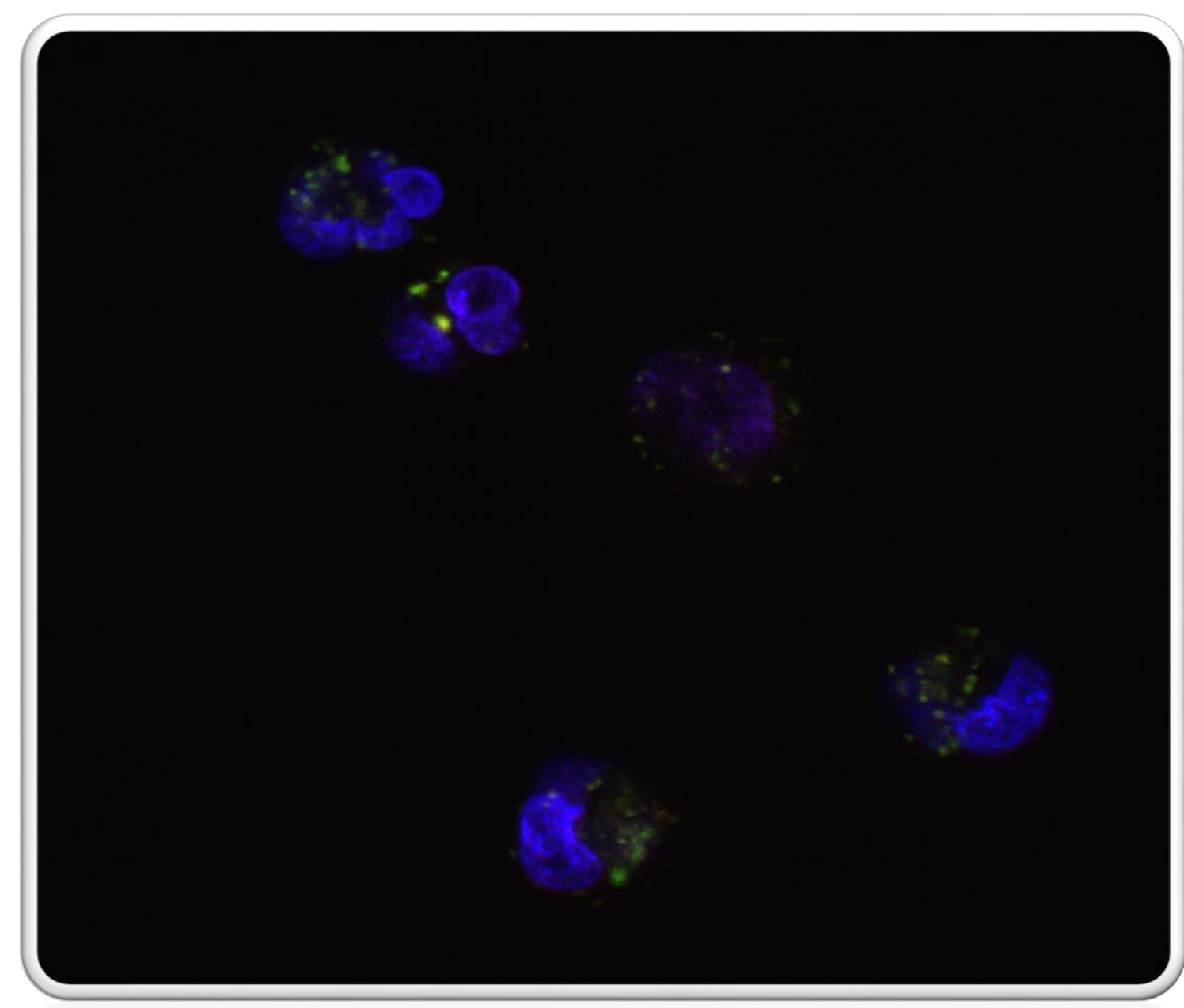

Imagen de microscopia confocal correspondiente a la localización intracelular de las nanopartículas en células MDA-MB-231. 


\section{Objetivos específicos:}

* Desarrollar una formulación de nanopartículas lipídicas para la vehiculización de Doxorrubicina (Doxo).

* Estudiar la eficiencia de encapsulación y los perfiles de liberación de Doxo en diferentes condiciones fisiológicas.

* Analizar las características físicoquímicas de las partículas y de las posibles interacciones con la Doxo.

* Estudiar la citotoxicidad de las partículas sin Doxo y evaluar los efectos de las partículas con Doxo sobre la viabilidad celular de una línea humana de cáncer de mama.

* Realizar estudios de internalización celular. 


\subsection{Introducción}

El desarrollo de un nanosistema de liberación controlada de Doxo contenida en nanopartículas lipídicas permitiría la administración del fármaco en pequeñas dosis de manera que pueda llevar adelante su acción citotóxica sin alcanzar concentraciones de fármaco libre demasiado elevadas en el lugar de aplicación. En consecuencia, se reducirían los efectos secundarios tóxicos sobre las células, tejidos y órganos (Esquema 1). Resulta indispensable establecer las posibles interacciones entre la Doxo, la matriz de transporte, y el ambiente fisiológico en donde se efectuaría la liberación (órgano blanco). El tamaño necesario para atravesar barreras fisiológicas, así como las características de superficie de la partícula son otras características relevantes a considerar.

Esquema 1. Perfiles de liberación de un fármaco obtenidos mediante el uso de un sistema convencional de administración y un sistema de liberación controlada. En este último caso se observa cómo se obtiene una dosis terapéutica de modo prolongado en el tiempo.

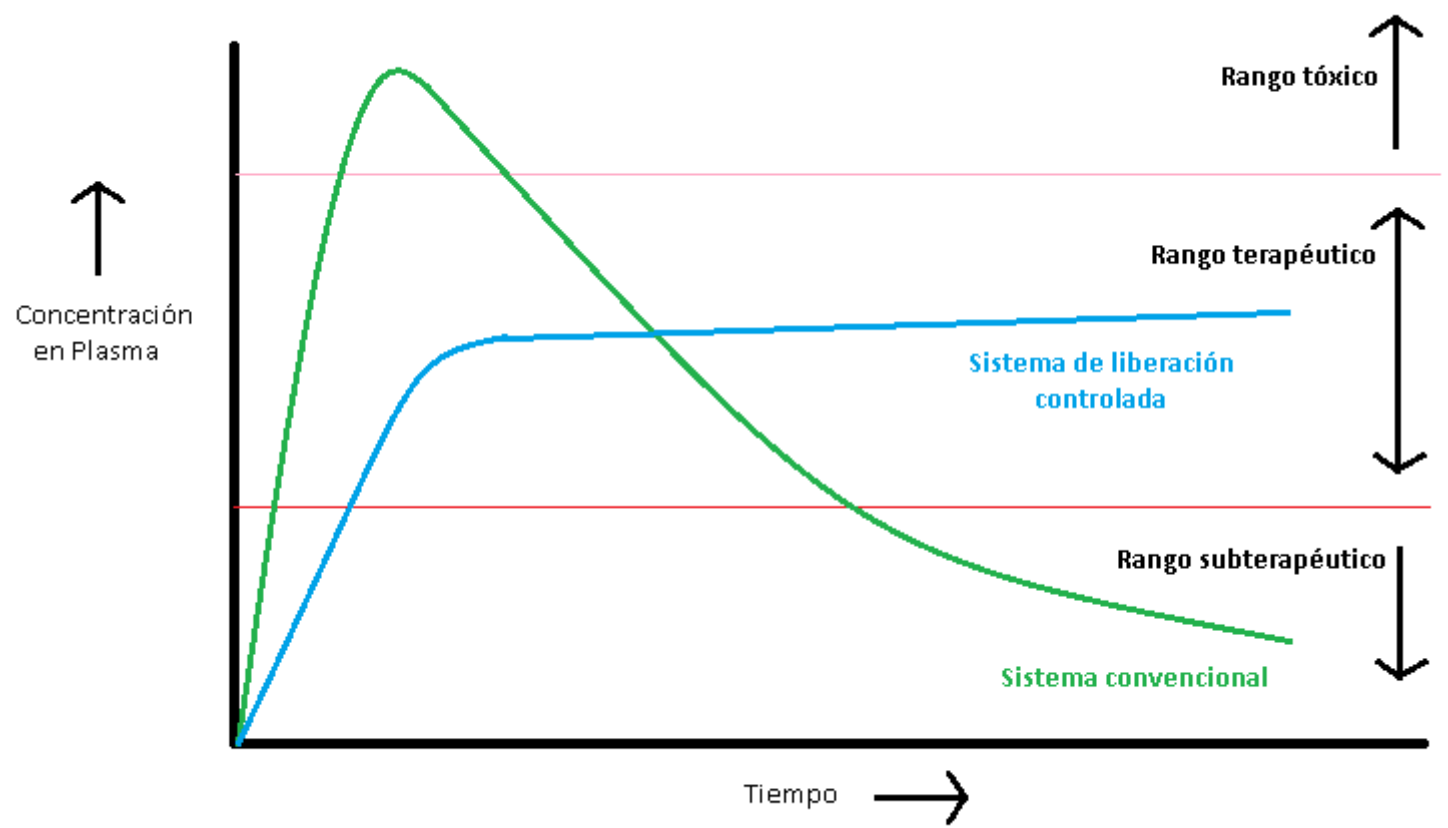

Como se mencionara anteriormente, ha habido un creciente interés en el uso de fármacos encapsulados en nanovehículos con el fin de mejorar la eficacia terapéutica y reducir el riesgo de efectos adversos debido a la toxicidad inherente de estas moléculas ${ }^{1}$. Grandes esfuerzos se realizan actualmente en el diseño de nanovehículos capaces de 
transportar con seguridad los diversos tipos de drogas y para liberar su carga de manera eficiente en su sitio de acción. Entre las diferentes clases de sistemas nanoparticulados mas estudiados se encuentran: nanopartículas polímericas ${ }^{2}$, micelas ${ }^{3}$, liposomas $^{4}$, nanopartículas solidas lipídicas ${ }^{5}$, nanopartículas magnéticas ${ }^{6}$.

Las nanopartículas lipídicas solidas (SLNs) se preparan utilizando lípidos sólidos (es decir, lípidos que son sólidos a temperatura ambiente, así como a la temperatura corporal). Entre estos lípidos, muchos de ellos son biocompatibles y biodegradables, GRAS (Generally Recognized As Safe, FDA, EE.UU.). Las SLNs son beneficiosas en muchos aspectos, tales como: (i) se puede evitar el uso de disolventes orgánicos en la producción, (ii) poseen baja o nula toxicidad, (iii) compuestos lipófilos pueden ser fácilmente encapsulados, (iv) se puede aumentar la biodisponibilidad de moléculas altamente lipofílicas a través de la absorción linfática, (v) la degradación de las moléculas sensibles a humedad/luz/oxidación química puede prevenirse mediante su incorporación en la matriz de nanopartículas, (vi) se hace posible una liberación sostenida del fármaco desde la matriz de nanopartículas y se minimizan los efectos secundarios adversos de la molécula encapsulada, (vii) la penetración a través de la piel o mucosa es posible debido al tamaño nanometrico ${ }^{7}$.

En general, las moléculas de fármaco se mantienen en medio de las cadenas de ácidos grasos o como racimos amorfos en imperfecciones del cristal dentro de la matriz de las SLNs. Cuando los lípidos se encuentran en la forma de baja energía, se forma una red cristalina perfecta que permite un espacio muy pequeño para que las moléculas del fármaco se puedan acomodar. En consecuencia, durante el almacenamiento, se puede observar la expulsión de dichas moléculas de fármaco encapsulado, especialmente cuando la matriz SLN se compone de un lípido altamente purificado, lo que reduce mucho la capacidad de carga del fármaco ${ }^{8}$. Por lo tanto, las propiedades del perfil de liberación del fármaco y de encapsulado de las SLNs puede alterarse con el transcurrir del tiempo de almacenamiento.

En el proceso de mejora y reducción de las desventajas de las SLNs, se han desarrollado sistemas evolucionados alternativos. En tal sentido, existen los sistemas de segunda generación de SLN denominados vehículos lipídicos nanoestructurados (NLCs) cuya matriz se compone de una mezcla de moléculas de lípidos en espacios diferentes, normalmente mezcla de lípidos sólidos y líquidos hace más imperfecta la matriz lo que permite producir nanopartículas con mayor espacio a que más moléculas de fármaco puedan acomodarse en comparación con las SLNs (Esquema 2). A pesar de 
la presencia de lípidos líquidos, la matriz de las NLCs es sólida a temperatura ambiente/corporal ${ }^{9}$. Con este tipo de estrucutras se espera que la capacidad de carga del fármaco sea optimizada, reduciéndose al mínimo la expulsión del fármaco durante el almacenamiento, debido a la red cristalina, y la liberación del fármaco puede modularse fácilmente variando la composición de la matriz de lípidos.

Esquema 2. Ilustración esquemática de SLNs y NLCs, donde se muestran las ventajas de un sistema sobre otro ${ }^{10}$.

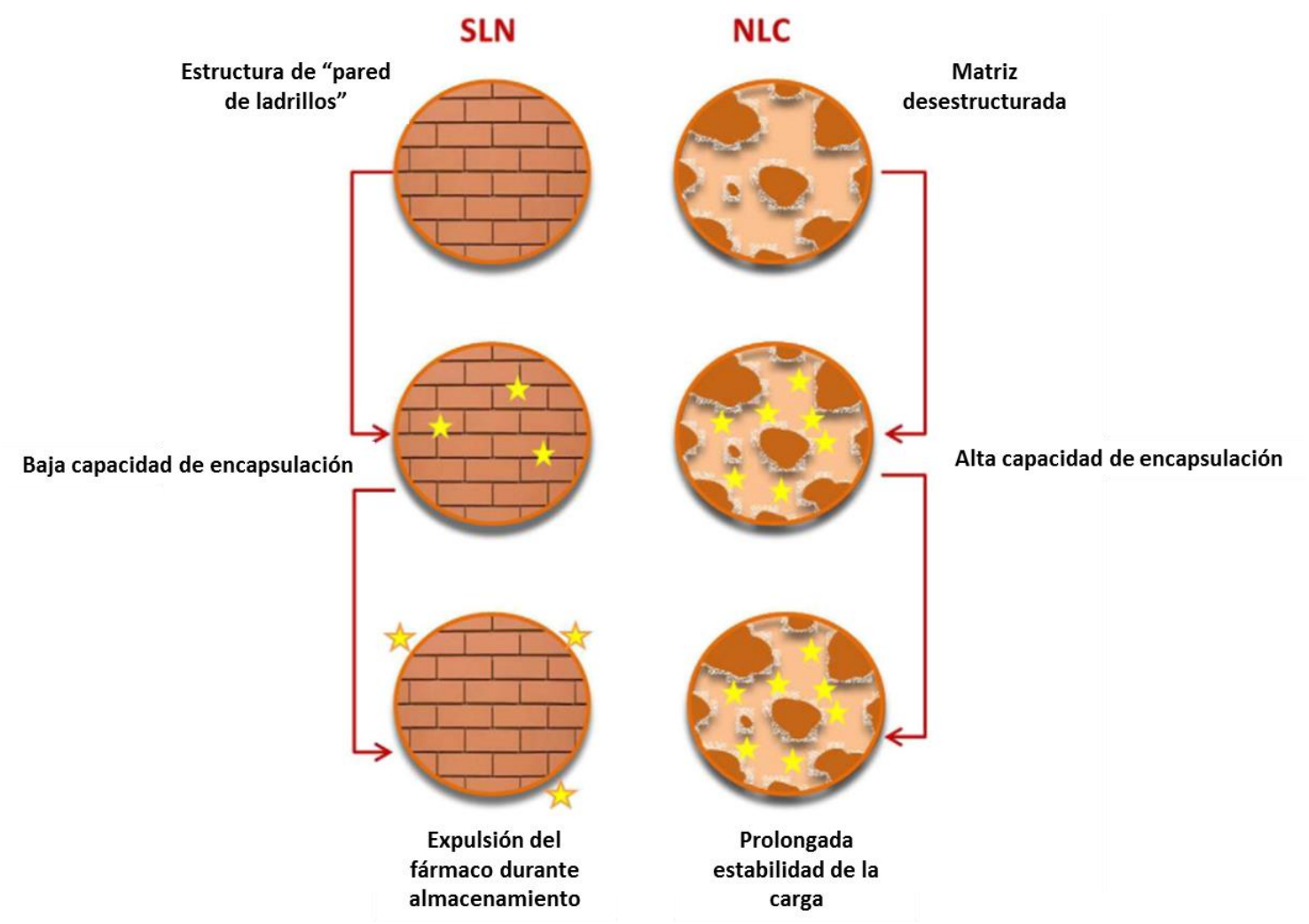

Luego del desarrollo de la matriz nanoestructurada y del estudio de sus propiedades, se procederá a evaluar las propiedades citotóxicas de las NLCs con y sin fármaco. Además, se estudiarán las cinéticas de internalización y se intentarán definir los mecanismos de ingreso a la célula. La integración de dicha información ayudará a comprender la efectividad sobre células cancerígenas por parte de las formulaciones desarrolladas en este capítulo. 


\subsection{Materiales y Métodos}

\subsubsection{Materiales}

El lípido miristil miristato (Crodamol ${ }^{\mathrm{TM}} \mathrm{MM}$ ) y el aceite (Crodamol ${ }^{\mathrm{TM}}$ GTCC-LQ) fueron donados por Croda (Argentina). La Doxorrubicina (Doxo, PM 543,0) fue donada por LKM pharmaceuticals (Argentina). Los demás reactivos fueron de grado analítico adquiridos a Merck (Darmstad, Alemania) o a marcas similares.

La Doxo fue cuantificada mediante espectrofluorimetría (Perkin Elmer LS 50B, Japón), utilizando $\lambda_{\text {exc }} 476 \mathrm{~nm}$ y $\lambda_{\text {em }} 588 \mathrm{~nm}$ con las correspondientes curvas de calibración.

\subsubsection{Síntesis de las nanoparticulas lipídicas nanoestructuradas (NLCs)}

NLCs conteniendo Doxo fueron sintetizadas por el método de ultrasonicación ${ }^{11}$. Dos formas de Doxo fueron utilizadas: Doxo protonada (Doxo-H) y Doxo neutralizada (Doxo-N). La doxorrubicina hidroclorada corresponde a la forma comercial, acida y fácilmente soluble en solventes acuosos. Para generar la Doxo protonada se disolvió el polvo de doxo hidroclorada en una solución acuosa a pH 3,0 ( $\mathrm{HCl} 1 \mathrm{mM})$. Luego, la solución de Doxo-H se la llevo a $\mathrm{pH} 8.5$ por medio del agregado de $\mathrm{NaOH} 0,1 \mathrm{~N}$. Seguido, ambas soluciones se congelaron a $-80^{\circ} \mathrm{C}$ y se liofilizaron. Para el proceso de síntesis de las NLCs, se colocaron $400 \mathrm{mg}$ de lípido $(2 \% \mathrm{p} / \mathrm{v})$ en un baño de agua a $60^{\circ} \mathrm{C}$ para fundirlo. Se agregaron $10 \mathrm{mg}$ de la forma de Doxo correspondiente en cada caso, previamente disueltos en $100 \mu \mathrm{l}$ de DMSO. También se adicionó el aceite $(0,065 \mathrm{v} / \mathrm{v})$. Luego de 10 minutos se adiciona una solución acuosa conteniendo 3\% (p/v) de Pluronic F68, previamente calentada a $60^{\circ} \mathrm{C}$. La mezcla se coloca inmediatamente a sonicar por 50 minutos (40\% de amplitud) utilizando un procesador ultrasónico (130 watts, ColePalmer, USA) equipado con una punta de titanio de $3 \mathrm{~mm}$. Luego, la dispersión se deja enfriar a temperatura ambiente y se almacena a $5^{\circ} \mathrm{C}$.

\subsubsection{Medidas de la eficiencia de carga}

El volumen final luego de la sonicación fue medido, debido a que ocurre evaporación durante el proceso. Luego se determinó la cantidad de Doxo libre. Se procede colocando $0,5 \mathrm{ml}$ de la formulación en tubos de ultrafiltración para centrifuga (MWCO 10,000, Microcon, Millipore, Ma.) y se centrifuga a 5.000 xg por 10 minutos. Se realizaron las diluciones correspondientes del filtrado y se determinó la fluorescencia. Utilizando una curva de calibración se calcula la cantidad de Doxo libre. La eficiencia de encapsulación se calcula con la siguiente ecuación: 


$$
\mathrm{EE}(\%)=\frac{(\mathrm{Q} 0(\mathrm{Cr} \times \mathrm{V}))}{\mathrm{Q} 0} \times 100
$$

En donde, $\mathrm{Q}_{0}$ es la cantidad inicial de Doxo, $\mathrm{Cr}$ es la concentración de Doxo en la solución filtrada y $\mathrm{V}$ es el volumen final luego de la sonicación.

Además, se analizó la cantidad total de Doxo en cada formulación. En primer lugar, se añadieron $450 \mu \mathrm{l}$ de metanol a $100 \mu \mathrm{l}$ de NLCs. A continuación, se incorporaron $450 \mu \mathrm{l}$ de cloroformo y se centrifugó a 10.000 xg durante 10 minutos. El sobrenadante se diluyó diez veces con una mezcla de metanol/cloroformo (50:50) y el Doxo total se estimó mediante espectroscopía de fluorescencia.

\subsubsection{Tamaño de partícula, potencial zeta e índice de polispersión}

El diámetro medio y la distribución del tamaño se midieron por espectroscopía de correlación de fotones (PCS) (Nano ZSizer, Malvern Instruments Corp, UK) a $25^{\circ} \mathrm{C}$ en cubetas de poliestireno con una longitud de camino de $10 \mathrm{~mm}$. El potencial zeta se determinó por anemometría Doppler láser también utilizando el Nano ZS Zetasizer. Las mediciones se realizaron en células capilares con longitudes de trayectoria de $10 \mathrm{~mm}$, utilizando agua desionizada obtenida de un sistema Milli-Q. Además, se determinó el valor PDI. Todas las mediciones fueron realizadas por triplicado.

\subsubsection{Ensayos de liberación del fármaco}

Los experimentos de liberación molecular se realizaron usando una membrana de diálisis (MWCO $10 \mathrm{kDa}$.). La membrana se hidrató en agua destilada durante 12 horas y se llenó con $5 \mathrm{ml}$ de cada formulación de NLCs, seguido de inmersión en $30 \mathrm{ml}$ de buffer acetato $10 \mathrm{mM}(\mathrm{pH}=5,0)$ y fosfato $10 \mathrm{mM}(\mathrm{pH}=7,4)$. A diferentes tiempos, se retiraron muestras de 10,0 ml y se midió la concentración de Doxo. Se realizaron los cálculos de la Doxo acumulada y se la refirió a la Doxo total encontrada en cada formulación.

\subsubsection{Caracterizaciones fisicoquímicas}

\subsubsection{Calorimetría diferencial de barrido (DSC)}

Las propiedades térmicas de las partículas de NLCs se determinaron por calorimetría de barrido diferencial (DSC, PerkinElmer Inc., Modelo Pyris 1, Waltham, MA, EE.UU.) en atmósfera de nitrógeno. Las exploraciones se realizaron a una velocidad de calentamiento de $10^{\circ} \mathrm{C} \cdot \mathrm{min}^{-1}$ en el rango de temperatura de $20-240^{\circ} \mathrm{C}$. 


\subsubsection{Análisis termogravimétrico (TGA)}

Las mediciones termogravimétricas dinámicas de las nanopartículas se realizaron utilizando un instrumento Shimadzu TGA-50. Los ensayos se realizaron de 0 a $600{ }^{\circ} \mathrm{C}$ a una velocidad de calentamiento de $10^{\circ} \mathrm{C} /$ min en atmósfera de $\mathrm{N} 2$.

\subsubsection{Análisis de dispersión de rayos X (DRX)}

Los patrones de DRX se recogieron en modo de reflexión sobre un sustrato de vidrio, y se analizaron mediante el software Origin y Sigma Plot. La medición se realizó con un instrumento analítico utilizando radiación $\mathrm{Cu}-\mathrm{K} \alpha(\lambda=1,54 \AA)$ desde $2 \theta=10$ a $60^{\circ}$ en modo continuo con paso de $0,07^{\circ}$. Los ángulos de dispersión se transformaron en espaciamientos cortos usando la ecuación de Bragg: $2 \mathrm{~d}(\sin \Theta)=\mathrm{n} \lambda$.

\subsubsection{Estudios de microscopia}

\subsubsection{Microscopía electrónica de barrido (SEM)}

Las muestras se secaron en primer lugar mediante la técnica del punto crítico. Después de esto, la superficie se pulverizó con oro usando un metalizado (Balzers SCD 030), obteniendo un espesor de capa de entre 15 y $20 \mathrm{~nm}$. Las superficies y morfologías de la película se observaron mediante SEM (modelo Philips SEM 505, Rochester, NY, EE.UU.), y las imágenes se procesaron mediante un programa de digitalización de imágenes (Soft Imaging System ADDA II).

\subsubsection{Microscopía Electrónica de Transmisión (TEM)}

La dispersión de nanopartículas se diluyó diez veces con agua ultrapura y se diseminó una gota de la dispersión sobre una rejilla de Cu revestida con colodión (malla 400). El exceso de líquido se drenó con papel de filtro y para realzar el contraste se agregó una gota de ácido fosfotúngstico a la dispersión de NLCs. Finalmente, el análisis TEM se realizó utilizando el microscopio Jeol-1200 EX II-TEM (Jeol Ma, US).

\subsubsection{Ensayos in vitro}

\subsubsection{Cultivo de células}

La línea celular de cáncer de mama MDA-MB-231 se obtuvo de la American Type Culture Collection (ATCC, LGC Standards, Barcelona, España) y se cultivó en medio Eagle modificado por Dulbecco (DMEM / F12, Invitrogen, Paisley, UK) 1,0\% de Lglutamina, $1,0 \%$ de aminoácidos no esenciales y 1,0\% de piruvato sódico (Life Technologies, Madrid, España), 10,0\% de suero fetal bovino (FBS, Lonza, Barcelona, 
España). Las células se mantuvieron en una atmósfera con 5\% de $\mathrm{CO} 2$ y 95\% de aire atmosférico humidificado a $37^{\circ} \mathrm{C}$.

\subsubsection{Pruebas de citotoxicidad}

Para la evaluación de la citotoxicidad, se sembraron células MDA-MB-231 en medio DMEM/F12 suplementado durante 24 horas en placas estándar de 96 pocillos (Cellstar, Greiner Bio-One, Courtaboeuf, Francia) a $6 \times 10^{3}$ células por pocillo. A continuación, se desechó el medio de cultivo y se trataron las células (incubación bolus) durante 1, 3 y 16 horas $(\mathrm{ON})$ con medio que contenía diferentes concentraciones de Doxo equivalentes $(0,0061-100 \mu \mathrm{M})$ de los siguientes compuestos: Doxo libre, NLCs-N y NLCs-H. Después de estos tiempos de incubación las células se lavaron con buffer PBS y se añadió medio fresco. Las células se cultivaron durante un tiempo total de 72 horas (incluido el tiempo de exposición del fármaco). En un ensayo paralelo y similar, las células se expusieron a una incubación continua con los compuestos durante 72 horas. La viabilidad celular se determinó usando un ensayo de colorante de tetrazolio (MTT) ${ }^{12}$. Las células se incubaron durante 4 horas conteniendo 0,5 g/l de MTT. A continuación, el medio se reemplazó con DMSO (dimetilsulfóxido) para disolver los cristales de formazan formados por las células viables. La absorbancia se midió a $540 \mathrm{~nm}$ usando un lector de placas de pocillos múltiples (ELX800, BioTek, Fisher Bioblock, Illkirch, Francia). Se determinó la concentración inhibitoria del 50\% (IC50) como la concentración de fármaco que dio como resultado una reducción del 50\% en la viabilidad celular. Los resultados se expresaron como una media de tres experimentos independientes.

\subsubsection{Ensayo de internalización}

Las células se sembraron durante 24 horas en placas estándar de 24 pocillos a $8 \times 10^{4}$ células por pocillo con el fin de probar la cinética de internalización de Doxo libre, NLCs-N y NLCs-H. Se utilizó una concentración de Doxo equivalente de 0,625 $\mu \mathrm{M}$. Las células se expusieron a los compuestos por tiempos de $30 \mathrm{~min}, 1$, 2, 3 y 6 horas; luego se realizaron dos lavados con buffer PBS. A continuación, se trataron con tripsina y se añadió $1 \mathrm{ml}$ de medio a cada pocillo. Después de eso, las muestras se recogieron en tubos de citometría y se centrifugaron durante 5 minutos a $1200 \mathrm{rpm}$. El sobrenadante se descartó y las células se resuspendieron en $350 \mu \mathrm{l}$ de buffer PBS. La intensidad de fluorescencia se monitorizó usando un FACS Calibur (Becton-Dickinson, Ma, EE.UU.). 


\subsubsection{Microscopia confocal}

Las células MDA-MB-231 se sembraron en una placa de 24 pocillos a una densidad de 50.000 células por pocillo en $0,5 \mathrm{ml}$ de DMEM/F12 con FBS al 10\%. Las células se incubaron a $37^{\circ} \mathrm{C}$ durante 24 horas. Las células fueron expuestas a Doxo libre y NLCs$\mathrm{N}$ a una concentración de $10 \mu \mathrm{M}$. Después de 2 horas de incubación, se descartó el medio y se lavaron las células con buffer PBS. A continuación, se añadió una solución de Lysotracker Green $(20 \mu \mathrm{M})$ en medio fresco a cada pocillo y se incubó durante 30 minutos a $37^{\circ} \mathrm{C}$. Después de dos lavados con PBS, se añadió Hoechst 33342 en solución con medio $(200 \mathrm{Ngr} / \mathrm{ml})$ y se incubó durante 15 minutos a temperatura ambiente. Finalmente, se realizaron dos lavados más con PBS y las células se mantuvieron en DMEM sin Rojo Fenol y se visualizaron mediante microscopio confocal (Leica, Alemania).

\subsubsection{Fluorescence confocal spectral imaging (FCSI)}

Se cultivaron células MDA-MB-231 adherentes a los vidrios de cubierta revestidos con poli-D-lisina en placas de 24 pocillos y se incubaron con NLCs-N a una concentración de $1 \mu \mathrm{M}$ durante 1 y 22 horas. Después de lavarlas tres veces con PBS, los vidrios se colocaron entre un portaobjetos de microscopio y un protector para ser escaneados mediante FCSI usando un microspectrómetro confocal de exploración láser LabRAM (Horiba SA, Villeneuve d'Ascq, Francia) / Mm de difracción y un detector CCD refrigerado por aire por efecto Peltier. La fluorescencia de la Doxo se excitó usando una línea de $491 \mathrm{~nm}$ de un láser sólido (Melles Griot), bajo un objetivo de microscopio focal largo $\times 50$. La potencia de la luz láser en la muestra fue de aprox. 0,2 $\mathrm{mW}$ y el tiempo de adquisición fue $0,05 \mathrm{seg}$ por espectro. La sección óptica ecuatorial de cada célula seleccionada se escaneó con un paso de $0,8 \mu \mathrm{m}$. Tanto la adquisición como el tratamiento de mapas espectrales se realizaron utilizando el software LabSpec. Los mapas espectrales se generaron como se describe en bibliografía ${ }^{13}$. En resumen, cada espectro de fluorescencia se ha ajustado con una suma proporcional de espectros de modelo característicos de ubicaciones subcelulares y / o interacciones. Los coeficientes de ajuste se utilizaron para generar los correspondientes mapas espectrales mostrados con pseudocolores. 


\subsection{Resultados y discusión}

\subsubsection{Síntesis y caracterización de vehículos lipídicos nanoestructurados (NLCs)}

Se prepararon sistemas de transporte de fármacos coloidales con el fin de encapsular Doxo. En este trabajo, las NLCs fueron sintetizadas por el método de ultrasonicación en presencia del fármaco quimioterapéutico. Las moléculas de Doxo existen en diferentes estados en equilibrio permanente relacionado con sus pKas y el predominio de cada una depende del $\mathrm{pH}$ del medio ${ }^{14}$. Mediante la aplicación de esta propiedad se pueden obtener dos formas de la droga: una Doxo hidrófobica y una más hidrófilica. Los $\mathrm{pK}_{\mathrm{a}} \mathrm{s}$ específicos para la desprotonación de Doxo son 7,34 para el grupo fenol y 8,46 para el grupo amino primario ${ }^{15}$. Por lo que se procedió a la obtención de la forma protonada (Dox-H) y neutra (Dox-N) de la Doxo. (Esquema 3). Posteriormente, ambas formas se encapsularon por separado en NLCs con el objetivo de obtener sistemas de administración de fármacos con diferentes características. Un sistema se cargó con Doxo hidrofílica (NLCs-H) y otro sistema con Doxo hidrofóbica (NLCs-N)

Esquema 3. Equilibrio iónico entre Doxo protonada (Dox-H) y Doxo neutra (Dox-N), $\mathrm{pKa}_{1}=7,34$ y $\mathrm{pKa}_{2}=8,46$ 

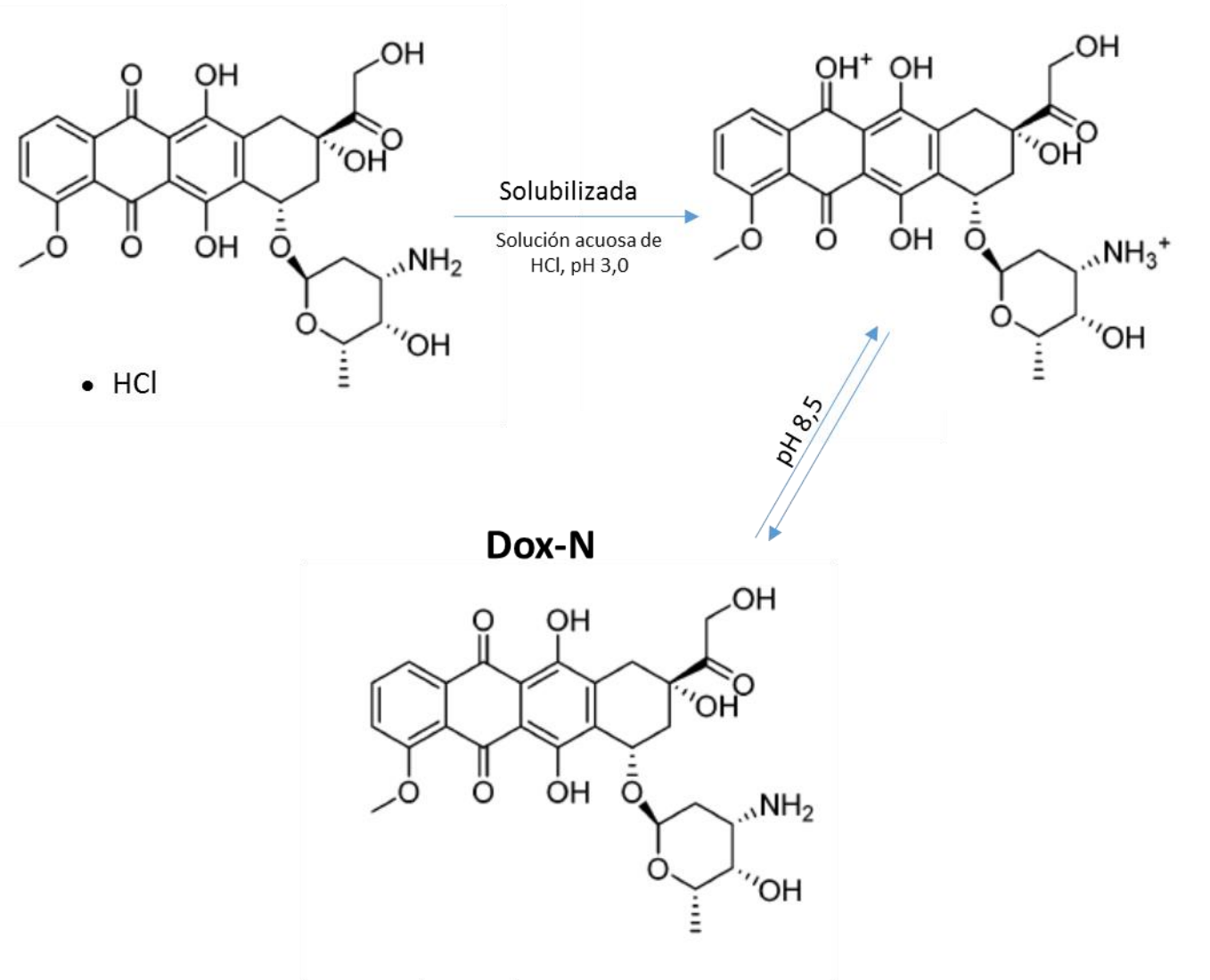

En primer lugar, las morfologías y las distribuciones de tamaño fueron analizados por TEM (Figuras 1A y 1B). Las imágenes mostraron una distribución estrecha del tamaño de las nanopartículas con un diámetro aproximado de $150 \mathrm{~nm}$, tanto para NLCs-N como para NLCs-H. A continuación, la dispersión dinámica de la luz y el análisis de potencial zeta confirmaron que ambos tipos de NLCs poseen valores similares de alrededor de $150 \mathrm{~nm}$ para el diametro y $+2,5 \mathrm{mV}$ de carga superficial (Tabla I). El tamaño y la carga ligeramente positiva de las nanopartículas sugirieron buenas propiedades para la internalización celular ${ }^{16}$. Además, los valores PDI indicaron que las distribuciones de tamaño para ambos nanotransportadores correspondían prácticamente a formulaciones mono-dispersas (Figuras 1C y 1D).

Figura 1. Imágenes de TEM obtenidas a 60.000x para (A) NLCs-N y (B) NLCs-H y los gráficos de distribución de tamaño obtenidos por análisis con DLS para (C) NLCs-N y (D) NLCs-H. 


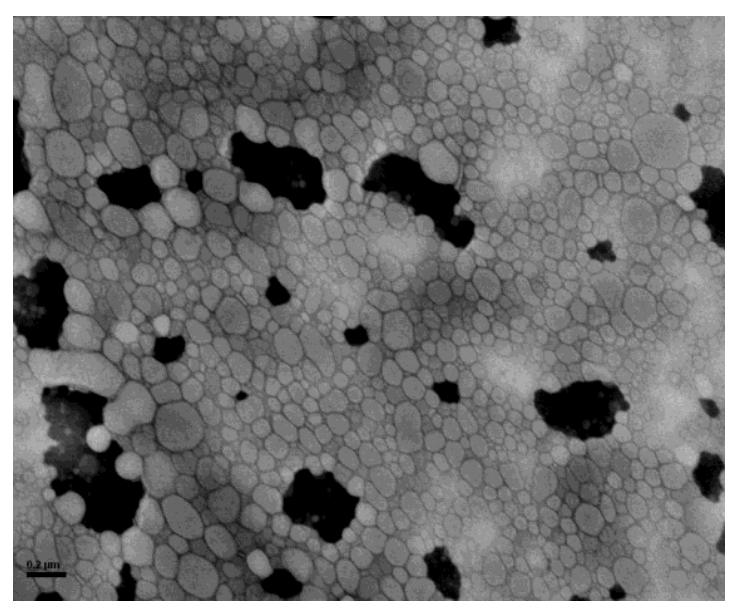

C

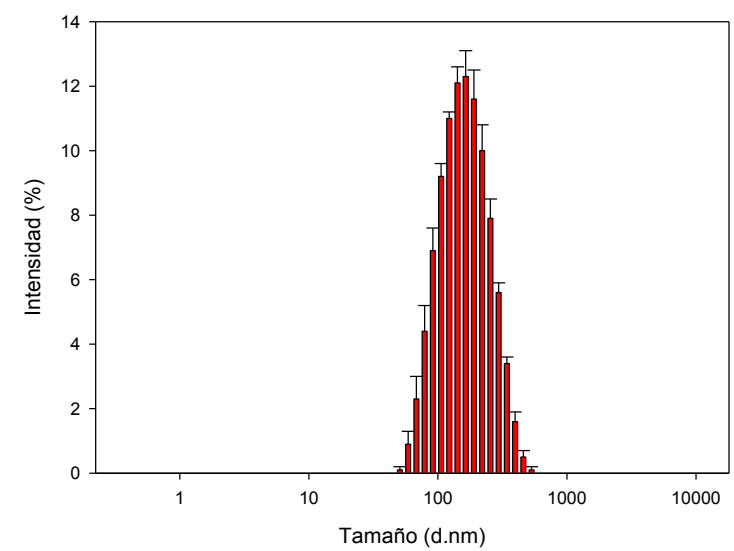

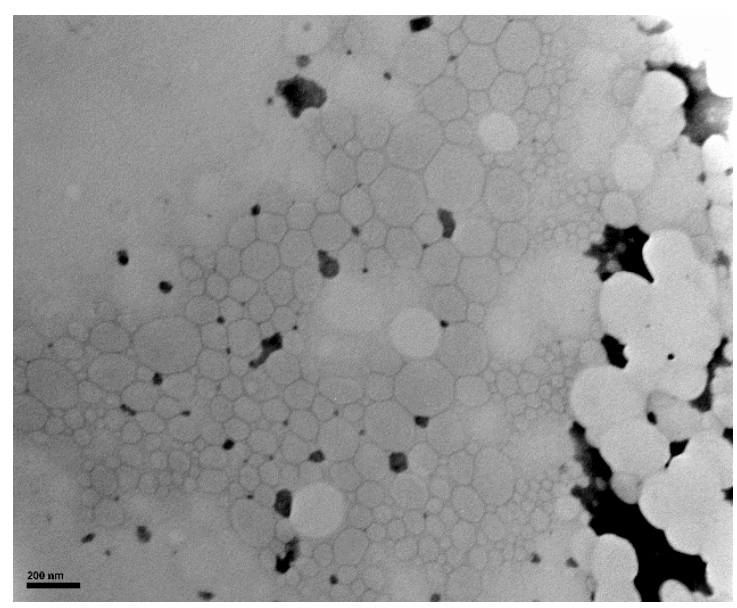

D

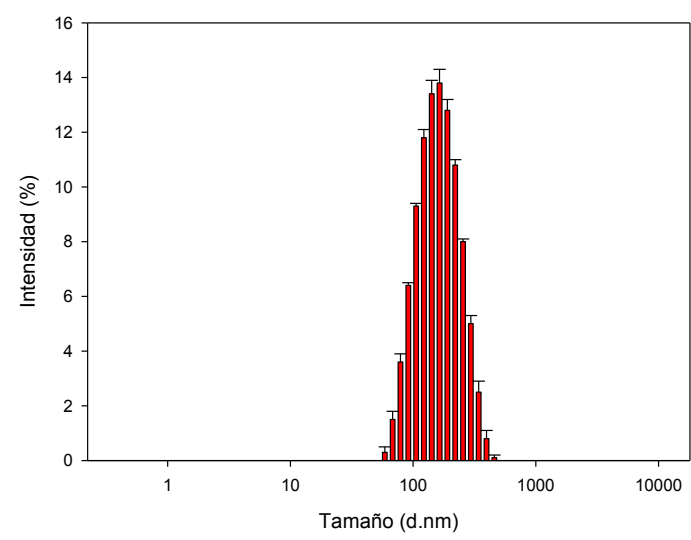

Adicionalmente, la Tabla I exhibe los valores de eficiencia de encapsulación (EE) para ambos nanotransportadores. La síntesis de NLCs con Dox-N generó una formulación con alta EE (96,60\%). Por otra parte, la síntesis de NLCs-H tenía una EE inferior con un valor de $48 \%$, lo que significa que un $52 \%$ de la Dox-H no fue encapsulada y permanecía libre en la formulación.

Tabla I. Eficiencia de encapsulación de NLCs (EE) y caracterización por potencial Zeta, diámetro hidrodinámico medio y análisis PDI. Los resultados corresponden a la media entre tres experimentos independientes, cada uno realizado por triplicado.

\begin{tabular}{ccccc}
\hline Formulación & EE (\%) & $\zeta$ pot $(\mathbf{m v})$ & Tamaño (d., nm) & PDI \\
\hline NLCs-N & $96,60 \pm 0,10$ & $+2,33 \pm 0,06$ & $154,3 \pm 9,5$ & $0,218 \pm 0,043$ \\
\hline NLCs-H & $48,06 \pm 2,68$ & $+2,64 \pm 0,91$ & $143,4 \pm 1,5$ & $0,170 \pm 0,015$
\end{tabular}


Se realizaron mediante análisis termogravimétrico (Figura 2A) mostró la derivada de las curvas TGA (DTGA). Fue observada una fuerte inflexión a $187^{\circ} \mathrm{C}$, que corresponde a la temperatura de fusión de la Doxo, confirmada a su vez por análisis DSC (Figura 2C). Se pudo observar la presencia de dos picos principales para las NLCs. Cada pico podría corresponder probablemente a la descomposición del lípido miristil miristato $\left(\right.$ Crodamol $^{\mathrm{TM}} \mathrm{MM}$ ) y del aceite (Crodamol ${ }^{\mathrm{TM}}$ GTCC-LQ). DTGA mostró dos cambios en los máximos, especialmente en el rango $200-300^{\circ} \mathrm{C}$ que corresponde a la descomposición miristil miristato ${ }^{17}$. Este hecho sugirió que el segundo escalón a $398,7^{\circ} \mathrm{C}$, observado en curvas TGA (Figura 2B), correspondía a la temperatura de descomposición del aceite. Tanto NLCs-N como NLCs-H mostraron un cambio desde $398,7^{\circ} \mathrm{C}$ a $385^{\circ} \mathrm{C}$ en comparación con NLCs vacíos. Además, no se observó ningún pico correspondiente a la fusión de cristales de Doxo ni para NLCs-N ni NLCs-H. Por otro lado, el pico a $245^{\circ} \mathrm{C}$ en la curva de DTGA para las NLCs-N parecía ser una superposición de dos picos. En este sentido, puede ser posible que el pico de Doxo y el pico de lípido se superpusieran. En este punto se hizo relevante notar que estos análisis dieron evidencia sobre la existencia de interacciones fuertes entre el lípido y la Doxo, especialmente para NLCs-N.

Figura 2. Curvas correspondientes a los análisis de DTGA (A) y TGA (B) para Doxo libre, NLCs, NLCs-H y NLCs-N. Además, se realizaron análisis de DSC para Doxo libre y NLCs (C). 

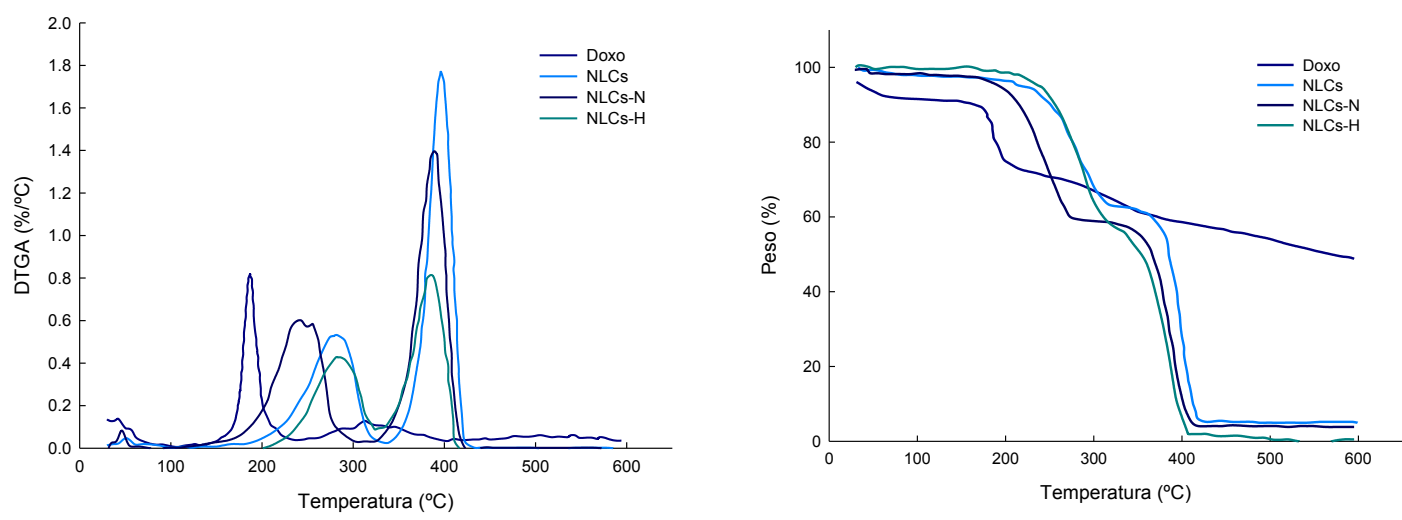

C

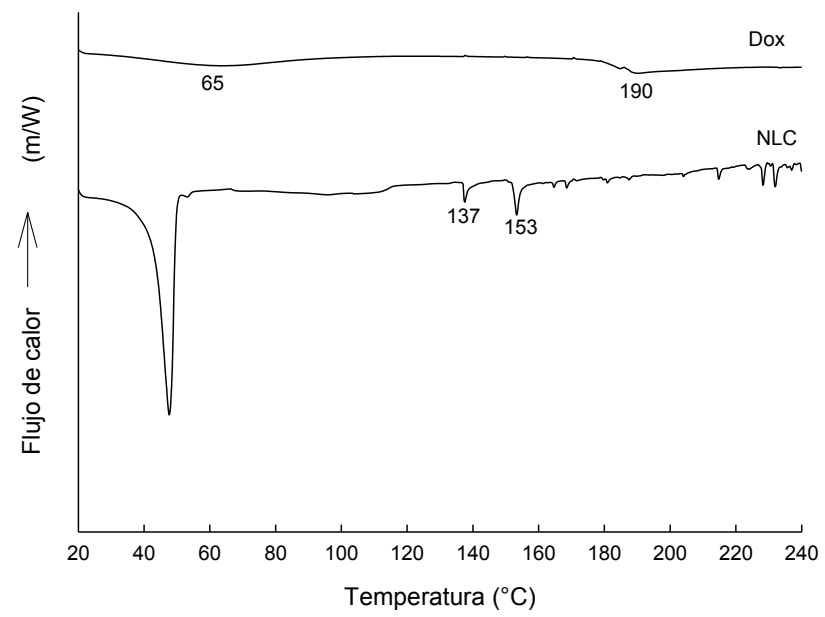

A su vez, los análisis de dispersión de rayos X (DRX) confirman la estructura cristalina sólida de NLCs y permiten identificar el polimorfismo de la matriz lipídica. Las sustancias farmacológicas poseen la propensión a exhibir diferentes disposiciones moleculares en el enrejado del nanocarrier. El análisis de la estructura cristalina del fármaco y de las NLCs puede ayudar en la optimización de la formulación. Además, se ha informado que la cristalinidad de los lípidos posee fuertes efectos sobre la eficacia de la encapsulación del fármaco y su liberación ${ }^{18,19}$. Las estructuras lipídicas pueden cristalizarse en tres formas polimórficas principales, en las cuales la forma $\alpha$ es inestable, $\beta$ es la más estable y la $\beta^{\prime}$ es una forma metaestable pero que aún posee regiones de cristalinas por lo que mantiene un estado amorfo parcial ${ }^{20}$. Con el objeto de evaluar estas características de NLCs, NLCs-N, NLCs-H y Doxo fueron analizados por DRX (Figura 3). Los vehículos nanoestructurados mostraron una mezcla de polimorfismos. Las formas polimórficas se caracterizan por las distancias interplanares (d) obtenidas a partir de patrones de DRX. Los patrones para las NLCs mostraron un 
espaciamiento corto característico a $0,47 / 0,38 / 0,37 \mathrm{~nm}$ (típico de la forma $\beta$ ) y 0,42/0,38 $\mathrm{nm}\left(\beta^{\prime}\right)^{20}$. El difractograma de Doxo expuso la presencia de tres picos $\left(2 \Theta=28,47^{\circ}\right.$, $31,81^{\circ}$ y $45,58^{\circ}$ ) lo que sugiere la existencia de cristales de Doxo en su forma pura ${ }^{21}$. Por otro lado, el difractograma de NLCs mostró los picos correspondientes al miristil de miristato $\left(2 \theta=19,11^{\circ}, 21,59^{\circ}, 23,23^{\circ}\right.$ y $\left.23,80^{\circ}\right)$, como se ha informado recientemente ${ }^{17}$. Cuando se cargaron las NLCs con Doxo, los patrones de DRX presentaron picos con ángulos $2 \Theta$ dispersos y similares de $18,66^{\circ} ; 20,94^{\circ} ; 22,75^{\circ}$ y $23,50^{\circ}$ para NLCs-N y $19,18^{\circ} ; 21,51^{\circ}, 23,32^{\circ}$ y $23,80^{\circ}$ para NLCs-H. La fusión de los dos últimos picos, en ambos casos, sugirió el predominio de la arquitectura $\beta^{\prime}$. Las NLCs-N mostraron una disminución en la intensidad del pico de $23,50^{\circ}$ y un aumento en el máximo a $22,75^{\circ}$. Este resultado indicó una transición parcial de la estructura de las NLCs de una forma más estable $(\beta)$ al polimorfismo metaestable $\left(\beta^{\prime}\right)$. Cuanto más estable es la estructura cristalina, más organizadas están las moléculas que se acumulan dentro de la red. Esto podría hacer que la partícula expulsara los compuestos atrapados dentro de ella ${ }^{22,23}$. Para una cinética de liberación sostenida del fármaco, se prefiere siempre un predominio del polimorfismo metaestable ${ }^{17,20}$.

Figura 3. Patrones de difracción de rayos $\mathrm{X}(\mathrm{DRX})$ correspondientes a la Doxo libre, NLCs, NLCs-H y NLCs-N. 


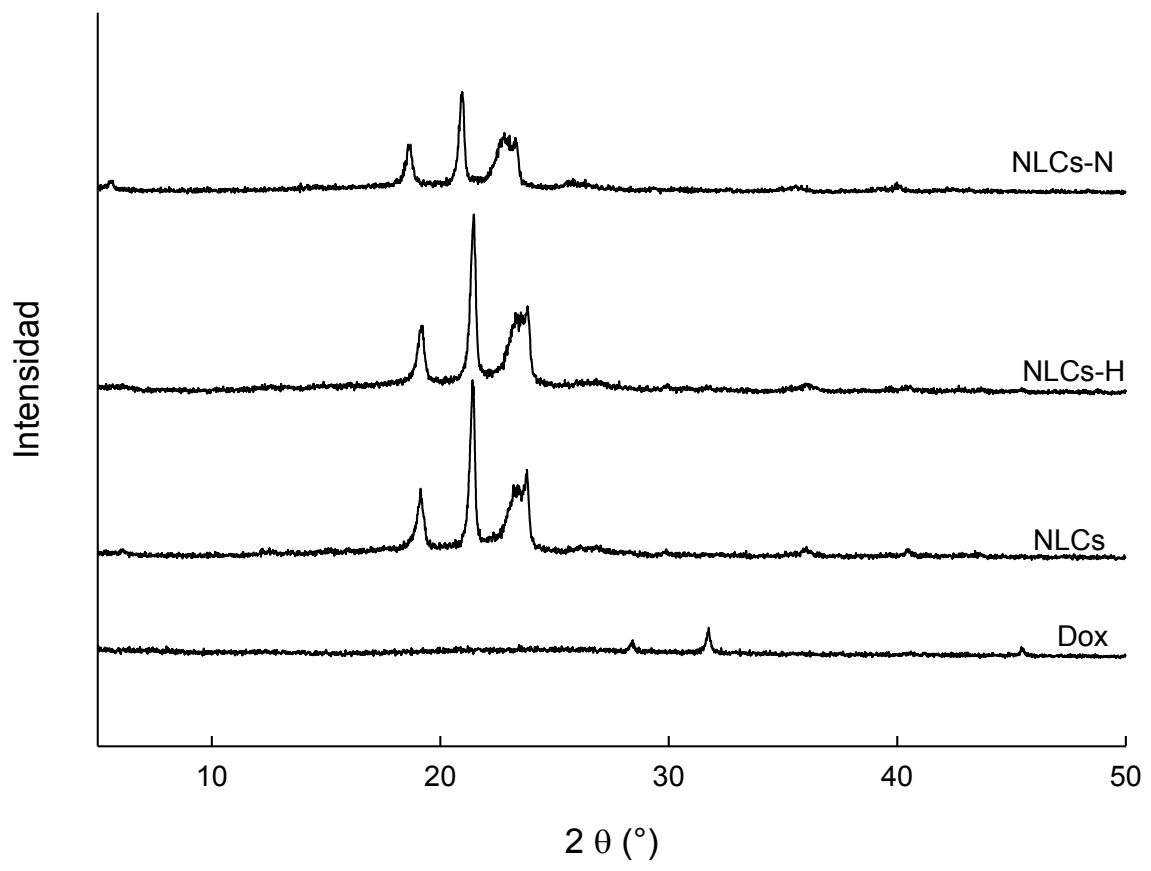

\subsubsection{Estudios de liberación de Doxo}

Experimentos de liberación del fármaco permitieron evaluar la capacidad de las NLCs para liberar Doxo de manera sostenida. La Figura 4 muestra las curvas hiperbólicas obtenidas para la Doxo liberada desde las NLCs. Se evaluaron dos condiciones de $\mathrm{pH}$ : 7,4 que simula un ambiente fisiológico y 5,0 que simula las condiciones ácidas a las que las NLCs podrían estar expuestas si la internalización celular ocurre por la vía endocítica, como sucede con muchos sistemas nanoparticulados ${ }^{24}$. Todas las cinéticas mostraron una liberación inicial del fármaco abrupta (burst), seguido de una disminución en la velocidad de liberación. Se encontraron diferencias significativas entre la cantidad de Doxo liberada por las NLCs-H y NLCs-N $(P \leq 0,05)$. Uno de los factores que contribuyeron al burst inicial de las NLCs-H fue la presencia de Doxo no encapsulada o libre. Además, las NLCs-H expusieron una alta velocidad de liberación alcanzando el 100\% a pH 5 y 66\% a pH 7,4 después de 5 días. Por el contrario, las NLCs-N mostraron mayor capacidad para retener la Doxo y, en consecuencia, se pudo observar una liberación más lenta. Después de 5 días, las NLCs-N todavía contenían entre el $80 \%$ y el $90 \%$ de la carga útil total de Doxo. Estas diferencias podrían explicarse por la naturaleza hidrófila e hidrófoba de las moléculas cargadas y neutras de Doxo. Estos resultados estuvieron en concordancia con el análisis obtenido en los 
patrones de DRX. Las NLCs-H mostraron una estructura más estable por lo que fueron más propensos a la expulsión del fármaco.

De esta manera, se puede concluir que fueron desarrollados dos nanocarriers con diferentes capacidades de liberación del fármaco. Las NLCs-N pudieron liberar Doxo a tasas muy bajas permitiendo observar una liberación de fármaco muy prolongada en el tiempo. Por otra parte, las NLCs-H funcionaron como un portador con altas velocidades de liberación. La integración de ambos sistemas de NLCs puede permitir obtener una formulación con propiedades mixtas. Por lo tanto, la formulación podría ser capaz de alcanzar niveles altos del fármaco en los tiempos iniciales del tratamiento gracias a la liberación rápida de los NLCs-H. En paralelo, las NLCs-N mantendrían los niveles terapéuticos de Doxo a dosis bajas durante un tiempo prolongado. En este sentido, la modificación de la relación NLCs-N/NLCs-H en la formulación podría permitir la generación de diferentes perfiles cinéticos. Además, las velocidades de liberación podrían ser moduladas dependiendo de la necesidad de cada tratamiento específico.

Figura 4. Doxo liberada desde las NLCs a pH 7,4 (buffer PBS, $10 \mathrm{mM}$ ) y 5,0 (buffer acetato, 10 mM) ( $\circ$ NLCs-N, pH 5,0; • NLCs-N, pH 7,4; $\Delta$ NLCs-H, pH 5,0; NLCs-H, pH 5,0). Los resultados corresponden a una media entre dos experimentos individuales, cada uno realizado por duplicado.

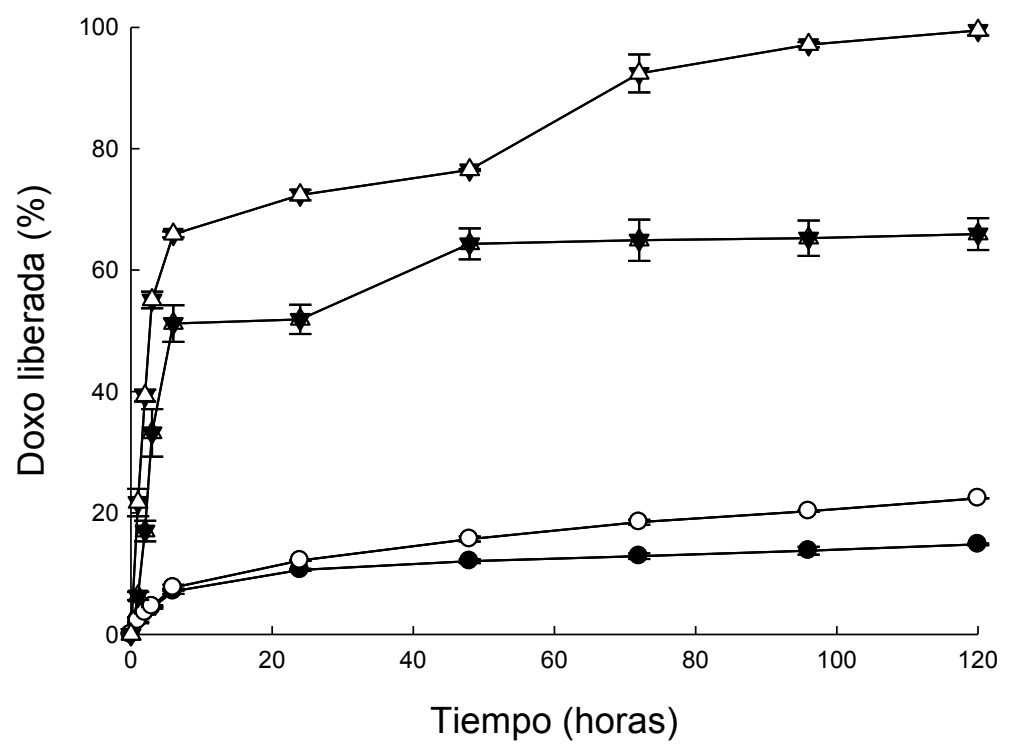




\subsubsection{Estudios in vitro para las NLCs}

\subsubsection{Estudios de viabilidad celular e internalización}

Se ensayó la capacidad para disminuir la viabilidad celular de las NLCs cargadas con ambas especies de Doxo. Para los experimentos se utilizó una línea celular de cáncer de mama metastásico (MDA-MB-231). Las células MDA-MB-231 corresponden a una línea celular agresiva, invasiva y poco diferenciada de cáncer de mama humano con un fenotipo mesenquimal. Además, MDA-MB-231 es una línea de células relativamente resistente a Doxo ${ }^{25}$. La concentración inhibitoria media (IC50) de Doxo se determinó mediante ensayos de MTT después de la incubación de las células con Doxo libre, NLCs-H y NLCs-N a concentraciones equivalentes del fármaco. Es importante considerar que las NLCs sin fármaco no mostraron disminución en la viabilidad celular en comparación con los controles sin tratamiento. Los períodos de exposición se dividieron en dos grupos principales. En primer lugar, la incubación bolus corresponde a aquella en donde las células eran incubadas durante un tiempo específico con los compuestos. A continuación, después de un lavado con PBS, se dejaba que las células proliferaran un periodo de tiempo total de 72 horas en medio fresco. La segunda condición correspondía a una incubación continua donde la exposición de las células al fármaco fue durante el tiempo total de 72 horas. Los valores de IC50 fueron diferentes para aquellos tiempos de exposición cortos (1 y 3 horas). Después de una hora de incubación con los compuestos, la IC50 para las NLCs-N fue el valor más alto $(94,90$ $\mu \mathrm{M})$ seguido del correspondiente a las NLCs-H $(59,83 \mu \mathrm{M})$ y Doxo $(40,12 \mu \mathrm{M})$ (Figura 5). En el caso de 3 horas, los valores de IC50 disminuyeron a $66,65 \mu \mathrm{M}$ y $22,28 \mu \mathrm{M}$ para las NLCs-N y NLCs-H, respectivamente. Adicionalmente, se observó una disminución en el valor de IC50 de Doxo libre que disminuyó de 40,12 $\mu \mathrm{M}$ a 5,81 $\mu \mathrm{M}$. 
Figura 5. Concentración inhibitoria media (IC50) para Doxo libre, NLCs-H y NLCs-N luego de la incubación en bolus (1 hora, 3 horas y $\mathrm{ON}$ ) y de la incubación continúa (72 horas). Los resultados corresponden a una media de tres experimentos independientes.

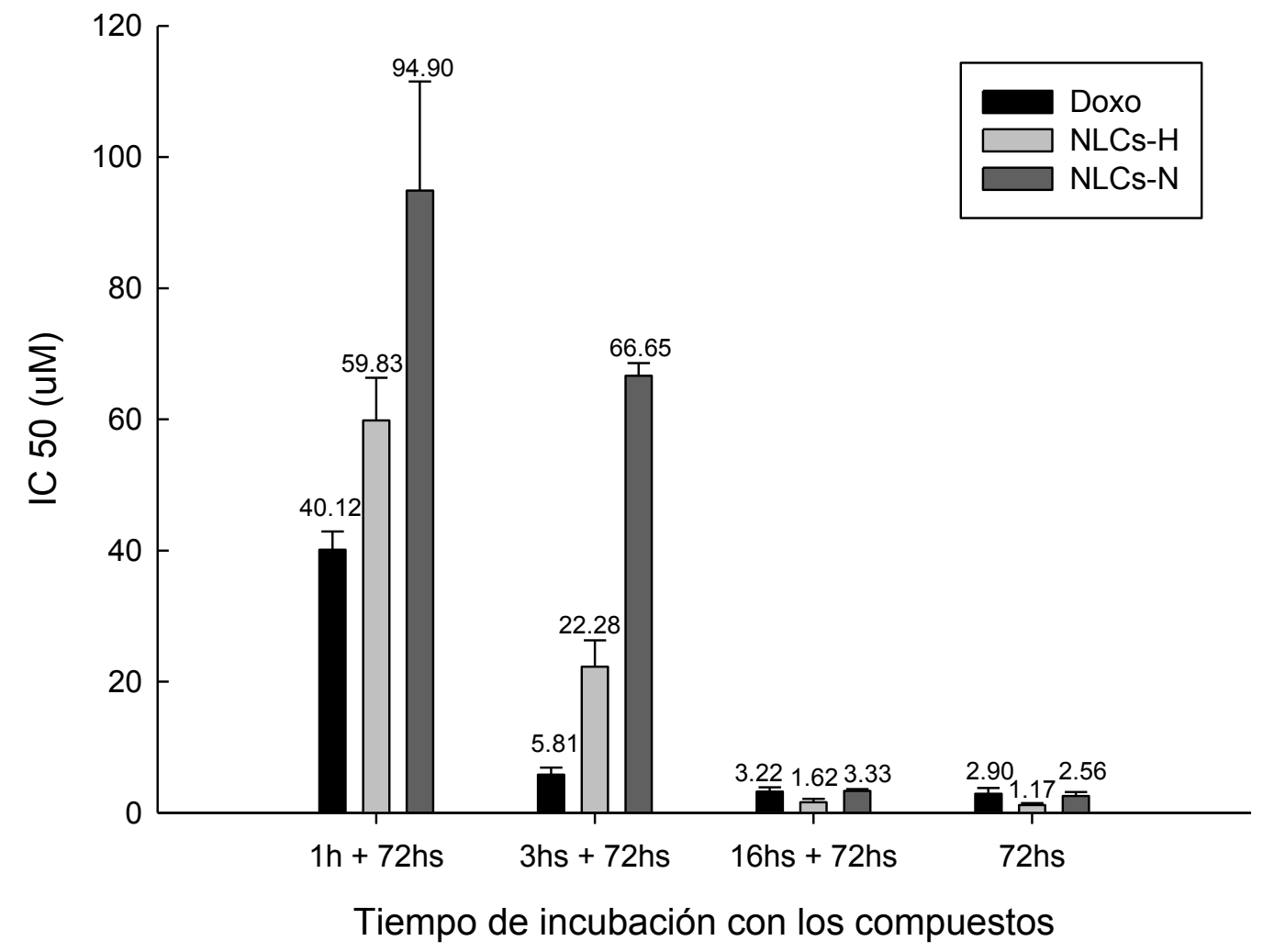

Los resultados pueden explicarse debido a las diferencias entre el perfil de liberación del fármaco para cada sistema y a los mecanismos de internalización celular. Se sabe que Doxo, al ser una molécula pequeña, internaliza simplemente por transporte pasivo (difusión). En contraste, las estructuras de mayor tamaño como las nanopartículas se internalizan normalmente por transporte activo como la endocitosis u otros ${ }^{16,24,26}$. El transporte activo es más costoso en términos de consumos de energía a nivel celular que la difusión. Esa es una de las razones de por qué este tipo de transporte es más lento que el pasivo ${ }^{27}$. Debido a la lenta internalización de las NLCs, podrían haber ocurrido que llegasen menos nanopartículas al interior de la célula después de los tiempos de incubación mencionados. Por lo tanto, menor cantidad de Doxo ingresó en el núcleo razón sugerente sobre el incremento en los valores de IC50. Las diferencias observadas entre NLCs-H y NLCs-N podrían explicarse considerando que NLCs-H tienen una tasa 
de liberación mucho mayor y que además poseen un elevado porcentaje de Doxo libre en solución, sin encapsular.

A tiempos de exposición mayores tanto las NLCs como Doxo libre mostraron una citotoxicidad similar. Los valores estaban en el mismo orden de magnitud y no se encontraron diferencias significativas en ningún caso $(\mathrm{p} \leq 0,05)$. Se pudo observar que la incubación por 16 horas tiene el mismo efecto sobre la disminución de la viabilidad celular que la incubación continua. Los resultados sugirieron que, después de estos períodos largos, la internalización rápida de Doxo se equiparó de alguna manera con la internalización de las NLCs. Además, estos tiempos parecen ser suficientes para que suficiente cantidad de Doxo sea liberada de las NLCs, penetre en el núcleo y lleve adelante su efecto citotóxico principal.

En función de corroborar la hipótesis planteada, la cinética de internalización celular de los compuestos ensayados se evaluó mediante citometría de flujo. Las células se incubaron durante períodos de tiempo específicos con Doxo libre y los dos tipos de NLCs. Luego de la incubación, se midió en cada caso la fluorescencia correspondiente a la Doxo que había ingresado en las células. Los tiempos de incubación ensayados fueron $6,3,2,1$ y 0,5 horas. Tiempos de incubación mayores a 6 horas mostraron no ser tan relevantes debido a que la totalidad de las células tenían una señal Doxo positiva e intensae. El histograma mostró los picos correspondientes para cada caso después de 6 horas de incubación. Se puede observar que los picos de la Doxo y NLCs-H se superponen (Figura 6A). Además, el comportamiento de las NLCs-H fue similar al de la Doxo libre. Esto podría atribuirse a la presencia de Doxo no encapsulada en la formulación. Por otro lado, las NLC-N mostraron un comportamiento completamente diferente, es decir, la cinética fue más lenta a pesar de que la morfología de las curvas fue muy similar (Figura 6B). 
Figura 6. Análisis de citometría de flujo de la Doxo internalizada. (A) picos correspondientes a Doxo libre (rojo), NLCs-H (violeta) y NLCs-N (azul) después de $6 \mathrm{~h}$ de incubación a $37^{\circ} \mathrm{C}$. (B) Perfiles de internalización, expresados como una media de tres experimentos independientes cada uno realizado por duplicado.

A

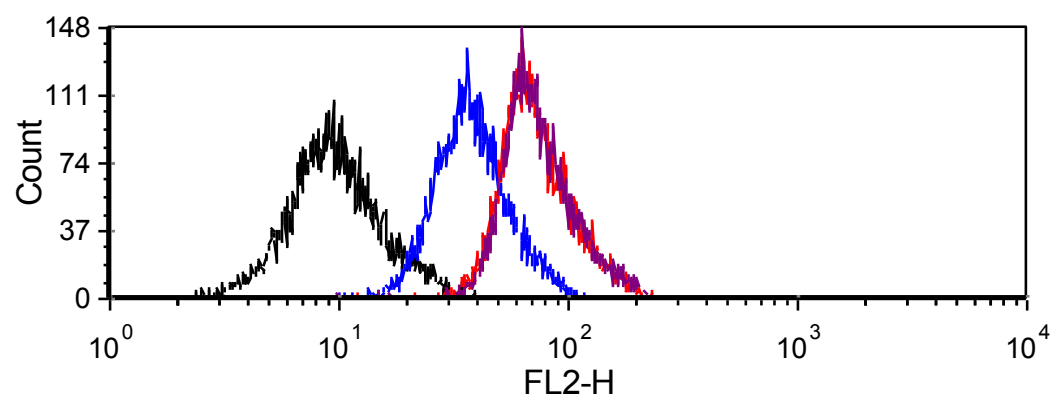

B

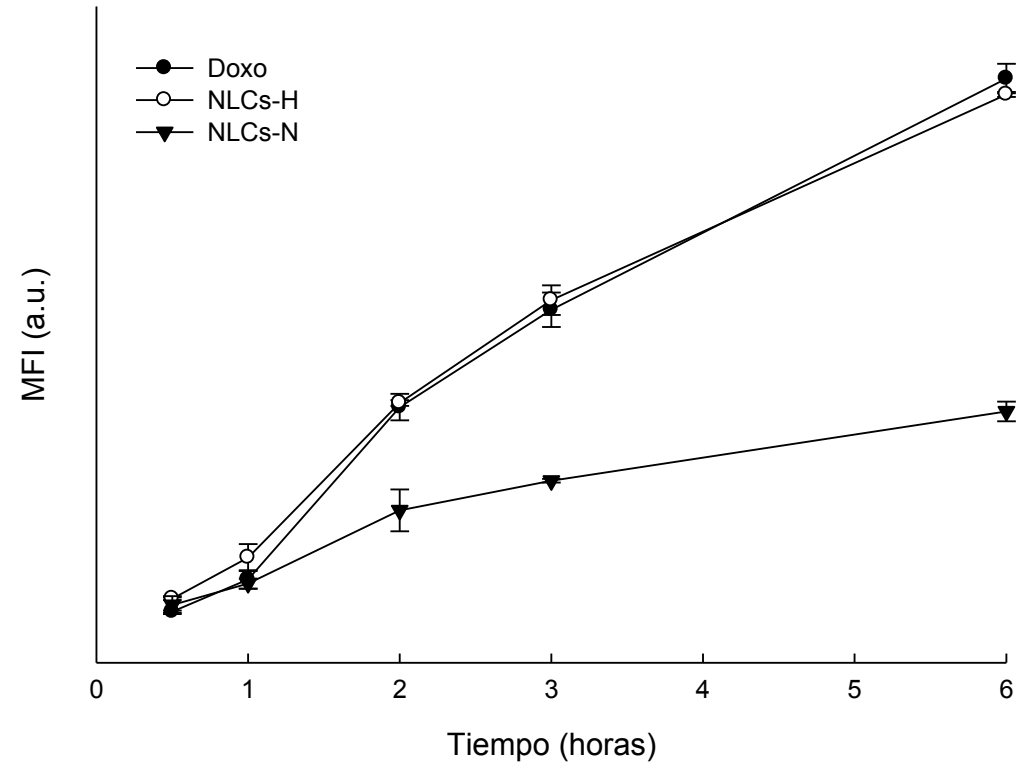




\subsubsection{Microscopía confocal}

Se realizaron estudios de microscopía confocal para evaluar las diferencias en los mecanismos de internalización y localización intracelular. Como se mencionara anteriormente, los estudios de internalización mostraron una cinética más lenta para NLCs-N en comparación con la Doxo libre y las NLCs-H. La Figura 7 muestra que la Doxo se concentra rápidamente en el núcleo celular. En comparación, las NLCs-N mostraron señal de fluorescencia sólo en zonas específicas del citoplasma celular. Cuando las células fueron tratadas con Lysotracker Green, con el fin de marcar los lisosomas, se obtuvo una co-localización con la señal de las NLCs-N. Estos hallazgos sugieren que las NLCs-N ingresan a la célula por una vía endocítica que más tarde termina con una localización lisosomal de las nanopartículas. Por su parte, las NLCs-H mostraron un efecto mixto localizándose la señal de la Doxo rápidamente en nucleó (similar a la Doxo libre) pero también en estructuras lisosomales (similar a las NLCsN). Estos resultados permiten confirmar que las NLCs-H podrían comportarse de manera similar a las NLCs-N en cuanto a su mecanismo de internalización.

Posteriormente, se enfocaron los estudios del estado molecular de la Doxo liberada desde las NLCs-N una vez dentro de la célula. El objetivo de estos estudios fue comprender cómo la Doxo fue administrada desde el nanocarrier una vez que ha ingresado en la célula. La técnica de fluorescencia confocal espectral (FCSI) se basa en la medición de los espectros de fluorescencia en diferentes puntos de la célula. De esta manera, la FCSI proporciona información valiosa sobre el estado molecular de los fármacos una vez que han sido internalizados en la célula. El mecanismo de acción de la Doxo implica la intercalación de la molécula en el ADN nuclear y la consiguiente inhibición de la replicación mediante la inhibición de la topoisomerasa, asociada al ADN. En este sentido, enfocamos nuestro análisis en especies de Doxo presentes el núcleo y en el citoplasma (Figura 8). El experimento consistió en la incubación de células durante 1 hora (condición 1) y 22 horas (condición 2) con las nanopartículas. La Figura 8A muestra la señal de fluorescencia dentro de la célula en ambas condiciones. Se encontraron dos perfiles espectrales diferentes, una correspondiente a la región citoplasmática (espectro azul en la Figura 8A y zona azulada en la Figura 8B) y la otra a la región nuclear (espectro rojo en la Figura 8A y zona roja en la Figura 8B). El espectro de fluorescencia de la Doxo en estas dos regiones celulares fue 
significativamente diferente al observados en la suspensión de NPs en PBS (Figura 8A, espectro verde).

Figura 7. Imágenes de microscopía confocal detallan el ingreso y la localización celular de la Doxo luego de exponer a las células MDA-MB-231 a Doxo libre, NLCs-N y NLCs-H.

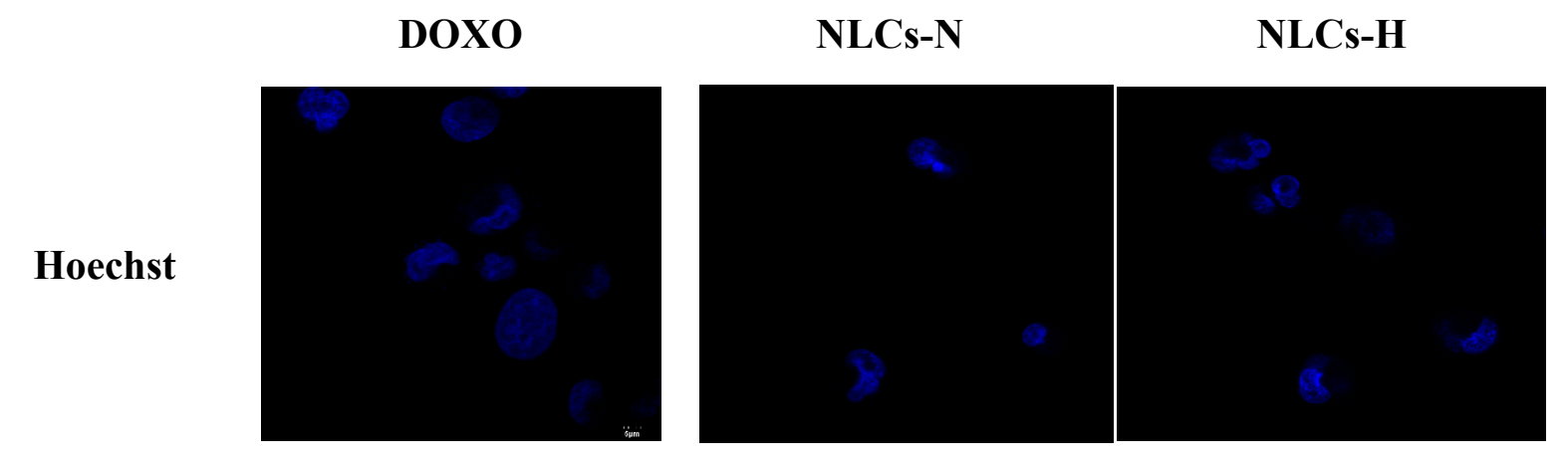

\section{Lysotracker}

Green
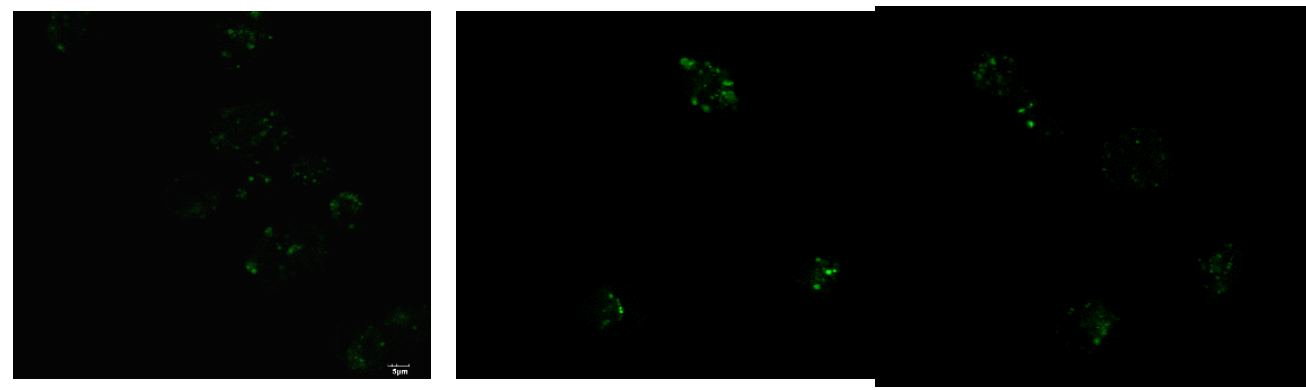

Doxo
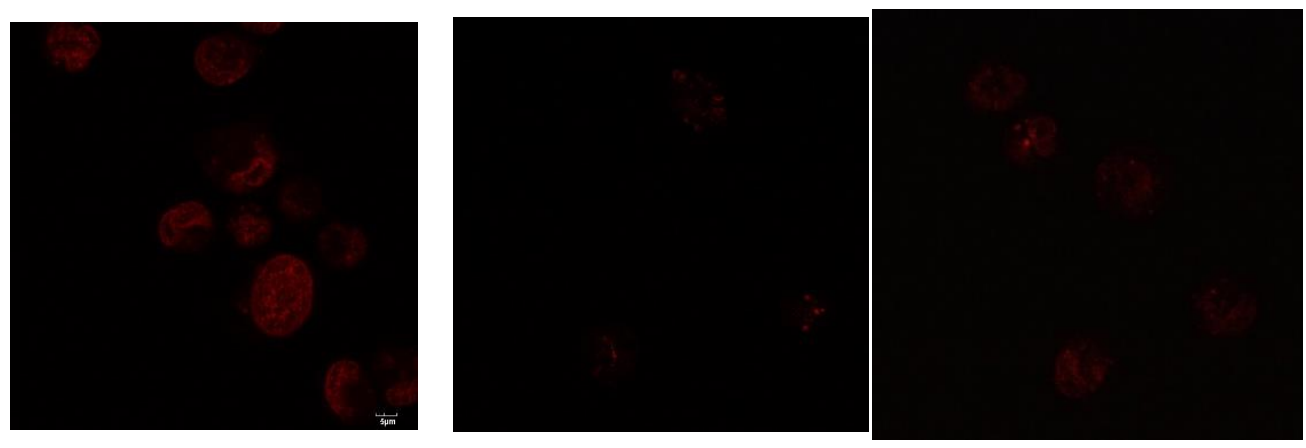

MERGE
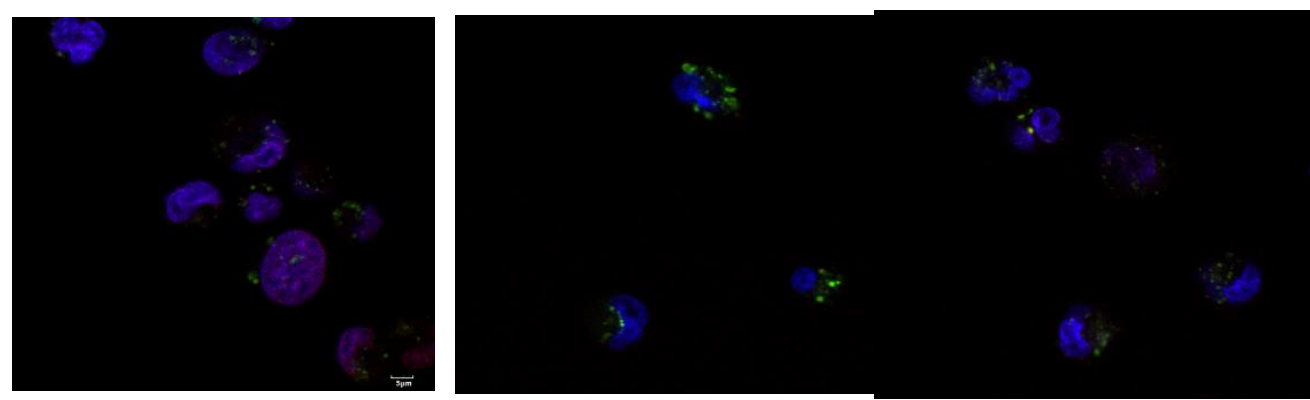

En la figura 8 se observa que el espectro citosólico mostró un aumento en el hombro izquierdo, que es una característica característica de la fluorescencia Doxo cuando la 
molécula se encuentra en ambientes de baja polaridad, tales como orgánelas citosólicas ricas en membranas tales como endosomas o lisosomas ${ }^{28,29}$.

Figura 8. (A) Espectros de fluorescencia característicos de la doxorrubicina en NLCs: formulación antes de tener contacto con las células (verde), en el núcleo celular (rojo) y en el citoplasma (azul). (B) Distribución subcelular de la fluorescencia de doxorrubicina en células de cáncer MDA-MB-231 y mapas espectrales confocales fusionados con imágenes de luz visible de las células, las líneas discontinuas muestran los límites del núcleo; (C) resumen estadístico de los datos de los mapas espectrales. Efecto de duración de la incubación: $1 \mathrm{~h}$ vs $22 \mathrm{~h}$.

A

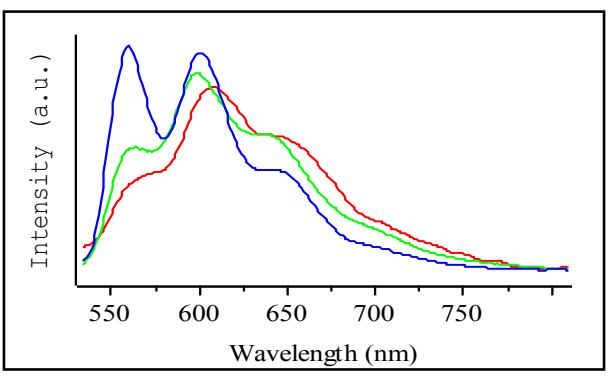

B

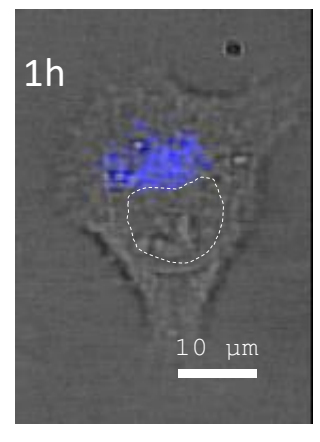

\section{$22 \mathrm{~h}$}

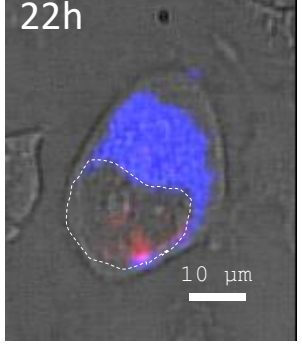

C

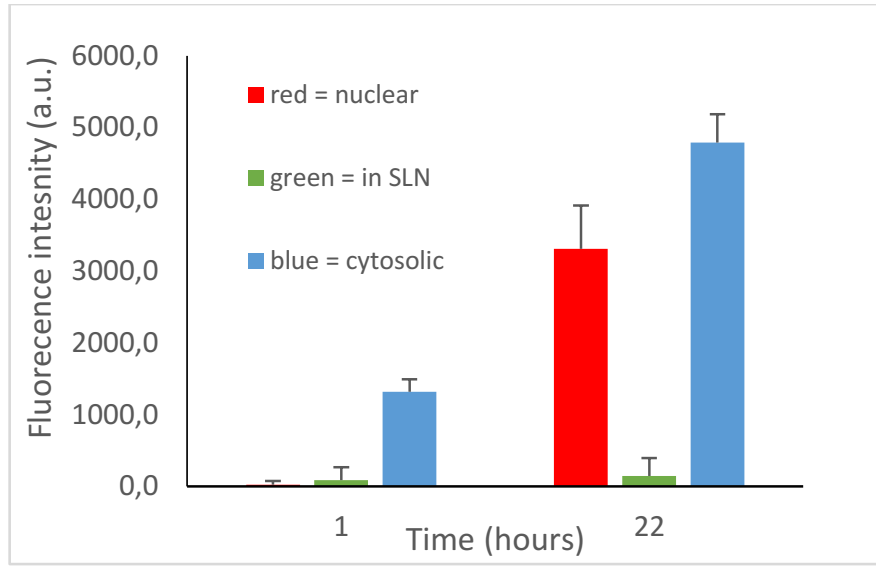

Los espectros de Doxo nuclear se desplazaron a una longitud de onda más alta debido a la intercalación del fármaco liberado entre los pares de bases de $\operatorname{ADN}^{29}$. Después de 1 hora de incubación no se encontró Doxo en el núcleo. Sin embargo, después de las 22 horas sí se pudo observar la fluorescencia correspondiente a la Doxo (Figura 8C). Como se mencionara anteriormente, la fluorescencia de la Doxo por 
administración directa a las células da como resultado una concentración de señal casi completa en el núcleo. Debido a estas razones, sugerimos que la señal de fluorescencia encontrada dentro del núcleo de la célula corresponde sólo a la Doxo liberada desde la región fluorescente citoplasmática de la célula.

La llegada tardía de la Doxo al núcleo celular para las NLCs-N en comparación con la exposición con Doxo libre puede conducir a una disminución de la citotoxicidad. Esta observación concuerda con los resultados mencionados en la Figura 5 después de 1 y 3 horas de incubación. Sin embargo, los efectos citotóxicos después de un tiempo de incubación más largo demostraron ser similares entre la Doxo liberada desde las NLCs y la Doxo libre. Este hecho sugiere que podrían existir mecanismos complementarios de acción de la Doxo cuando el fármaco no se concentra directamente en el núcleo, lugar donde tiene lugar su principal acción biocida.

\subsection{Conclusiones}

El desarrollo de un sistema lipídico nanoparticulado sólido para el tratamiento de tumores sólidos implica lograr generar un dispositivo que sea implantable en la zona del tumor. En el presente trabajo se ha logrado diseñar una formulación de nanopartículas solidas lipídicas con capacidad para cargar Doxorrubicina y liberarla de manera sostenida en el tiempo. Se han descripto las propiedades estructurales de las NLCs sugiriendo que la Doxo efectivamente se encuentra en contacto íntimo con los componentes de las partículas mediante interacciones hidrofóbicas. La carga de dos especies diferentes de Doxo permitió obtener perfiles de liberación muy distintos pudiendo ofrecer una formulación final con la capacidad de adaptarse a las necesidades específicas de cada caso a tratar. Por último, se realizaron ensayos in vitro para evaluar la capacidad citotóxica de las NLCs en cultivo de células de adenocarcinoma de mama humano (MDA-MB-231). Se determinaron las concentraciones inhibitorias máximas para matar el 50\% de las células (IC50) bajo distintos tiempos de exposición. Los resultados mostraron una IC50 superior en las NLCs para tiempos de exposición cortos (1 y 3 horas) en comparación con la exposición con la Doxo libre. Esto sugiere mecanismos de acción distintos, la Doxo libre se internaliza y concentra rápidamente en núcleo en comparación con la Doxo vehiculizada en NPs. Entre las NLCs-N y NLCs-H también se observaron diferencias, las NLCs-H mostraron una mayor toxicidad debido 
principalmente a la presencia de Doxo libre en la formulación y también debido a una cinética de liberación más rápida. A tiempos más prolongados de exposición, las IC50 fueron similares indicando que la Doxo encapsulada posee capacidad citotóxica similar a la libre. Por último, se obtuvieron imágenes de las células tratadas con los transportadores s por medio de microscopia confocal y de barrido espectral en microscopio confocal observándose los espectros característicos de la Doxo. Se pudo evidenciar las NLCs-N se localizan en estructuras lisosomales, una vez que ingresan a la célula y desde allí se produce la llegada del fármaco al núcleo. En cambio, la Doxo libre se concentra rápidamente en núcleo sin observarse su presencia en otras estructuras celulares. De esta manera, se pone de manifiesto una liberación gradual y sostenida del fármaco una vez que las nanopartículas han ingresado a la célula.

\subsection{Referencias}

(1) Mura, S.; Bui, D. T.; Couvreur, P.; Nicolas, J. Lipid Prodrug Nanocarriers in Cancer Therapy. J. Control. Release 2015, 208, 25-41.

(2) Nicolas, J.; Mura, S.; Brambilla, D.; Mackiewicz, N.; Couvreur, P. Design, Functionalization Strategies and Biomedical Applications of Targeted Biodegradable/biocompatible Polymer-Based Nanocarriers for Drug Delivery. Chem. Soc. Rev. 2013, 42 (3), 1147-1235.

(3) Bae, Y.; Kataoka, K. Intelligent Polymeric Micelles from Functional Poly(ethylene Glycol)Poly(amino Acid) Block Copolymers. Adv. Drug Deliv. Rev. 2009, 61 (10), 768-784.

(4) Al-Jamal, W. T.; Kostarelos, K. Liposomes: From a Clinically Established Drug Delivery System to a Nanoparticle Platform for Theranostic Nanomedicine. Acc. Chem. Res. 2011, 44 (10), 10941104.

(5) Muller, R.; Mader, K.; Gohla, S. Solid Lipid Nanoparticles (SLN) for Controlled Drug Delivery: A Review of the State of the Art. Eur. J. Pharm. Biopharm. 2000, 50 (1), 161-177.

(6) Reddy, L. H.; Arias, J. L.; Nicolas, J.; Couvreur, P. Magnetic Nanoparticles: Design and Characterization, Toxicity and Biocompatibility, Pharmaceutical and Biomedical Applications. Chem. Rev. 2012, 112 (11), 5818-5878.

(7) Das, S.; Ng, W. K.; Tan, R. B. H. Are Nanostructured Lipid Carriers (NLCs) Better than Solid Lipid Nanoparticles (SLNs): Development, Characterizations and Comparative Evaluations of Clotrimazole-Loaded SLNs and NLCs? Eur. J. Pharm. Sci. 2012, 47 (1), 139-151.

(8) Das, S.; Chaudhury, A. Recent Advances in Lipid Nanoparticle Formulations with Solid Matrix for Oral Drug Delivery. AAPS PharmSciTech 2011, 12 (1), 62-76.

(9) Chen, C. C.; Tsai, T. H.; Huang, Z. R.; Fang, J. Y. Effects of Lipophilic Emulsifiers on the Oral Administration of Lovastatin from Nanostructured Lipid Carriers: Physicochemical Characterization and Pharmacokinetics. Eur. J. Pharm. Biopharm. 2010, 74 (3), 474-482. 
(10) Beloqui, A.; Solinís, M. Á.; Rodríguez-gascón, A.; Almeida, A. J.; Préat, V. Nanostructured Lipid Carriers : Promising Drug Delivery Systems for Future Clinics. Nanomedicine Nanotechnology, Biol. Med. 2016, 12 (1), 143-161.

(11) Venkateswarlu, V.; Manjunath, K. Preparation, Characterization and in Vitro Release Kinetics of Clozapine Solid Lipid Nanoparticles. J. Control. Release 2004, 95 (3), 627-638.

(12) Mosmann, T. Rapid Colorimetric Assay for Cellular Growth and Survival: Application to Proliferation and Cytotoxicity Assays. J. Immunol. Methods 1983, 65 (1-2), 55-63.

(13) Perillo, E.; Allard-Vannier, E.; Falanga, A.; Stiuso, P.; Vitiello, M. T.; Galdiero, M.; Galdiero, S.; Chourpa, I. Quantitative and Qualitative Effect of gH625 on the Nanoliposome-Mediated Delivery of Mitoxantrone Anticancer Drug to HeLa Cells. Int. J. Pharm. 2015, 488 (1-2), 59-66.

(14) Ahmadi, M.; Madrakian, T.; Afkhami, A. Solid Phase Extraction of Doxorubicin Using Molecularly Imprinted Polymer Coated Magnetite Nanospheres prior to Its Spectrofluorometric Determination. New J. Chem. 2015, 39 (1), 163-171.

(15) NIH U.S. National Library of Medicine National Center for Biotechnology Information.

Doxorubicin Hydrochloride - PubChem

https://pubchem.ncbi.nlm.nih.gov/compound/Doxorubicin_Hydrochloride\#section=Stability (accessed Feb 19, 2017).

(16) He, C.; Hu, Y.; Yin, L.; Tang, C.; Yin, C. Effects of Particle Size and Surface Charge on Cellular Uptake and Biodistribution of Polymeric Nanoparticles. Biomaterials 2010, 31 (13), 3657-3666.

(17) Islan, G. A.; Tornello, P. C.; Abraham, G. A.; Duran, N.; Castro, G. R. Smart Lipid Nanoparticles Containing Levofloxacin and DNase for Lung Delivery. Design and Characterization. Colloids Surfaces B Biointerfaces 2016.

(18) Tupal, A.; Sabzichi, M.; Ramezani, F.; Kouhsoltani, M.; Hamishehkar, H. Dermal Delivery of Doxorubicin-Loaded Solid Lipid Nanoparticles for the Treatment of Skin Cancer. $J$.

Microencapsul. 2016, 2048 (June), 1-9.

(19) Dong, Y. Da; Boyd, B. J. Applications of X-Ray Scattering in Pharmaceutical Science. Int. J. Pharm. 2011, 417 (1-2), 101-111.

(20) Bunjes, H.; Unruh, T. Characterization of Lipid Nanoparticles by Differential Scanning Calorimetry, X-Ray and Neutron Scattering. Adv. Drug Deliv. Rev. 2007, 59 (6), 379-402.

(21) Margaritis, A.; Manocha, B. Controlled Release of Doxorubicin from Doxorubicin/??Polyglutamic Acid Ionic Complex. J. Nanomater. 2010, 2010.

(22) Yang, J.; Ciftci, O. N. Formation of Hollow Solid Lipid Micro- and Nanoparticles Using Supercritical Carbon Dioxide. Food Bioprod. Process. 2016, 98, 151-160.

(23) Lawler, P. J.; Dimick, P. S. Crystallization and Polymorphismof Fats. In Food Lipids: Chemistry,Nutrition and Biotechnology.; Akoh, C. C., Min, D. B., Eds.; CRC Press, Boca Raton, FL, 2008; p 253.

(24) Oh, N.; Park, J. H. Endocytosis and Exocytosis of Nanoparticles in Mammalian Cells. Int. J. Nanomedicine 2014, 9 (SUPPL.1), 51-63.

(25) Wu, A.; Loutherback, K.; Lambert, G.; Estévez-Salmerón, L.; Tlsty, T. D.; Austin, R. H.; Sturm, J. C. Cell Motility and Drug Gradients in the Emergence of Resistance to Chemotherapy. Proc. 
Natl. Acad. Sci. 2013, 110 (40), 16103-16108.

(26) Gratton, S. E. A.; Ropp, P. A.; Pohlhaus, P. D.; Luft, J. C.; Madden, V. J.; Napier, M. E.;

DeSimone, J. M. The Effect of Particle Design on Cellular Internalization Pathways. Proc. Natl. Acad. Sci. U. S. A. 2008, 105 (33), 11613-11618.

(27) Mahmoudi, M.; Azadmanesh, K.; Shokrgozar, M. A.; Journeay, W. S.; Laurent, S. Effect of Nanoparticles on the Cell Life Cycle. Chem. Rev. 2011, 111 (5), 3407-3432.

(28) Gautier, J.; Munnier, E.; Paillard, A.; Hervé, K.; Douziech-Eyrolles, L.; Soucé, M.; Dubois, P.; Chourpa, I. A Pharmaceutical Study of Doxorubicin-Loaded PEGylated Nanoparticles for Magnetic Drug Targeting. Int. J. Pharm. 2012, 423 (1), 16-25.

(29) Gautier, J.; Munnier, E.; Souc??, M.; Chourpa, I.; Douziech Eyrolles, L. Analysis of Doxorubicin Distribution in MCF-7 Cells Treated with Drug-Loaded Nanoparticles by Combination of Two Fluorescence-Based Techniques, Confocal Spectral Imaging and Capillary Electrophoresis. Anal. Bioanal. Chem. 2015, 3425-3435. 


\section{Capítulo 4}

Encapsulación de NLCs en membranas de celulosa bacteriana y estudios anti-tumorales in vivo
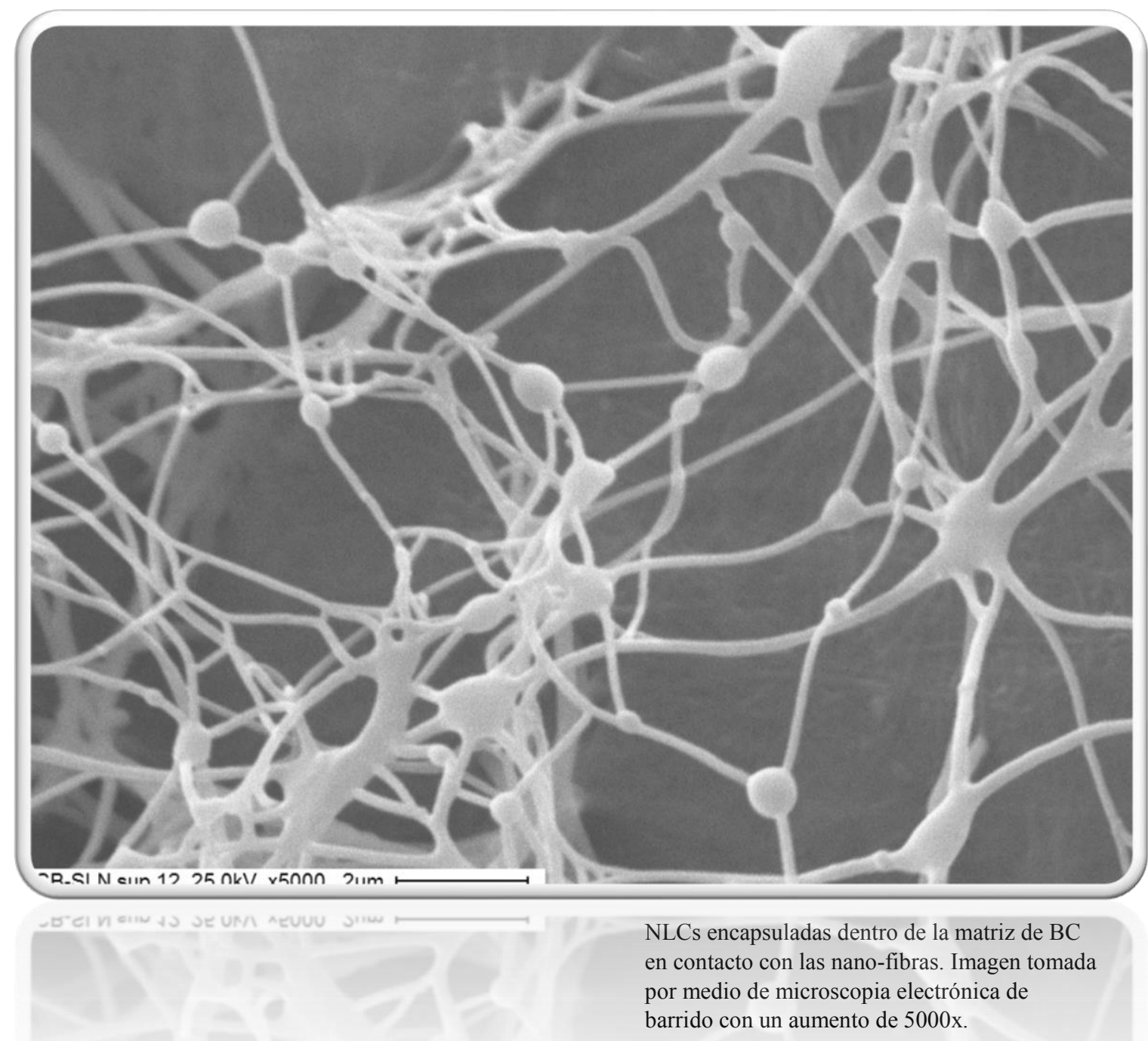


\section{Objetivos específicos:}

* Estudiar la capacidad de incorporación de las NLCs en una matriz de celulosa bacteriana.

* Evaluar la estabilidad de las nanopartículas dentro de la red polimérica y una vez liberadas de la misma, mediante microscopia electrónica.

* Realizar estudios de liberación en condiciones fisiológicas para poder describir los distintos perfiles.

* Generar un modelo ortotópico de cáncer de mama utilizando la línea MDA-MB231.

* Llevar a cabo pruebas de implantación de las membranas de BC de manera subcutánea y sobre el tumor desarrollado.

* Evaluar la capacidad anti-tumoral del sistema desarrollado, así como también los efectos adversos de la terapia. 


\subsection{Introducción}

Los hidrogeles así como las nanopartículas se han utilizado durante mucho tiempo en el desarrollo de distintos tipos de sistemas de liberación controlada de fármacos ${ }^{1}$. Por un lado, los hidrogeles constituyen estructuras cuyas propiedades son similares a los tejidos y por esta razón son ampliamente utilizados en las áreas de ingeniería de tejidos en el desarrollo de diferentes tipos de implantes ${ }^{2,3}$. Por el otro lado, los sistemas de nanopartículas han sido exhaustivamente desarrollados en los últimos años con el objetivo principal de mejorar el índice terapéutico de los fármacos mediante la modificación de su farmacocinética, toxicidad y biodistribución ${ }^{4}$. Las nanopartículas terapéuticas pueden ser combinadas con hidrogeles para formar diferentes estructuras jerárquicas. De esta manera, se generan nuevos materiales híbridos capaces de presentar propiedades nuevas y/o mejoradas ${ }^{5}$. Los sistemas híbridos de nanoparticulas-hidrogel, comúnmente llamados NP-geles" integran entonces dos materiales distintos en una formulación con propiedades fisicoquímicas y biológicas únicas que ninguno de los dos materiales posee por separado ${ }^{1}$. Como ya se mencionara, los hidrogeles poseen un sin número de características que los hacen excelentes candidatos para funcionar como implantes. Sin embargo, cuando son cargados con moléculas pequeñas como fármacos se hace muy difícil evitar la liberación rápida de estos principios activos desde la matriz ${ }^{6}$. Su porosidad permite la carga de fármacos en la matriz de gel y posterior liberación a una velocidad que depende del coeficiente de difusión de la molécula pequeña o macromolécula a través de la red de gel. Los beneficios de los hidrogeles para la administración de fármacos pueden ser en gran parte farmacocinéticos. Específicamente se genera una estructura que funciona de depósito a partir de la cual los fármacos eluyen, manteniendo una alta concentración en los tejidos circundantes ${ }^{7}$. Mientras tanto, las nanopartículas presentan una liberación controlada a través de su estructura adaptada, tamaño de partícula, y condiciones de síntesis ${ }^{8}$. Al integrar las dos plataformas, los NP-geles crean matrices con una notable versatilidad en la modulación de la cinética de liberación de fármacos. Además de la administración de un solo fármaco, los NP-geles también pueden combinar la liberación controlada por difusión rápida de moléculas de fármacos directamente dispersos en la red del hidrogel junto con fármacos de liberación lenta de los depósitos de nanopartículas, una característica única. Sumado a esto, puede lograrse una liberación secuencial de fármaco controlando el tamaño y la superficie de las diferentes nanopartículas ${ }^{1}$. 
En el presente capítulo se llevará a cabo la integración de las membranas de BC junto con las formulaciones de nanoparticulas (NLCs) desarrolladas en el capítulo 3, el cual es esquematizado en el Esquema 1. El sistema híbrido, cargado con dos formas de doxorrubicina, se caracterizará y se realizarán ensayos in vivo implantándolo en el sitio del tumor de un modelo de cáncer de mama (BCa) ortotópico intramamario (i.m.f.p.). Se evaluará la eficacia antitumoral y las toxicidades locales y sistémicas.

Esquema 1. Representación del tratamiento localizado de un tumor solido con una membrana BC-NLCs-NH.

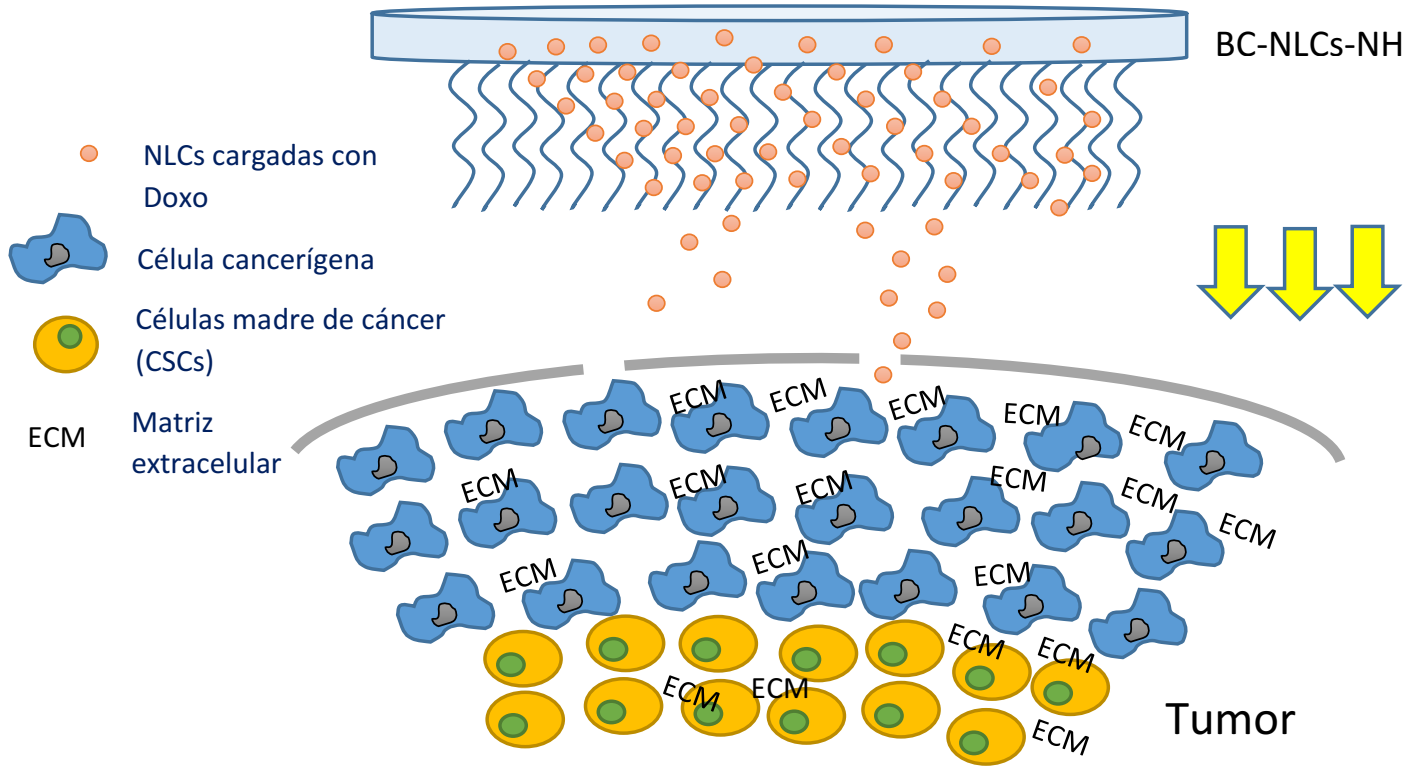

\subsection{Materiales y métodos}

\subsubsection{Materiales}

Los materiales utilizados fueron descritos en los anteriores capítulos. El lípido miristil miristato (Crodamol ${ }^{\mathrm{TM}} \mathrm{MM}$ ) y el aceite (Crodamol ${ }^{\mathrm{TM}}$ GTCC-LQ) fueron donados por Croda (Argentina). La Doxorrubicina (Doxo, PM 543,0) fue donada por LKM pharmaceuticals (Argentina). Los demás reactivos fueron de grado analítico adquiridos a Merck (Darmstad, Alemania) o a marcas similares.

La Doxo fue cuantificada mediante espectrofluorimetria (Perkin Elmer LS 50B, Japón), utilizando $\lambda_{\text {exc }}=476 \mathrm{~nm}$ y $\lambda_{\text {em }}=588 \mathrm{~nm}$ con las correspondientes curvas de calibración. 


\subsubsection{Encapsulación de NLCs en matriz de BC}

La síntesis de celulosa bacteriana (BC) por K. hansenii (ATCC 23769) se realizó en un medio que contenía $\left(\mathrm{g}^{-1}\right)$ : 25,0 manitol, 5,0 extracto de levadura, 3,0 Peptona y se ajustó a pH 6,5 con solución de $\mathrm{NaOH}$ 0,1 M antes esterilización. El cultivo se mantuvo estáticamente en placas de 48 pocillos a $27^{\circ} \mathrm{C}$ durante 14 días. Las películas de $\mathrm{BC}$ se recogieron de las placas y se lavaron con agua destilada. BC se realizó incubando las membranas en $\mathrm{NaOH} 100 \mathrm{mM}$ a $60^{\circ} \mathrm{C}$ durante $24 \mathrm{~h}$ seguido de lavados sucesivos con agua destilada, después de ajustar el $\mathrm{pH}$ a 7,0. Posteriormente, las películas de BC se esterilizaron en autoclave $\left(121^{\circ} \mathrm{C}\right.$ durante $\left.20 \mathrm{~min}\right)$. A continuación, las películas de $\mathrm{BC}$ se cargaron con Doxo libre, NLCs-N y una mezcla de NLCs-H y NLCs-N en una relación 80:20 respectivamente (NLCs-NH).

Para realizar la evaluación de la carga total se sumergieron las películas BC en las soluciones correspondientes con una concentración equivalente de Doxo de $1.000 \mu \mathrm{M}$. Después de 24 horas de incubación las películas se lavaron con solución fisiológica. A continuación, se realizaron etapas de extracción con solventes orgánicos con el objetivo de extraer la cantidad total de Doxo de la matriz polimérica. En primer lugar, las películas de $\mathrm{BC}$ se sumergieron en metanol durante 2 horas seguido de una inmersión en metanol/cloroformo (50:50) durante otras 2 horas. Finalmente, se realizó otra inmersión en metanol durante 2 horas. Estos pasos fueron considerados suficientes para una extracción total de Doxo de las películas mediante análisis de fluorescencia. La Doxo se cuantificó mediante mediciones espectrofluorimétricas. La cantidad total de Doxo se expresó en $\mu$ moles por membrana.

\subsubsection{Liberación de Doxo y NLCs desde membrana de BC}

Las membranas de $\mathrm{BC}$ cargadas con los compuestos se colocaron en tubos tipo Eppendorf de 2,0 $\mathrm{ml}$ conteniendo 1,5 $\mathrm{ml}$ de solución fisiológica ( $\mathrm{NaCl}$ 0,9\%). Los tubos se termostatizaron a $37^{\circ} \mathrm{C}$ y se tomaron muestras de $200 \mu 1$ a los distintos tiempos. La liberación acumulada de Doxo se determinó por la correspondiente medida de fluorescencia. Fueron realizados tres ensayos independientes, cada uno por duplicado.

\subsubsection{Estudios de microscopía}

\subsubsection{Microscopía electrónica de barrido (SEM)}

Las membranas cargadas con la formulación NLCs-NH fueron secadas mediante liofilización. Posteriormente, la superficie se metalizó pulverizándola con oro (Balzers SCD 030), obteniendo un espesor de capa comprendido entre 15 y $20 \mathrm{~nm}$. Las 
superficies y morfologías de la película se observaron mediante SEM (modelo Philips SEM 505, Rochester, NY, EE.UU.), y las imágenes se procesaron mediante un programa de digitalización de imágenes (Soft Imaging System ADDA II).

\subsubsection{Microscopía Electrónica de Transmisión (TEM)}

El día 14 de liberación, se tomaron muestras desde el sobrenadante para las membranas conteniendo la mezcla NLCs-NH. La dispersión de nanopartículas se diluyó diez veces con agua ultrapura y se diseminó una gota de la dispersión sobre una rejilla de $\mathrm{Cu}$ revestida con colodión (malla 400). El exceso de líquido se drenó con papel de filtro y para realzar el contraste se agregó una gota de ácido fosfotúngstico a la dispersión de NLCs. Finalmente, el análisis TEM se realizó utilizando el microscopio Jeol-1200 EX II-TEM (Jeol Ma, US).

\subsubsection{Ensayos tumorigénicos in vivo}

Los ratones hembras desnudos atímicos (Harlan Interfauna Ibérica, Barcelona, España) se mantuvieron en condiciones libres de patógenos y se usaron a las 7 semanas de edad. El cuidado de los animales fue manejado de acuerdo con la Guía para el Cuidado y Uso de Animales de Laboratorio de la Instalación de Animales del Hospital Universitario Vall Hebron y de acuerdo a los criterios establecidos por la UE. Los procedimientos experimentales fueron aprobados por el Comité de Ética Experimental Animal de la institución. Todos los estudios in vivo fueron realizados por el ICTS "NANBIOSIS", más específicamente en la Plataforma Experimental in vivo del CIBER-BBN del Área de Validación Funcional y Preclínica (FVPR) (http://www.nanbiosis.es/portfolio/u20 -in vivo-experimental-plataforma/) (Barcelona, España).

Células MDA-MB-231.Fluc $\left(2.0 \times 10^{6}\right)$ fueron suspendidas en $200 \mu \mathrm{lde}$ PBS con matrigel (1:1) (BD Bioscience, Bedford, MA, EE.UU.) se implantaron en la grasa mamaria abdominal derecha (i.m.f.p.). El crecimiento del tumor se monitoreó dos veces a la semana mediante mediciones convencionales con caliper $(\mathrm{D} \times \mathrm{d} 2 / 2$, donde $\mathrm{D}$ es el diámetro mayor y $\mathrm{d}$ el diámetro menor) y con la bioluminiscencia in vivo (BLI) y tomografía computada (CT). Doce días (Ensayo 1) y dieciséis días (Ensayo 2) después de la inoculación del tumor, una película circular $\mathrm{BC}(\mathrm{d}=12 \mathrm{~mm})$ cargada con una mezcla de NLCs-N y NLCs-H en una relación de 20:80 (BC-NLCs-NH), respectivamente, y que contenía una carga de Doxo de 0,21 mg para el ensayo 1 y 0,14 mg para el ensayo 2, se colocó en el sitio del tumor primario durante una segunda cirugía, entre la almohadilla de grasa mamaria con tumor y la pared abdominal. Los 
grupos de control consistieron en un grupo de Doxo libre inyectada intratumoralmente (i.t.) $(0,21 \mathrm{mg}$ y $0,14 \mathrm{mg}$ en $25 \mu \mathrm{l}$ como una dosis única) y uno no tratado. En el ensayo 1 se utilizó también un grupo control con Doxo liposomal (Doxil, Caelix ${ }^{\circledR}$ ) administrado por una única vez por vía intravenosa (i.v.). Durante el tratamiento, la supervisión de los animales y la medición del peso corporal se realizaron dos veces por semana. Las observaciones clínicas incluyeron cambios en la piel, ojos, membranas mucosas, alteraciones en el patrón respiratorio, comportamiento, postura, respuesta a la manipulación y la presencia de movimientos anormales. Al final del experimento, los tumores primarios, los pulmones y el corazón fueron extirpados y ponderados. Los tejidos se limpiaron con PBS, se fijaron en solución de formaldehído al $4 \%$ y se embebieron en parafina para tinción con hematoxilina-eosina.

Las medidas de BLI se realizaron utilizando un sistema de imagen espectral IVIS (PerkinElmer Life Science, Boston, MA, EE.UU.), y se adquirieron y analizaron las imágenes y las mediciones utilizando el software Living Image 4.5 (PerkinElmer). Para BLI in vivo, los animales se anestesiaron con isofluorano al 1-3\% (Abbott Laboratories, IL, USA) y se inyectaron intraperitonealmente (i.p.) con $150 \mathrm{mg} / \mathrm{kg}$ de D-luciferina (Promega) en PBS estéril. Se fotografiaron cinco ratones a la vez, y se fijaron los ajustes de imagen en función de los tumores bioluminiscentes. Las regiones de interés (ROI) de las imágenes visualizadas se dibujaron automáticamente alrededor de las señales bioluminiscentes y se cuantificaron como fotones por segundo $(\mathrm{ph} / \mathrm{s})$.

Se tomaron imágenes de manera no invasiva utilizando tomografía computada de rayos X (CT) mediante un equipo Quantum FX microCT (PerkinElmer $\left.{ }^{\circledR}\right)$. Se utilizaron las siguientes condiciones de escaneo: nn kV, $160 \mathrm{~mA}$, FOV 30 y $3 \mathrm{~min}$. El análisis de CT fue realizado por el Dr. J.A. Cámara Serrano (Jefe de la Plataforma de Imagen Preclínica en VHIR).

Para cada ensayo se evaluaron parámetros representativos de la efectividad terapéutica de cada tratamiento. Por un lado, el tiempo de duplicación (Td) expresa el tiempo en días necesario para que el tumor duplique su volumen, y se calcula en referencia al volumen tumoral del control no tratado. Luego, el retraso absoluto de crecimiento o Absolute Growth Delay ( $A G D$ ), en inglés, es definido como el tiempo en días que le lleva a un tumor duplicar su tamaño menos el tiempo medio que le lleva a un tumor del grupo control sin tratamiento en crecer de la misma manera. El AGD fue calculado como: 


$$
\mathrm{AGD}=\mathrm{Td} \text { tratamiento }-\mathrm{Td} \text { sin tratamiento }
$$

Por ultimo $\log$ cell kill" es una medida de cuantas células tumorales proliferativas fueron, teóricamente, muertas por el tratamiento (los valores son expresados en ordenes de magnitud de potencia de 10) ${ }^{9,10}$. Este parámetro se evaluó con la siguiente ecuación:

$$
\log \text { cell kill }=\frac{0,301 \times A G D}{T d}
$$

\subsubsection{Análisis estadístico}

Se determinaron y trazaron las intensidades BLI medias o medianas in vivo y los errores estándar correspondientes de la media (SEM). Se usaron gráficos de regresión no lineal para describir la relación entre la intensidad de BLI in vivo y el tiempo después del tratamiento. Se aplicó una prueba no paramétrica de Mann-Whitney para el peso del tumor. El umbral de significación se estableció en $\mathrm{p}<0,05$, y se asignaron esquemáticamente los niveles de significación * $(0,01 \leq \mathrm{p}<0,05)$. Los análisis y gráficos se realizaron utilizando el software GraphPad Prism 5 (GraphPad, San Diego).

\subsection{Resultados y discusión}

\subsubsection{Encapsulación de NLCs en una matriz biopolimérica de BC}

Las NLCs desarrolladas en el anterior capítulo fueron cargadas dentro de membranas de celulosa bacteriana $(\mathrm{BC})$ con el objetivo de generar un sistema polimérico para administración localizada de fármacos. El objetivo principal fue evaluar la eficiencia de la encapsulación de la matriz de BC para la Doxo y las NLCs. De previos resultados (capítulos 1 y 2), sabíamos que las membranas de BC nativas no poseen una buena capacidad de atrapar y almacenar pequeñas moléculas como la Doxo ${ }^{11,12}$. Como primera hipótesis se sugiere que la encapsulación de Doxo en un nanocarrier seguido por la carga del nanocarrier en membranas de BC podría ayudar a aumentar la eficacia de la encapsulación del fármaco (EE), a la vez que se aumentaría la efectividad terapéutica del fármaco. En este sentido, las películas de $\mathrm{BC}$ se sumergieron en tres soluciones con una concentración equivalente de Doxo de $1.000 \mu \mathrm{M}$ durante 24 horas en agitación continua. Las soluciones ensayadas fueron: Doxo libre (BC-Dox), NLCs-N 
(BC-NLCs-N) y una solución mixta con NLCs-H y NLCs-N en una relación de 80:20 respectivamente (BC-NLCs-NH). Los resultados observados fueron de gran interés debido a que la Doxo libre podía ser encapsulada en cantidades bajas, mientras que las NLCs demostraron aumentar la EE en más del doble (Tabla II). Además, se observó que las NLCs-N generaban los valores de EE más elevados. Se consideró que la presencia de Doxo no encapsulada en la formulación NLCs-H contribuyó a una menor EE en la mezcla NLCs-NH. Fue notable observar que la cantidad de carga útil equivalente de Doxo con NLCs estaba en el mismo rango que las dosis de Doxo administradas en muchos experimentos in vivo en modelos tumorales ortotópicos ${ }^{13-15}$.

Tabla II. La eficiencia de encapsulación (EE) para las películas BC cargadas con dox libre (BC-Dox), NLCs-N (BC-NLCs-N) y una mezcla de NLCs-H y NLCs-N en la relación 80/20 (BC-NLCs-NH). La EE se expresó en $\mu$ moles de Doxo encapsulada por membrana de $\mathrm{BC}$. Los resultados son una media de dos experimentos independientes, cada uno realizado por cuadruplicado.

\begin{tabular}{cccc}
\hline Sistema & BC-Dox & BC-NLCs-N & BC-NLCs-NH \\
\hline EE $(\mu$ moles/film) & $0,043 \pm 0,005$ & $0,147 \pm 0,014$ & $0,105 \pm 0,015$ \\
\hline
\end{tabular}

\subsubsection{Ensayos de liberación desde matriz de BC}

A continuación de los ensayos de encapsulación, se realizaron los experimentos de liberación in vitro. Las membranas cargadas se colocaron en solución fisiológica a $37^{\circ} \mathrm{C}$ y se tomaron muestras a diferentes tiempos. Como se puede observar en la Figura 6, los perfiles de liberación se describieron mediante curvas hiperbólicas. BC-Dox liberó casi toda la carga útil durante el primer día del experimento. Por el contrario, BC-NLCs-N permitió obtener una liberación sostenida y prolongada del fármaco con sólo un $24,5 \%$ de liberación después de 4 semanas. En la zona media del grafico se pudo encontrar el perfil de liberación de BC-NLCs-NH con un 55\% del fármaco liberado al día 30. Como se mencionra anteriormente, ambos tipos de NLCs permitieron generar una formulación mixta de acuerdo con las necesidades de la terapia. Las curvas de liberación demostraron que la presencia de NLCs-H, que son las nanopartículas que liberan Doxo más rápidamente, permitió obtener un burst más fuerte en los tiempos iniciales. Además, dicha formulación contiene un elevado porcentaje de Doxo libre como se mostró en el anterior capitulo. Este es otro factor clave para explicar el incremento en la 
velocidad inicial de liberación y también el detrimento en la capacidad de carga respecto a BC-NLCs-N. Por otro lado, la presencia de NLCs-N garantiza una liberación prolongada y sostenida del fármaco (Figura 6).

Figura 6. Doxo liberada desde membranas de $\mathrm{BC}$ cargadas (• BC-Dox; ○ BC-NLCs-N; $\nabla$ BC-NLCs-NH). El experimento de liberación se realizó en solución fisiológica termostatizada a $37^{\circ} \mathrm{C}$. Los resultados corresponden a una media entre tres experimentos individuales, cada uno realizado por duplicado.

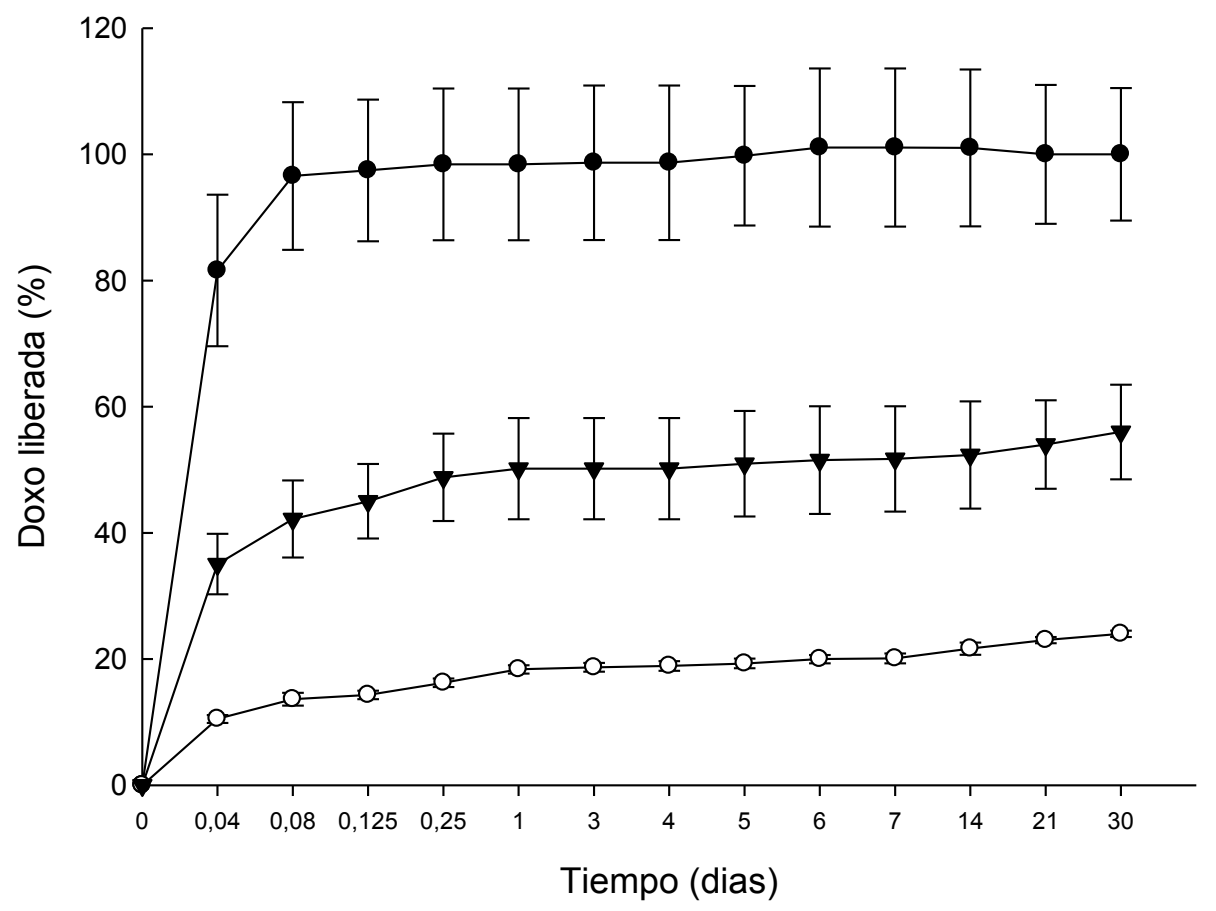

La matriz BC cargada con la mezcla de NLCs se caracterizó por SEM. Las imágenes permitieron observar cómo las NLCs permanecieron atrapadas dentro de la red polimérica de BC (Figura 7A y 7B). Además, se realizaron observaciones por medio de TEM de los sobrenadantes de los ensayos de liberación. El estudio mostró que las NLCs fueron liberadas de la matriz y la morfología esférica de las nanopartículas se conservó (Figura 7C y 7D). 
Figura 7. Imágenes SEM de BC-NLCs-NH a 5000x (A) y 10000x (B). También, las imágenes TEM del sobrenadante de 14 días de los experimentos de liberación de BC-NLCs-NH. Las NLCs se pueden observar a 50.000 x (C) y $100.000 \times(D)$.

A

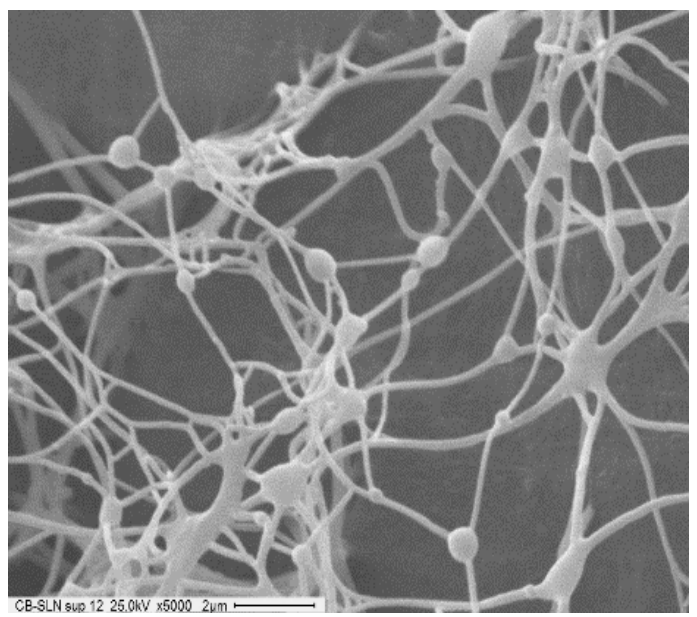

$\mathrm{C}$

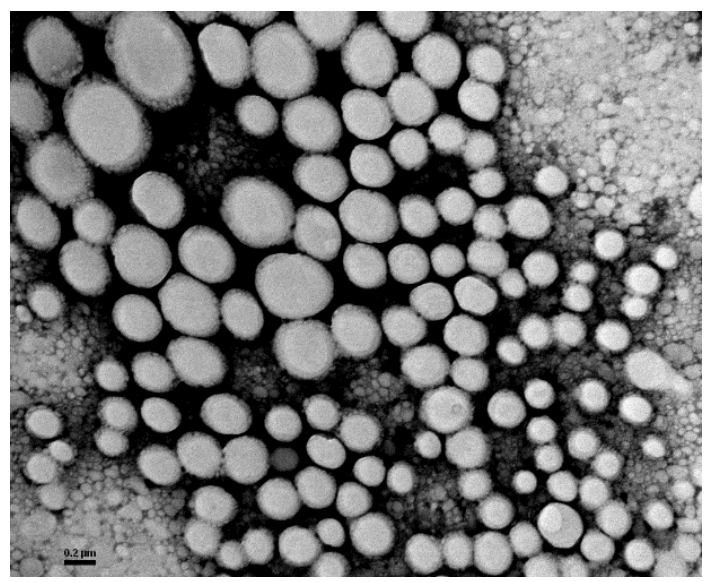

B

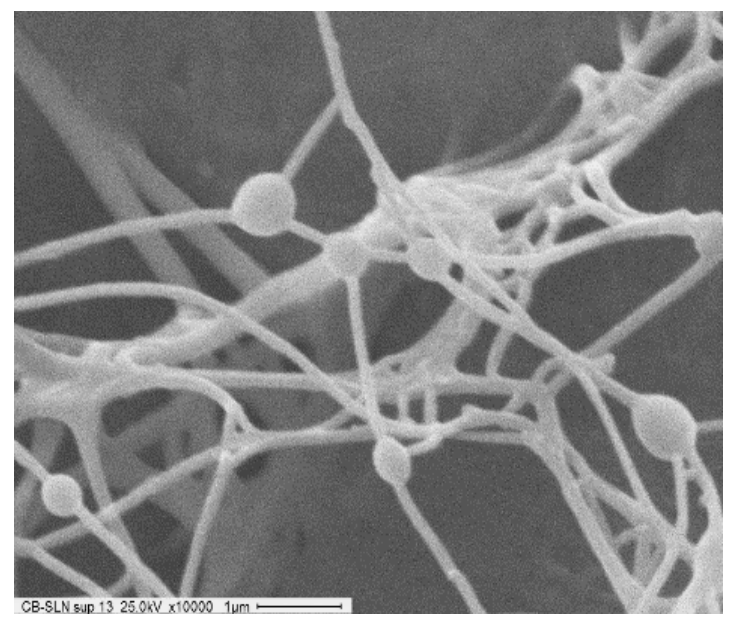

$\mathrm{D}$

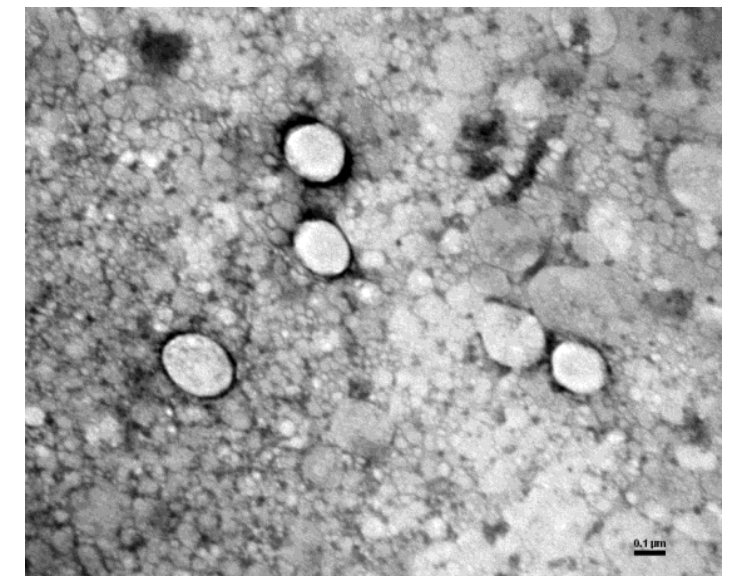

\subsubsection{Ensayos in vivo}

Con el objetivo de evaluar el potencial terapéutico de las membranas BC-NLCs-NH, se llevaron a cabo ensayos in vivo en un modelo tumoral bien caracterizado. Dichos ensayos permitirán también evaluar la respuesta del animal al tratamiento, dejando en evidencia reacciones y efectos adversos que puedan surgir como consecuencia del tratamiento localizado. En paralelo se procederá a elegir tratamientos control para poder realizar estudios comparativos con el tratamiento con BC-NLCs-NH.

Se procedió a la generación de un tumor ortotópico de mama a partir de la implantación de células MDA-MB-231 en la materia grasa de uno de los extremos de la cadena mamaria de ratones atímicos. Resulta relevante mencionar que el termino 
ortotópico relativo al modelo tumoral corresponde a que el tumor se genera en el mismo tejido diana respectivo al tipo de línea celular que se utilizará. En nuestro caso particular, la inyección de células se realiza en el tejido mamario del animal debido a que la línea proviene de un adenocarcinoma de mama humano. Por otro lado, también cabe mencionar que la utilización de ratones atímicos fue debido a la utilización de una línea celular humana para generar el tumor. Los ratones atimicos nude carecen de glándula del timo normal y tienen un sistema inmunitario defectuoso debido a una mutación genética. De esta manera, este tipo de ratones no generan una respuesta inmune a las células implantadas.

Se realizaron dos ensayos in vivo para el mismo tipo de sistema implantable. Debido a que la vía de administración no es habitual se debieron llevar a cabo varios ajustes en cuanto al modo de implantación de la matriz y al tipo de cirugía a realizar. Algunos ejemplos de los puntos clave en donde se trabajó son: el tipo de hilo de sutura, la forma en que debió generarse el espacio subcutáneo para implantar la matriz polimérica disgregando el tejido conectivo, la manera en que la matriz debió ser lavada antes de la implantación, el tipo de sutura y el tipo de control diario que se le debía hacer a los animales, entre otros. Considero importante mencionar estos puntos debido a que fueron vitales al momento de realizar los ensayos, y son factores que afectan el resultado final pero que no se pueden ser expresados en gráficos y/o tablas. La experiencia de las personas a cargo de la cirugía también fue muy importante para conservar la salud y bienestar de los animales, así como también para alcanzar resultados confiables.

Uno de los primeros puntos de discusión al momento de realizar el planeamiento de los ensayos fue la dosis de fármaco a utilizar. Buscando información en bibliografía pudimos encontrar una gran variedad de formas de dosificar Doxo en modelos tumorales. La Tabla III especifica las dosis utilizadas, así como también los periodos de administración. 
Tabla III. Diversas formas de dosificación de doxo en modelos tumorales

\begin{tabular}{|c|c|c|c|c|c|c|}
\hline Línea celular & Animal & $\begin{array}{c}\text { Dosis total } \\
\text { Doxo }\end{array}$ & $\begin{array}{l}\text { Administración } \\
\text { (periodos) }\end{array}$ & $\begin{array}{c}\text { Eficacia/sobrevida } \\
\text { o reducción en } \\
\text { tamaño tumor } \\
\text { (tiempo) }\end{array}$ & $\begin{array}{l}\text { Volumen } \\
\text { de tumor } \\
\text { al inicio }\end{array}$ & Ref. \\
\hline $\begin{array}{l}\text { MDA-MB-231 } \\
\text { (subcut) }\end{array}$ & Swiss un/nu & $30 \mathrm{mg} / \mathrm{Kg}$ & $\begin{array}{c}1 \text { i.v./ sem, } \\
10 \mathrm{mg} / \mathrm{Kg}, 3 \text { sem }\end{array}$ & $50 \%, 3$ semanas & $\begin{array}{c}150-250 \\
\mathrm{~mm} 3\end{array}$ & 16 \\
\hline $\begin{array}{c}\text { MDA-MB-231 } \\
\text { (subcut) }\end{array}$ & SCID & $\begin{array}{c}5,10 \text { y } 15 \\
\mathrm{mg} / \mathrm{Kg}\end{array}$ & $1 \mathrm{i.v}$ & $60 \% 15$ dias & $50 \mathrm{~mm} 3$ & 17 \\
\hline $\begin{array}{l}\text { MDA-MB- } \\
\text { 231/GFP }\end{array}$ & $\mathrm{BALB} / \mathrm{c}$ nude & $5,10 \mathrm{mg} / \mathrm{Kg}$ & ¿? & $50 \% 12$ dias & ¿50mm3? & 18 \\
\hline $\begin{array}{l}\text { MDA-MB-231 } \\
\text { (ort.) }\end{array}$ & $\begin{array}{l}\mathrm{NCr} \text { nu/nu, } \\
\text { athymic nude }\end{array}$ & $16 \mathrm{mg} / \mathrm{Kg}$ & $\begin{array}{l}\text { i.v. } 1 \text { vez por sem, } \\
\text { por } 4 \text { sem ( } 4 \text { dosis) } \\
\quad 4 \mathrm{mg} / \mathrm{Kg}\end{array}$ & $30 \%$ reduc. 4 sem & $3-5 \mathrm{~mm}$ & 14 \\
\hline 4T1 (subcut) & $\mathrm{BALB} / \mathrm{c}$ & $20 \mathrm{mg} / \mathrm{kg}$ & $\begin{array}{c}\text { i.v. } 5 \mathrm{mg} / \mathrm{Kg} \text { días } \\
0,4,7,11\end{array}$ & $50 \%$ reduc, 15 dias & 10 dias & 19 \\
\hline $\begin{array}{l}\text { MDA-MB-231 } \\
\text { (armpit) }\end{array}$ & $\mathrm{BALB} / \mathrm{c}$ nude & $8 \mathrm{mg} / \mathrm{Kg}$ & $\begin{array}{l}\text { i.v. } 2 \mathrm{mg} / \mathrm{Kg} \text { every } \\
\text { other day, } 4 \text { times }\end{array}$ & $\begin{array}{l}50 \%, 21 \text { dias en } \\
\text { total (9 dias trat) }\end{array}$ & Dia 12 & 20 \\
\hline $\begin{array}{l}\text { MDA-MB-231 } \\
\text { (ort.) }\end{array}$ & NUDE/SCID & $3.2 \mathrm{mg} / \mathrm{Kg}$ & $\begin{array}{l}\text { i.v. } 3.2 \mathrm{mg} / \mathrm{Kg} \\
(80 \mathrm{ug})\end{array}$ & $50 \%, 6$ sem & Dia 12 & 13 \\
\hline $\begin{array}{c}\text { SNU-601, } \\
\text { gastrico(S.C.) }\end{array}$ & $\begin{array}{l}\mathrm{BALB} / \mathrm{C} \\
\mathrm{nu} / \mathrm{nu}\end{array}$ & $30 \mathrm{mg} / \mathrm{Kg}$ & $\begin{array}{c}\text { i.t. } 30 \mathrm{mg} / \mathrm{Kg}, 100 \\
\mathrm{ul}\end{array}$ & $60 \%$ reduc, 24 dias & $\begin{array}{c}200-300 \\
\mathrm{~mm} 3\end{array}$ & 21 \\
\hline $\begin{array}{c}\text { MDA-MB-436 } \\
\text { cells (S.C.) }\end{array}$ & $\mathrm{CD} 1 \mathrm{nu} / \mathrm{nu}$ & $12 \mathrm{mg} / \mathrm{Kg}$ & $\begin{array}{l}\text { i.v. } 2 \mathrm{mg} / \mathrm{Kg} \text { por } \\
\text { sem, } 6 \text { sem }\end{array}$ & ¿? & $200 \mathrm{~mm} 3$ & 22 \\
\hline $\begin{array}{l}\text { MDA-MB- } \\
\text { 468LN (ort.) }\end{array}$ & nude & $7 \mathrm{mg} / \mathrm{Kg}$ & $\begin{array}{c}\text { i.v. } 3.5 \mathrm{mg} / \mathrm{Kg} \text {, dos } \\
\text { veces }\end{array}$ & $50 \%$, sem 8 & $3-4$ sem & 15 \\
\hline $\begin{array}{l}\text { Murine H22 } \\
\text { hepatoma } \\
\text { cells (S.C.) }\end{array}$ & ICR & $20 \mathrm{mg} / \mathrm{Kg}$ & $\begin{array}{l}\text { i.t Doxo y Doxil, } \\
200 \mathrm{ul}(4 \mathrm{mg} / \mathrm{ml})\end{array}$ & $70 \%, 21$ dias & $300 \mathrm{~mm} 3$ & 23 \\
\hline
\end{tabular}

\subsubsection{Primer ensayo in vivo}

Las dosis utilizadas en bibliografía pertenecen a un rango comprendido entre 3 y 30 $\mathrm{mg} / \mathrm{Kg}$. En nuestro caso, para el primer ensayo a realizar se decidió utilizar una dosis de $8.5 \mathrm{mg} / \mathrm{Kg}$ debido a que esta correspondía a una dosis dentro del rango reportado y con una tolerabilidad aparentemente aceptable.

En un primer ensayo se procedió a generar los tumores a partir de células MDA-MB231.Fluc, estas células poseen un gen recombinante con capacidad de expresar luciferasa y pueden ser seguidas in vivo por medio de medidas de fluorescencia. Se inyectaron en el mamary fat pad $2 \times 10^{6}$ células por animal y se permitió proliferar por 12 días antes de iniciar el tratamiento. Los ratones fueron pesados dos veces por semana como medida indicativa de su salud y bienestar, con la misma frecuencia se realizaron 
medidas manuales del volumen tumoral por medio de caliper. La randomización de los animales se llevó adelante por medio de las medidas de BLI debido a que los volúmenes tumorales iniciales eran muy bajos para poder ser medidos con precisión por medio de caliper $\left(\sim 50 \mathrm{~mm}^{3}\right)$. Dicha randomización es un factor muy importante en los ensayos clínicos debido a que coloca a todos los individuos en un mismo estado al momento de iniciar el tratamiento.

Los ratones se dividieron en 4 grupos de 10 individuos cada uno, a saber:

- Grupo 1: corresponde al grupo control de animales sin tratamiento.

- Grupo 2: control de tratamiento utilizando Doxil ${ }^{\mathrm{TM}}$, por su relevancia clínica. Administración por via intravenosa (i.v.), única dosis.

- Grupo 3: control de tratamiento con Doxo administrada por inyección intratumoral (i.t.), control de administración local. Dosis única.

- Grupo 4: tratamiento con membrana de BC implantable conteniendo NLCsH/NLCs-N.

En todos los grupos se pudo observar una cierta tolerabilidad a los tratamientos de acuerdo a los efectos observados en los cambios de peso corporal (Figura 8).

Figura 8. Cambios en el peso corporal de los ratones durante el tratamiento.

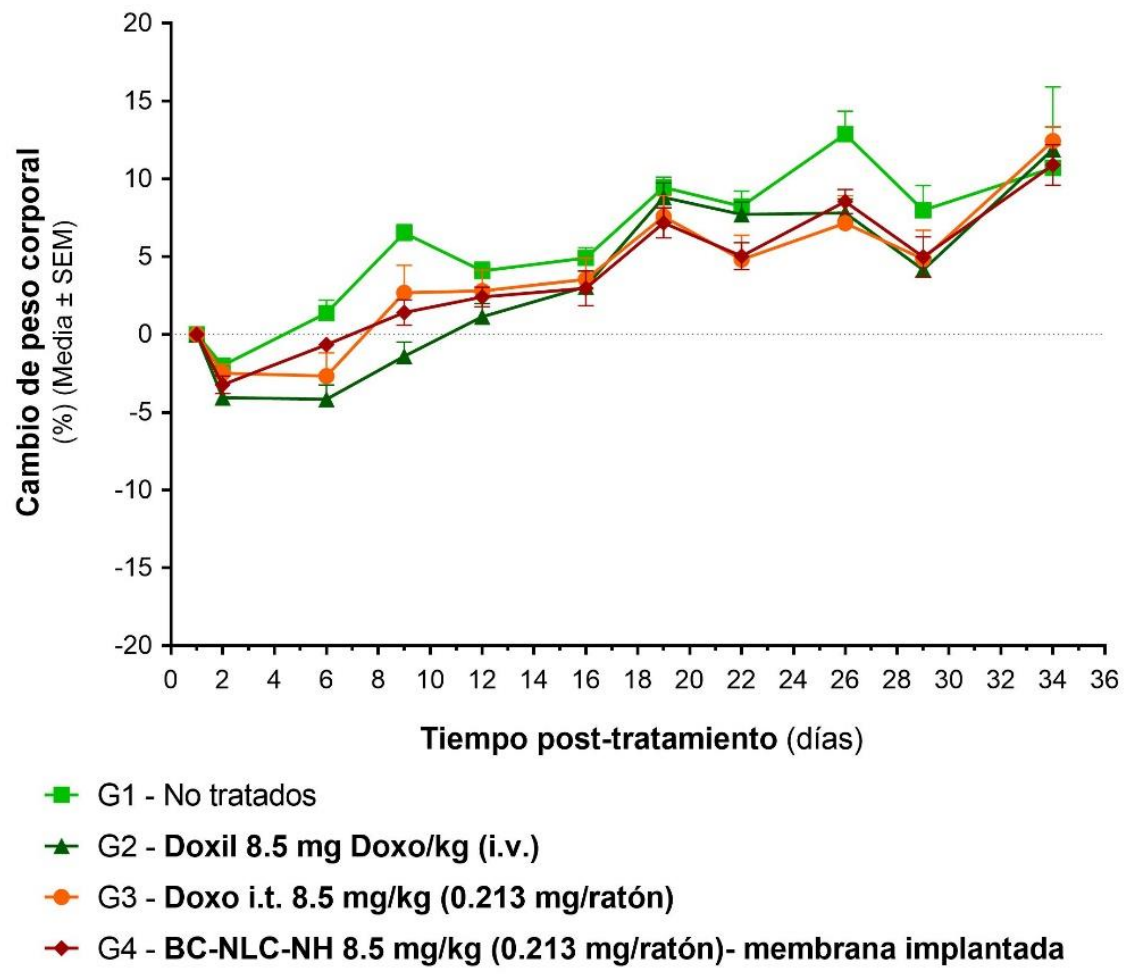


Durante el experimento se evidenciaron efectos secundarios en todos los grupos tratados. En el caso de los animales tratados con Doxil ${ }^{\mathrm{TM}}$ se evidenció un buen efecto anti-proliferativo, pero también edema e inflamación durante los primeros 10 días de tratamiento en los miembros posteriores. Por otro lado, el grupo control correspondiente a la inyección i.t. de Doxo presentó serias lesiones necróticas en la zona de administración a causa de la presencia del fármaco. La vía i.t. suele ser muy efectiva debido a la administración del quimioterapéutico en la zona misma de acción. Sin embargo, los tumores sólidos poseen una densa matriz interna con una elevada presión y por dichas causas la inyección de una solución dentro del tumor suele generar una posterior expulsión de la misma. Consecuentemente, el tejido circundante se ve expuesto a concentraciones excesivamente elevadas de los compuestos citotóxicos sufriendo severos daños como ulceraciones, necrosis, sangrado, dolor, inflamación, entre otros ${ }^{24-26}$.

Finalmente, el grupo correspondiente al tratamiento con los sistemas de BC desarrollados presentó capacidad anti-tumoral sin observarse edemas o inflamación. Sin embargo, se presentó un serio problema de inhibición en la cicatrización de la incisión realizada durante la cirugía. Estos problemas de cicatrización se presentan como uno de los principales inconvenientes a solucionar en tratamientos de tipo localizado contra el cáncer $^{27}$. Existe una incongruencia en la zona del tumor donde los compuestos citotóxicos generan un efecto no solo sobre las células cancerígenas sino también en aquellas propias de la herida post-quirúrgica que debería estar cerrando ${ }^{28}$. En este grupo de animales las heridas encontradas no pudieron cicatrizar a lo largo de todo el experimento. Se observó que las membranas de celulosa permanecieron a modo de parche" sobre la herida evitando comprometer el bienestar y la salud del animal. No se encontraron signos de infección o de dolor durante todo el periodo del ensayo. Sin embargo, se estima que sí se afectó la liberación del fármaco desde la membrana pues, al estar en contacto con el aire exterior, la membrana se fue secando siendo este un factor que afecta la liberación. Un efecto negativo en la cinética de liberación de las NLCs que estaría indudablemente asociado a un menor efecto anti-tumoral.

A continuación, la Figura 9 muestra las curvas de crecimiento para los tumores de los cuatro grupos mencionados. 
Figura 9. Seguimiento del volumen tumoral durante el primer ensayo in vivo. El volumen tumoral se calculó de acuerdo a medidas manuales por medio de caliper (A) y por medio de tomografía computada de los animales (B).

A

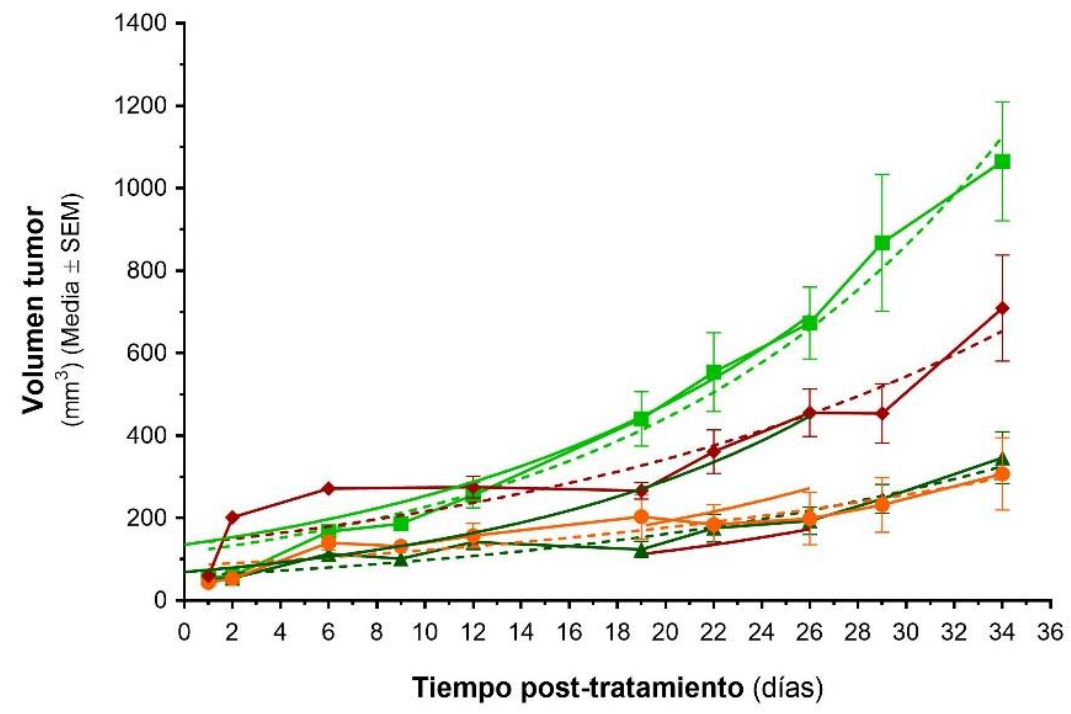

- $\mathrm{G} 1$ - No tratados

$\star \mathrm{G} 2$ - Doxil $8.5 \mathrm{mg} / \mathrm{kg}$ (i.v.)

- G3 - Doxo i.t. $8.5 \mathrm{mg} / \mathrm{kg}(0.213 \mathrm{mg} / \mathrm{ratón})$

$\rightarrow$ G4 - BC-NLC-NH $8.5 \mathrm{mg} / \mathrm{ml}$ (0.213 mg/ratón) - membrana implantada

B

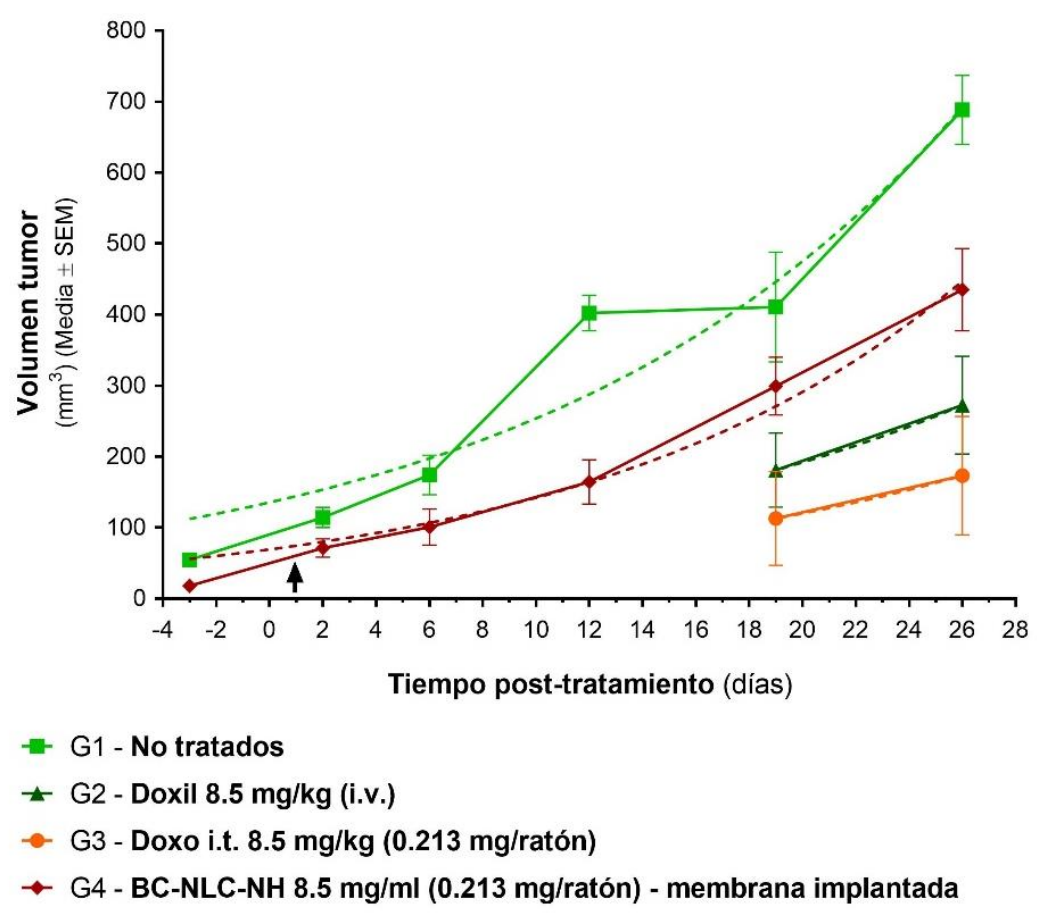

El volumen tumoral se midió por dos técnicas distintas. Por un lado, se midió manualmente por medio de caliper; tomando en cuenta el diámetro mayor y menor del 
tumor se calcula el volumen. Por el otro lado, se tomaron tomografías computadas de los tumores. En este caso, para el cálculo del volumen tumoral también se tiene en cuenta la profundidad del tumor; dicho valor no puede ser medido por caliper. Ambas formas de medición mostraron buena correlación entre sí, como puede observarse en la Figura 9. En todos los tratamientos se pudo observar un efecto anti-proliferativo hacia el tumor incipiente. El tratamiento i.t. con Doxo generó una mejor respuesta observándose valores de volumen tumoral muy bajos y con poco crecimiento en función del tiempo. En grado de efectividad, el segundo lugar lo ocupó la administración i.v. de Doxil $^{\mathrm{TM}}$, seguida de las membranas de $\mathrm{BC}$. Cabe recordar la diferencia considerable en cuanto a la reducción de los efectos adversos entre la membrana de Doxo y la inyección i.t. Además, se pudo advertir que hasta el día 12 de tratamiento los volúmenes tumorales se mantuvieron muy cercanos en todos los grupos tratados.

En paralelo, se fueron realizando las medidas de bioluminiscencia correspondientes una vez a la semana para 5 individuos de cada grupo. La observación de imágenes de bioluminiscencia (BLI) permite tener una visión de la actividad metabólica de las células tumorales $^{29}$. Las células de la línea MDA-MB-231 fueron modificadas de modo recombinante para poder expresar de manera constitutiva el gen Fluc codificante para luciferasa. A continuación, los individuos son inyectados con luceferina, molécula blanco de la luciferasa. Se genera una reacción bioquímica sobre la luciferina catalizada por la enzima utilizando ATP y generando $l u z^{30}$. Este método de medida de la BLI resulta de sumo interés debido a que permite realizar un seguimiento de los tumores de modo no-invasivo. Además, el background de BLI es extremadamente bajo generando un elevado valor en la relación señal/ruido haciendo de esta una herramienta muy sensible para detectar las células marcadas ${ }^{31}$.

Se puede observar en la Figura 10.A la proliferación de los tumores en función del tiempo. El grupo 1, sin tratamiento, presento un rápido aumento en la actividad de las células del tumor hasta el día 19 post-tratamiento. Posteriormente se observa que los tumores de este grupo sufren una caída considerable en la BLI, a pesar de que su volumen tumoral continuaba creciendo según se observó en la Figura 9. Una de las causas probables a ese respecto era la existencia de procesos de necrosis en aumento dentro del tumor ${ }^{29}$, hecho que se pudo observar al evaluar los tumores ex vivo al finalizar el ensayo. Los individuos tratados con Doxil ${ }^{\mathrm{TM}}$ sufrieron un aumento de la BLI igual que el que se presentaba en el control sin tratamiento hasta el día 12. A partir de 
este punto se observó un descenso considerable en la BLI, alcanzando los valores más bajos en comparación con el resto de los grupos.

Figura 10. Medidas de BLI de los ratones pertenecientes a los 4 grupos experimentales.

(A) curvas de BLI cuantificada en función del tiempo de ensayo, (B) imágenes de los animales

A

BLI crecimiento tumoral

(13 min luego de adición de D-luciferina)

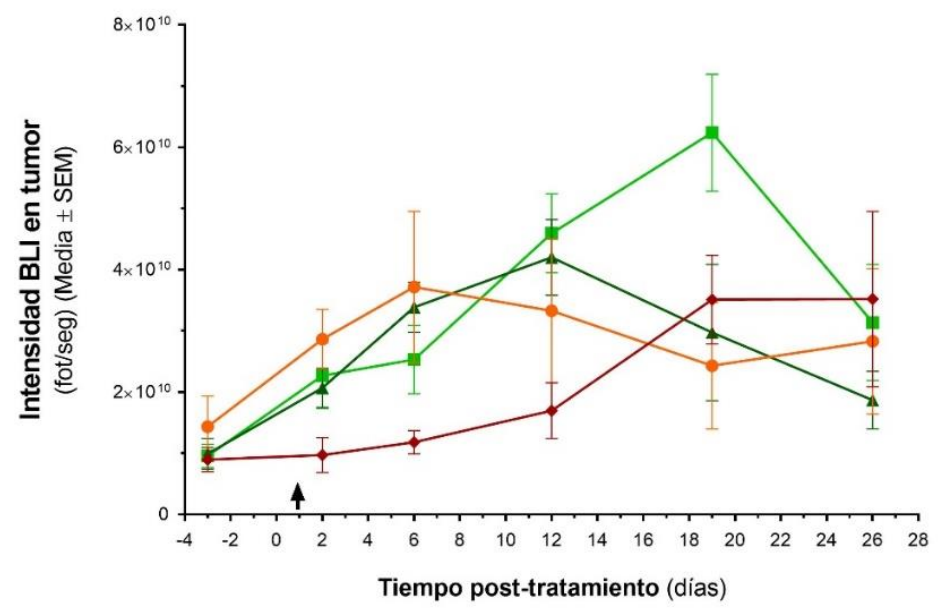

$-\mathrm{G} 1$ - No tratados

$\star \mathrm{G} 2$ - Doxil $8.5 \mathrm{mg} / \mathrm{kg}$ (i.v.)

- G3 - Doxo i.t. $8.5 \mathrm{mg} / \mathrm{kg}(0.213 \mathrm{mg} / \mathrm{ratón})$

$\rightarrow$ G4 - BC-NLC-NH $8.5 \mathrm{mg} / \mathrm{ml}$ (0.213 mg/ratón) - membrana implantada

B

G1

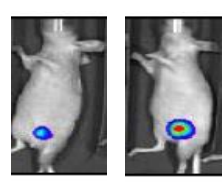

D6

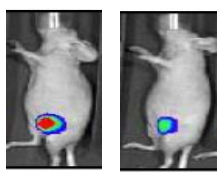

D12

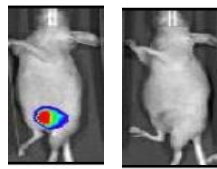

D19

D26
G2
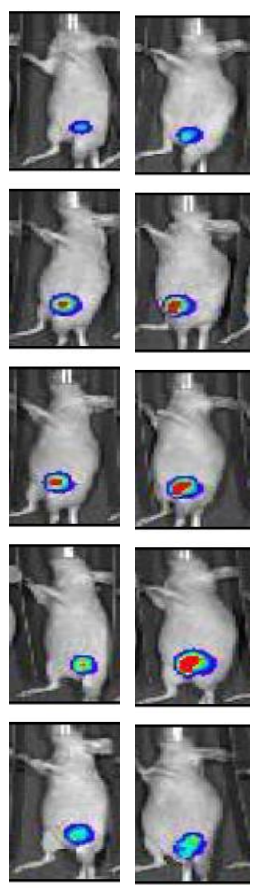

G3
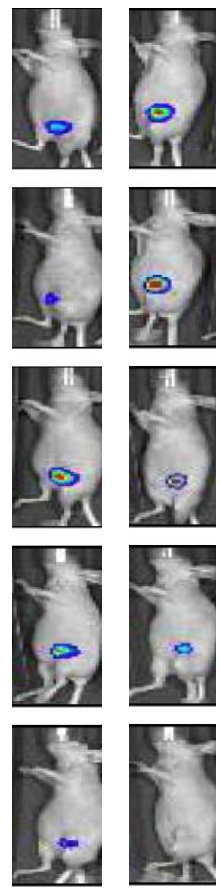

G4
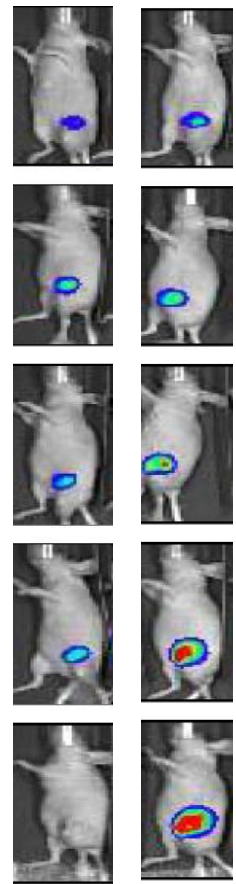
Aquellos animales del grupo 3, tratados con Doxo intratumoral, presentaron un comportamiento similar al Doxil ${ }^{\mathrm{TM}}$ aunque con un perfil de descenso en la BLI desde el día 6 hasta el 19. A partir de aquí se observó un plateau en la medida de BLI, llegando a valores aparentemente de mayor intensidad en comparación con el grupo del Doxil ${ }^{\mathrm{TM}}$. Por último, se puede apreciar lo sucedido en el grupo donde se implantaron las matrices de celulosa. Peculiarmente, en este caso se observaron valores de BLI muy bajos en comparación con el resto de los grupos hasta el día 12, a partir del cual los valores de intensidad aumentan drásticamente hasta el plateau en el día 19.

En la Figura 10.B se pueden observar las imágenes de dos individuos de cada grupo donde se muestra la bioluminiscencia de los tumores con sus respectivos cambios de intensidad.

Lamentablemente, luego de este ensayo quedó pendiente la explicación de porqué los individuos tratados con el sistema implantable presentaron diferencias tan considerables en la BLI durante los primeros días. Se realizaron pruebas para evaluar si la presencia de las membranas podía generar algún tipo de atenuación de la señal, pero no se encontraron cambios considerables en la misma.

Como se mencionara anteriormente, la bioluminiscencia es una función del número de células tumorales metabólicamente activas. Esta habilidad hace que esta herramienta sea de extrema utilidad para evaluar la fisiología del tumor por sobre las medidas tradicionales del volumen tumoral, las cuales incluyen la contribución de células muertas y zonas necróticas ${ }^{29}$.

A continuación, en la Figura 11 se pueden observar las evaluaciones realizadas a los tumores una vez estos fueron extirpados de los ratones en el punto final del ensayo. En este caso, el grupo correspondiente al tratamiento con Doxil ${ }^{\mathrm{TM}}$ no se sacrificó debido a que los animales presentaban una regresión del tumor casi completa y un buen estado de salud. Por tal motivo, se decidió dejarlos con vida para ensayos posteriores. Sumado a esto, el efecto del Doxil ${ }^{\mathrm{TM}}$ fue bastante diferente al de los tratamientos con aplicación local (grupos 3 y 4). Este motivo fue suficiente para considerar continuar trabajando solo con el grupo control (sin tratamiento), el grupo con aplicación i.t. de Doxo y el grupo con implantación de la matriz de celulosa. El análisis ex vivo del volumen tumoral mostró resultados muy similares a los observados mediante las medidas in vivo. En tal sentido, se observó que tanto la aplicación de Doxo por vía i.t. como por medio de la implantación de las membranas permitió obtener una regresión de los tumores en 
comparación con el grupo sin tratamiento. Adicionalmente, se pudieron evidenciar también las diferencias entre el efecto de las membranas y de la inyección i.t. siendo esta ultima la que permitió obtener volúmenes más pequeños. Estos resultados se correlacionaron directamente con lo observado con los pesos de los tumores, como se puede apreciar en la Figura 11.B. Por último, la Figura 11.C muestra las imágenes tomadas de los tumores extirpados donde claramente se puedo observar el efecto antitumoral de los dos tratamientos arriba mencionados.

Figura 11. Análisis ex vivo de los tumores realizados al finalizar el ensayo. Se muestran los gráficos correspondientes al volumen tumoral (A) y al peso de los tumores (B), para los grupos control, Doxo i.t. y con la implantación del sistema de BC. También se pueden observar las imágenes correspondientes a los tumores para los mismos grupos mencionados (C).

A

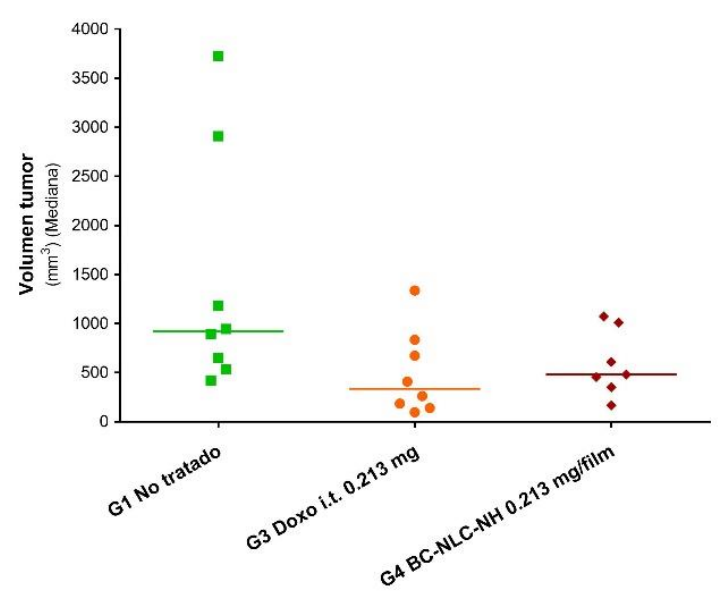

B

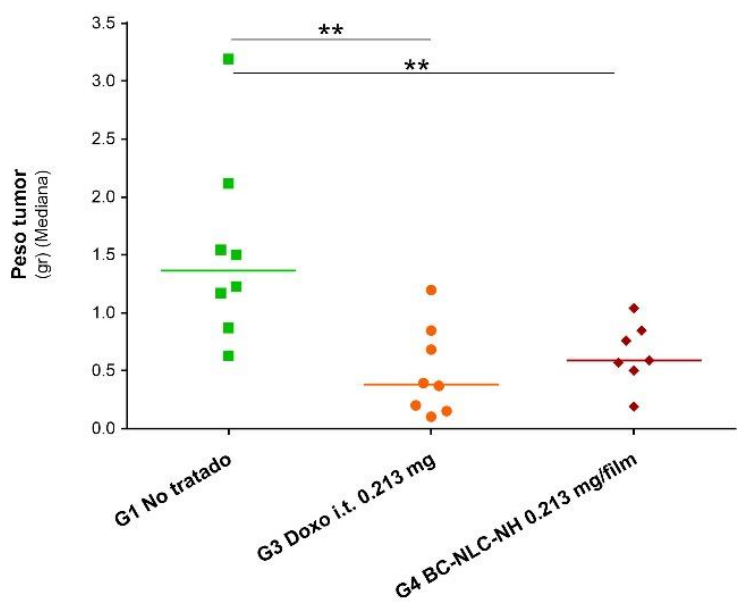

$\mathrm{C}$

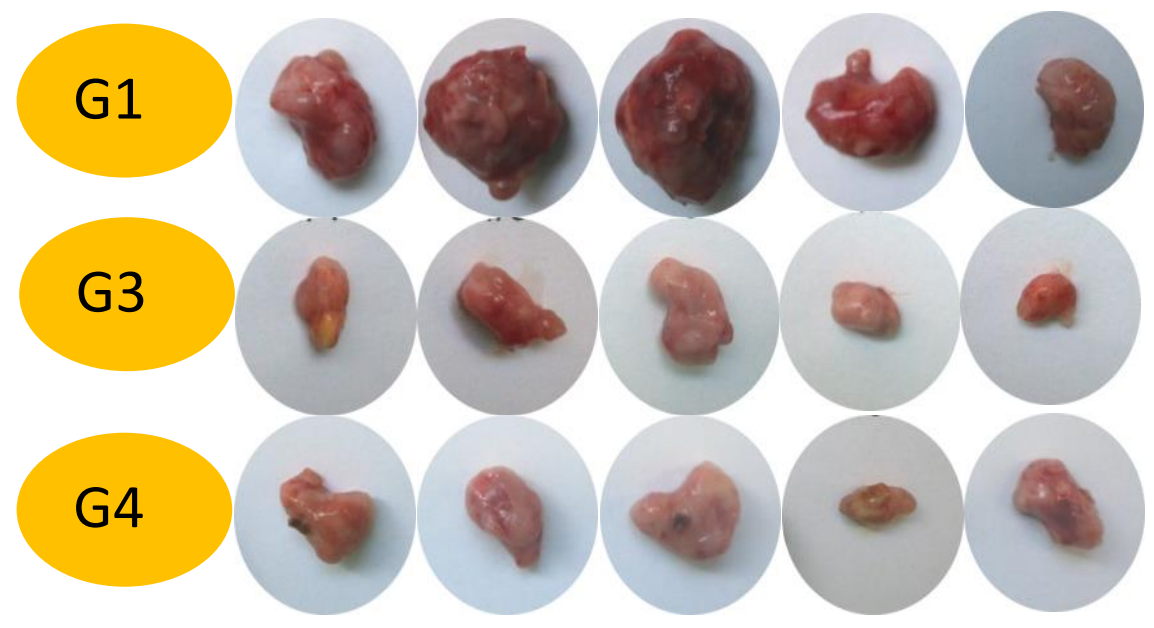


A continuación, se estudiaron las incidencias correspondientes al grado de metástasis en los individuos. La tabla IV muestra los valores relativos de las incidencias encontradas al analizar los individuos post-mortem. Se encontró diseminación de metástasis por vía hematógena (pulmones) y linfática (LN lumbar), especialmente en el grupo control. Los grupos con los tratamientos locales demostraron disminuir considerablemente el grado de metástasis. Como consecuencia de estos resultados se pudo sugerir que la administración localizada del quimioterapéutico no solo tiene un efecto en la zona de aplicación, sino que también existe la posibilidad de generarlo en la vía sistémica.

Tabla IV. Grados de incidencias de metástasis observados de manera macroscópica durante la necropsia al finalizar el ensayo.

\begin{tabular}{cccc}
\hline \multicolumn{4}{c}{ Incidencia macroscópica de metástasis $\left[\%,\left(\mathbf{n} / \mathbf{n}_{\mathrm{T}}\right)\right]$} \\
\hline G1 & G3 & G4 \\
\hline Diseminación hematologica & & $0(0 / 8)$ & $0(0 / 9)$ \\
\hline Pulmón & $14(1 / 7)$ & & $11(1 / 9)$ \\
\hline Diseminación linfatica & & $0(0 / 8)$ & $89(8 / 9)$ \\
\hline Linfonodo Lumbar & $43(3 / 7)$ & $88(7 / 8)$ & \\
\hline $\begin{array}{c}\text { Linfonodo axilar } \\
\text { (inflamación) }\end{array}$ & $71(5 / 7)$ & & \\
\hline
\end{tabular}

Finalmente, se analizaron los efectos adversos que pudieron sufrir los individuos con los diferentes tratamientos. Se evaluaron los pesos de los corazones y pulmones como medidas indirectas de daño en el órgano. Se detectó un aumento en la media del peso del corazón para el grupo tratado con Doxo i.t. pero las diferencias no fueron estadísticamente significativas (Figura 12). Por otro lado, no se encontraron variaciones en el peso de los pulmones en comparación con el control. 
Figura 12. Evaluación del peso de corazón (A) y pulmones (B) para analizar daño en órganos.

A

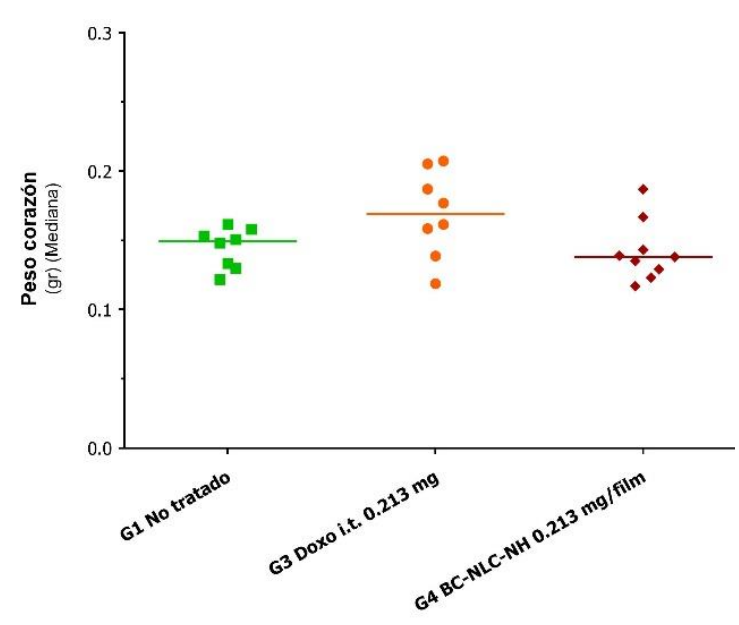

$\mathrm{B}$

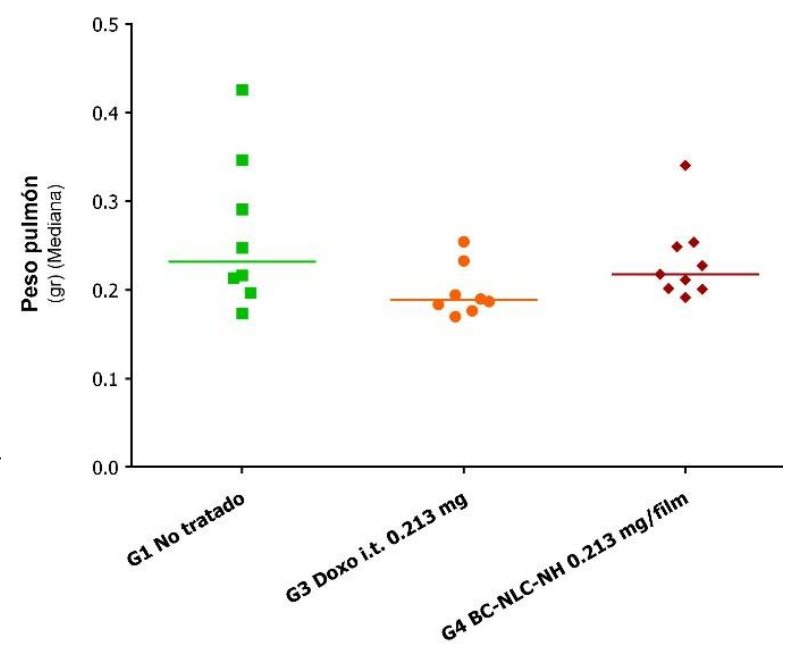

\subsubsection{Segundo ensayo in vivo}

Se planteó un segundo ensayo in vivo con las mismas características generales que en el primero. En este caso se expusieron los siguientes desafíos:

1- Mejorar la capacidad de inhibición del crecimiento tumoral para las membranas BC-

NLCs respecto de la administración intratumoral de Doxo.

2- Reducir los efectos secundarios del tratamiento

3- Mejorar la capacidad de cicatrización en la zona de implantación de la matriz.

De la misma manera que en el ensayo anterior, se procedió a generar los tumores a

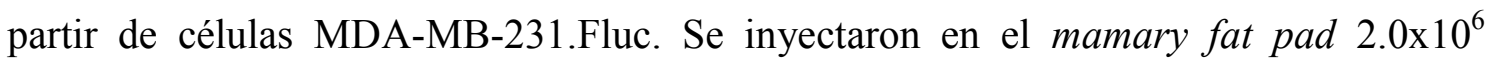
células por animal y se permitió proliferar hasta alcanzar un volumen medio de 120 $\mathrm{mm}^{3}$. Se esperó a que los tumores alcancen este tamaño para poder medirlos bien por caliper y además de manera de poder evaluar más un efecto inhibidor del crecimiento tumoral por parte del sistema de BC. Como en el ensayo 1 se comenzó el tratamiento con tumores muy pequeños $\left(50 \mathrm{~mm}^{3}\right)$, consideramos que en ese caso se realizó una evaluación más enfocada en el efecto preventivo del sistema sobre los tumores.

Al comenzar el tratamiento, la randomización se llevó adelante por medio de la medida convencional del volumen tumoral. Seguido se realizaron algunos ajustes en el protocolo de implantación de las matrices de $\mathrm{BC}$ de manera de evitar la liberación del fármaco durante la cirugía. Los ajustes mencionados incluyen una deshidratación parcial de las membranas seguido por dos lavados exhaustivos con agua bidestilada 
antes de la implantación. Además, en la zona de implantación se abrió bien el espacio entre el tejido conectivo de manera de permitir que la membrana pueda ingresar correctamente. A continuación, ya con la membrana implantada, la zona se lavó con solución fisiológica. Por último, se realizaron varios puntos de sutura cerrando bien la herida con la ayuda de Histoacryl ${ }^{\circledR}$, un pegamento utilizado para tal fin. La Figura 13 resume el procedimiento de implantación de las matrices de $\mathrm{BC}$ sobre la zona del tumor.

Figura 13. Fotografías tomadas durante una cirugía de implantación de las matrices.
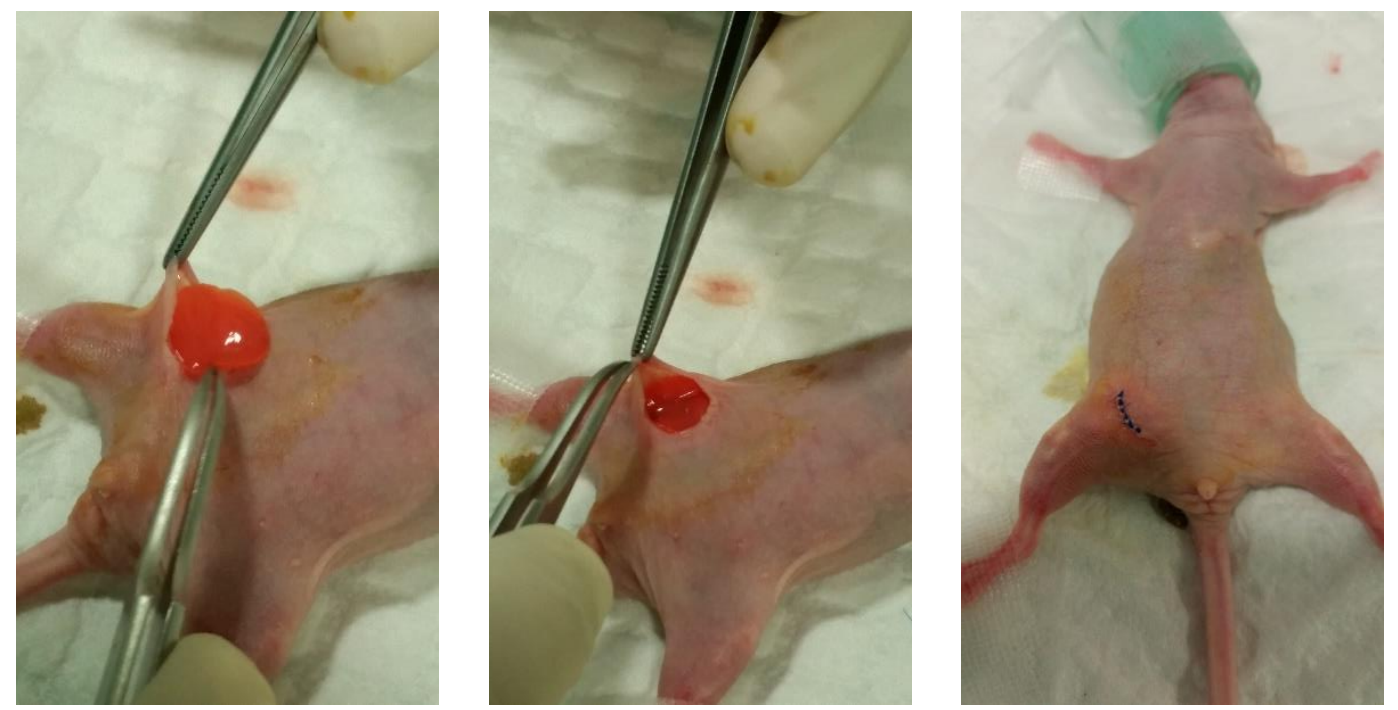

Otro de los cambios que se realizaron fue disminuir la dosis utilizada a 5,6 mg/Kg, de manera de que los individuos sufrieran menos efectos adversos.

Como consecuencia de los ajustes mencionados las heridas permanecieron cerradas durante los primeros 10 días post-tratamiento. Luego, las suturas se empezaron a abrir y las heridas volvieron a permanecer abiertas. Sin embargo, el tamaño de las mismas fue menor en comparación con las del primer ensayo. Algunas de las heridas incluso llegaron a cerrarse por completo durante las etapas finales del tratamiento.

A lo largo del ensayo se monitoreó el peso de los animales, como se muestra en la Figura 14. No se observaron cambios abruptos en el peso de los individuos de los diferentes grupos, esto sugirió que se conservó el bienestar y la salud de los animales. Sumado a esto, los animales no presentaron signos observables de efectos adversos como consecuencia de los tratamientos. Luego, las Figuras 15A y 15B exponen el crecimiento tumoral expresado en volumen del tumor medido de forma convencional y por CT, respectivamente. Se pudo observar que ambos tratamientos aplicados generaron un efecto anti-proliferativo sobre los tumores. Además, se presentó una buena 
correlación entre los datos observados por medio de las mediciones por caliper y CT para todos los grupos. En las medidas de CT se observó un distanciamiento mayor entre las curvas correspondientes a Doxo i.t y a BC-NLCs-NH. Tal distanciamiento expresa un mejor efecto por parte de la vía i.t. Sin embargo, cabe remarcar que el efecto obtenido por medio de las membranas BC-NLCs-NH fue mucho mejor en comparación al primer ensayo teniendo en cuenta que fue prácticamente igual al de la agresiva administración intratumoral del fármaco libre.

Figura 14. Medidas de los cambios en el peso corporal de los animales durante todo el ensayo.

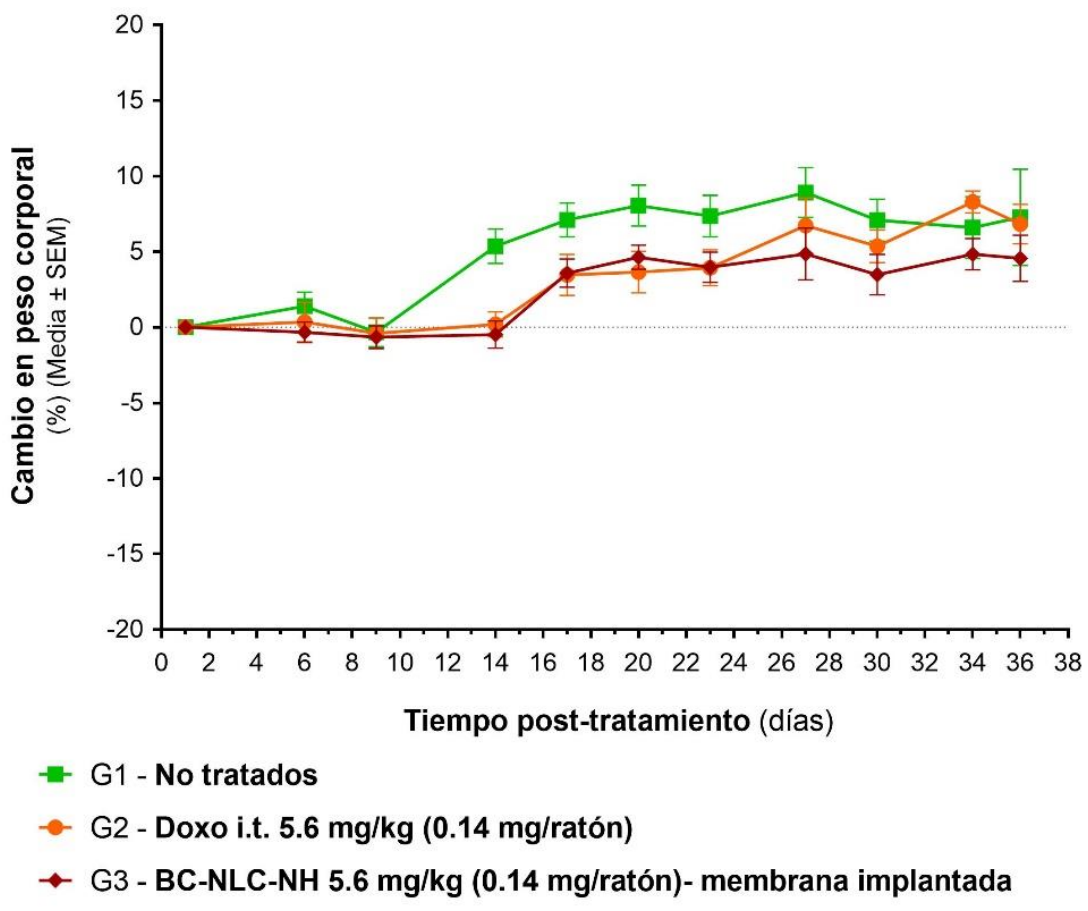


Figura 15. Crecimiento del volumen tumoral medido de manera convencional (A) y por CT (B).

A

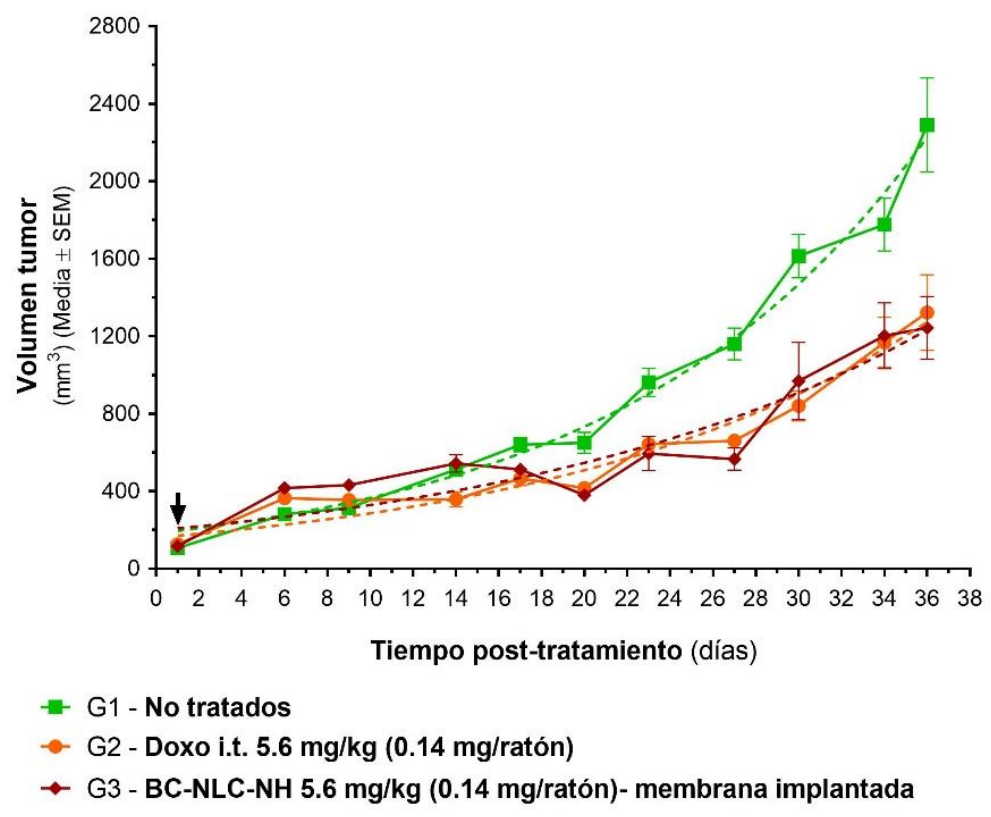

B

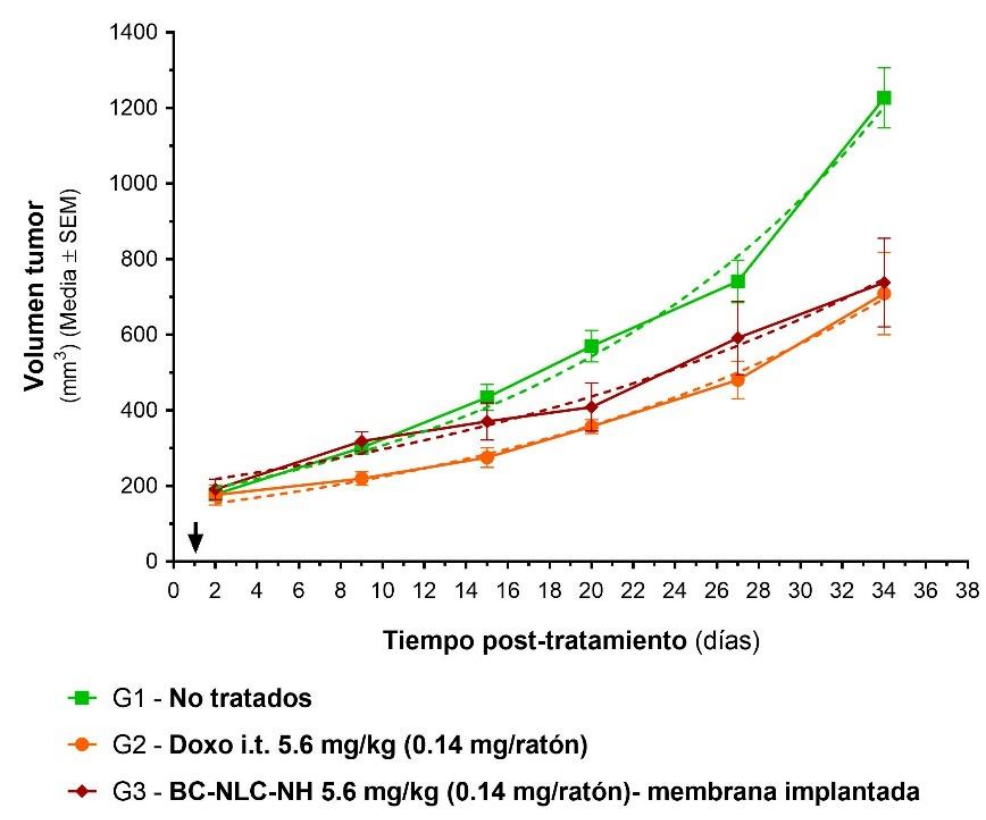

De la misma manera que en el ensayo anterior, el volumen y peso de los tumores fue valorado al finalizar en ensayo (ex vivo). Estas medidas ayudaron a comprender mejor, y de una manera más directa, la efectividad del tratamiento con BC-NLCs-NH y del control i.t. En la Figura 16 se pueden observar las medias correspondientes tanto al peso como al volumen tumoral. Los resultados demostraron una correcta correlación con lo valorado in vivo durante todo el ensayo. En este sentido, el control i.t. resultó ser 
más efectivo sin distanciarse demasiado del efecto anti-tumoral que tuvieron las membranas BC-NLCs. La Figura 16C permite observar el tamaño de los tumores para cada grupo al final del ensayo.

Figura 16. Análisis ex vivo de los tumores realizados al finalizar el ensayo. Se muestran los gráficos correspondientes al volumen tumoral (A) y al peso de los tumores (B), para los grupos control, Doxo i.t. y con la implantación del sistema de BC. (C) Fotografías de los tumores al final del ensayo.

A

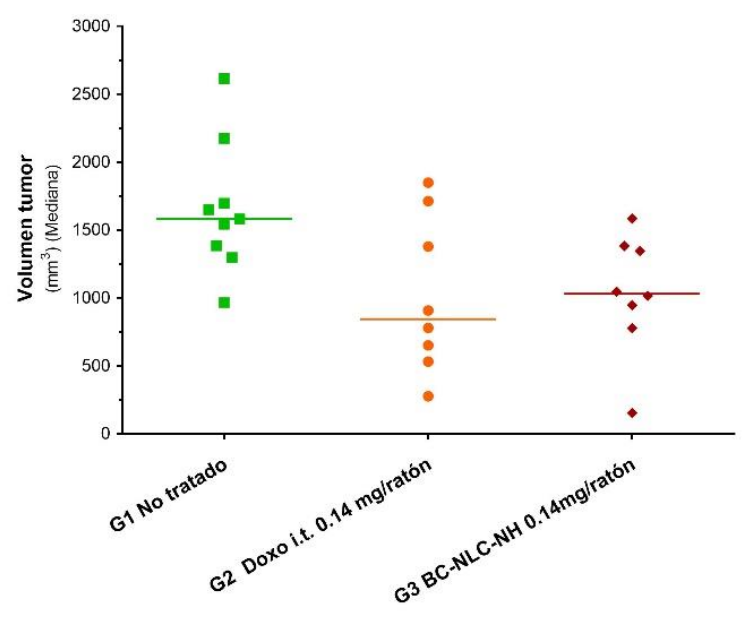

B

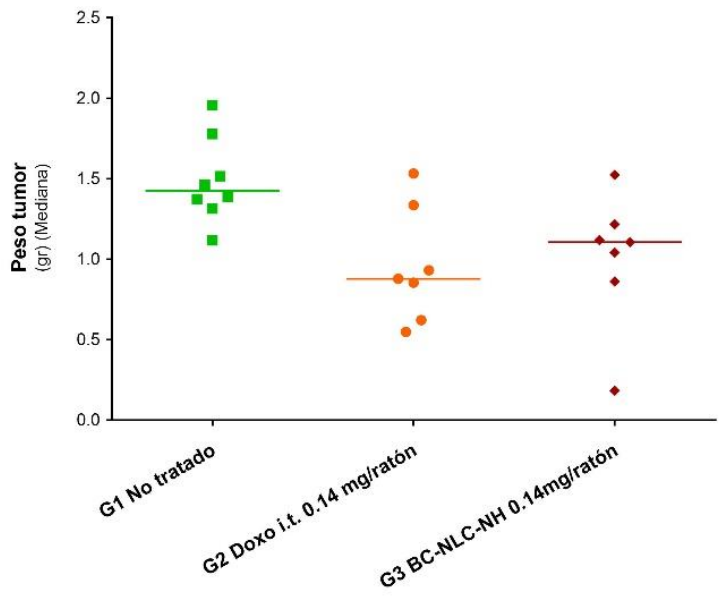

C

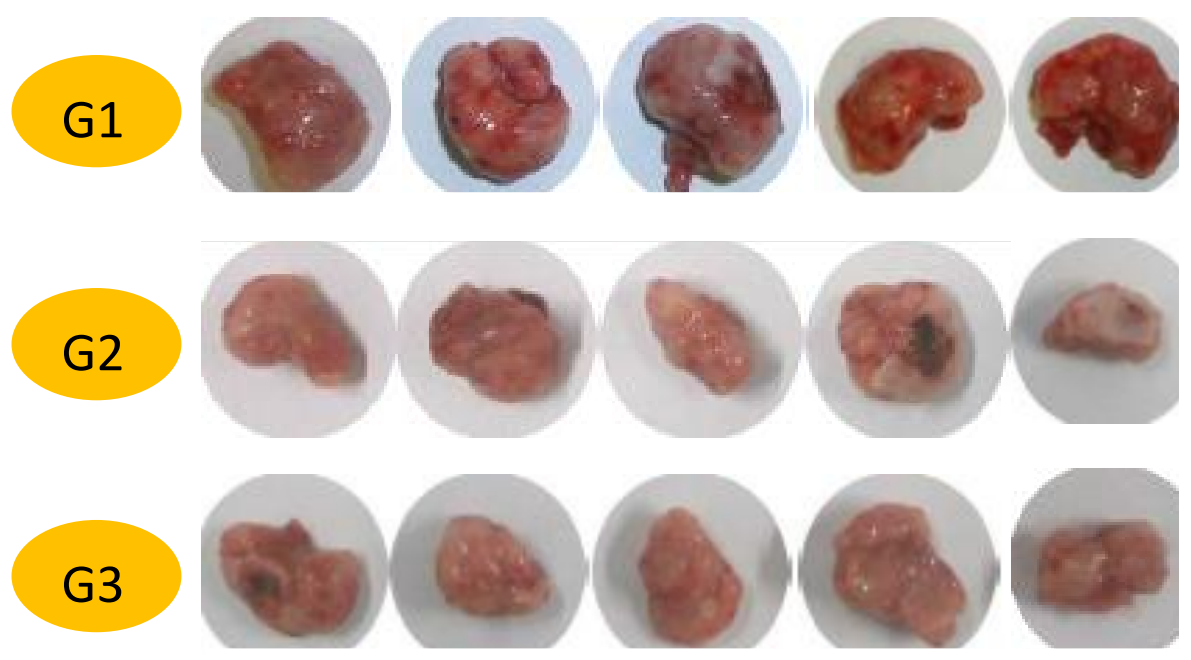

A continuación, en la Tabla $\mathbf{V}$ se presentan los cálculos de la relación $\mathrm{T} / \mathrm{C}$ realizados ex vivo para el volumen y peso de los tumores. Los valores de $\mathrm{T} / \mathrm{C}$ corresponden a la relación entre la media de los datos del Tumor (T) vs. el Control sin tratamiento (C). Como se puede observar el índice de efectividad del tratamiento con BC-NLCs-NH mejoró en el segundo ensayo tanto para los valores de volumen como de peso. Los aumentos en T/C para la administración i.t. (G2) fueron debidos a la disminución en la 
dosis utilizada para el ensayo dos. En contraste, no se registró un cambio de T/C para las medidas de volumen tumoral en el grupo correspondiente a las membranas de BC. Existe la posibilidad que durante el primer ensayo, los problemas en el proceso de implantación así como en la cicatrización de las heridas, hayan colaborado en generar una disminución de la efectividad del tratamiento para este caso. Como ya se ha mencionado, en el segundo ensayo se optimizaron estas variables permitiendo mejorar la efectividad del tratamiento y disminuir los inconvenientes generados por el mismo sobre los individuos.

Tabla V. Comparación en la relación T/C para el volumen tumoral medido por caliper ex vivo al final del ensayo. Se muestran los valores correspondientes para el ensayo 1 y 2 .

\section{Volumen tumoral Peso tumoral}

\begin{tabular}{cccccccc}
\hline------- & ------- & G1 & G2 & G3 & G1 & G2 & G3 \\
\hline Ensayo 1 & Relación T/C (\%) & 100 & 36 & 66 & 100 & 28 & 56 \\
\hline Ensayo 2 & Relación T/C (\%) & 100 & 49 & 66 & 100 & 62 & 81 \\
\hline
\end{tabular}

A modo de continuar analizando los resultados del segundo ensayo y compararlos con los resultados del primero, se analizó una serie de parámetros que permitieron determinar el éxito terapéutico en cada caso. Los resultados fueron expresados en la Tabla VI para las medidas tomadas de manera convencional y para las medidas tomadas por CT. Los valores de los parámetros permitieron sugerir que en el ensayo 1, los tratamientos posibilitaron retrasar el crecimiento tumoral considerablemente. Por su parte, la administración intratumoral resultó en un tratamiento más efectivo en comparación con las matrices BC-NLCs-NH implantadas con un tiempo de duplicación de 18,64 días y 15,04 días, respectivamente. Además, en la Doxo i.t. se observó un retraso en el crecimiento del tumor mayor que en el grupo de las membranas (AGD, 8 vs. 5). Es importante mencionar que los valores correspondientes a las medidas de CT no se tuvieron en cuenta debido a que no se poseían datos suficientes para evaluar los parámetros correctamente. Por otro lado, en el ensayo 2 se vio invertida la tendencia en cuanto a la efectividad del tratamiento. De acuerdo a las medidas realizadas por el método convencional, el grupo 3 correspondiente a BC-NLCs-NH mostró valores mayores en los parámetros calculados (Td, 13,64; AGD, 4; log cell kill, 0,088) en comparación con el grupo 2 de la Doxo i.t. (Td, 12,22; AGD, 2; log cell kill, 0,049). 
Cabe remarcar que en los valores de los parámetros calculados con las medidas de CT se observó una marcada diferencia entre ambos tratamientos. En tal sentido, se evidenció un aumento de casi un $25 \%$ en el Td para el grupo tratado con BC-NLCs-NH en comparación con el tratado con Doxo i.t. Además, el valor de AGD se triplicó desde 2 (Doxo i.t) hasta 6 (BC-NLCs-NH). Finalmente, los valores de tog cell kill" mostraron que el tratamiento con BC-NLCs-NH habría, teóricamente, matado a más del doble de células tumorales proliferativas (Tabla VI). Entonces, para este segundo ensayo se puede sugerir que el tratamiento con las membranas BC-NLCs-NH mostró una cierta efectividad terapéutica, la cual fue mayor o al menos igual que la administración intratumoral del fármaco.

Tabla VI. Valores relativos a las curvas de crecimiento tumoral para las medidas tomadas mediante caliper (convencional) y tomografía computada (CT). Los parámetros calculados fueron el tiempo de duplicación (Td), Absolute Growth Delay (AGD) y log cell kill.

\section{Ensayo 1}

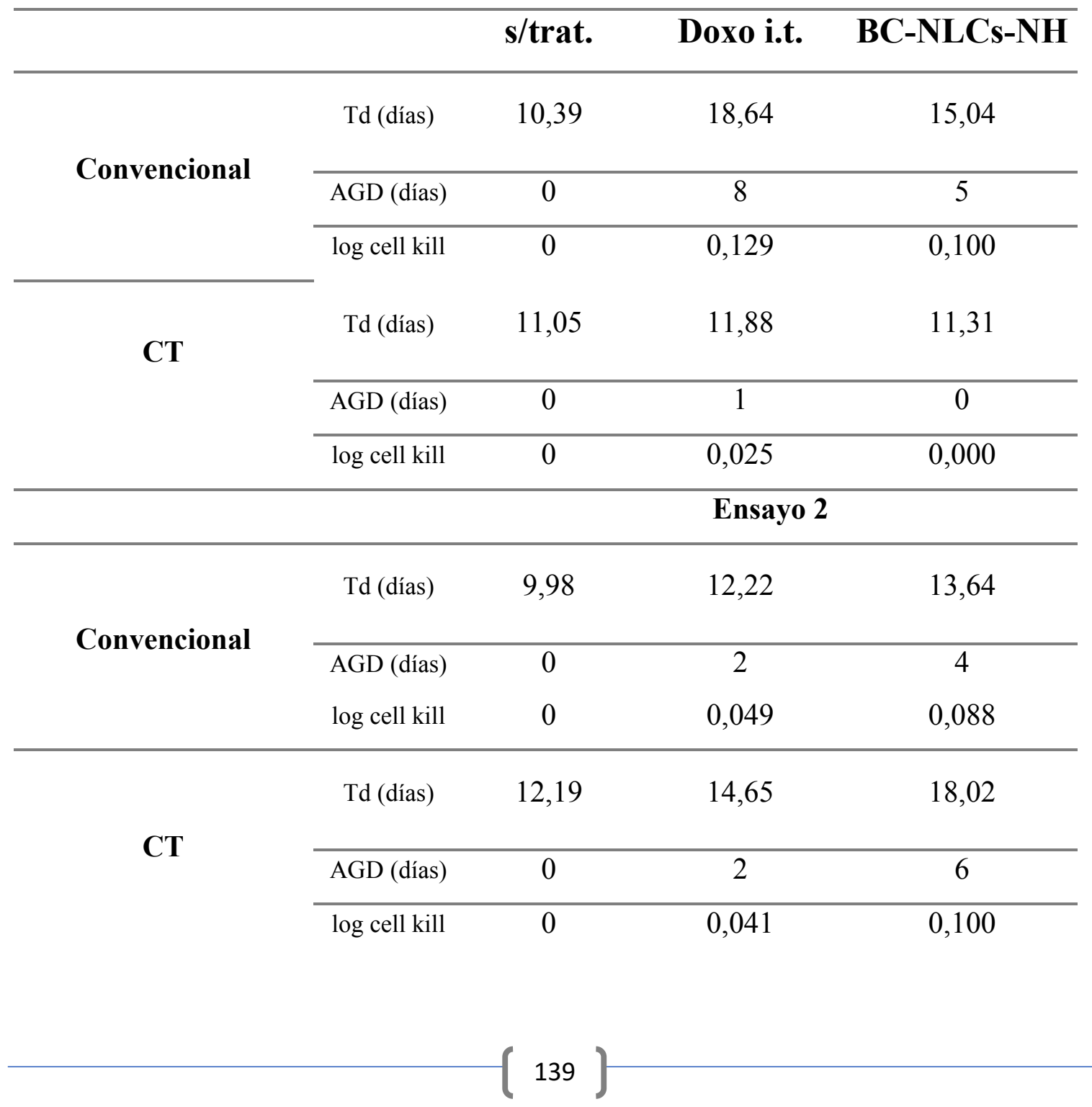


Al finalizar el ensayo, también se evaluaron las incidencias macroscópicas de metástasis en cada uno de los individuos (Tabla VII). Se pudieron detectar tres vías de diseminación, la vía locoregional que corresponde a la cadena mamaria en sí, la vía hematológica que corresponde a la diseminación del cáncer a los tumores y la vía linfática que involucra principalmente a los nodos lumbares por una cuestión de cercanía con el tumor. En el caso del grupo control, se observaron metástasis en todas las vías mencionadas especialmente en el caso de la vía linfática donde se encontraron diseminaciones en un $44 \%$ de los casos. Los tratamientos locales mostraron un gran efecto anti-metástasis disminuyendo el grado de incidencias considerablemente, como se puede apreciar en la Tabla VII. Esto último, es en coincidencia con lo evaluado en el ensayo 1. Y permite confirmar que la administración localizada del fármaco genera un efecto no sólo locoregional sobre el tumor sino también que genera un efecto de inhibición en la metástasis.

Tabla VII. Grados de incidencias de metástasis observados de manera macroscópica durante la necropsia al finalizar el ensayo.

\begin{tabular}{cccc}
\hline \multicolumn{4}{c}{ Incidencia macroscópica de metástasis $\left[\%,\left(\mathbf{n} / \mathbf{n}_{\mathrm{T}}\right)\right]$} \\
\hline G1 & G2 & G3 \\
\hline Diseminación locoregional & & $11(1 / 9)$ & $0(0 / 9)$ \\
\hline Cadena mamaria & $22(2 / 9)$ & & $11(1 / 9)$ \\
\hline Diseminación hematologica & & $0(0 / 9)$ & $11(1 / 9)$
\end{tabular}

Por último, se evaluó el peso de los corazones y pulmones ex vivo para valorar indirectamente los efectos adversos de los tratamientos sobre estos órganos (Figura 17). A pesar de observarse que la relación T/C de los corazones fue mayor para los tratamientos (G2 y G3), especialmente para el caso de la administración i.t. (Tabla VII), no se detectaron diferencias significativas entre los grupos. Por otro lado, no se observaron cambios significativos en los valores de T/C para los pulmones. 
Figura 17. Peso ex vivo del corazón (A) y pulmón (B) de los animales al final del ensayo.

A

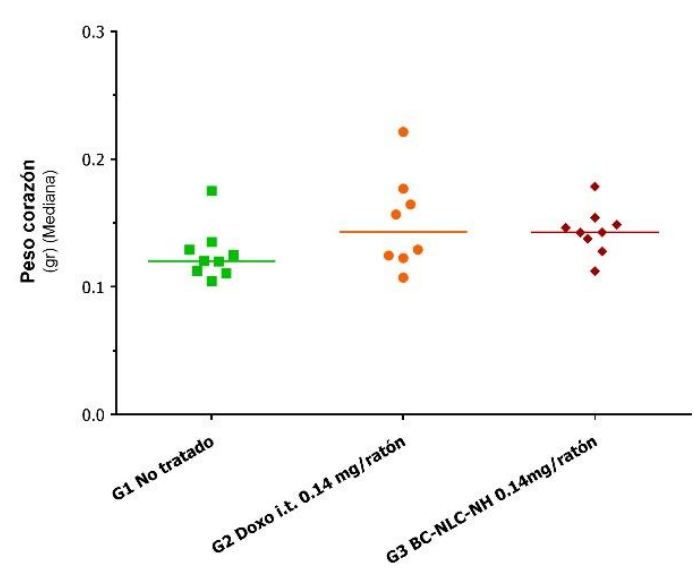

B

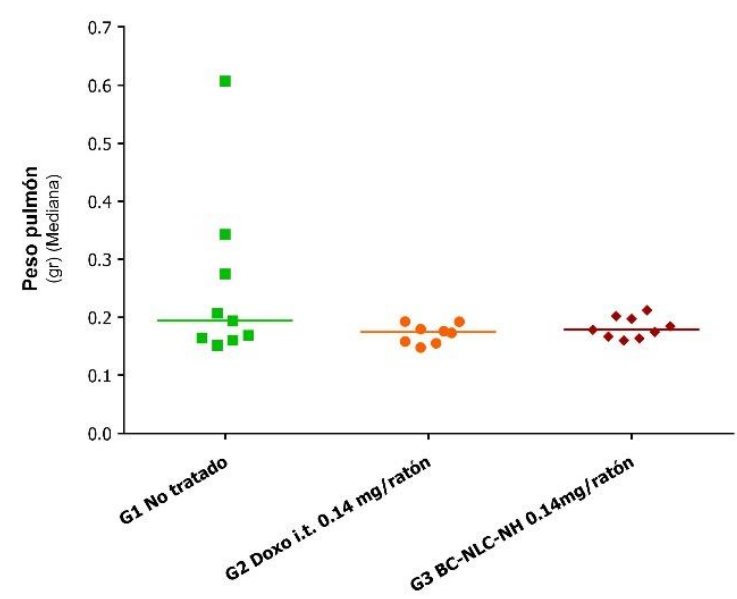

Tabla VII. Calculo de la relación T/C porcentual para los pesos de los corazones y pulmones ex vivo.

\begin{tabular}{cccc}
\hline \multicolumn{4}{c}{ Relación T/C } \\
\hline---- & G1 & G2 & G3 vivo \\
\hline T/C Corazón (\%) & 100 & 130 & 119 \\
\hline T/C Pulmón (\%) & 100 & 91 & 92 \\
\hline
\end{tabular}

\subsection{Conclusiones}

En el presente trabajo se ha observado la posibilidad de integrar una formulación terapéutica de nanopartículas junto con una matriz polimérica de hidrogel. La matriz hibrida ha demostrado una buena capacidad de encapsulación del fármaco y una liberación sostenida en el tiempo. Se ha tomado como punto de comparación la carga de Doxo libre, demostrando un considerable aumento en la eficiencia de encapsulación al utilizarse las nanopartículas. Además, se ha establecido la encapsulación de una formulación mixta utilizando NLCs-H y NLCs-N. Esto permitió modular los perfiles de liberación obteniendo las propiedades características de ambas formulaciones. La presencia de Doxo libre en las NLCs-H ayudó a obtener un burst inicial relativamente alto para garantizar un primer golpe" terapéutico. Luego las NLCs-H y NLCs-N con sus diferentes velocidades de liberación del fármaco permitieron garantizar una 
concentración terapéutica efectiva a lo largo del tiempo, a la vez que también se logró obtener un periodo de liberación prolongado superando un tiempo de 4 semanas. Las técnicas de microscopia electrónica permitieron observar la presencia y morfología de las NLCs dentro de la matriz de BC. También se demostró que las NLCs liberadas desde la matriz conservaban su morfología esférica y tamaño. Estos ensayos permitieron llegar a la conclusión de que la matriz hibrida desarrollada (BC-NLCs-NH) contenía una significativa potencialidad terapéutica que necesitaba ser evaluada en un modelo tumoral in vivo. En consecuencia, se generó un modelo tumoral ortotópico mediante la implantación i.m.f.p. de células MDA-MB-231. Se monitoreó el crecimiento tumoral y la salud de los animales durante las primeras dos semanas. Luego se procedió a implantar las membranas BC-NLCs-NH mediante un protocolo establecido. Se continuó monitoreando el volumen tumoral mediante medidas convencionales y con CT. Se realizaron dos ensayos observándose resultados diferentes. En el primer ensayo, se utilizó una dosis de $8.5 \mathrm{mg} / \mathrm{Kg}$ exhibiendo efectos adversos de relativa gravedad para el tratamiento con BC-NLCs-NH y los tratamientos control (Doxo i.t. y Doxil). Se observó una efectividad antitumoral de las BC-NLCs-NH, pero menor a la de la Doxo i.t. En el segundo ensayo, se observó que la utilización de una dosis un poco menor $(5.6 \mathrm{mg} / \mathrm{Kg})$ disminuyó los efectos adversos observados (necrosis, ulceraciones, dolor, inflamación, edema). Por otro lado, en ambos ensayos se estableció la presencia de un problema habitual para aquellos sistemas de liberación local de quimioterapéuticos. Dicho problema consiste en una deficiencia en la capacidad de cicatrización de la herida postquirúrgica. El responsable es el efecto del agente citotóxico sobre las células encargadas de la cicatrización, lo cual además puede desencadenar en infecciones locales graves. En el primer ensayo se observó una importante inhibición de la cicatrización en todos los animales tratados con las membranas. Para el segundo ensayo se realizaron ajustes en el protocolo de implantación tales como el lavado de la membrana y parcial deshidratación antes de su implantación, la utilización de varios puntos de sutura, así como también la colocación del pegamento de sutura Histoacryl ${ }^{\circledR}$. Dichas medidas garantizaron que las heridas permanezcan cerradas en todos los casos durante los primeros diez días post-implantación. Luego, algunas de ellas de abrieron cicatrizando en el transcurso del ensayo. Otras permanecieron abiertas, pero con un tamaño considerablemente menor al observado en el primer ensayo. Como conclusión parcial, se pudo reducir este efecto indeseado tan habitual en los sistemas quimioterapéuticos implantados. Adicionalmente, se calculó la efectividad terapéutica mediante parámetros 
tales como Td, AGD y log cell kill. Se pudo observar que en el segundo ensayo estos parámetros mostraron una mejor efectividad terapéutica para el sistema BC-NLCs-NH, en comparación con la Doxo i.t. Este efecto fue inverso en el caso del primer ensayo. Además, se observó un efecto antitumoral no solo locoregional sino también sobre la inhibición de procesos de metástasis en la misma cadena mamaria y sobre las vías hematógena y linfática. Los mencionados resultados permiten concluir que el sistema BC-NLCs-NH posee una cierta efectividad terapéutica comparable con la administración i.t. del fármaco. Las inyecciones i.t. no suelen ser muy utilizadas en la clínica por los efectos colaterales que suelen presentarse, especialmente en el área de inyección ${ }^{24-26}$. El sistema BC-NLCs-NH presenta una opción como matriz polimérica a ser utilizada como sistema de liberación controlada para aplicación local. Podría ser utilizado en aquellos casos donde el tumor solido es inoperable o también donde, previo a la extirpación del tumor, se necesita generar un efecto anti-neoplásico.

\subsection{Referencias}

(1) Gao, W.; Zhang, Y.; Zhang, Q.; Zhang, L. Nanoparticle-Hydrogel: A Hybrid Biomaterial System for Localized Drug Delivery. Ann. Biomed. Eng. 2016, 44 (6), 2049-2061.

(2) Van Vlierberghe, S.; Dubruel, P.; Schacht, E. Biopolymer-Based Hydrogels as Scaffolds for Tissue Engineering Applications: A Review. Biomacromolecules 2011, 12 (5), 1387-1408.

(3) Khademhosseini, A.; Langer, R. Microengineered Hydrogels for Tissue Engineering. Biomaterials 2007, 28 (34), 5087-5092.

(4) Shi, J.; Votruba, A. R.; Farokhzad, O. C.; Langer, R. Nanotechnology in Drug Delivery and Tissue Engineering: From Discovery to Applications. Nano Lett. 2010, 10 (9), 3223-3230. Dvir, T.; Timko, B. P.; Kohane, D. S.; Langer, R. Nanotechnological Strategies for Engineering Complex Tissues. Nat. Nanotechnol. 2011, 6 (1), 13-22.

(6) Dang, T. T.; Thai, A. V.; Cohen, J.; Slosberg, J. E.; Siniakowicz, K.; Doloff, J. C.; Ma, M.; Hollister-Lock, J.; Tang, K. M.; Gu, Z.; Cheng, H.; Weir, G. C.; Langer, R.; Anderson, D. G. Enhanced Function of Immuno-Isolated Islets in Diabetes Therapy Byco-Encapsulation with an Anti-Inflammatory Drug. Biomaterials 2013, 34 (23), 5792-5801.

(7) Zhang, J.; Zhao, L.; Zhang, J.; Zhang, Z.; Le, Y.; Wen, N.; Wang, J. In Situ Incorporation of Monodisperse Drug Nanoparticles into Hydrogel Scaffolds for Hydrophobic Drug Release. $J$. Appl. Polym. Sci. 2016, 133 (10), 1-6.

(8) Sethi, M.; Sukumar, R.; Karve, S.; Werner, M. E.; Wang, E. C.; Moore, D. T.; Kowalczyk, S. R.; Zhang, L.; Wang, A. Z. Effect of Drug Release Kinetics on Nanoparticle Therapeutic Efficacy and Toxicity. Nanoscale 2014, 6 (4), 2321-2327. 
(9) Beck, R.; Röper, B.; Carlsen, J. M.; Huisman, M. C.; Lebschi, J. A.; Andratschke, N.; Picchio, M.; Souvatzoglou, M.; Machulla, H.-J.; Piert, M. Pretreatment 18F-FAZA PET Predicts Success of Hypoxia-Directed Radiochemotherapy Using Tirapazamine. J Nucl Med 2007, 48 (6), $973-$ 980.

(10) Papadopoulou, M. V.; Ji, M.; Bloomer, W. D.; Hollingshead, M. G. Enhancement of the Antitumor Effect of Cyclophosphamide with the Hypoxia-Selective Cytotoxin NLCQ-1 against Murine Tumors and Human Xenografts. J. Exp. Ther. Oncol. 2002, 2 (5), 298-305.

(11) Cacicedo, M. L.; E. León, I.; S. Gonzalez, J.; M. Porto, L.; A. Alvarez, V.; Castro, G. R. Modified Bacterial Cellulose Scaffolds for Localized Doxorubicin Release in Human Colorectal HT-29 Cells. Colloids Surfaces B Biointerfaces 2016, 140, 421-429.

(12) Cacicedo, M. L.; Cesca, K.; Bosio, V. E.; Porto, L. M.; Castro, G. R. Self-Assembly of Carrageenin-CaCO3 Hybrid Microparticles on Bacterial Cellulose Films for Doxorubicin Sustained Delivery. J. Appl. Biomed. 2015, 13 (3), 239-248.

(13) Seib, F. P.; Kaplan, D. L. Doxorubicin-Loaded Silk Films: Drug-Silk Interactions and in Vivo Performance in Human Orthotopic Breast Cancer. Biomaterials 2012, 33 (33), 8442-8450.

(14) Tekedereli, I.; Alpay, S. N.; Akar, U.; Yuca, E.; Ayugo-Rodriguez, C.; Han, H.-D.; Sood, A. K.; Lopez-Berestein, G.; Ozpolat, B. Therapeutic Silencing of Bcl-2 by Systemically Administered siRNA Nanotherapeutics Inhibits Tumor Growth by Autophagy and Apoptosis and Enhances the Efficacy of Chemotherapy in Orthotopic Xenograft Models of ER (-) and ER (+) Breast Cancer. Mol. Ther. Nucleic Acids 2013, 2 (May), e121.

(15) Cai, S.; Thati, S.; Bagby, T. R.; Diab, H. M.; Davies, N. M.; Cohen, M. S.; Forrest M. Laird, M. L. Localized Doxorubicin Chemotherapy with a Biopolymeric Nanocarrier Improves Survival and Reduces Toxicity in Xenografts of Human Breast Cancer. J. Control. Release 2010, 146 (2), $212-218$.

(16) Mamot, C.; Ritschard, R.; Wicki, A.; Küng, W.; Schuller, J.; Herrmann, R.; Rochlitz, C. Immunoliposomal Delivery of Doxorubicin Can Overcome Multidrug Resistance Mechanisms in EGFR-Overexpressing Tumor Cells. J. Drug Target. 2012, 20 (5), 422-432.

(17) Huan, M.; Zhang, B.; Teng, Z.; Cui, H.; Wang, J.; Liu, X.; Xia, H.; Zhou, S.; Mei, Q. In Vitro and In Vivo Antitumor Activity of a Novel pH-Activated Polymeric Drug Delivery System for Doxorubicin. PLoS One 2012, 7 (9), 1-11.

(18) Sun, C. Y.; Dou, S.; Du, J. Z.; Yang, X. Z.; Li, Y. P.; Wang, J. Doxorubicin Conjugate of Poly(ethylene Glycol)-Block-Polyphosphoester for Cancer Therapy. Adv. Healthc. Mater. 2014, 3 (2), 261-272.

(19) Yang, C.; Liu, S. Q.; Venkataraman, S.; Gao, S. J.; Ke, X.; Chia, X. T.; Hedrick, J. L.; Yang, Y. Y. Structure-Directing Star-Shaped Block Copolymers: Supramolecular Vesicles for the Delivery of Anticancer Drugs. J. Control. Release 2015, 208, 93-105.

(20) Guo, Z.; He, B.; Yuan, L.; Dai, W.; Zhang, H.; Wang, X.; Wang, J.; Zhang, X.; Zhang, Q. Dual Targeting for Metastatic Breast Cancer and Tumor Neovasculature by EphA2-Mediated Nanocarriers. Int. J. Pharm. 2015, 493 (1-2), 380-389.

(21) Al-Abd, A. M.; Hong, K. Y.; Song, S. C.; Kuh, H. J. Pharmacokinetics of Doxorubicin after 
Intratumoral Injection Using a Thermosensitive Hydrogel in Tumor-Bearing Mice. J. Control. Release 2010, 142 (1), 101-107.

(22) Ottewell, P. D.; Lefley, D. V.; Cross, S. S.; Evans, C. A.; Coleman, R. E.; Holen, I. Sustained Inhibition of Tumor Growth and Prolonged Survival Following Sequential Administration of Doxorubicin and Zoledronic Acid in a Breast Cancer Model. Int. J. Cancer 2010, 126 (2), $522-$ 532.

(23) Ren, S.; Li, C.; Dai, Y.; Li, N.; Wang, X.; Tian, F.; Zhou, S.; Qiu, Z.; Lu, Y.; Zhao, D.; Chen, X.; Chen, D. Comparison of Pharmacokinetics, Tissue Distribution and Pharmacodynamics of Liposomal and Free Doxorubicin in Tumour-Bearing Mice Following Intratumoral Injection. $J$. Pharm. Pharmacol. 2014, 66 (9), 1231-1239.

(24) Lammers, T.; Subr, V.; Ulbrich, K.; Huber, P.; Peschke, P.; Ku, R.; Hennink, W.; Storm, G. Effect of Intratumoral Injection on the Biodistribution and the Therapeutic Potential of HPMA Copolymer - Based Drug Delivery Systems 1 , 2. 2006, 8 (10), 788-795.

(25) Goldberg, E. P.; Hadba, A. R.; Almond, B. a; Marotta, J. S. Intratumoral Cancer Chemotherapy and Immunotherapy: Opportunities for Nonsystemic Preoperative Drug Delivery. J. Pharm. Pharmacol. 2002, 54 (2), 159-180.

(26) Duvillard, C.; Polycarpe, E.; Romanet, P.; Chauffert, B. La Chimiothérapie Intratumorale: Aspects Expérimentaux et Applications Aux Tumeurs de La Tête et Du Cou. Ann. d'Otolaryngologie Chir. Cervico-faciale 2007, 124 (2), 53-60.

(27) Arbor Pharmaceuticals, L. Gliadel http://gliadel.com/hcp/ (accessed Jan 11, 2017).

(28) Bland, K. I.; Palin, W. E.; von Fraunhofer, J. A.; Morris, R. R.; Adcock, R. A.; Tobin, G. R. 2 nd. Experimental and Clinical Observations of the Effects of Cytotoxic Chemotherapeutic Drugs on Wound Healing. Ann. Surg. 1984, 199 (6), 782-790.

(29) Fernández, Y.; Forarada, L.; García-Aranda, N.; Mancilla, S.; Suárez-López, L.; Céspedes, M. V.; Herance, J. R.; Arango, D.; Mangues, R.; Schwartz, S.; Abasolo, I. Bioluminescent Imaging of Animal Models for Human Colorectal Cancer Tumor Growth and Metastatic Dissemination to Clinically Significant Sites. J. Mol. Biol. Mol. Imaging 2015, 2 (2), 1019-1033.

(30) Ilyná, A. . Sistema Bioluminiscente Luciferina-Luciferasa de Las Luciérnagas Parte 1: Propiedades Bioquímicas Y Catalíticas de La Enzima Luciferasa. Rev. la Soc. química Mex. 1998, 42 (3), 99-108.

(31) Wang, Y.; Tseng, J.-C.; Sun, Y.; Beck, A. H.; Kung, A. L. Noninvasive Imaging of Tumor Burden and Molecular Pathways in Mouse Models of Cancer. Cold Spring Harb. Protoc. 2015, 2015 (2), 135-144. 


\section{Conclusiones finales,}

\section{logros y perspectivas}


En el presente trabajo de Tesis se han logrado desarrollar diversos tipos de matrices poliméricas utilizando estructuras basadas en celulosa bacteriana. Luego de comprender los procesos de producción y purificación de la celulosa se procedió a generar modificaciones en las matrices con el objetivo de lograr que puedan encapsular Doxo y liberarla de manera sostenida. Todas las matrices desarrolladas fueron diseñadas para ser utilizadas específicamente como sistemas de liberación controlada para una aplicación antitumoral localizada.

La primera modificación realizada en las membranas de celulosa fue una modificación ex situ que permitió inmovilizar micropartículas hibridas de $\mathrm{CaCO}_{3}$, utilizando dichas partículas como núcleos de carga del fármaco. Las caracterizaciones fisicoquímicas realizadas sobre el biomaterial permitieron identificar la conservación de la esfericidad y tamaño de las micropartículas. Además, se determinó un incremento en la estabilidad del material asociado a la presencia de las micropartículas. A continuación, se evidenció una buena capacidad de encapsulación del fármaco y una liberación sostenida en el tiempo y dependiente de la carga y del pH circundante.

En una siguiente etapa se realizó una modificación in situ en las membranas mediante el agregado de alginato en el medio de cultivo del microorganismo productor de celulosa ( $K$. Hansenii). Este tipo de modificación se realizó por dos cuestiones básicas. Por un lado, necesitábamos conocer el comportamiento de la celulosa ante el agregado de otro polímero en su medio de cultivo. Por el otro lado, se necesitaba conseguir que el nuevo material lograra liberar Doxo en concentraciones más elevadas. La síntesis de la matriz hibrida BC-Alg dio lugar a un biomaterial con propiedades muy diferentes a las de la celulosa nativa. En primera medida se pudo determinar la presencia del alginato integrado con la red de celulosa. Dicha integración permitió obtener una red cooperativa entre ambos biopolímeros otorgándole a la matriz propiedades diferentes, tales como aumento de su fase amorfa e incremento considerable en la porosidad y área superficial del biomaterial. Dichas nuevas características demostraron ser relevantes al momento de encapsular Doxo. La nueva matriz demostró una buena versatilidad en cuanto a su capacidad de carga del fármaco y también se demostró la capacidad de liberar el mismo de modo sostenido en el tiempo. Por último, se evaluó la acción citotóxica sobre una línea celular de adenocarcinoma de 
colon (HT-29) la cual posee una relativa resistencia a la Doxo. Los resultados fueron de sumo interés debido a que la Doxo liberada desde las membranas demostró ser más efectiva que la exposición de las células a Doxo libre. En este sentido, se sugirió que la encapsulación del fármaco y liberación lenta podían estar evitando procesos de precipitación de la Doxo.

Hasta este punto, se habían podido generar sistemas capaces de encapsular y liberar Doxo de manera sostenida en el tiempo. Sin embargo, con el objetivo de poder garantizar un aumento en la efectividad del tratamiento se decidió avanzar en el diseño de una formulación de nanopartículas capaces de encapsular y liberar Doxo. Las mismas serian liberadas a su vez desde las membranas de celulosa. El sistema elegido y desarrollado consistió en nanopartículas lipídicas nanoestructuradas (NLCs). En las mismas se logró la encapsulación de dos especies iónicas de la Doxo. Por la naturaleza de las nanoparticulas la especie de Doxo más hidrofóbica fue la que presentó una EE más elevada y una liberación más lenta. Además, las técnicas fisicoquímicas permitieron determinar la existencia de interacciones entre la matriz lipídica y las moléculas de Doxo, especialmente en el caso de la especie hidrofóbica. Se demostró que el tamaño, dispersión y carga superficial de las partículas era muy similar en ambas formulaciones, y además era indicativo de la potencialidad para obtener una buena capacidad de internalización celular. Los ensayos in vitro demostraron que las NLCs presentaban una capacidad citotóxica dependiente del tiempo. Las NLCs-H mostraron su capacidad para generar más daño que las NLCs-N. A continuación, los ensayos de internalización demostraron diferencias en los mecanismos utilizados por la célula en comparación con la Doxo libre. Aquí se determinó que el mecanismo utilizado era por vía endosómica, terminando en lisosomas y accediendo desde ahí al núcleo celular y posiblemente a otros blancos de acción.

Por último, utilizando ambas formulaciones de NLCs se generó una matriz hibrida de tipo NP-Gel integrando las nanoparticulas en la red de celulosa. Este nuevo sistema fue caracterizado mostrando la capacidad de contener a las NLCs sin modificar su tamaño y morfología. Se realizaron pruebas de encapsulación y liberación sostenida, mostrando ser un sistema apto para ser evaluado en ensayos in vivo. Dichos ensayos se realizaron mediante la implantación de las membranas BC-NLCs-NH en un modelo tumoral ortotópico de cáncer de mama. Los resultados obtenidos exhibieron una capacidad antiproliferativa por parte de las membranas y comparable con el efecto obtenido con el control de Doxo i.t. Además, se observó un efecto de inhibición en la generación de 
metástasis. De esta forma el sistema BC-NLCs-NH demostró poseer una cierta potencialidad como sistema de liberación controlada de Doxo para aplicación local. Este sistema pretende ser utilizado como quimioterapia adyuvante a la administración sistémica de fármacos. De esta manera, se intentaría disminuir las dosis elevadas y, consecuentemente, toxicas de los quimioterapéuticos administrados por vía intravenosa. Los casos donde este sistema pretende cobrar valor podrían ser aquellos donde la extirpación del tumor primario es demasiado riesgosa por tamaño o locación. Este tipo de implantes promete ser una herramienta que permita atacar el problema sin someter a un paciente inmunodeprimido a una quimioterapia sistémica con elevada toxicidad.

Los tratamientos existentes en fases pre-clínicas o incluso clínicas poseen parámetros y factores que deben ser optimizados. En tal sentido, el sistema BC-NLCs-NH no es la excepción y por esta razón a continuación se presentarán perspectivas o desafíos futuros al respecto. Existen varios puntos donde el sistema debe ser optimizado:

- Capacidad de carga, de manera de generar un efecto antitumoral mayor: aquí se podría incluso sumar otro activo como por ejemplo el paclitaxel, el cual tiene un mecanismo de acción diferente al de la Doxo. Una de las ventajas de los NPGeles es que se pueden encapsular formulaciones de NPs con distintos activos y con distintas propiedades.

- Eliminar el problema de cicatrización post-implantación: en este punto se debe trabajar en limitar la liberación del fármaco solo hacia la zona del tumor. Otra alternativa es generar una variante del NP-Gel que pueda ser inyectable, evitando así la cirugía. En este caso se debe garantizar la estabilidad de las formulaciones de NPs una vez el gel ha sido inyectado.

- Inmovilización de factores de crecimiento epidérmicos en la matriz de manera de permitir una correcta cicatrización post-cirugía.

- Modificaciones de las NPs: se debe intentar generar nanopartículas con moléculas que posibiliten realizar un targeting específico para generar un efecto citotóxico, predominantemente, en las células cancerígenas.

- Inmovilización de enzimas terapéuticas: la inmovilización de la matriz de colágenasa promete ser un factor determinante para aumentar la capacidad de penetración intratumoral de las NPs liberadas. Aquí se deberá tener la precaución de que la enzima no genere un daño importante sobre el tejido sano, especialmente el de la herida post-cirugía. 
Finalmente, se debe mencionar que los resultados presentados en el presente trabajo de Tesis han sido parcialmente publicados en revistas científicas internacionales con referato, capítulos de libro y presentaciones en reuniones científicas, las cuales se mencionan a continuación:

- Artículos publicados:

M.L. Cacicedo, I.E. León, J.S. González, L.M. Porto, V.A. Álvarez, G.R. Castro. Modified bacterial cellulose scaffolds for localized doxorubicin release in human colorectal HT-29 cells" Colloids and Surfaces B: Biointerfaces (2016) 140:421-429.

M.L. Cacicedo, M.C. Castro, I. Servetas, L. Bosnea, K. Boura, P. Tsafrakidou, A. Dima, A. Terpou, A. Koutinas, G.R. Castro. Progress in bacterial cellulose matrices for biotechnological applications". Bioresource Technology (2016) 213:172-80. doi: 10.1016/j.biortech.2016.02.071

M.L. Cacicedo, K. Cesca, V.E. Bosio, L. Porto, G.R. Castro. Đevelopment of microbial cellulose films containing carrageenan- $\mathrm{CaCO}_{3}$ microparticles for the delivery of doxorubicin". Journal of Applied Biomedicine. (2015) 13: 239-248. http://dx.doi.org/10.1016/j.jab.2015.03.004

V. E. Bosio, M.L. Cacicedo, B. Calvignac, I. leon, T. Beuvier, F. Boury, G.R. Castro. Synthesis and characterization of $\mathrm{CaCO} 3$-biopolymers hybrid microparticles for cancer damaged bone therapy". Colloids and Surfaces B: Biointerfaces. (2014) 123: 158-169. doi:10.1016/j.colsurfb.2014.09.011

G.A. Islan, M.L. Cacicedo, V.E. Bosio, G.R. Castro. Đevelopment and characterization of new enzymatic modified hybrid $\mathrm{CaCO}_{3}$ microparticles to obtain nano-architectured surfaces for enhanced drug loading" Journal of Colloid and Interface Science. (2015) 439:76-87. doi: 10.1016/j.jcis.2014.10.007

E. Goldschmidt, M. Cacicedo, S.A. Kornfeld., M. Valinoti, M. Ielpi, M. Loresi, P. Ajler, C. Yampolsky, G.R. Castro, P. Argibay Construction and in vitro testing of a cellulose dura mater graft". Neurological Research (2016) 38: 25-31. doi: 10.1080/01616412.2015.1122263.

G. A. Islan, M. Durán, M. L. Cacicedo, G. Nakazato, R. K. T. Kobayashi, D. S. T. Martinez, G. R. Castro, N. Durán. Nanopharmaceuticals as a solution to neglected diseases: Is it possible?". Acta Tropica (2017) Aceptado, en prensa. doi: http://dx.doi.org/doi:10.1016/j.actatropica.2017.02.019. 
- Artículos en preparación:

M.L. Cacicedo, G.A. Islan, M.F. Drachemberg, L C. Bartel, A.D. Bolzán, G.R. Castro. Biopolymeric films based on bacterial cellulose and pectins for transdermal delivery of active molecules" (2017)

M.L. Cacicedo, G.A. Islan, I. León, V.A. Álvarez, E. Munnier, I. Chourpa, I. Abasolo, Y. Fernández, V. Samira Díaz, S. Schwartz, G.R. Castro. Hydrogel/NLCs system for localized treatment of an ortothopic breast cancer model" (2017)

- Capítulos de libro:

G.A. Islan, M.L. Cacicedo, V.E. Bosio, G.R. Castro. Advances in Smart Nanopreparations For Oral Drug Delivery; Book: Smart Pharmaceutical Nanocarriers. Imperial College Press. FEB 2016. ISBN: 978-1-78326-722-4

M.L. Cacicedo, G.A. Islan, P. Gurman, G.R. Castro. Drug delivery devices for infectious diseases. Book: Drug Delivery: An Integrated Clinical and Engineering Approach. CRC Press - Taylor \& Francis Group. MAR 2017. ISBN 9781466565944 - CAT\# K16126

- Reuniones científicas:

M.L. Cacicedo, G.A. Islan, G.R. Castro (2012). Carrageenan based microspheres for oral controlled release of Enrofloxacin in biomedical applications. IFIB 2012, $5^{\text {th }}$. International Conference on Industrial Bioprocesses. Octubre 7-10. Taipei, Taiwan.

V.E. Bosio, M.L. Cacicedo, B. Calvignac, I. leon, T. Beuvier, F. Boury, G.R. Castro (2012) Synthesis and characterization of $\mathrm{CaCO}_{3}$-biopolymers hybrid microparticles for cancer damaged bone therapy. XI International Conference on Nanostructured Materials. Agosto 26-31. Rhodes, Greece.

M.L. Cacicedo, G.A. Islan, Y. Martinez, V.E. Bosio, G.R. Castro (2012). Biopolímeros como herramientas biotecnológicas. II Simposio Argentino de Procesos Biotecnologicos, Presentación de poster. Mayo 10-11. La Plata, Argentina.

M.L. Cacicedo, K. Cesca, V.E. Bosio, L. Porto, G.R. Castro (2013). Desarrollo de matrices hibridas de celulosa para aplicaciones biomédicas. VIII Encuentro Latinoamericano y del Caribe de Biotecnología. Noviembre 18-22. Mar del Plata, Argentina. 
M.L. Cacicedo, K. Cesca, V.E. Bosio, L. Porto, G.R. Castro (2013). BaCarb ${ }^{\mathrm{TM}}$ : A Novel Bioinorganic Matrix for Local Drug Delivery. 5th congress of the Brazilian Society of Biotechnology. Florianópolis, Brasil. Noviembre 10-14.

G.A. Islan, M.L. Cacicedo, V.E. Bosio, G.R. Castro (2014). Development and characterization of inhalable hybrid nanostructured microparticles for lung infections treatment. 10th European Symposium on Biochemical Engineering Sciences. Septiembre 7-10. Lille, Francia.

M.L. Cacicedo, I.E. León, J.S. González, L.M. Porto, V.A. Álvarez, G.R. Castro (2014). Novel microbial cellulose/alginate composite for biomedical applications: synthesis and characterization. 10th European Symposium on Biochemical Engineering Sciences. Septiembre 7-10. Lille, Francia.

M.E. Ruiz, J.F. Morales, A.V. Enrique, M.L. Sbaraglini, A. Talevi, G.A. Islan, M.L. Cacicedo, L E. Bruno-Blanch (2014). Development and validation of an HPLC-UV method for determination of Levofloxacin in lung tissue, suitable for the quantification of the drug after nasal administration of polymeric microparticles. 3st International Meeting on Pharmaceutical Sciences (RICiFa 2014). Septiembre 1819.

M.L. Cacicedo, G.R. Castro (2015). Producción de celulosa bacteriana para aplicaciones terapéuticas. XXIII Jornadas de Jóvenes Investigadores de la Asociación de Universidades Grupo Montevideo. Agosto 25-27. La Plata, Argentina.

J. Rasmussen, E. Goldschmidt, M.L. Cacicedo, S. Kornfeld, M. Valinoti, M. Ielpi, P. Ajler, C. Yampolsky, P. Argibay (2015). Construction and in vitro testing of a cellulose dura mater graft. 15th Interim meeting of the world federation of neurosurgical societies. Septiembre 8 -12. Roma, Italia.

E. Goldschmidt \& M. Cacicedo (2015) Bacterias que ayudan a la cicatrización en cirugías de cerebro. INNOVAR 2015, exposición anual de productos de la Décimo Primera Edición del Concurso Nacional de Innovaciones: proyecto ID 18425. Octubre 15-18. Buenos Aires, Argentina.

G.A. Islan, M.L. Cacicedo, G.R. Castro (2015). Nuevo tratamiento dual a base de micropartículas para las afecciones pulmonares en Fibrosis Quística. INNOVAR 2015, exposición anual de productos de la Décimo Primera Edición del Concurso Nacional de Innovaciones: proyecto ID 18533. Octubre 15-18. Buenos Aires, Argentina. 
B. Bayon, M.L. Cacicedo, G.R. Castro (2015). Apósito terapéutico para el tratamiento de heridas y quemaduras. INNOVAR 2015, exposición anual de productos de la Décimo Primera Edición del Concurso Nacional de Innovaciones: proyecto ID 17780. Octubre 15-18. Buenos Aires, Argentina.

K. Cesca, M.L. Cacicedo, V. García, F. Berti, G.R. Castro, L.M. Porto. (2015). Drug delivery system based on bacterial nanocelulose for in situ treatment of recurrent breast cancer. XXI Congresso Brasileiro de Engenharia Quimica (COBEQ 2016). Septiembre 25-29. Fortaleza, Brasil.

M.L. Cacicedo, G.A. Islan, N. Duran, G.R. Castro (2015). Nanocomposite bacterial cellulose film containing doxorubicin loaded solid lipid nanoparticles for local antitumoral treatment. Biospectrum 2015 International Conference on Advances in Bioprocess Technology. Noviembre 26-28. India.

M.L. Cacicedo, G.R. Castro (2015). Design of nanotechnological scaffolds for the treatment of pathologies. Biospectrum 2015 International Conference on Advances in Bioprocess Technology. Noviembre 26-28. India. 